Review

\title{
Structure, synthesis, and catalytic properties of nanosize cerium-zirconium-based solid solutions in environmental catalysis
}

\author{
Jixing Liu a, Zhen Zhao a,b, Chunming Xu a, Jian Liu a,* \\ a State Key Laboratory of Heavy Oil, China University of Petroleum, Beijing 102249, China \\ ${ }^{\mathrm{b}}$ Institute of Catalysis for Energy and Environment, Shenyang Normal University, Shenyang 110034, Liaoning, China
}

\section{A R T I C L E I N F O}

\section{Article history:}

Received 28 May 2019

Accepted 3 July 2019

Published 5 October 2019

\section{Keywords:}

Cerium-zirconium solid solution

Synthesis

Method

Structure

Environmental catalysis

\begin{abstract}
A B S T R A C T
Nanosize cerium-zirconium solid solution (CZO) with a special fluorite structure has received an increasing research interest due to their remarkable advantages such as excellent oxygen storage capacity and great flexibility in their composition and structure. By partial metal (including rare earth, transition, alkaline earth or other metal) doping into CZO, the physicochemical properties of these catalytic materials can be controllable adjusted for the study of specific reactions. To date, nanosize CZO has been prepared by co-precipitation, sol-gel, surfactant-assisted approach, solution combustion, micro-emulsion, high energy mechanical milling, etc. The advent of these methodologies has prompted researchers to construct well-defined networks with customized micromorphology and functionalities. In this review, we describe not only the basic structure and synthetic strategies of $\mathrm{CZO}$, but also their relevant applications in environmental catalysis, such as the purification for $\mathrm{CO}$, nitrogen oxides ( $\mathrm{NO}_{x}$ ), volatile organic compounds (VOC), soot, hydrocarbon (HC), $\mathrm{CO}_{2}$ and solid particulate matters (PM), and some reaction mechanisms are also summarized.
\end{abstract}

(C) 2019, Dalian Institute of Chemical Physics, Chinese Academy of Sciences. Published by Elsevier B.V. All rights reserved.

\section{Introduction}

Nowadays, the issue of the environment is receiving ever increasing attention. One of the primary efforts of environmental protection is concentrated on controlling the emission of toxic pollutants from combustion of fossil fuels in automotive engines and industrial production [1-3]. Three-way catalysts (TWCs) are widely employed to lessen the emissions of carbon monoxide (CO), nitrogen oxides $\left(\mathrm{NO}_{x}\right)$, and hydrocarbons (HC) from automobile exhausts [4-6]. Among these catalysts, ceria $\left(\mathrm{CeO}_{2}\right)$ is a key component, which exhibits cubic fluorite type of structure and has attracted much attention in recent decades due to its good redox property and high storage/release oxygen capacity, associated with the abundant oxygen vacancy and facile shift of $\mathrm{Ce}^{3+} / \mathrm{Ce}^{4+}[7-10]$. It has also been used in many heterogeneous catalytic reactions [11-18], including methane combustion, water-gas shift, water steam reforming reaction, etc. Moreover, a large number of reports have shown that partial incorporation of zirconium ion $\left(\mathrm{Zr}^{4+}\right)$ into ceria lattice can substantially enhance the redox properties and oxygen storage capacity (OSC) [19-30]. This is an interesting finding, considered that $\mathrm{Zr}^{4+}$ is isovalent with the host $\mathrm{Ce}^{4+}$ ion and also a fixed valent ion, so that it can not induce the valency change such as with $\mathrm{Pr}^{3+/ 4+}$ or creation of charge compensating defects such as with $\mathrm{Gd}^{3+}$ [31-35]. Instead, the smaller $\mathrm{Zr}^{4+}$, in comparison with $\mathrm{Ce}^{4+}$, prefers a 7 -fold coordination, in contrast to the 8-fold coordination of the fluorite cation, resulting in a driving force to form oxygen vacancies associated with structural relaxation through reduction of the smaller $\mathrm{Ce}^{4+}$ to the bigger $\mathrm{Ce}^{3+}$ [36-39]. Based on the first principle calculations, a $\mathrm{Zr}$ dopant

\footnotetext{
* Corresponding author. Tel: +86-10-89732278; Fax: +86-10-69724721; E-mail: liujian@cup.edu.cn This work was financially supported by the National Natural Science Foundation of China (21673290, U1662103).

DOI: S1872-2067(19)63400-5 | http://www.sciencedirect.com/science/journal/18722067 | Chin. J. Catal., Vol. 40, No. 10, October 2019
} 
acts as low energy regions for the formation and clustering of oxygen vacancy [40-43]. In addition, the long-term thermal morphology and/or redox stability of pure $\mathrm{CeO}_{2}$ has been enhanced by the introduction of $\mathrm{Zr}[20,28,44,45]$. Furthermore, owing to the special redox ability of Ce-Zr solid solution (CZO), it can be employed to support noble metals and transition metal oxides or to design ternary solid solutions by doping small amounts of other transition or rare earth metals [46-53]. CZO has been widely employed in the abatement of $\mathrm{CO}, \mathrm{NO}_{x}$ and toxic volatile organic compounds (VOC) and many other heterogeneous catalysis reactions. This review primarily focuses on the structure, synthesis, and application of Ce-Zr-based solid solutions in environmental catalysis. The first part of the review presents advances in the structure and synthesis of CZO, and the catalytic properties of CZO are thereafter reviewed in the second part.

\section{The structure of nanosize cerium-zirconium-based solid solutions}

Ceria has a special cubic fluorite structure and is the most widely used rare earth oxide. It is also a good catalyst support that can promote the uniform distribution of active components and enhance the catalytic activity [17]. However, pure ceria easily aggregates at high temperatures, and $\mathrm{Zr}$ doping can enhance the stability of cerium-based materials. CZO exhibits a main cubic fluorite structure when $\mathrm{Zr}$ content is low, as shown in Fig. 1. However, CZO undergoes a cubic to tetragonal fluorite phase transition with increasing $\mathrm{Zr}$ content and ultimately forms a monoclinic phase at high $\mathrm{Zr}$ contents [39,54-56]. The bond length ratio of $c$ - to $a$-axis $(c / a)$ is equal to 1.4 for the tetragonal phase ( $t$-phase), which is attributed to the $P 4_{2} / \mathrm{nmc}$ space group and shows two distortions $t^{\prime}(c / a=1.01)$ and $t^{\prime \prime}$ $(c / a=1)$ [57]. One can distinguish between the $t^{\prime}$ and $t^{\prime \prime}$ phases from the measurement of lattice parameters, though some similarity between the $t^{\prime \prime}$ and cubic structures. The phase change from cubic to $t^{\prime \prime}$ would induce an increase in the wavenumber of Raman vibrational modes and remarkable changes in ionic bond strength $[54,58]$. Similar to the cubic to tetragonal distortion in CZO, the relaxation of oxygen atoms away from their ideal fluorite positions and the formation of ordered domains have been observed in cubic fluorite and hafnia by electron diffraction. The structure of CZO materials exhibits some primary features, which have been reported by Yashima and Fábregas et al. $[59,60]$. One of the important features is that the

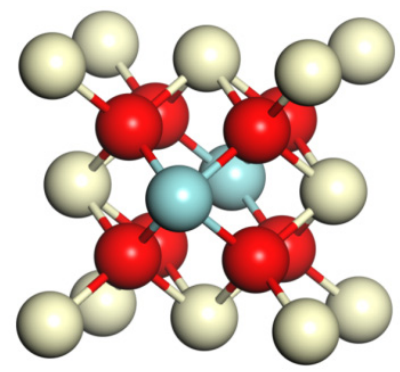

Fig. 1. Schematic diagram of $\mathrm{Ce}_{\mathrm{x}} \mathrm{Zr}_{1-\mathrm{x}} \mathrm{O}_{2}$ lattice structure: $\odot \mathrm{O}, \odot \mathrm{Zr}$, and $\mathrm{Ce}$. first oxygen shell around Ce exhibits the characteristics expected for pure $\mathrm{CeO}_{2}$ (fluorite-type crystal structure, one shell with 8 oxygen atoms) even if the crystallite phase is $t\left(t^{\prime}\right.$ and $t^{\prime \prime}$ forms) or $c$. In contrast, the first shell around $\mathrm{Zr}$ atoms shows obvious differences from the changes in the crystal structure. This means that it splits into two oxygen subshells for the tetragonal forms and displays only one shell for the $c$ phase. In other words, the tetragonal-to-cubic phase transition is closely related to a symmetry change of the first oxygen shell around $\mathrm{Zr}$ atoms, whereas that around Ce atoms remains unchanged. The appearance of cubic, $t^{\prime}$, and $t^{\prime \prime}$ phases in CZO depends strongly on the $\mathrm{Zr}$ content. Yashima et al. [54] proposed a phase diagram according to XRD and Raman analysis, as shown in Fig. 2 , and it could be depicted as follows. A cubic fluorite phase $c$ is present (group Fm3m) for $x>0.85$ at temperature below 1000 ${ }^{\circ} \mathrm{C}$. A tetragonal phase $t$ (group $P 4_{2} / \mathrm{nmc}$ ) can be produced at high temperature by solid-state synthesis and then cooling to room temperature for $0.10<x<0.30$, and it is thermodynamical stable. A monoclinic phase (group $P 21 /$ ) is formed for $x<$ 0.10 , while a metastable phase $t^{\prime}$ is seen for $0.30<x<0.65$. In the end, $t^{\prime \prime}$ or pseudo-cubic phase is intermediate between the $c$ and $t^{\prime}$ phases $(0.65<x<0.85$ or $0.5<x<0.85$ for small particles). This is characterized by a cubic cation sublattice, while its oxygen sublattice is tetragonally distorted $\left(P 4_{2} / n m c\right)$. The phase boundaries should be very approximate. As a matter of fact, in the case of the metastable tetragonal phases, the structure distortion of CZO should be highly depended on the calcination temperature and the particle size of the materials.

Due to the complexity of the phase diagram, it is difficult to determine the phase homogeneity of $\mathrm{CZO}$, even though a great effort has been made. Small changes in oxygen ion-cation coor-

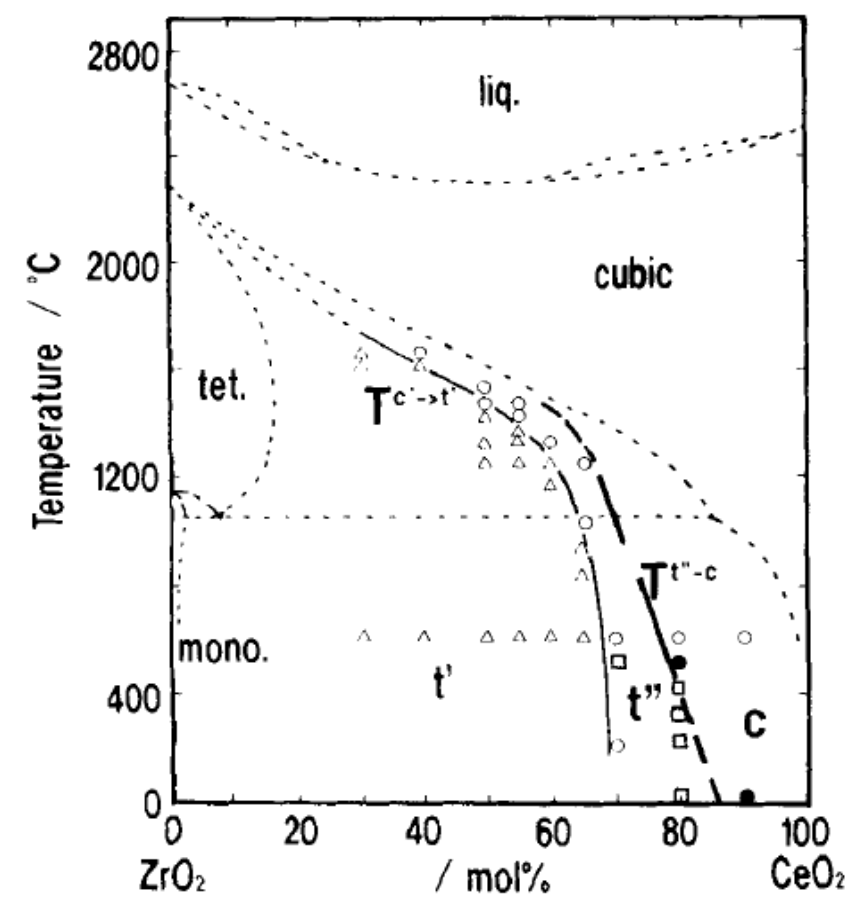

Fig. 2. Metastable-stable phase diagram in $\mathrm{Ce}_{x} \mathrm{Zr}_{1-x} \mathrm{O}_{2}$ tem: Cphase, $\square^{\prime}$-phase, $\mathbf{O}^{\prime}$-phase, $\quad \Delta^{\prime}$-phase. The dash lines represent the metastable phase boundaries. Reprinted from [54] with permission. 
dination are not always detectable as additional peaks (or peak splitting) by XRD. However, Raman and other vibrational spectroscopy methods may be used to distinguish the primary oxygen ion distortions between the $t^{\prime \prime}$ and cubic phases [54]. Raman spectroscopy can play a critical role in the determination of all these phases and in the identification of the mechanical stress. In fact, laser-excited Raman spectra are extremely sensitive to M-O bonds, while powder XRD patterns are essentially determined by the arrangement of the lattice cations. Unfortunately, these conventional techniques fail in the investigation of the low crystallization degree materials, however, which are very important in heterogeneous catalysis. More advanced techniques, such as neutron diffraction and EXAFS, have proved to be effectively on determining inhomogeneity and detecting complementary structural information [36,62-65]. Moreover, Montini et al. [66] investigated the potential of luminescence spectroscopy for identifying the homogeneity of CZO materials using Eu(III) ion as a structural probe. This technique provides a detailed picture of local environment of the cations in these materials due to the fact that the luminescence properties of Eu(III) are strongly affected by the local surrounding around the cation ion (Fig. 3).

Great efforts to establish a correlation between structure and physicochemical properties have been devoted to a lot of research concerning CZO materials. The presence of surface domains $[67,68]$, formation of ordered defective structures [69-71], disordered oxygens coordinated around zirconium [72], and distortion in the oxygen sublattice [38,66-68] have improved redox properties of $\mathrm{CZO}$ with respect to $\mathrm{CeO}_{2}$. Com-

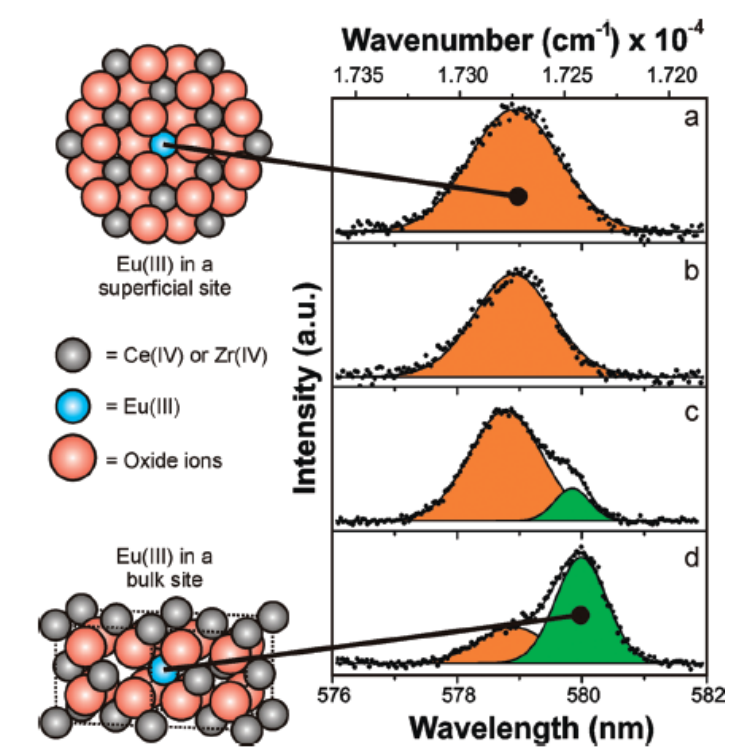

Fig. 3. Eu(III) emission spectra of the thermodynamically stable cubic $\mathrm{Ce}-\mathrm{Zr}-\mathrm{EuO}_{2}$ (CZE) samples with the schematic representation of Eu surface site located on the stable (111) surface of cubic $\mathrm{Ce}_{0.8} \mathrm{Zr}_{0.2} \mathrm{O}_{2}$ and of the single Eu bulk site in $\mathrm{Ce}_{0.8} \mathrm{Zr}_{0.2} \mathrm{O}_{2}$ by EXAFS data. The details of ${ }^{5} \mathrm{D} \rightarrow \mathrm{f}^{7} \mathrm{~F}_{0}$ transition are reported for both surface and bulk Eu(III)-doped materials after different thermal treatments. (a) Surface-doped CZE calcination at $500{ }^{\circ} \mathrm{C}$ for $5 \mathrm{~h}$; (b) Surface-doped CZE calcination at 1000 ${ }^{\circ} \mathrm{C}$ for $5 \mathrm{~h}$; (c) Bulk-doped CZE calcination at $500{ }^{\circ} \mathrm{C}$ for $5 \mathrm{~h}$; (d) Bulk-doped CZE calcination at $1000^{\circ} \mathrm{C}$ for $5 \mathrm{~h}$. Reprinted from [66] with permission. parison of CZO powders with different particle sizes between $\sim 6$ and $80 \mathrm{~nm}$, the phase boundaries exhibit an apparent shift to slightly higher zirconia contents with the decrease of the particle size and the increase of the solubility of zirconia in each phase [73]. The position of the phase boundaries for CZO can only be taken as approximate because $t^{\prime}$ and $t^{\prime \prime}$ are metastable phases and the degree of distortion of the cubic fluorite structure strongly depends on the synthesis method, particle size, morphology, metal doping and supported active phase type [74].

\section{Recent advances in the synthesis and morphology of nanosize cerium-zirconium-based solid solutions}

It is well known that morphology and microstructure significantly influence the physicochemical properties and the performances of CZO materials, especially the high surface area, which can supply a large number of active sites for the proceeding of catalytic reactions [75]. Materials with nanosize (1 100 nm) will exhibit special properties due to the following effects: a) quantum size effect; b) small size effect; c) surface effect; d) macroscopic quantum tunneling effect. Hence, it is well worthy to pay attention and spare efforts on the study of the synthesis of nanosize CZO with different morphology and catalytic performances.

\subsection{Synthesis methods for nanosize cerium-zirconium-based solid solutions}

A synthesis method is significantly important for nanosize CZO due to its influence on the size, morphology, structure, surface state, and oxygen vacancies. It is closely related to the reducibility of cerium-based composite of the as-prepared materials [76-80]. The controllable synthesis research is an issue worthy to concern. To date, various synthetic routes have been developed for the synthesis of nanosize cerium-zirconium-based solid solutions, such as co-precipitation (CP), sol-gel (SG), self-assembly, template-assisted approach, solution combustion (SC), micro-emulsion (ME), high energy mechanical milling, etc.

\subsubsection{Co-precipitation method}

$\mathrm{CP}$ is one of the most commonly used methods for nanosize CZO synthesis owing to its simple synthesis process. In general, it includes room-temperature [81-85], medium-to-high temperature [86-88], surfactant-modified [89,90], and ultrasound-induced CP [91]. Precipitants (ammonia water and ammonium carbonate) are employed to react with the soluble components of cerium and zirconium compounds and form precipitate in soluble precursors. After a series of process of separation, washing, drying and calcination, the final products are obtained. The reaction is as follows (Eqs. (1)-(4)):

$$
\begin{gathered}
\mathrm{Ce}^{3+}+3 \mathrm{NH}_{3} \cdot \mathrm{H}_{2} \mathrm{O} \rightarrow \mathrm{Ce}(\mathrm{OH})_{3} \downarrow+3 \mathrm{NH}_{4}^{+} \\
\mathrm{Zr}^{4+}+4 \mathrm{NH}_{3} \cdot \mathrm{H}_{2} \mathrm{O} \rightarrow \mathrm{Zr}(\mathrm{OH})_{4} \downarrow+4 \mathrm{NH}_{4}^{+} \\
4 \mathrm{Ce}(\mathrm{OH})_{3}+\mathrm{O}_{2}+2 \mathrm{H}_{2} \mathrm{O} \rightarrow 4 \mathrm{Ce}(\mathrm{OH})_{4} \\
\mathrm{Ce}(\mathrm{OH})_{4}+\mathrm{Zr}(\mathrm{OH})_{4}+\chi \mathrm{H}_{2} \mathrm{O} \rightarrow \mathrm{Ce}(\mathrm{OH})_{4} \cdot \mathrm{Zr}(\mathrm{OH})_{4} \cdot \chi \mathrm{H}_{2} \mathrm{O}
\end{gathered}
$$


This method can make an excellent mixing of the different components. The surface area of CZO prepared by this traditional CP method is $20-120 \mathrm{~m}^{2} / \mathrm{g}$, which would decrease to about $20 \mathrm{~m}^{2} / \mathrm{g}$ after being calcined at $1000^{\circ} \mathrm{C}$. Hsiang et al. [92] prepared $\mathrm{Ce}_{0.6} \mathrm{Zr}_{0.4} \mathrm{O}_{2}$ powders by the $\mathrm{CP}$ method and studied the correlation between the crystallite structure and reductive property. The results indicated that $\mathrm{Ce}_{0.6} \mathrm{Zr}_{0.4} \mathrm{O}_{2}$ decomposed into Ce-rich (cubic) and Zr-rich (tetragonal) phases from a single cubic phase after being calcined above $1100{ }^{\circ} \mathrm{C}$. Moreover, the cation diffusion may result in the structural alteration under reduction/re-oxidation treatment. In this synthesis process, because the precursors are made of hydroxides or salts of cerium and zirconium, a calcination process at high temperature is needed to form solid solution. Nevertheless, high temperature would lead to the loss of surface area seriously. Furthermore, during the drying process, the particles might aggregate due to the effect of surface tension of water (or other solvents). Therefore, a lot of improved ways were developed to enhance the property of nanosize CZO. Chen et al. [93] proposed a modified CP method with triethylamine assisting to prepare CZO with a big surface area and high thermal stability. They found that the adsorbed surfactant (triethylamine) on the surface of particles might form a protective layer, which could serve as an effective barrier to inhibit the grains from aggregating. Consequently, the added surfactants could remarkably improve the particle dispersion and increase the surface area of CZO.

\subsubsection{Sol-gel method}

The SG method is also widely used for nanosize CZO synthesis. Metal compounds are mixed with the highly active coordination compounds and undergo hydrolysis and condensation reaction to form sol and then transform to gel with three dimension net-work structure. Final products are obtained after drying and calcination. Generally, SG synthesis is a suitable method to prepare CZO with high degree of homogeneity by controlling hydrolysis of alkoxide or similar precursors. However, when the rates of hydrolysis between the two metals are quite different, it may be difficult to simultaneously hydrolyze both precursors, particularly when $\mathrm{Zr}\left(n-\mathrm{C}_{3} \mathrm{H}_{7} \mathrm{OH}\right)_{4}$ is employed as a precursor. Therefore, appropriate chemical modifications of the hydrolyzing process are needed to control the rate of hydrolysis. Meeyoo et al. [94] adopted an SG technique to prepare $\mathrm{Ce}_{1-\mathrm{x}} \mathrm{Zr}_{x} \mathrm{O}_{2}(x=0 \sim 1.0)$ mixed oxide catalysts for CO oxidation. The initial solution was synthesized by mixing $0.4 \mathrm{~mol} / \mathrm{L}$ of urea solution with $0.1 \mathrm{~mol} / \mathrm{L}$ of metal salt solutions with volumetric ratio equal to 0.5 , and the ratio was changed depending on the desired solid solution. The catalytic activities of these mixed oxide catalysts were found to be dependent on $\mathrm{Ce} / \mathrm{Zr}$ ratio, and $\mathrm{Ce}_{0.75} \mathrm{Zr}_{0.25} \mathrm{O}_{2}$ exhibited the highest $\mathrm{CO}$ conversion. Kozlov et al. [76] prepared an $\mathrm{Al}_{2} \mathrm{O}_{3}$-supported $\mathrm{Ce}_{0.45} \mathrm{Zr}_{0.55} \mathrm{O}_{2}$ catalyst by a modified SG method. In this preparation process, 2-methyl-2,4-pentanediol was added to affect the substitution of the isopropoxy ligand by the diol. As a result, CZO exhibited a high content of readily reducible $\mathrm{Ce}^{4+}$. Additionally, the mixed oxide particles still retained small and homogeneous single phase even after reduction at $980{ }^{\circ} \mathrm{C}$ and reoxidation at $900{ }^{\circ} \mathrm{C}$. Yu et al. [95] synthesized a series of
M- $\mathrm{Ce}_{0.7} \mathrm{Zr}_{0.3} \mathrm{O}_{2}(\mathrm{M}=\mathrm{Li}, \mathrm{Na}, \mathrm{K})$ using a modified SG method. In the synthesis process, a proper amount of citric acid (CA) was added to control the hydrolysis of precursors and then calcined at $600{ }^{\circ} \mathrm{C}$ for $6 \mathrm{~h}$ to obtain the final products. The as-prepared materials exhibited a higher catalytic activity for soot combustion than that prepared by the CP method.

\subsubsection{Template-assisted method}

The template-assisted method is widely employed for the preparation of nanostructural CZO due to the advantages of convenience, simplicity and inducing effect of various templates with special structures or morphology. Two types of templates are available as follows.

(a) Soft template

Surfactants can form micelles with different shape or morphology when dissolved into water up to a certain concentration, and thus the micelles can be used as templates for nanomaterial synthesis. In recent years, numerous studies have been reported on the use of cationic, anionic and nonionic surfactants as template to synthesize nanosize CZO with mesoporous structure [96]. The commonly used surfactants are cetyltrimethylammonium bromide (CTAB) and tri-block copolymers Pluronic P123 and F127. Trovarelli et al. [89] prepared CZO with high surface area by a soft template-assisted approach. In a typical preparation process, the mixed oxide was synthesized by adding an aqueous solution of the cationic surfactant CTAB to precursor solution made of hydroxides or salts of cerium and zirconium. Cationic surfactants effectively incorporated into cerium and zirconium hydrous oxides under basic conditions. The presence of cerium inhibited alkyl-trimethyl-ammonium salt acting as the template to form regular pore structure. The removal of surfactants after calcination gave rise to the formation of fluorite-structured CZO with high specific surface area. Yuan et al. [97] demonstrated a novel straightforward and reproducible method to prepare a highly ordered mesoporous CZO with a 2-D hexagonal structure. The general synthesis strategy was based on an SG method combined with evaporation-induced self-assembly (EISA) in ethanol, and P123 was used as the template and ceric nitrate and zirconium oxide chloride as the precursors. A series of mesoporous $\mathrm{CZO}$ with different $\mathrm{Ce} / \mathrm{Zr}$ ratios was obtained under the optimal temperature and humidity conditions.

(b) Hard template

The ordinary hard templates contain porous anodic alumina (AAO), molecular sieves, carbon nanotubes (CNTs) and silica nanowires. They can be used as rigid templates for nanomaterial synthesis. Zamani et al. [98] prepared mesoporous CZO using mesoporous silica (SBA-15 and KIT-6) as template agents, which were impregnated with precursor materials. Structural analysis of the products confirmed the formation of mesostructures, and thermogravimetry measurements showed the remarkable increase of material OSC compared with pure ceria. In the case of $\mathrm{Ce}_{0.95} \mathrm{Zr}_{0.05} \mathrm{O}_{2}$, response measurements showed the relatively fast and stable response of the sensor to oxygen-containing atmospheres.

Some special structures require specific hard templates. The three-dimensional ordered macroporous (3DOM) structure is 
prepared via organic polymer templates such as polystyrene (PS), polymethyl methacrylate (PMMA), and polystyrene-methyl methacrylate-acrylic acid microspheres. Some works have been reported on this aspect [99-104]. Zhao et al. [102] prepared a series of 3DOM CZO using PMMA colloidal crystal as template agent, as shown in Fig. 4a. In a typical synthesis process, the first step was to prepare an ordered colloidal crystal template (CCT) with monodispersed PMMA spheres (444 nm) and PS spheres (454 nm). The second step was to synthesize the liquid precursor. The stoichiometric amount of cerium nitrate and zirconium oxide chloride were dissolved in an mixed solvent including ethylene glycol (EG) and methanol (20-40 vol\%) followed by pouring into a volumetric flask. Then, the dried PMMA or PS colloidal crystal was soaked in the solution for several hours. Excess solution was removed by filtration. Finally, 3DOM CZO was obtained by removing the template via calcining at $650{ }^{\circ} \mathrm{C}$ for $5 \mathrm{~h}$. The as-prepared $\mathrm{Ce} 0.7 \mathrm{Zr}_{0.3} \mathrm{O}_{2}$ material exhibited a well-ordered 3DOM structure, which consisted of interconnected networks of spherical voids through open windows, ca. $120 \mathrm{~nm}$ in diameter, as shown in Fig. $4 \mathrm{~b}$ and $4 \mathrm{c}$. The walls of the macroporous samples were crystallited.

\subsubsection{Hydrothermal and solvothermal method}

The hydrothermal method refers to a synthesis route via reaction of species in the water media (solvent) under the condition of certain temperature $\left(100-1000{ }^{\circ} \mathrm{C}\right)$ and pressure (1-100 MPa). It is well known that CP and SG methods can be used to prepare catalytic materials of high purity. However, the as-prepared materials usually show amorphous structures. Hydrothermal synthesis can overcome this drawback and may be regarded as an effective strategy for synthesis of specific nanosize catalytic materials in liquid phase. This technique has attracted more attention since the 1980s when nanoceria was first synthesized via a hydrothermal method by Matijevic et al. [105]. In the solvothermal method, organic solvents are employed instead of water. The whole process of hydrothermal or solvothermal synthesis is controllable and can be regarded as a

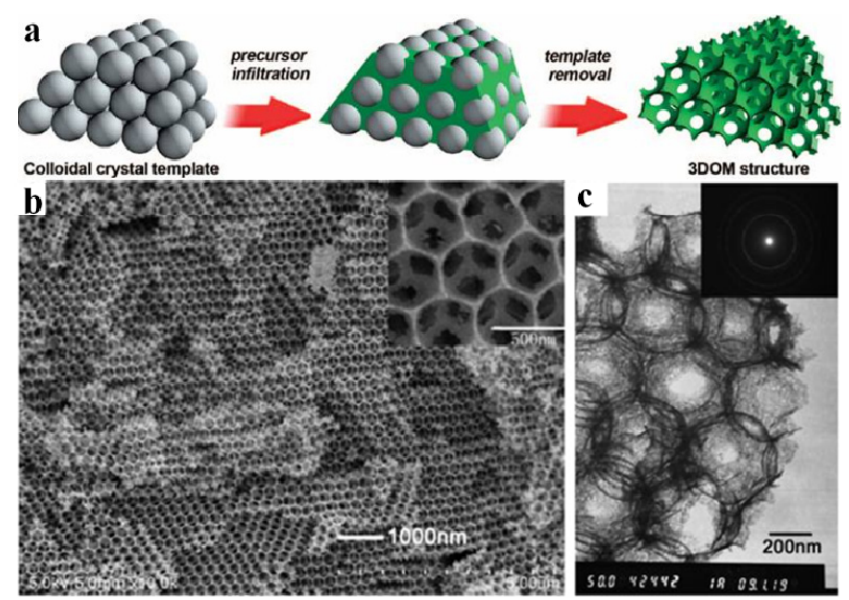

Fig. 4. (a) The schematic diagram for the preparation of 3DOM CZO by the colloidal crystal template method; (b) SEM and (c) TEM images of a representative $3 \mathrm{DOM} \mathrm{Ce} \mathrm{Ce}_{0.7} \mathrm{Zr}_{0.3} \mathrm{O}_{2}$. Inset: (b) an enlarged area of 3DOM $\mathrm{Ce}_{0.7} \mathrm{Zr}_{0.3} \mathrm{O}_{2}$, (c) the corresponding SAED pattern. green chemistry process due to the very good control of volatizing of organic solvents, non-toxic gas releasing. And the synthesis can conveniently obtain the nanomaterials with regular shape, size and crystallite phases. Walton et al. [106] reported a simple one-step hydrothermal method for preparation of nanocrystallite CZO, whose redox properties depended crucially on the reaction conditions. Ihm et al. [107] fabricated CZO by a continuous hydrothermal method in supercritical water. The supercritical synthesis led to CZO with better thermal stability and higher OSC than that synthesized by the CP method.

The solvothermal method is a direct and rapid method, which has been used for the synthesis of metal oxide nanoparticles (NPs) for various applications [108,109]. Devaraju et al. [110] adopted the solvothermal method under supercritical and high autogenous pressure conditions $\left(400^{\circ} \mathrm{C}, 40 \mathrm{MPa}\right)$ for the direct preparation of nanocrystallite powders $\mathrm{CZO}$, which exhibited a high OSC value.

\subsubsection{Solution combustion method}

The SC method is simple and fast, and yields high surface area products with desired composition. It is an attractive synthetic route especially for the preparation of multicomponent oxide materials because the homogeneity of the aqueous solution of the salts is preserved in the combustion residue. The materials prepared by this method not only possess better homogeneity and purity, but also have high surface areas. Reddy et al. [111] reported a single synthesis step of nanosize $\mathrm{CeO}_{2}-\mathrm{M}_{x} \mathrm{O}_{y}$ mixed oxides $\left(\mathrm{M}_{x} \mathrm{O}_{y}=\mathrm{SiO}_{2}, \mathrm{TiO}_{2}, \mathrm{ZrO}_{2}\right.$ and $\left.\mathrm{Al}_{2} \mathrm{O}_{3}\right)$ by the $\mathrm{SC}$ method. Among these samples, $\mathrm{CeO}_{2}-\mathrm{SiO}_{2}$ showed the highest surface area compared with other oxides. The decreasing order of specific surface areas was as follows: $\mathrm{CeO}_{2}-\mathrm{SiO}_{2}$ $\left(125 \mathrm{~m}^{2} / \mathrm{g}\right)>\mathrm{CeO}_{2}-\mathrm{TiO}_{2}\left(79 \mathrm{~m}^{2} / \mathrm{g}\right)>\mathrm{CeO}_{2}-\mathrm{ZrO}_{2}\left(56 \mathrm{~m}^{2} / \mathrm{g}\right)>$ $\mathrm{CeO}_{2}-\mathrm{Al}_{2} \mathrm{O}_{3}\left(38 \mathrm{~m}^{2} / \mathrm{g}\right)$. Chen et al. [112] prepared mesoporous CZO via a salt-assisted combustion method using EG as the fuel and nitrate as the oxidant, and the effect of added salt on the properties of the products was studied. The presence of salt led to a more than 10 -fold increase in the specific surface area of the products at a given molar ratio of EG/nitrate. It was owing to that the instant salt in-situ precipitation inhibited the formation of hard agglomerates and sintering of naonocrystallites. Therefore, this method provided a novel and effective strategy to tailor the material properties. Zhang et al. [113] synthesized $\mathrm{Ce}_{0.6} \mathrm{Zr}_{0.4} \mathrm{O}_{2}$ solid solutions by $\mathrm{CP}, \mathrm{SG}, \mathrm{SC}$ and template-assisted approaches. The catalytic activities of bulk and $\gamma-\mathrm{Al}_{2} \mathrm{O}_{3}$ supported $\mathrm{Ce}_{0.6} \mathrm{Zr}_{0.4} \mathrm{O}_{2}$ solid solutions were investigated for the oxidation of soluble organic fractions from diesel engine exhausts. $\mathrm{Ce}_{0.6} \mathrm{Zr}_{0.4} \mathrm{O}_{2}$ mixed oxide was active for lube oxidation. Among these materials, the sample prepared by the SC method showed the best catalytic activity due to the reservation of the high surface area and small particle size.

\subsubsection{Micro-emulsion method}

Surface and interfacial catalysis plays a key role in the integrated synthesis and construction of functional architectures particularly for nanosize thin film due to the effect of surface tension and viscosity $[114,115]$. Zhou et al. [116] prepared five types of CZO-modified $\mathrm{Al}_{2} \mathrm{O}_{3}$ (CZA) by SG, ME, CP with super- 
critical drying (CPS), CP with common drying (CPC), and impregnation (IM) methods and investigated the effect of preparation method on the properties of CZA. The results revealed that CZA prepared by CPS and ME methods exhibited better textural and structural properties as well as better reducibility, which led to the higher catalytic activity and wider air-to-fuel operation window of the corresponding Pd-only three-way catalysts. Boutonnet et al. [117] adopted a novel and direct approach for the preparation of inorganic NPs by an oil-in-water (o/w) ME method, in contrast to the typical water-in-oil ME method. As shown in Fig. 5, the strategy involves the use of organometallic precursors, which are dissolved in oil droplets in a nanometer scale (stabilized by surfactant) and dispersed in a continuous aqueous phase.

\subsubsection{Self-assembly method}

The self-assembly method refers to structure units such as molecules or NPs integrating spontaneously via non-covalent bons to form aggregation with thermodynamically stable structure. The driving force of this process contains the electrostatic force, hydrogen bond, electronic effect, van der Waals force, and space effect of functional groups [118]. The self-assembly materials are all with ordered structure and morphology, and the formation process is according to the principle that free energy should be minimized and without extra external force. Chane-Ching et al. [119] developed a two-step self-assembly approach for the preparation of ordered 2-D or 3-D nanostructured materials with a large surface area. Ceria NPs were functionalized by using the $\mathrm{CH}_{2} \mathrm{CH}_{2} \mathrm{O}$ groups of the surfactant. According to the cooperative self-assembly of colloidal NPs, hexagonal arrays of $\mathrm{CeO}_{2}$ were obtained and the symmetry of the arrays was maintained upon heating up to $500{ }^{\circ} \mathrm{C}$. Chou et al. [120] facilely synthesized a series of mesoporous CZO nanocrystallite with excellent thermal stabilities through the EISA strategy. Fig. 6 exhibited the orderedly mesoporous structure for as-prepared different $\mathrm{Ce} / \mathrm{Zr}$ ratio materials.

\subsubsection{Sonochemical synthesis method}

Sonochemical process has proved to be an effective method for the preparation of novel materials with unusual properties [121]. Moreover, it is an environmentally friendly synthesis route for functional materials and may be a good approach that can be used to synthesize nanoporous transition metal oxide solid solutions. Nevertheless, only a few studies on sonochemical synthesis of multicomponent materials have been found.

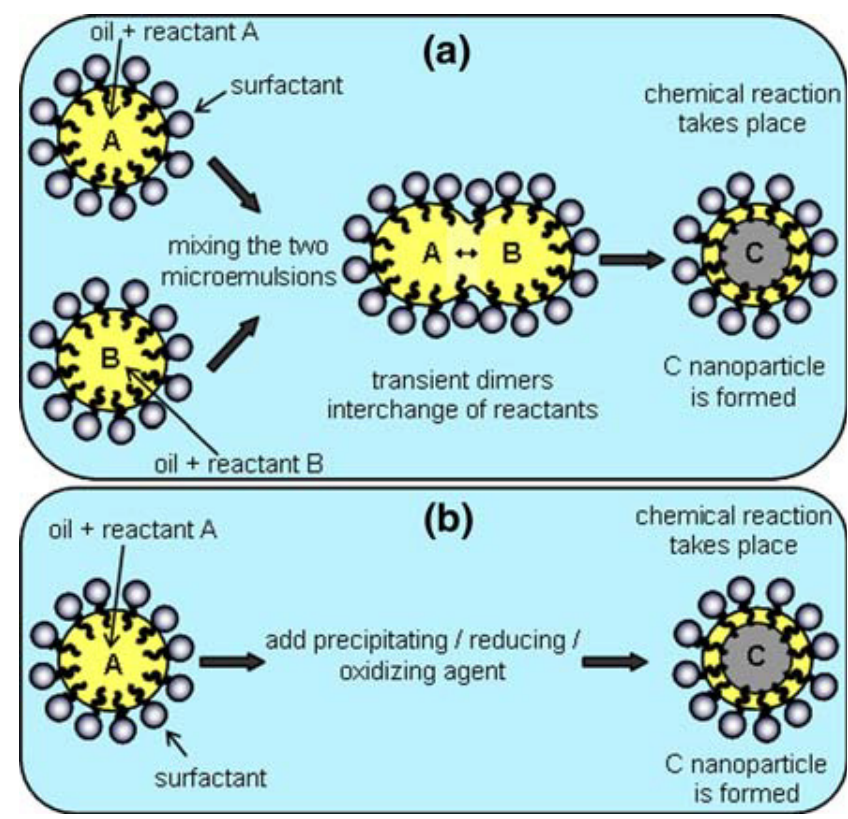

Fig. 5. Strategies for the preparation of inorganic nanosize CZO by the o/w microemulsion reaction approach. (a) Mixing two microemulsions of identical composition except for reactants A organometallic precursor and B precipitating/reducing/oxidizing agent; (b) Using a microemulsion containing reactant $\mathrm{A}$, and then directly adding reactant $\mathrm{B}$. Reprinted from [117] with permission.

Gurav et al. [122] investigated the sonochemical synthesis of nanoporous ceria and CZO with high surface area via high-intensity ultrasound irradiation. Zhang et al. [123] prepared nanosize CZO with a very big surface area of $226 \mathrm{~m}^{2} / \mathrm{g}$ and average size about $3.7 \mathrm{~nm}$ by a sonochemical method in the presence of polyethylene glycol (PEG). Moreover, its surface area and nanosize rarely changed after being calcined at $500{ }^{\circ} \mathrm{C}$. Recently, Nikitenko et al. [124] prepared $\mathrm{Ce}_{0.5} \mathrm{Zr}_{0.5} \mathrm{O}_{2}$ nanocrystallite mixed oxide with external mesopores using simultaneous sonohydrothermal treatment. The obtained material exhibited higher surface area than the similar material prepared by an ultrasonically assisted CP method.

\subsubsection{Physical method}

\subsubsection{High-energy milling}

The high-energy milling method relies on the high pressure and mechanic force to make particles with high density of lattice defects, and thus the as-prepared materials possess high OSC. Trovarelli et al. [125] synthesized nanosize CZO via

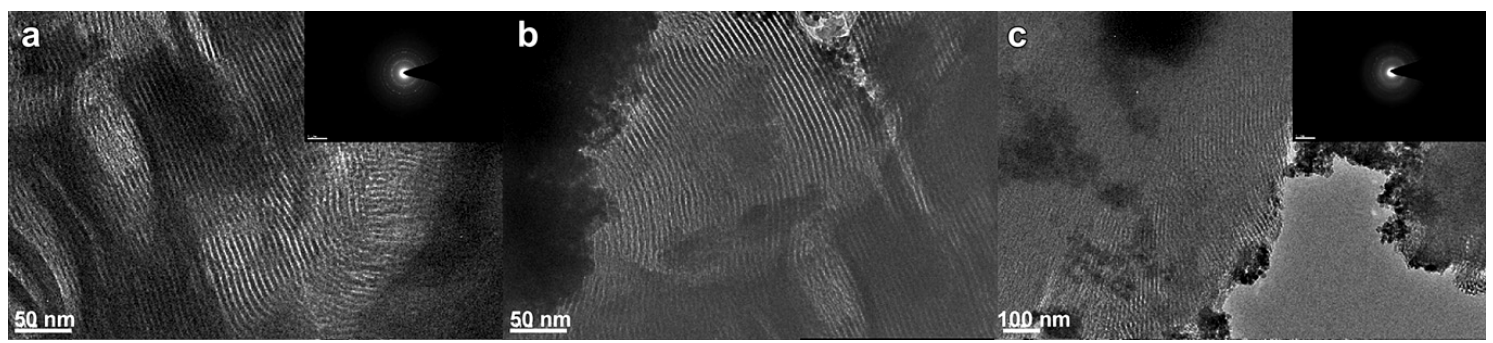

Fig. 6. TEM images of $\mathrm{Mn}-\mathrm{Ce}_{\mathrm{x}} \mathrm{Zr}_{1-\mathrm{x}} \mathrm{O}_{2}$ with different $\mathrm{Ce} / \mathrm{Zr}$ ratios by calcination at $600{ }^{\circ} \mathrm{C}$. (a) $\mathrm{Mn}-\mathrm{Ce}_{0.2} \mathrm{Zr}_{0.8} \mathrm{O}_{2}$; (b) $\mathrm{Mn}_{-}-\mathrm{Ce}_{0.4} \mathrm{Zr}_{0.6} \mathrm{O}_{2}$; (c) $\mathrm{Mn}-\mathrm{Ce}_{0.5} \mathrm{Zr}_{0.5} \mathrm{O}_{2}$. Reprinted from [121] with permission. 
high-energy milling, and $\mathrm{ZrO}_{2}$ was doped into fluorite structural $\mathrm{CeO}_{2}$ lattice when the milling speeds gradually increased. Recently, they successfully prepared CZO particles wrapped in a 2-D carbon envelope by high-energy milling of CZO powders and soot, and the atomic ratio of metal-to-carbon increased with more milling time. Consequently, the activation and transfer of the oxygen in ceria were shifted to very low temperatures, which significantly boosted the soot combustion rate [126].

\subsubsection{Electrospinning method}

The electrospinning method is a cost-effective method for preparing electrospun fibers with high surface areas and adequately small grain sizes, which are indispensible for good reducibility and fast low-temperature reoxidation in solar-driven redox cycles. The high surface area of electrospun structures can accelerate the reoxidation surface kinetics at low temperature and inhibit sintering at high reduction temperatures. Davidson and Jackson prepared a series of CZO fibers with a uniform diameter by a controlled electrospinning method [127]. The electrospinning set-up was shown in Fig. 7. These CZO fibers exhibited remarkable sinter-resistance, which maintained their structure even after 108 redox cycles with reduction at $1400{ }^{\circ} \mathrm{C}$ and oxidation with $\mathrm{CO}_{2}$ at $800{ }^{\circ} \mathrm{C}$. It was higher than those observed for other ceria-based materials conducting under similarly high temperature conditions.

\subsubsection{Other methods}

Liquid-feed flame spray pyrolysis (LF-FSP) is a facile method which was developed in recent years for material synthesis. In this synthesis strategy, organometallic alcohol solutions are usually used and are aerosolized with oxygen and ignited. The combustion process produces flames up to $1500-2000{ }^{\circ} \mathrm{C}$. If the combustion process derived metal oxide ions are quenched rapidly enough, e.g., $1000{ }^{\circ} \mathrm{C} / \mathrm{ms}$, it is possible to prepare a large variety of unaggregated (easily dispersed) nanopowders whose compositions are almost completely determined by the precursors in solution [128-130]. Kim et al. [128] synthesized

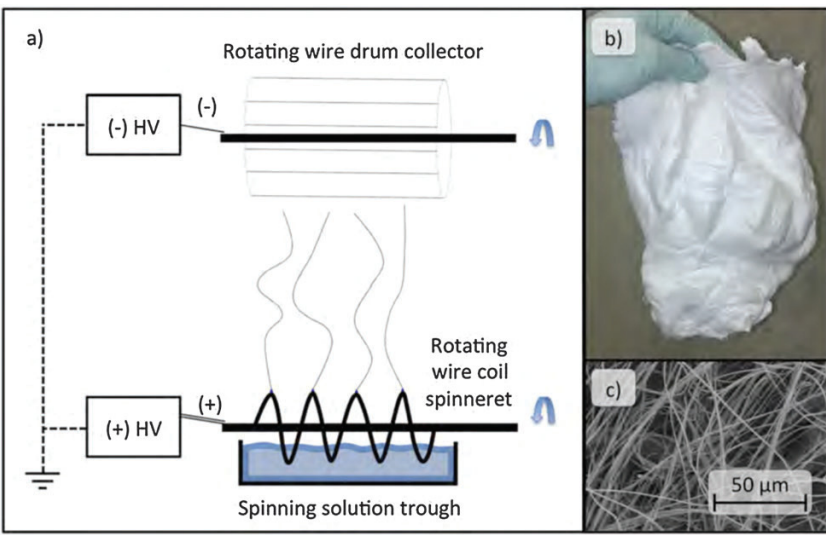

Fig. 7. Fiber production via electrospinning set-up. (a) Wire coil spinneret rotating through a bath of spinning solution, fibers on a rotating wire drum collector; (b) Removal of the collected fibers from the wire drum, leaving a non-woven mat of polymer and ceramic precursor fibers; (c) SEM image of the ceramic + precursor fibers. Reproduced from [127] with permission from the PCCP Owner Societies.
CZO and $\left(\mathrm{Ce}_{0.7} \mathrm{Zr}_{0.3} \mathrm{O}_{2}\right)_{\times}\left(\mathrm{Al}_{2} \mathrm{O}_{3}\right)_{1-x}$ core-shell nanopowders by LF-FSP using metallo-organic precursors $\mathrm{Ce}\left(\mathrm{O}_{2} \mathrm{CCH}_{2} \mathrm{CH}_{3}\right)_{3}(\mathrm{OH})$, alumatrane $\mathrm{N}\left(\mathrm{CH}_{2} \mathrm{CH}_{2} \mathrm{O}\right)_{3} \mathrm{Al}$, and $\mathrm{Zr}\left(\mathrm{O}_{2} \mathrm{CCH}_{2} \mathrm{CH}_{3}\right)_{2}(\mathrm{OH})_{2}$. The as-prepared materials possessed mean particle size below 20 $\mathrm{nm}$ and specific surface area of $30-50 \mathrm{~m}^{2} / \mathrm{g}$ and showed good catalytic activity for $\mathrm{HC}$ oxidation and $\operatorname{deNO}_{x}$ reaction even without co-catalyst of noble metals.

In addition, some other methods have also been developed for cerium-zirconium based material synthesis, including supercritical anti-solvents [131,132], microwave-assisted method [133-136], electrochemical deposition [137-139], microwave method [140], etc.

\subsubsection{Summary of synthesis methods for nanosize cerium-zirconium-based solid solutions}

To date, a great variety of methods have been developed for the synthesis of nanosize CZO, and these methods have a great impact on the properties of materials, such as specific surface area, crystal phase, redox, OSC, and thermal stability, as listed in Table 1. The preparation of nanosize CZO usually involves four steps: the synthesis of precursor, the pretreatment of precursor, the transformation of precursor into solid solutions, and post-treatment of solid solutions. At present, the primary preparation methods for nanosize CZO are CP, SG, surfactant-assisted template, hydrothermal, SC, and ME methods, and each of them possesses its feature and certain deficiencies.

The high energy ball milling method is highly costly and time consuming, and the material prepared by this method exhibits low specific surface area and OSC value. Thus, this method is rarely employed to prepare nanosize CZO. Generally, SG synthesis is a suitable method to prepare CZO with high degree of homogeneity by controlling the hydrolytic process of the precursor like alkoxide. However, it should be taken into account that when the rates of hydrolysis between the two metals are quite different, it may be difficult to simultaneously hydrolyze the both precursors. Consequently, CZO prepared by this method often exists split phase. But the homogeneity of CZO can be improved via suitable chemical modification or adding certain solvent to control the hydrolysis rate of the both precursors. The SC method is usually used to prepare nanostructural $\mathrm{CZO}$ by burning $\mathrm{Ce}\left(\mathrm{NO}_{3}\right)_{3}, \mathrm{ZrO}\left(\mathrm{NO}_{3}\right)_{2}$, oxalyl dihydrazide, and carbohydrazide. Its advantage is that the samples possess high specific surface area, and the disadvantages are high cost, waste gas producing, and low OSC value. The hydrothermal method is employed to prepare $\mathrm{CeO}_{2}$ and $\mathrm{ZrO}_{2}$-containing materials, and $\mathrm{CZO}$ prepared by this method under supercritical conditions shows good homogeneity, high OSC value, and excellent thermal stability. However, its production amount is very little. In general, the hydrothermal method is used in laboratory and not industrialized yet. The CP method is one of the common methods to prepare CZO. It uses a precipitant to transform soluble components into complex compounds and the corresponding solid solution is obtained by separation, washing, drying, and roasting. Currently, the CP method is convenient for industrial production due to its simple process, controllable condition, cheap raw materials, and low preparation cost. Nevertheless, high temperature calcina- 
Table 1

Main characteristics of different synthesis methods for nanosize CZO materials.

\begin{tabular}{|c|c|c|}
\hline Synthesis method & Characteristics of the method & Characteristics of the materials \\
\hline Co-precipitation method & $\begin{array}{l}\text { Simple synthesis process, controllable condition, cheap raw } \\
\text { materials, and low preparation cost }\end{array}$ & $\begin{array}{l}\text { An excellent mixing of the different components, } \\
\text { surface area } 20-120 \mathrm{~m}^{2} / \mathrm{g}\end{array}$ \\
\hline Sol-gel method & Mild synthetic conditions, but time consuming & Existing split phase, but high surface area \\
\hline Template-assisted method & $\begin{array}{l}\text { Convenience, simplicity and inducing effect of various tem- } \\
\text { plates with special structures or morphology }\end{array}$ & $\begin{array}{l}\text { Controllable size, morphology and structure as well } \\
\text { as high surface area }\end{array}$ \\
\hline $\begin{array}{l}\text { Hydrothermal and solvothermal } \\
\text { method }\end{array}$ & $\begin{array}{l}\text { Direct and rapid, high temperature }\left(100-1000^{\circ} \mathrm{C}\right) \text {, high } \\
\text { pressure }(1-100 \mathrm{MPa})\end{array}$ & Homogeneous, high OSC and good thermal stability \\
\hline Solution combustion method & Simple, fast, but high cost and waste gas producing & $\begin{array}{l}\text { Uniform crystalline particle size and high surface } \\
\text { area but low OSC }\end{array}$ \\
\hline Micro-emulsion method & Especially for nanosize thin film & $\begin{array}{l}\text { Better textural and structural properties as well as } \\
\text { better redox behavior }\end{array}$ \\
\hline Self-assembly method & $\begin{array}{l}\text { Cheap, fast, simple and convenient, but difficult to prepare } \\
\text { materials with complex structure }\end{array}$ & Ordered structure and morphology \\
\hline Sonochemical synthesis method & $\begin{array}{l}\text { Useful technique in the synthesis of novel materials with } \\
\text { unusual properties and environmentally friendly synthesis } \\
\text { route for functional materials }\end{array}$ & Remarkably high surface area \\
\hline High energy ball milling method & High cost and time consuming & Low surface area and OSC \\
\hline Electrospinning method & Cost-effective & High surface areas and adequately small grain sizes \\
\hline
\end{tabular}

tion can induce a serious decrease of specific surface area of solid solution. Moreover, when precipitation is performed in water, the particles size would aggregate and grow up in the process of drying owing to the effect of surface tension. Therefore, the various preparation technologies for nanosize CZO material synthesis still need to be improved.

\subsection{Morphology for nanosize cerium-zirconium-based solid solutions}

As is known to all, properties and functions of CZO materials highly depend on their morphology and size. Hence, the controllable synthesis of CZO with unique morphology is significantly important $[141,142]$. Meanwhile, CZO with nanometer size usually possesses high OSC value and specific surface areas, which can greatly enhance the catalytic activity. Nanopowders and one-dimensional (1-D) nanostructure nowadays have been the most popular realm of synthesis of cerium-zirconium-based materials, including nanowires, nanobelts, nanorods, and nanotubes. Moreover, nanoplates, nanodisks, linearly-mesoporous structure (two-dimensional, 2-D), and nanocages, or 3-D mesoporous or macroporous structure (three-dimensional, 3-D) and various specific morphology of CZO have also arouse the interests of researchers. CZO can be divided into five categories according to the different morphology: nanopowders, 1-D, 2-D, 3-D, and other morphology such as core-shell structure, as shown in Table 2.

\subsubsection{Nanopowders}

Nanopowder is an important part of the nanomaterial family, which is composed of NPs with the size of 1-100 nm. Nanopowder is a transition state between atoms (or molecules) and macroscopic objects. The quantitative change of NPs may lead to the remarkable change of material properties. In fact, the crystal symmetry, space lattice, defects, dislocations, and crystal boundaries of macroscopic objects have been deeply and systematically investigated. Nanopowders may be a prom- ising material in both fundamental research and application development due to its special properties. Especially, CZO nanopowders have attracted much attention in recent years $[143,144]$. They are synthesized mainly via CP, hydrothermal, and SG methods. Despite of many studies on the synthesis technique of CZO nanopowders, it is still a tough issue to obtain products with high stability and uniform size.

To prepare nanopowders with high stability, surfactants are employed in synthesis processes to promote the dispersion of precursors. PVP (polyvinylpyrrolidone) can be used in different dispersion systems as a stabilizer agent for preventing reaction product aggregation. Si et al. [145] used $\mathrm{Ce}\left(\mathrm{NO}_{3}\right)_{3} \cdot 6 \mathrm{H}_{2} \mathrm{O}$ as precursor and PVP as stabilizing agent in alcohol solution to prepare $\mathrm{CeO}_{2}$ colloidal particles with sizes of ca. $4 \mathrm{~nm}$. Du et al. [146] used CTAB as template to induce the assembly of $\mathrm{Ce} 0.7 \mathrm{Zr}_{0.3} \mathrm{O}_{2}$ nanopowders via the $\mathrm{CP}$ method. Under the condition of plenitudinous reaction and aging time, CZO with a pure crystal phase was obtained. The as-prepared material possessed an average size of $15 \mathrm{~nm}$, pore diameter of 2-4 nm, and specific surface area of $179 \mathrm{~m}^{2} / \mathrm{g}$ and showed high stability. Liu et al. [147] prepared a series of Ce-Zr-Pr nanopowder oxide catalysts via uniting solution-combustion and rotating evaporation techniques. The catalysts exhibited a cubic fluorite structure with particle sizes in the range of 6-8 nm. Darr et al. [143] prepared La- and Y- doped nanosize CZO with different compositions by a hydrothermal method. Both samples showed an average particle size of $4.5 \mathrm{~nm}$. For nanopowder synthesis, the raw material utilization is usually inefficient and the process of preparation may also be not environmentally friendly. Thus, seeking for the efficient and comfortable synthesis of CZO nanopowders of regular morphology with high stability and activity is an imperative issue.

\subsubsection{1-D cerium-zirconium-based solid solutions}

\subsubsection{Nanowires, nanobelts, and nanofibers}

Nanowires, nanobelts, and nanofibers are 1-D nanostuc- 
Table 2

Main characteristics and synthesis methods of nanosize CZO materials with the different morphology.

\begin{tabular}{|c|c|c|c|}
\hline \multicolumn{2}{|l|}{ Morphology } & Synthesis method & Characteristics \\
\hline 0-D nanomaterials & Nanopowders & \multicolumn{2}{|c|}{ Co-precipitation, hydrothermal and sol-gel method Particle sizes of 1-100 nm } \\
\hline \multirow[t]{5}{*}{ 1-D nanomaterials } & Nanowires & Sol-gel, hydrothermal method & Ultrasmall diameter of $\sim 1 \mathrm{~nm}$ and a length of $70 \mathrm{~nm}$ \\
\hline & Nanobelts & Electrochemical deposition & Ultrathin \\
\hline & Nanofibers & Electrospinning, hydrothermal, co-precipitation, & Uniform size from $300-400 \mathrm{~nm}$ in length \\
\hline & Nanorods & $\begin{array}{l}\text { Template-assisted method hydrothermal (sol- } \\
\text { vothermal), ME, template-assisted method }\end{array}$ & $10-40 \mathrm{~nm}$ in diameter and $30 \mathrm{~nm}$ to $2 \mu \mathrm{m}$ in length \\
\hline & Nanotubes & Template-assisted and hydrothermal method; & $\begin{array}{l}\sim 15 \mathrm{~nm} \text { in wall thicknesses and } 100 \mathrm{~nm} \text { to } 8 \mu \mathrm{m} \text { in } \\
\text { length, high surface areas }\end{array}$ \\
\hline 2-D nanomaterials & Thin film & $\begin{array}{l}\text { One-step, sol-gel, template assisted hydrothermal } \\
\text { method }\end{array}$ & Highly thermal stability \\
\hline \multirow[t]{4}{*}{ 3-D nanomaterials } & Nanocages & Hydrolysis process & Controlled shapes, sizes and high surface areas \\
\hline & Mesoporous materials & $\begin{array}{l}\text { Self-assembly, co-precipitation, hydrothermal } \\
\text { synthesis and hard template method }\end{array}$ & High surface area and special porous structure \\
\hline & Macroporous materials & Template-assisted method & $\begin{array}{l}\text { Ordered macroporous materials with controlled pore } \\
\text { size }\end{array}$ \\
\hline & $\begin{array}{l}\text { Hierarchically porous } \\
\text { materials }\end{array}$ & $\begin{array}{l}\text { Dual-template assisted colloidal crystal templating } \\
\text { method }\end{array}$ & $\begin{array}{l}\text { High surface area, controllable composition, thermal } \\
\text { and chemical stability, high porosity }\end{array}$ \\
\hline \multirow[t]{2}{*}{ Other nanomaterials } & $\begin{array}{l}\text { Flower-like } \\
\text { nanostructures }\end{array}$ & $\begin{array}{l}\text { Electrodepositon and template-assisted hydro- } \\
\text { thermal method }\end{array}$ & $\begin{array}{l}\text { Flexibility in controlling the sizes, shapes, and com- } \\
\text { positions }\end{array}$ \\
\hline & Core-shell structure & Sol-gel and chemical deposition method & \\
\hline
\end{tabular}

tures, but studies on the morphology of CZO materials are not sufficient compared with nanopowders. Despite of this, some work has been reported. Song et al. [148] prepared CZO nanofibers via an electrospinning technique. In this process, P123 and polyethylene oxide (PEO) were used as co-template agents and ceric nitrate and zirconium nitrate as precursors. P123 and PEO mixture allowed the formation of microphase domains during the electrospinning process. A handful of PVP was also introduced to control the viscosity of the composite solutions for better electrospinning. The as-prepared material has a uniform size of 300-400 nm in length. Li et al. [149] synthesized ceria-based nanobelts by electrochemical deposition on $\mathrm{Cu}$ substrates. The surface morphology was highly dependent on the additive and current density of electrochemical deposition, and this method could be applied to prepare other nanosize rare earth oxide materials. Hyeon et al. [150] fabricated ceria nanowires with a length of $71 \mathrm{~nm}$ and an ultrasmall diameter of $1.2 \mathrm{~nm}$ by a nonhydrolytic sol-gel method. During the thermolysis of the precursor complexes, the selective adsorption of capping ligand onto particular crystallographic facets was important for the formation of ultrathin nanowires, whose lengths were tunable by altering the amount of oleylamine. This strategy is effective in adjusting the length/diameter ratio of nanowires.

\subsubsection{Nanorods}

A number of pure $\mathrm{CeO}_{2}$ nanorods have been synthesized via hydrothermal (solvothermal), ME, template-assisted, and chemical vapor deposition methods. However, compared with the synthesis of $\mathrm{CeO}_{2}$ nanorods, $\mathrm{CZO}$ nanorods are more difficult to fabricate. Du et al. [151] synthesized nanorod-like $\mathrm{Ce}_{0.7} \mathrm{Zr}_{0.3} \mathrm{O}_{2}$ solid solutions by a sodium dodecyl sulfate-assisted precipitation method. Typical $\mathrm{Ce}_{0.7} \mathrm{Zr}_{0.3} \mathrm{O}_{2}$ nanorods were 450 $\mathrm{nm}$ in length and $40 \mathrm{~nm}$ in average diameter, with specific surface area and OSC of $194 \mathrm{~m}^{2} / \mathrm{g}$ and $374 \mu \mathrm{mol} / \mathrm{g}$, respectively.
Shen et al. [152] prepared $\mathrm{Ce}_{1-x} \mathrm{Zr}_{x} \mathrm{O}_{2}(0 \leq x \leq 0.2)$ nanorods with an average length of $\sim 40 \mathrm{~nm}$ and a mean diameter of $\sim 8 \mathrm{~nm}$ by an aqueous-phase $\mathrm{CP}$ method. The reaction was under the conditions of $95^{\circ} \mathrm{C}$ in the solvent media and lasted for $8 \mathrm{~h}$. Lee et al. [153] employed a two-step route under hydrothermal conditions and prepared CZO nanorods with average diameter and length in a range from $20-30$ to $100-200 \mathrm{~nm}$, respectively. Shi and Zhang et al. [154] designed the synthesis of $\mathrm{MnO}_{\mathrm{m}} / \mathrm{CZO}$ nanomaterials and investigated the effect of the morphology of CZO on the catalytic activity of $\mathrm{MnO}_{m} / \mathrm{CZO}$ for the SCR of NO with $\mathrm{NH}_{3}$. Three different shapes of CZO nanomaterials such as nanorods, nanocubes, and nanopolyhedra were prepared by a hydrothermal method and the temperature was maintained at $100{ }^{\circ} \mathrm{C}$ for nanorods. Zhang et al. [155] prepared $\mathrm{Ce}_{0.9} \mathrm{Zr}_{0.1} \mathrm{O}_{2}$-supported manganese oxides $\left(\mathrm{MnO}_{m}\right)$ nanorods through a hydrothermal method with the reactants at $100{ }^{\circ} \mathrm{C}$ for 24 h. TEM images in Fig. 8 showed $\mathrm{Ce}_{0.9} \mathrm{Zr}_{0.1} \mathrm{O}_{2}$ nanorods with a length range of 15-90 $\mathrm{nm}$ and a uniform diameter (11 \pm $3 \mathrm{~nm})$.

Many metal-doped CZO samples were also investigated by researchers. Dai et al. [156] prepared $\mathrm{Ce}_{0.6} \mathrm{Zr}_{0.3} \mathrm{Y}_{0.1} \mathrm{O}_{2}$ (CZY) solid solution nanorods with cubic fluorite structure by adopting the strategy of CTAB-assisted hydrothermal treatment at 120 and $160{ }^{\circ} \mathrm{C}$ for $72 \mathrm{~h}$. Fig. 9 shows that both samples exhibited a rodlike shape with length variation from $30 \mathrm{~nm}$ to $2 \mu \mathrm{m}$ and uniform diameters of $\sim 10 \mathrm{~nm}$, and the samples contained some irregular NPs. Yan et al. [157] synthesized monodisperse and large-scale Pr-doped ceria nanorods by combination of low-temperature aging and high-temperature precipitation without further sintering. The morphology of the products was $400 \mathrm{~nm}$ in length and $30 \mathrm{~nm}$ in diameter, and Pr-doped ceria nanorods exhibited relatively high specific surface area (153 $\left.\mathrm{m}^{2} / \mathrm{g}\right)$.

\subsubsection{Nanotubes}




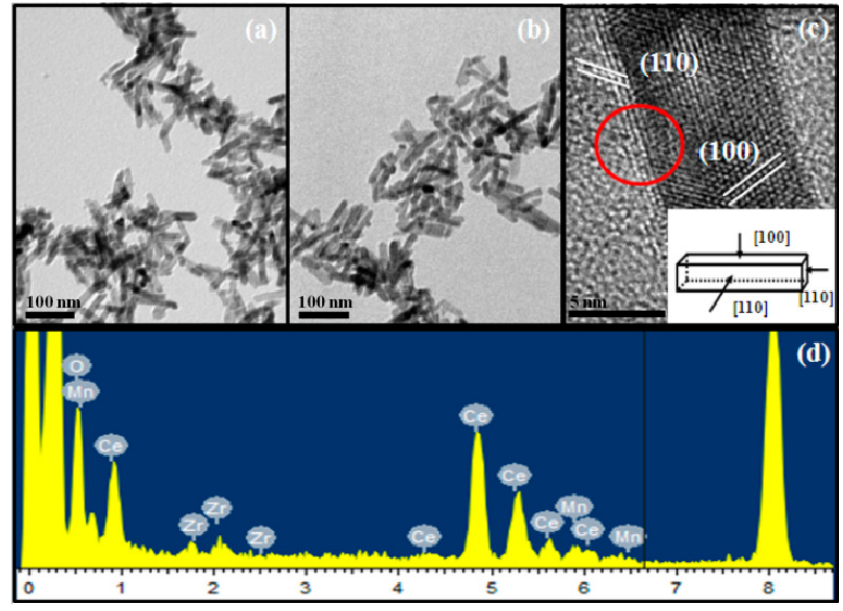

Fig. 8. TEM images of (a) $\mathrm{Ce}_{0.9} \mathrm{Zr}_{0.1} \mathrm{O}_{2}$ and (b) $\mathrm{MnO}_{\mathrm{m}} / \mathrm{Ce}_{0.9} \mathrm{Zr}_{0.1} \mathrm{O}_{2}$ nanorods. HRTEM image (c) and EDS pattern (d) of $\mathrm{MnO}_{\mathrm{m}} / \mathrm{Ce}_{0.9} \mathrm{Zr}_{0.1} \mathrm{O}_{2}$ nanorods. Reprinted from [155] with permission.

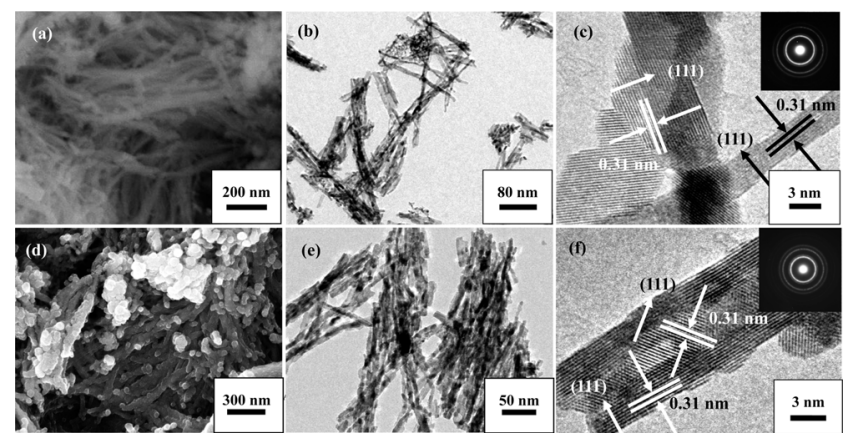

Fig. 9. SEM $(a, d)$ and HRTEM $(b, c, e, f)$ images as well as their SAED patterns (insets) of $(a-c)$ CZY-CTAB-120 and (d-f) CZY-CTAB-160. Reprinted from [156] with permission.

Nanotube research has become a hot spot in the material science field because of several reasons [158-160]. First of all, nanotubes with sufficient small dimensions possess high specific surface areas, good atomic efficiencies, rapid response to reaction conditions, and high activities in catalyst systems. Secondly, the tubular nanostructure may endow itself additional advantages, such as high thermal and chemical and structural stability. Finally, these structures may lead to completely new applications in nanotechnology, for example, if the nanotubes can be aligned. CZO nanotubes can be prepared via template (CNTs, polycarbonate, etc.)-assisted and hydrothermal methods. Fuentes and Baker et al. [161] synthesized CZO nanotubes with $\mathrm{CeO}_{2}$ contents of $50 \mathrm{~mol} \%, 70 \mathrm{~mol} \%$, and 90 mol\% using polycarbonate membrane with pore diameter of $800 \mathrm{~nm}$ as template. The obtained nanotubes were $1-8 \mu \mathrm{m}$ in length, $500 \mathrm{~nm}$ in diameter, and $20 \mathrm{~nm}$ in wall thicknesses, as shown in Fig. 10. Lee et al. [162] prepared zirconium-doped ceria nanotubes by mixing $\mathrm{Ce}\left(\mathrm{NO}_{3}\right)_{3} \cdot 6 \mathrm{H}_{2} \mathrm{O}$ and zirconium dioxide powder in $\mathrm{NaOH}$ solution under hydrothermal conditions. The influence of zirconium on the growth of ceria nanotubes was also investigated, and the Kirkendall effect would affect the formation of nanotube structure. They reported a straightforward synthesis method of CZO nanotubes with high yield, several hundred $\mathrm{nm}$ in length, $\sim 52 \mathrm{~nm}$ in average pore size, and 76

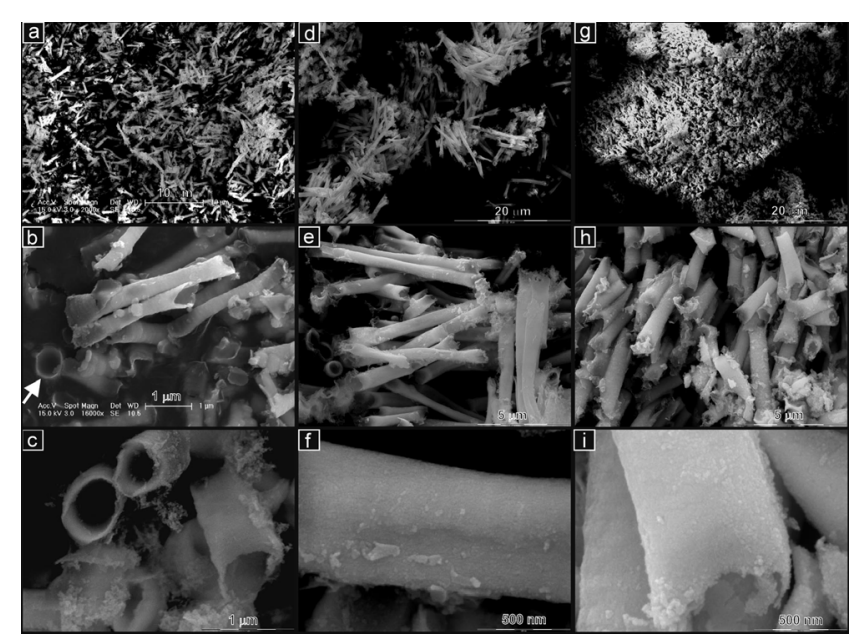

Fig. 10. SEM images of (a, b) $\mathrm{Ce}_{0.5} \mathrm{Zr}_{0.5} \mathrm{O}_{2}$, (c-f) $\mathrm{Ce}_{0.7} \mathrm{Zr}_{0.3} \mathrm{O}_{2}$, and (g-i) $\mathrm{Ce}_{0.9} \mathrm{Zr}_{0.1} \mathrm{O}_{2}$ at low magnification, showing the high yield of nanotubes; at intermediate magnification, showing the structure of individual nanotubes, including several tubes viewed end-on; and at high magnification, showing the nanoparticulate nature of the nanotube walls. Reprinted from [161] with permission.

$\mathrm{m}^{2} / \mathrm{g}$ in specific surface area. Moreover, the nanotubes possessed inner diameter ranging from 30 to $50 \mathrm{~nm}$, and wall thickness was about $15 \mathrm{~nm}$.

\subsubsection{2-D cerium-zirconium-based solid solutions}

Sanchez et al. [163] prepared a highly linearly mesoporous CZO thin film with 2-4 nm pores by a one-step method. This kind of material exhibited highly thermal stability, which still retained their structural integrity even after crystallization and thermal treatment at $700{ }^{\circ} \mathrm{C}$. Niklasson et al. [164] fabricated CZO films by the SG method. Cerium nitrite together with zirconium oxychloride was dissolved in ethanol to prepare precursor solutions. Veszelei et al. [165] prepared CZO films by reactive direct current magnetron cosputtering. The films could remain completely transparent under repeated $\mathrm{Li}^{+}$and electron insertion/extraction and were, therefore, of much interest as counter electrodes in transparent optoionic devices such as smart window. Brezesinski et al. [166] synthesized mesostructural thin films of CZO using a novel type of amphiphilic block copolymer as template, and the films possessed highly crystallited pore walls and ordered arrays of mesopores. Zelcer et al. [167] adopted a straightforward and reproducible way to prepare $\mathrm{Ce}_{x} \mathrm{Zr}_{1-x} \mathrm{O}_{2}(0 \leq x \leq 0.5)$ thin films with linearly mesoporous structure. $\mathrm{Zr}(\mathrm{PrO})_{4}$ and $\mathrm{CeCl}_{3} \cdot 7 \mathrm{H}_{2} \mathrm{O}$ were used as the inorganic sources, acetylacetone as stabilizing agent, and F127 as pore template. Janek et al. [168] reported a series of ordered mesoporous thin films of CZO with $17 \mathrm{~nm}$ diameter pores and nanocrystallite walls. The mesoporous oxide films were thermally stable and still kept their structure up to $600^{\circ} \mathrm{C}$.

Dai et al. [156] synthesized a bowknot-like $\mathrm{Ce}_{0.6} \mathrm{Zr}_{0.3} \mathrm{Y}_{0.1} \mathrm{O}_{2}$ entity, consisting of a variety of nano- and microslices with 2-6 $\mu \mathrm{m}$ in width and 5-10 $\mu \mathrm{m}$ in length, by adopting the strategy of P123-assisted hydrothermal treatment. These nano- and microslices were aligned along the reverse orientation of the center of the microbowknot, forming rather coarse surfaces of the 
ends of a microbowknot.

\subsubsection{3-D cerium-zirconium-based solid solutions}

\subsubsection{Nanocages}

CZO nanocages may exhibit excellent catalytic performance owing to the special morphology and may be also employed as novel nanoreactors due to the hollow structure. Li et al. [169] fabricated monodisperse $\mathrm{CeO}_{2}$ spheres via a hydrolysis process, which then were employed as precursors and reacted with zirconium(IV) to prepare CZO nanocages with controlled compositions, sizes, and shapes according to a modified Kirkendall effect. Fig. 11 exhibited that the materials showed a special nanocage morphology which possessed high surface areas of $142 \mathrm{~m}^{2} / \mathrm{g}$ for nearly cubic nanocages, and $183 \mathrm{~m}^{2} / \mathrm{g}$ for spherical nanocages, respectively. Xu and Huang et al. [170] prepared the uniform monodisperse CZO nanocages with an apparent interior void. The diameters of the nanocages were about 80-100 nm.

\subsubsection{3-D mesoporous cerium-zirconium-based solid solutions}

Nanocrystallite structured materials are desired in the practical applications due to their high surface area and special porous structure. 3-D mesoporous materials with high specific surface area, highly ordered channels, and narrow pore size distribution have provoked intensive interest, thus widespread application on catalysis. 3-D mesoporous Ce-based materials were reported in the 1990s. This material shows a broad arrangement of mesopores in the region of 2-8 $\mathrm{nm}$ with an optimal value at around $3.5-4.0 \mathrm{~nm}$, and surfactants are significantly important to obtain high surface area mesoporous ceria because they can lower the surface tension of water in the pores during drying [171]. Many methods were developed to synthesize mesoporous ceria and CZO with crystallite framework, including self-assembly [97,172], direct hydrothermal synthesis [173], and hard-template assisted method [174,175].

Deshpande et al. [176] synthesized a series of CZO beads via a nanocasting approach by employing commercially available PS beads as templates. The as-prepared materials offered advantages of ease of handling and recovery and good flow properties. Moreover, the materials retained a high compositional homogeneity even after thermal treatment, and the surface

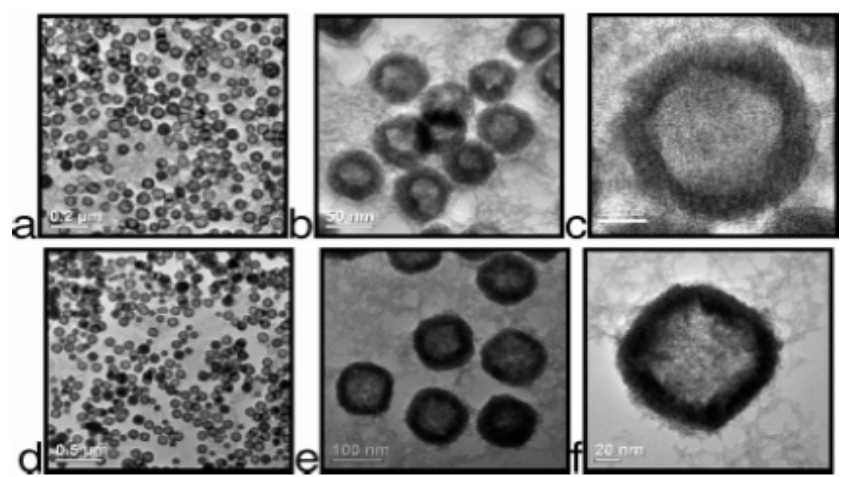

Fig. 11. (a-c) TEM images of spherical CZO nanocages with different magnifications, (d-f) TEM images of nearly cubic-like CZO nanocages with different magnifications. Reprinted from [169] with permission. area after calcination at $500{ }^{\circ} \mathrm{C}$ was in the range of $78-113$ $\mathrm{m}^{2} / \mathrm{g}$. Other nanocasting techniques have also been reported that siliceous KIT-6 was employed as the template [177]. As expected, relatively high surface area was achieved $(>163$ $\mathrm{m}^{2} / \mathrm{g}$ ) despite of high calcination temperatures for example $550{ }^{\circ} \mathrm{C}$. And the aging temperature of the siliceous template was of importance because it was directly related to both the pore size and specific surface area of the target materials. The as-prepared 3-D mesoporous CZO was used for the complete oxidation of naphthalene and exhibited higher catalytic activity than $\mathrm{CeO}_{2}$. Additionally, these mesoporous CZO oxides also demonstrated a high stability. Lu et al. [178] synthesized mesoporous $\mathrm{Ce}_{0.6} \mathrm{Zr}_{0.4} \mathrm{O}_{2}$ solid solution via combining $\mathrm{CP}$ and self-assembly methods. Thereupon, the solid solution consisted of homogeneous nanocrystals with uniform mesopores of ca. 4 $\mathrm{nm}$ and showed highly thermal stability. Moreover, different surfactants had little influence on the mesoporous structures. Although many methods are developed, further research is still needed, which should be concentrated on how to improve the mesopore regularity and raise the tolerated maximum temperature.

\subsubsection{Macroporous cerium-zirconium-based solid solutions}

3DOM materials have attracted much attention because of their peculiar structure and wide application in photonic crystal, catalysis, and separation science. To date, the main technique for 3DOM material synthesis is the template-assisted method. Colloidal crystals are usually used to prepare ordered macroporous materials with controlled pore size. Li et al. $[179,180]$ employed PS microspheres as templates and CA as complexing agent to prepare $3 \mathrm{DOM} \mathrm{CeO}_{2}$ via the $\mathrm{SG}$ method and reported the synthesis of $3 \mathrm{DOM} \mathrm{ZrO}_{2}$ by two steps. They prepared 3DOM carbon framework by using $\mathrm{SiO}_{2}$ as templates, and then $\mathrm{ZrOCl}_{2}$ was impregnated on the carbon framework. The final 3DOM product was obtained after the removal of carbon framework under a high-temperature condition.

Zhao et al. [99-102,181-184] carried out research on CZO with 3DOM morphology. 3DOM CZO was synthesized by the CCT method using EG-methanol solution of $\mathrm{Ce}\left(\mathrm{NO}_{3}\right)_{3} \cdot 6 \mathrm{H}_{2} \mathrm{O}$ and $\mathrm{ZrOCl}_{2} \cdot 8 \mathrm{H}_{2} \mathrm{O}$ as precursor solution. To obtain 3DOM metal oxides, the solidification of these salts was necessary before the removal of PMMA. The heteropolynuclear complex containing cerium and zirconium ions using EG-methanol solution as solvent was formed at low temperature during the dry process, indicating that the solidification of the two salts occurred. The inorganic precursors were introduced to CCT and permeated the voids between the close-packed spheres, and condensed into a hard inorganic framework upon drying. After removal of excessive liquid, drying at room temperature for $12 \mathrm{~h}$, and calcination at $550{ }^{\circ} \mathrm{C}$ for $5 \mathrm{~h}$, a 3DOM CZO material possessing perfect crystal phase was obtained.

\subsubsection{Hierarchically porous cerium-zirconium-based solid solutions}

Arandiyan et al. [185] reported a facile dual-template synthesis of Pt NPs supported on 3DOM-structured $\mathrm{Ce}_{0.6} \mathrm{Zr}_{0.3} \mathrm{Y}_{0.1} \mathrm{O}_{2}$ (3DOM CZY) with nanovoid-like or mesoporous skeletons. It 
was based on the use of a CTAB-assisted gas bubbling reduction route with $\mathrm{H}_{2} \mathrm{PtCl}_{6} / \mathrm{NaBH}_{4}$ and $\mathrm{P} 123$ as soft template and well-arrayed colloidal crystal PMMA microspheres as hard template to generate a 3DOM structure, as shown in Fig. 12 . Pt/3DOM CZY catalysts possessed great utility because of their high surface area, diverse composition, crystallinity, thermal and chemical stability, high porosity, and uniform pore size distribution as well as their excellent catalytic performance for $\mathrm{CH}_{4}$ combustion. Huang et al. [186] synthesized hierarchical CZO nanospheres with an outer diameter of about $90 \mathrm{~nm}$ by a modified approach (Kirkendall effect). The nanospheres showed uniform and monodisperse characteristic, which could be employed as effective adsorbents for arsenic removal. Yu et al. [187] developed a series of high-efficiency $\mathrm{Pd} / \mathrm{Ce}_{x} \mathrm{Zr}_{1-x} \mathrm{O}_{2}(x=$ 0.2-0.8) catalysts with mesoporous structures and macrochannels by a combined surfactant and CCT method. The non-interconnected macrochannels have a length of 20-60 mm and diameter of 1-2 $\mathrm{mm}$. The high-magnification SEM images revealed that the walls of these macro-channels derived from the packing of fine particles. The intraparticle spacing was related well to the mesopores in the product and hence both macro and meso-textural structures coexisted in the system. Wei et al. [188] innovatively fabricated a series of 3-D ordered meso-macroporous $\mathrm{PdCo} / \mathrm{CZO}$ catalysts by a combined CCT and EISA method, in which F127 and PMMA were used as mesopore and macropore templates, respectively. The resulting catalysts show $\sim 240 \mathrm{~nm}$ in macropore diameter and $\sim 5 \mathrm{~nm}$ in mesopore.

\subsubsection{Other morphology}

The other special morphology has been successfully synthesized and studied, such as flower-like, bowknot-like, core-shell and so on. This greatly broadened the application area of nanosize CZO materials. Li et al. [189] synthesized CZO flower-like nanostructures via the electrochemical deposition technique. By tailoring the electrodepositon conditions, various CZO flower-like structures were readily prepared, as shown in Fig. 13. CZO may be greatly influenced by different surfactants used. Zhang et al. [156] prepared a series of CZY with different morphology via hydrothermal treatment, in which P123 or CTAB surfactants were employed and the reaction time and temperature were regulated. The morphology of the as-prepared

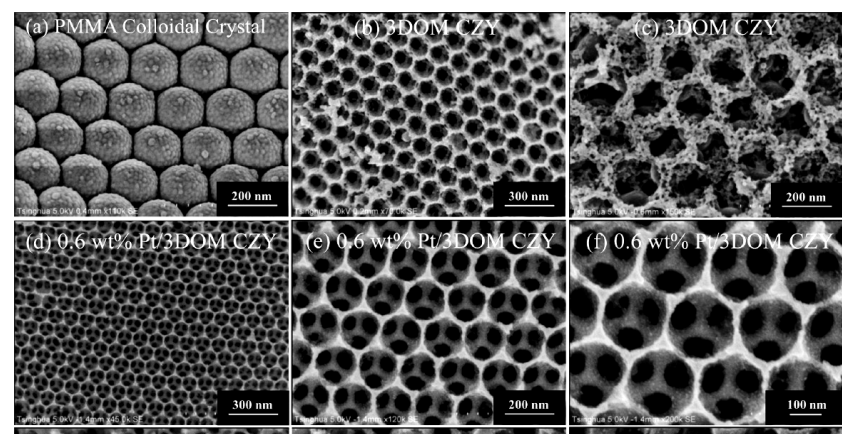

Fig. 12. SEM images of 3DOM CZY support and $y \%$ Pt/3DOM CZY and Bulk CZY catalysts. (a) PMMA colloidal crystal; (b) 3DOM CZY; (c) 3DOM CZY; (d) $0.6 \%$ Pt/3DOM CZY; (e) $0.6 \%$ Pt/3DOM CZY; (f) $0.6 \%$ $\mathrm{Pt} / 3 \mathrm{DOM}$ CZY. Reprinted from [185] with permission.

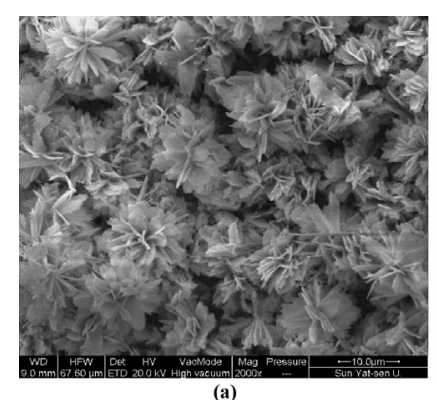

(a)

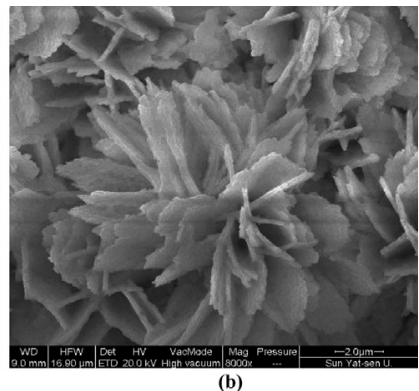

(b)
Fig. 13. SEM images of CZO flower-like nanostructures prepared in solution of $0.02 \mathrm{~mol} / \mathrm{L} \mathrm{Ce}\left(\mathrm{NO}_{3}\right)_{3}+0.005 \mathrm{~mol} / \mathrm{L} \mathrm{Zr}\left(\mathrm{NO}_{3}\right)_{4}+0.1 \mathrm{~mol} / \mathrm{L}$ $\mathrm{NH}_{4} \mathrm{NO}_{3}$ with current density of $2 \mathrm{~mA} / \mathrm{cm}^{2}$. Reprinted from [189] with permission.

products included rods, spheres, bowknot-like shape, and octahedral shape.

Core-shell structure nanosize CZO is a good material for ion conductivity. In order to introduce more conductive interfaces, Li et al. [190] synthesized the doped CZO core-shell nanocomposites via a simple and cost-saving SG method. Nitrates, CA, and PEG were used as the starting materials, and the compositions of the core and the shell parts were $\mathrm{Ce}_{0.9} \mathrm{Gd}_{0.1} \mathrm{O}_{1.95}$ and 8 mol\% $\mathrm{Sc}_{2} \mathrm{O}_{3}$-doped $\mathrm{ZrO}_{2}$, respectively. The grain size of core and shell was 6 and $8 \mathrm{~nm}$, respectively. The core-shell nanostructure contained about $60 \mathrm{~nm}$ diameter core and about $20 \mathrm{~nm}$ thick shell. Ozawa et al. [191] prepared core-shell type CZO support by precipitation of $\mathrm{CeO}_{2}$ NPs followed by heat treatment at $800{ }^{\circ} \mathrm{C}$ on pure zirconia surface. Li et al. [169] prepared $\mathrm{CeO}_{2} @ \mathrm{CZO}$ nanocages with different morphology by Kirkendall effect using the colloid ceria clusters as both chemical precursors and physical templates. This approach showed great flexibility in controlling the compositions, shapes, and sizes of the solid solution.

\subsubsection{Summary of cerium-zirconium-based material with different morphology}

To date, nanosize cerium-zirconium-based materials with ordered space morphology have attracted much attention due to their special and remarkable physicochemical properties in different areas. The ordered morphology includes nanopowders, 1-D nanorods, nanotubes, nanobelts, nanowires and 2-D nanofilms, nanomembranes, nanopaltes and 3-D nanocages, 3-D mesoporous, macroporous and hierarchical pores. In addition, many other special morphologies have been reported, and the synthesis routes and techniques are also different. Based on the nanosize morphology, space ordered structures for CZO materials have been developed for different applications. CZO materials have been widely used in heterogeneous catalysis because of their remarkable redox properties. However, as for the research of CZO materials with different morphology, some work should be still improved: (a) stability and mechanic strength of the as-synthesized materials; (b) environmentally friendly synthesis route exploring; (c) morphology dependence factors, such as reaction time, temperature, $\mathrm{pH}$ value, concentration of cerium and zirconium source, raw material configuration, metal doping, etc; (d) physicochemical properties of 
CZO nanomaterials with different morphologies; (e) correlation among structures, morphologies, and catalytic performance of CZO nanomaterials.

\section{Cerium-zirconium-based solid solutions for heterogeneous catalytic reactions}

\subsection{Cerium-zirconium-based solid solutions for catalytic oxidation of environmental pollutants}

CZO is a common active component used for the preparation of automotive exhaust TWCs catalysts for oxidation and reduction of combustion byproducts. $\mathrm{CO}, \mathrm{NO}_{x}$, and uncombusted HC can be transformed into environmentally friendly forms by tailoring their oxidation states. CZO serves as an 'oxygen reservoir' in which concurrent oxidation/reduction reactions take place, either removing oxygen to create oxygen vacancies or storing it to fill the vacancies in the solid material. In most cases, CZO porous solid is supported with metal NPs $(\mathrm{Cu}, \mathrm{Ag}$, $\mathrm{Au}, \mathrm{Pt}, \mathrm{Pd}$ ), which can promote oxygen transport into and out of the 'reservoir'. For CZO-supported metal catalysts, factors such as metal type, $\mathrm{CZO}$ particle size, $\mathrm{Ce} / \mathrm{Zr}$ ratio, pretreatment conditions, preparation method, dopants, and choice of the support may affect the catalytic activities of the final catalysts [192-196].

\subsubsection{CO oxidation}

Although CO oxidation is a conceptually simple reaction, it is very important to meet the rigorous environmental regulations. It is also a vital reaction occurring in the preferential oxidation of CO (CO-PROX) in a hydrogen purification system connected to polymer electrolyte membrane fuel cells
[197-200]. Therefore, a great amount of work has been devoted to this aspect, as summarized in Table 3 .

\subsubsection{Effect of the material composition}

The different $\mathrm{Ce} / \mathrm{Zr}$ ratios markedly affect the catalytic activity of CO oxidation over CZO catalysts. Meeyoo et al. [94] found that CO oxidation activity was strongly dependent on $\mathrm{Ce} / \mathrm{Zr}$ ratio because of the difference in phase compositions of the mixed oxides. The cubic fluorite structure mainly existed in $\mathrm{Ce}_{1-x} \mathrm{Zr}_{x} \mathrm{O}_{2}$ (where $x<0.5$ ) and tetragonal phase was found in $\mathrm{Ce}_{1-x} \mathrm{Zr}_{x} \mathrm{O}_{2}$ (where $x>0.5$ ). The former phase could be reduced easily than the latter one. Trovarelli et al. [201] proposed that the catalytic activities of CZO were dependent on textural properties and composition of samples. The rate of $\mathrm{CO}_{2}$ formation under stationary conditions was almost proportional to the amount of ceria, whereas, under cyclic feed stream conditions the rate reached a maximum when $\mathrm{CeO}_{2}$ was within the range of $50 \mathrm{~mol} \%-80 \mathrm{~mol} \%$. Zhao et al. [202] reported that the zirconium-doped $\mathrm{CeO}_{2}$-supported cobalt catalysts were more active than the pure $\mathrm{CeO}_{2}$ and $\mathrm{ZrO}_{2}$-supported cobalt ones $\left(\mathrm{Co}_{3} \mathrm{O}_{4} / \mathrm{CeO}_{2}\right.$ and $\left.\mathrm{Co}_{3} \mathrm{O}_{4} / \mathrm{ZrO}_{2}\right)$. When the ratio was 0.85-0.95, especially 0.85 , the $\mathrm{Co}_{3} \mathrm{O}_{4} / \mathrm{Ce}_{0.85} \mathrm{Zr}_{0.15} \mathrm{O}_{2}$ catalyst exhibited much higher catalytic activity than the others.

Reddy et al. [203] investigated the effect of $\mathrm{Tb}, \mathrm{Pr}$, and Hf dopant cations on the structure and catalytic properties of nanosize CZO-supported Pd catalysts for $\mathrm{CO}$ oxidation. They found that $\mathrm{CO}$ oxidation activity strongly relied on the nature of the dopant cations, and Pr cation incorporating CZO exhibited the best activity when being calcined at $800{ }^{\circ} \mathrm{C}$. The catalytic activity was closely related to the redox couples $\mathrm{Pr}^{4+} / \mathrm{Pr}^{3+}$ and calcination temperature.

Ayastuy et al. [204] investigated $\mathrm{Ce}_{x} \mathrm{Zr}_{1-x} \mathrm{O}_{2}(x=0-1.0)$ sup-

Table 3

Catalytic activities of nanosize CZO materials for CO oxidation.

\begin{tabular}{|c|c|c|c|c|c|}
\hline Catalyst & Particle size (nm) & BET area $\left(\mathrm{m}^{2} / \mathrm{g}\right)$ & Reaction conditions & $T_{50}\left({ }^{\circ} \mathrm{C}\right)$ & Ref. \\
\hline $\mathrm{CeO}_{2}$ & - & 10 & $2.0 \% \mathrm{O}_{2}+4.0 \% \mathrm{CO}(100 \mathrm{~mL} / \mathrm{min}, 0.08 \mathrm{~g}$ sample $)$ & 311 & [201] \\
\hline $\mathrm{Ce}_{0.5} \mathrm{Zr}_{0.5} \mathrm{O}_{2}$ & 4.7 & 84 & $10.2 \% \mathrm{O}_{2}+9.98 \% \mathrm{CO}(50 \mathrm{~mL} / \mathrm{min}, 0.1 \mathrm{~g}$ sample $)$ & 421 & [203] \\
\hline $\mathrm{Ce}_{0.75} \mathrm{Zr}_{0.25} \mathrm{O}_{2}$ & $9-10$ & 9.6 & $1.0 \% \mathrm{O}_{2}+1.0 \% \mathrm{CO}(50 \mathrm{~mL} / \mathrm{min}, 0.1 \mathrm{~g}$ sample $)$ & 355 & [103] \\
\hline $\mathrm{Ce}_{0.5} \mathrm{Zr}_{0.3} \mathrm{Hf}_{0.2} \mathrm{O}_{2}$ & 3.3 & 86 & $10.2 \% \mathrm{O}_{2}+9.98 \% \mathrm{CO}(50 \mathrm{~mL} / \mathrm{min}, 0.1$ g sample $)$ & 384 & [203] \\
\hline $\mathrm{Ce}_{0.5} \mathrm{Zr}_{0.3} \mathrm{Pr}_{0.2} \mathrm{O}_{2}$ & 3.5 & 88 & $10.2 \% \mathrm{O}_{2}+9.98 \% \mathrm{CO}(50 \mathrm{~mL} / \mathrm{min}, 0.1 \mathrm{~g}$ sample $)$ & 364 & [203] \\
\hline $\mathrm{Ce}_{0.5} \mathrm{Zr}_{0.3} \mathrm{~Tb}_{0.2} \mathrm{O}_{2}$ & 3.2 & 92 & $10.2 \% \mathrm{O}_{2}+9.98 \% \mathrm{CO}(50 \mathrm{~mL} / \mathrm{min}, 0.1 \mathrm{~g}$ sample $)$ & 355 & [203] \\
\hline $\mathrm{Ce}_{0.67} \mathrm{Zr}_{0.33} \mathrm{O}_{2}-\mathrm{Al}_{2} \mathrm{O}_{3}$ & 4.0 & 146 & $10.2 \% \mathrm{O}_{2}+9.98 \% \mathrm{CO}(50 \mathrm{~mL} / \mathrm{min}, 0.1$ g sample $)$ & 387 & [206] \\
\hline $\mathrm{Ce}_{0.67} \mathrm{Zr}_{0.33} \mathrm{O}_{2}-\mathrm{TiO}_{2}$ & 3.7 & 105 & $10.2 \% \mathrm{O}_{2}+9.98 \% \mathrm{CO}(50 \mathrm{~mL} / \mathrm{min}, 0.1 \mathrm{~g}$ sample $)$ & 392 & [206] \\
\hline $\mathrm{Ce}_{0.67} \mathrm{Zr}_{0.33} \mathrm{O}_{2}-\mathrm{SiO}_{2}$ & 3.1 & 172 & $10.2 \% \mathrm{O}_{2}+9.98 \% \mathrm{CO}(50 \mathrm{~mL} / \mathrm{min}, 0.1 \mathrm{~g}$ sample $)$ & 507 & {$[206]$} \\
\hline $7 \% \mathrm{CuO} / \mathrm{CeO}_{2}$ & $6-7.9$ & 150 & $1.0 \% \mathrm{O}_{2}+1.0 \% \mathrm{CO}(200 \mathrm{~mL} / \mathrm{min}, 0.1 \mathrm{~g}$ sample $)$ & 88 & [204] \\
\hline $5 \% \mathrm{CuO} / \mathrm{Ce}_{0.5} \mathrm{Zr}_{0.5} \mathrm{O}_{2}$ & $6-8$ & 169 & $3.3 \% \mathrm{O}_{2}+2.0 \% \mathrm{CO}+50 \% \mathrm{H}_{2}(30 \mathrm{~mL} / \mathrm{min}, 0.1 \mathrm{~g}$ sample $)$ & 89 & {$[207]$} \\
\hline $7 \% \mathrm{CuO} / \mathrm{Ce}_{0.8} \mathrm{Zr}_{0.2} \mathrm{O}_{2}$ & $6-7.9$ & 90 & $1.0 \% \mathrm{O}_{2}+1.0 \% \mathrm{CO}(200 \mathrm{~mL} / \mathrm{min}, 0.1 \mathrm{~g}$ sample $)$ & 102 & {$[204]$} \\
\hline $7 \% \mathrm{CuO} / \mathrm{Ce}_{0.5} \mathrm{Zr}_{0.5} \mathrm{O}_{2}$ & $6-7.9$ & 90 & $1.0 \% \mathrm{O}_{2}+1.0 \% \mathrm{CO}(200 \mathrm{~mL} / \mathrm{min}, 0.1 \mathrm{~g}$ sample $)$ & 120 & {$[204]$} \\
\hline $7 \% \mathrm{CuO} / \mathrm{Ce}_{0.15} \mathrm{Zr}_{0.85} \mathrm{O}_{2}$ & $6-7.9$ & 76 & $1.0 \% \mathrm{O}_{2}+1.0 \% \mathrm{CO}(200 \mathrm{~mL} / \mathrm{min}, 0.1 \mathrm{~g}$ sample $)$ & 134 & {$[204]$} \\
\hline $7 \% \mathrm{CuO} / \mathrm{Ce}_{0.9} \mathrm{Zr}_{0.1} \mathrm{O}_{2}$ & - & 78 & $1.0 \% \mathrm{O}_{2}+1.0 \% \mathrm{CO}+50 \% \mathrm{H}_{2}(30 \mathrm{~mL} / \mathrm{min}, 0.1 \mathrm{~g}$ sample $)$ & 62 & [205] \\
\hline $7 \% \mathrm{CuO} / \mathrm{Ce}_{0.8} \mathrm{Zr}_{0.2} \mathrm{O}_{2}$ & - & 73 & $1.0 \% \mathrm{O}_{2}+1.0 \% \mathrm{CO}+50 \% \mathrm{H}_{2}(30 \mathrm{~mL} / \mathrm{min}, 0.1 \mathrm{~g}$ sample $)$ & 77 & {$[205]$} \\
\hline $7 \% \mathrm{CuO} / \mathrm{Ce}_{0.5} \mathrm{Zr}_{0.5} \mathrm{O}_{2}$ & - & 65 & $1.0 \% \mathrm{O}_{2}+1.0 \% \mathrm{CO}+50 \% \mathrm{H}_{2}(30 \mathrm{~mL} / \mathrm{min}, 0.1 \mathrm{~g}$ sample $)$ & 89 & [205] \\
\hline $8 \% \mathrm{Co}_{3} \mathrm{O}_{4} / \mathrm{Ce}_{0.85} \mathrm{Zr}_{0.15} \mathrm{O}_{2}$ & $5.4-6.1$ & & $1.0 \% \mathrm{O}_{2}+1.0 \% \mathrm{CO}+50 \% \mathrm{H}_{2}(50 \mathrm{~mL} / \mathrm{min}, 0.2 \mathrm{~g}$ sample $)$ & 135 & [202] \\
\hline $16 \% \mathrm{Co}_{3} \mathrm{O}_{4} / \mathrm{Ce}_{0.85} \mathrm{Zr}_{0.15} \mathrm{O}_{2}$ & $5.4-6.1$ & & $1.0 \% \mathrm{O}_{2}+1.0 \% \mathrm{CO}+50 \% \mathrm{H}_{2}(50 \mathrm{~mL} / \mathrm{min}, 0.2 \mathrm{~g}$ sample $)$ & 119 & [205] \\
\hline $20 \% \mathrm{Co}_{3} \mathrm{O}_{4} /$ meso- $\mathrm{Ce}_{0.85} \mathrm{Zr}_{0.15} \mathrm{O}_{2}$ & 6.8 & 85 & $1.0 \% \mathrm{O}_{2}+1.0 \% \mathrm{CO}+50 \% \mathrm{H}_{2}(50 \mathrm{~mL} / \mathrm{min}, 0.1 \mathrm{~g}$ sample $)$ & 108 & [208] \\
\hline $0.8 \% \mathrm{Pd} /$ meso-macro- $\mathrm{Ce}_{0.6} \mathrm{Zr}_{0.4} \mathrm{O}_{2}$ & 7.6 & 69 & $20 \% \mathrm{O}_{2}+1.0 \% \mathrm{CO}+50 \% \mathrm{H}_{2}(50 \mathrm{~mL} / \mathrm{min}, 0.2 \mathrm{~g}$ sample $)$ & 65 & {$[187]$} \\
\hline
\end{tabular}

$T_{50}$ is denoted as temperature corresponding to $50 \%$ CO conversion. 
ported copper oxide catalysts for CO oxidation and found that the catalytic activity of this system depended on the amount of active sites located at the copper-ceria interface, which decreased with increasing of $\mathrm{ZrO}_{2}$ loading amounts particularly for $\mathrm{ZrO}_{2}>50 \%$. The optimum activity in $\mathrm{CO}$ oxidation was observed for the $\mathrm{CuO} / \mathrm{CeO}_{2}$ catalyst. Linear correlations were found for ceria-containing catalysts between pre-exponential factor and surface $\mathrm{Ce} / \mathrm{Cu}$ ratio, and a compensation effect also exhibited between pre-exponential factor and $E_{\mathrm{a}}$, as displayed in Fig. 14. Chen et al. [205] prepared a series of $\mathrm{CuO} / \mathrm{Ce}_{x} \mathrm{Zr}_{1-\mathrm{x}} \mathrm{O}_{2}$ $(x=0.1-0.5)$ catalysts for $\mathrm{CO}$ oxidation. The catalytic activity for $\mathrm{CO}$ oxidation increased with the decrease of the amount of incorporating $\mathrm{Zr}^{4+}$, and $7 \% \mathrm{CuO} / \mathrm{Ce}_{0.9} \mathrm{Zr}_{0.1} \mathrm{O}_{2}$ exhibited the best catalytic activity.

It is reported that the catalytic activity of CZO is strongly influenced by the crystal structure, defects and Ce content, the degree of reducibility, and the mobility of oxygen in the bulk. Despite all these implications, inadequate textural/structural stability and mechanical strength and fall of specific surface area at high temperatures are some problems encountered in the case of unsupported CZO, because many applications require high temperatures. Stabilization of CZO on an inert support to form stable and active catalysts is an effective way to overcome these drawbacks. Reddy et al. [206] synthesized CZO dispersed over $\mathrm{Al}_{2} \mathrm{O}_{3}, \mathrm{SiO}_{2}$, and $\mathrm{TiO}_{2}$ by the $\mathrm{CP}$ method and studied the influence of various supports on the thermal stability, OSC, and $\mathrm{CO}$ oxidation activity. $\mathrm{Al}_{2} \mathrm{O}_{3}$-supported $\mathrm{CZO}$ showed the best performance, followed by $\mathrm{TiO}_{2-}$ and $\mathrm{SiO}_{2}$-supported systems. The OSC properties exhibited a strong influence on the catalytic performances of ceria-based nanocomposite oxides for CO oxidation.

\subsubsection{Effect of the pore structure}

The different pore structure of CZO affects the dispersion of active species of reactant molecules and the diffusion. Luo et al. [207] synthesized a series of mesoporous CuO/CZO catalysts to be investigated for $\mathrm{CO}$ oxidation. Mesoporous $\mathrm{CuO} / \mathrm{CZO}$ was much more active than non-mesoporous $\mathrm{CuO} / \mathrm{CZO}$ in $\mathrm{CO}$ oxidation because of its higher oxygen vacancy concentration and

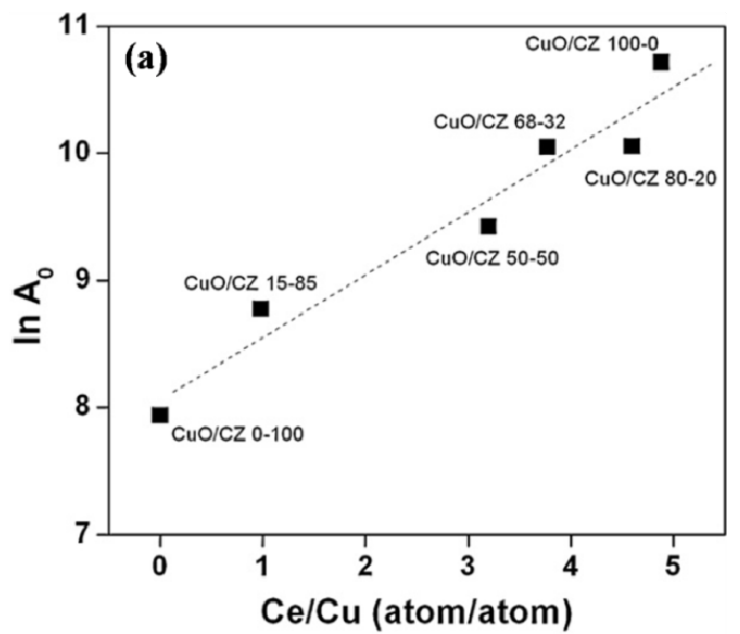

structural defects, larger surface area $\left(181 \mathrm{~m}^{2} / \mathrm{g}\right)$ and better chemical homogeneity. Zhang et al. [208] prepared a series of $\mathrm{Co}_{3} \mathrm{O}_{4} /$ meso-Ce $\mathrm{Zr}_{1-\mathrm{x}} \mathrm{O}_{2} \quad(x=0.75-1.0)$ catalysts using cationic surfactant $\mathrm{CTAB}$ and anionic surfactant ammonium dodecylbenzenesulfonate as structure-directing agent. $\mathrm{Co}_{3} \mathrm{O}_{4} /$ meso-Ce $0.85 \mathrm{Zr}_{0.15} \mathrm{O}_{2}$ catalysts showed an outstanding catalytic activity for CO-PROX reaction. Moreover, compared to the conventional $\mathrm{Co}_{3} \mathrm{O}_{4} / \mathrm{CZO}$ catalysts with the same composition [202], $\mathrm{Co}_{3} \mathrm{O}_{4} /$ meso-CZO with orderly mesoporous architecture displayed higher $\mathrm{CO}$ oxidation activity and $\mathrm{CO}_{2}$ selectivity, which should be due to the presence of mesoporous structure affecting the cobalt oxide dispersion and redox behavior of catalyst. Yu et al. [187] reported a series of meso- and macroporous $\mathrm{Pd} / \mathrm{Ce}_{\mathrm{x}} \mathrm{Zr}_{1-\mathrm{x}} \mathrm{O}_{2}(x=0.2-0.8)$ catalysts using the surfactant template-assisted method. The meso-macrostructural $\mathrm{Pd} / \mathrm{Ce}_{\mathrm{x}} \mathrm{Zr}_{1-\mathrm{x}} \mathrm{O}_{2}$ showed a higher $\mathrm{CO}$ oxidation activity than that with mesochannel structures and the one prepared by the CP method due to the high homogeneity of crystal phase, more oxygen vacancies available, and large specific surface area.

\subsubsection{Mechanism of CO oxidation over ceria-zirconium-based solid solutions}

Liu et al. [209] reported that Zr was not effective for CO oxidation reaction. Yang et al. [210] and Tang et al. [211] revealed that $\mathrm{Zr}$ had almost no influence on the electronic structure of ceria. Therefore, $\mathrm{CeO}_{2}$ has been widely used to represent $\mathrm{CZO}$ for simplicity to investigate the reaction mechanism that $\mathrm{CO}$ oxidation involved. A detailed CO oxidation mechanism over CZO was proposed by Trovarelli et al. [212]. It is supposed that $\mathrm{CO}_{2}$ chemisorption should be statistically favored on $\mathrm{CeO}_{2}$ rather than on CZO mixed oxides due to its more $\mathrm{Ce}^{3+}$ sites. In fact, $\mathrm{ZrO}_{2}$ can only weakly adsorb $\mathrm{CO}$ or $\mathrm{CO}_{2}$ and usually is not capable of forming stable carbonates. Moreover, preferential adsorption on pure $\mathrm{CeO}_{2}$ could also be dependent on the properties of the adsorption sites. Furthermore, it was reported that the most stable surface for polycrystallite high surface area ceria was (111) among the three low index surfaces, namely $\mathrm{CeO}_{2}$ (111), (110), and (100). After reduction this surface re-

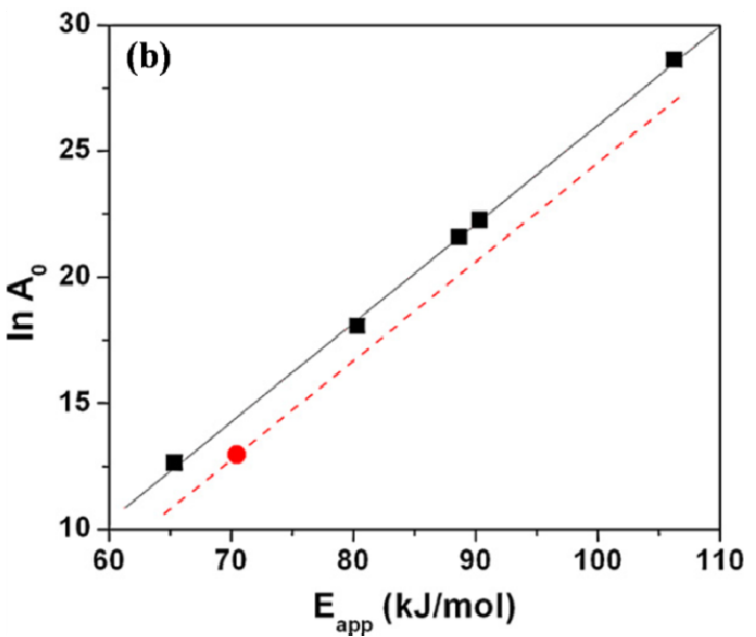

Fig. 14. (A) Linear dependency of $\ln A_{0}$ with catalyst composition (Ce/Cu ratio); (B) Constable-Cremer plot for CO oxidation over CuO/Ce $\mathrm{Zr}_{1-\mathrm{x}} \mathrm{O}_{2}$ catalysts. Reprinted from [204] with permission. 
laxed with a vacancy association mechanism. This mechanism could account for highly unsaturated sites onto which $\mathrm{CO}_{2}$ would be preferentially adsorbed. Vacancy association had lower probability to occur in CZO due to the higher mobility resulting from the addition of a smaller cation in the lattice. Finally, zirconia could stabilize other surfaces with reactivity characteristics different from those of the (111) plane. The following five steps were proposed to account for CO oxidation reaction (Eqs. (5) -(9)):

$$
\begin{gathered}
\mathrm{CO}_{(\mathrm{g})}+2 \mathrm{CeO}_{2} \rightarrow \mathrm{CO}_{2(\mathrm{~g})}+2 \mathrm{CeO}_{1.5} \\
\mathrm{CO}_{(\mathrm{g})}+2 \mathrm{CeO}_{2} \rightarrow \mathrm{CO}_{2(\mathrm{~s})} *+2 \mathrm{CeO}_{1.5} \\
\mathrm{O}_{2(\mathrm{~g})}+\mathrm{CeO}_{1.5} \rightarrow\left(\mathrm{O}_{2}\right)_{\mathrm{ads}}-\mathrm{CeO}_{1.5} \\
\left(\mathrm{O}_{2}\right)_{\mathrm{ads}} \rightarrow 2 \mathrm{O}_{\mathrm{ads}} \\
\mathrm{CO}_{2(\mathrm{~s})} *+2 \mathrm{O}_{\mathrm{ads}}+4 \mathrm{CeO}_{1.5} \rightarrow \mathrm{CO}_{2(\mathrm{~g})}+4 \mathrm{CeO}_{2}
\end{gathered}
$$

Among which, the initial two steps accounted for CO oxidation. In Eq. (5), $\mathrm{CO}_{2}$ entered gas phase, while Eq. (6) accounted for the adsorption of $\mathrm{CO}_{2}$ as carbonate-like species. The rate of the two competing steps determined the intensity and the ratio of the two peaks, which were strongly dependent on the composition and specific surface area of the oxide. Eqs. (7)-(9) expressed the phenomena observed during the second half of the cycle: oxygen adsorption during the second half cycle was expressed in Eqs. (7) and (8), and reaction (9) was the reoxidation step. Moreover, it was assumed that Eq. (8) was the rate-limiting step in the oxygen dissociative adsorption process, while Eq. (7) was instantaneous. Thus, the rates of Eqs. (7) and (9) determined the observed time lag between oxygen consumption and $\mathrm{CO}_{2}$ release.

\subsubsection{NO oxidation}

$\mathrm{NO}$ oxidation to $\mathrm{NO}_{2}$ under $\mathrm{O}_{2}$-rich condition is attracting more and more attention as it is involved in many diesel de-pollution processes such as: (a) NSR strategy, where a noble metal/alkaline-earth oxide component accomplishes $\mathrm{NO}_{x}$ storage and the subsequent reduction to $\mathrm{N}_{2}$ by adding a reducing gas in the exhaust [213]; (b) $\mathrm{NO}_{2}$-assisted soot combustion, where $\mathrm{NO}_{2}$ initiates and continues along with $\mathrm{O}_{2}$ to promote soot oxidation even under loose contact between catalyst and soot [214]; and (c) SCR of $\mathrm{NO}_{x}$, where $\mathrm{NO}_{x}$ are selectively reduced in an $\mathrm{O}_{2}$-rich environment. CZO showed extremely attractive as possible substitutes of noble metals for catalytic applications where $\mathrm{NO}$ oxidation to $\mathrm{NO}_{2}$ must be accomplished [215].

\subsubsection{Effect of the support composition}

Among the various physicochemical properties, the surface composition appears to be the most relevant one influencing the NO oxidation capacity of CZO. García-García et al. [216] prepared two CZO with a ceria-rich and zirconia-rich surface, respectively. They found that the phase composition seemed not to be the direct factor affecting the catalytic activity for NO oxidation (as shown in Fig. 15), and that the formation of a proper solid solution prevented important surface segregation of $\mathrm{Zr}$ upon calcination at high temperature.

Zhong et al. [217] reported Cr/CZO NPs with nonuniform dopant concentration of $\mathrm{Ce}$ and $\mathrm{Cr}$ enriched on the surface as NO oxidizing catalysts. Nonuniform dopant concentration promoted the utilization of $\mathrm{Ce}$ and $\mathrm{Cr}$, and the strong polar ability of $\mathrm{Zr}$ in the aqueous solution made it become the nucleation site in the hydrolysis process, resulting in Ce enriched on the surface. The adsorption of $\mathrm{Cr}$ by the porous structure of CZO during the impregnation resulted in nonuniform. Zr-rich sample with tetragonal structure was favorable for the increasing of surface area and the decreasing of particle size and led to a higher adsorption capacity of $\mathrm{NO}$ and $\mathrm{O}_{2}$ than Ce-rich sample.

\subsubsection{Effect of the different preparation conditions}

Zhong et al. [218] prepared the rigid benzene-muti-carboxylate ligand-modified $\mathrm{Cr} / \mathrm{CZO}$ for NO oxidation. The catalyst prepared with cinnamic acid as precipitant exhibited a larger specific surface area, a lower band gap, and a stronger ability to adsorb reactant gas. By contrast, $\mathrm{Cr} / \mathrm{CZO}$ synthesized with terephthalic and trimesic acid was unbeneficial for the preparation of CZO owing to the long distance between the carboxyl groups. Subsequently, they studied the effect of precursor solution of cinnamic acid as complex ligand for the preparation of $\mathrm{Cr}$-doped $\mathrm{Ce}_{0.2} \mathrm{Zr}_{0.8 \mathrm{O}_{2}}$ on the oxidation activity of NO [219,220]. The solvent with appropriate polarity could decrease the band gap of the catalysts and benefit for more generation of $\mathrm{Ce}^{3+}$ and $\mathrm{Cr}^{6+}$ on the catalyst surface, which was beneficial to the adsorption of $\mathrm{NO}$ and $\mathrm{O}_{2}$. Moreover, Zhong et al. [221] synthesized Co/CZO using citrate acid as complexing agent and by an impregnation method. The sample pre-
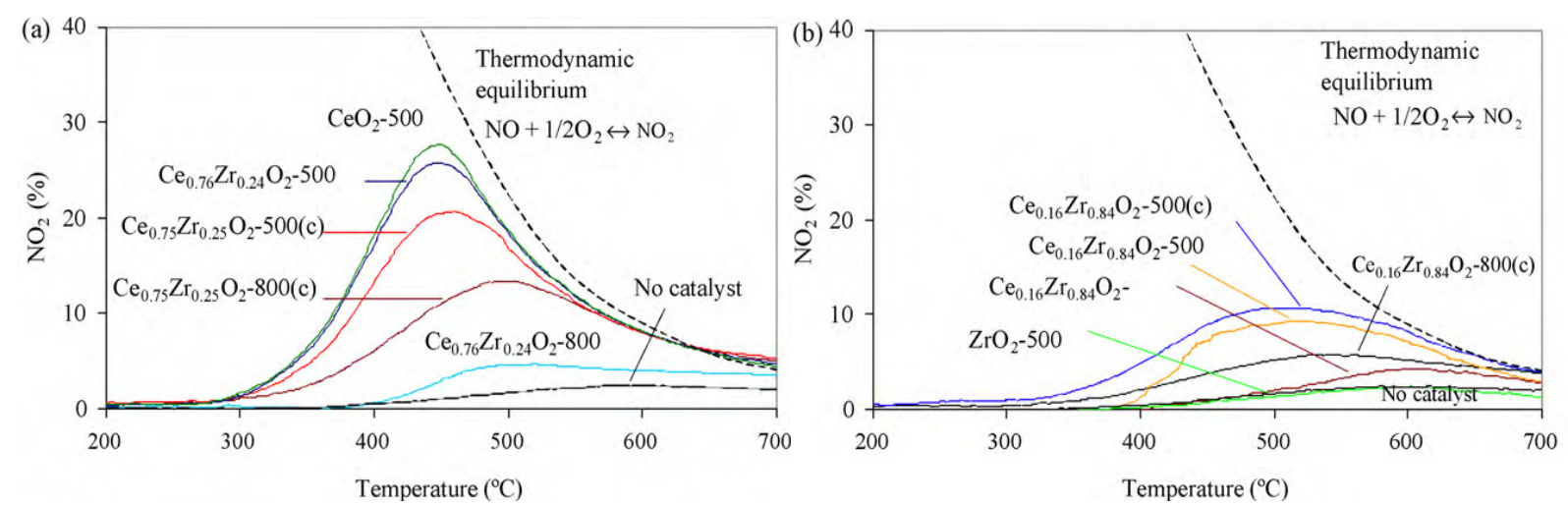

Fig. 15. $\mathrm{NO}_{2}$ production profiles during TPR experiments for $\mathrm{NO}+1 / 2 \mathrm{O}_{2}$ reaction. (a) Ceria-rich catalysts; (b) Zirconia-rich catalysts. Double arrow (as symbol): $\mathrm{NO}_{2}$. Reprinted from [216] with permission. 
pared by the former method showed better catalytic performance for NO oxidation than that synthesized by the latter one due to its lower crystallite size, higher content of $\mathrm{Ce}^{3+}$, and easier reducibility.

\subsubsection{Volatile organic compounds (voc) elimination}

VOC emitted from a large diversity of sources, such as transport and industrial processes as well as household products, are identified as main contributors to air pollution either through their toxic nature and/or as precursors of ozone and photochemical smog [2,222]. Catalytic oxidation is one of the most useful and economically feasible techniques for the oxidation of VOC into $\mathrm{CO}_{2}, \mathrm{H}_{2} \mathrm{O}$, and other less harmful compounds [223,224]. Compared to $\mathrm{CO}, \mathrm{NO}$, and $\mathrm{CH}_{4}$ oxidation, fewer studies were devoted to VOC elimination over CZO. It is rather surprising if one considers their very good activity in oxidation reactions. The performance of CZO in eliminating hydrocarbons (alkanes, alkenes, aromatics), alcohols and other oxygenates, and finally miscellaneous compounds will be successively reviewed below, and the results are listed in Table 4.

\subsubsection{Alkanes}

\subsubsection{1. $\mathrm{CH}_{4}$ oxidation}

Catalytic combustion of $\mathrm{CH}_{4}$ is an important technology for energy production and environmental pollution abatement. CZO-supported noble metals and transition metals have been widely investigated for $\mathrm{CH}_{4}$ oxidation $[48,225,226]$.

(a) Effect of different $\mathrm{Ce} / \mathrm{Zr}$ ratio

Meeyoo et al. [227] prepared highly uniform $\mathrm{Ce}_{1-\mathrm{x}} \mathrm{Zr}_{x} \mathrm{O}_{2}(x=$ $0-1.0)$ materials via urea hydrolysis for $\mathrm{CH}_{4}$ combustion. The incorporation of $\mathrm{Zr}$ into $\mathrm{CeO}_{2}$ lattice promoted the reductive behavior. The $\mathrm{CH}_{4}$ combustion activity of the mixed oxides was closely related to the $\mathrm{Ce} / \mathrm{Zr}$ ratio, and $\mathrm{Ce}_{0.75} \mathrm{Zr}_{0.25} \mathrm{O}_{2}$ showed the highest activity for $\mathrm{CH}_{4}$ combustion with $T_{50}$ about $540{ }^{\circ} \mathrm{C}$. Luo et al. prepared $\mathrm{Ce}_{x} \mathrm{Zr}_{1-\mathrm{x}} \mathrm{O}_{2}$-supported $\mathrm{PdO}$ catalysts $(x=0-1.0)$

Table 4

Catalytic activities of VOCs combustion over nanosize CZO materials.

\begin{tabular}{|c|c|c|c|c|}
\hline Catalyst & BET area $\left(\mathrm{m}^{2} / \mathrm{g}\right)$ & Reaction conditions & $T_{50}\left({ }^{\circ} \mathrm{C}\right)$ & Ref. \\
\hline $\mathrm{Ce}_{0.75} \mathrm{Zr}_{0.25} \mathrm{O}_{2}$ & 108 & $2.0 \% \mathrm{CH}_{4}+21 \% \mathrm{O}_{2}(100 \mathrm{~mL} / \mathrm{min}, 0.1 \mathrm{~g}$ sample $)$ & 540 & {$[227]$} \\
\hline $\mathrm{Ce}_{0.6} \mathrm{Zr}_{0.3} \mathrm{Y}_{0.1} \mathrm{O}_{2}$ & 69 & $2.0 \% \mathrm{CH}_{4}+20 \% \mathrm{O}_{2}(125 \mathrm{~mL} / \mathrm{min}, 0.25 \mathrm{~g}$ sample $)$ & 671 & {$[185]$} \\
\hline $3 \mathrm{DOM} \mathrm{Ce}{ }_{0.6} \mathrm{Zr}_{0.3} \mathrm{Y}_{0.1} \mathrm{O}_{2}$ & 94 & $2.0 \% \mathrm{CH}_{4}+20 \% \mathrm{O}_{2}(125 \mathrm{~mL} / \mathrm{min}, 0.25$ g sample $)$ & 590 & {$[185]$} \\
\hline $7 \% \mathrm{Mn} / \mathrm{Ce}_{0.67} \mathrm{Zr}_{0.33} \mathrm{O}_{2}$ & 62 & $1.0 \% \mathrm{CH}_{4}+4 \% \mathrm{O}_{2}(100 \mathrm{~mL} / \mathrm{min}, 0.5 \mathrm{~g}$ sample $)$ & 525 & {$[234]$} \\
\hline 8.0\% $\mathrm{Fe}_{2} \mathrm{O}_{3} / \mathrm{Ce}_{0.67} \mathrm{Zr}_{0.33} \mathrm{O}_{2}-\mathrm{Al}_{2} \mathrm{O}_{3}$ & 164 & $1.0 \% \mathrm{CH}_{4}+4 \% \mathrm{O}_{2}(50 \mathrm{~mL} / \mathrm{min}, 0.2$ g sample $)$ & 520 & {$[232]$} \\
\hline $30 \% \mathrm{Co}_{3} \mathrm{O}_{4} / \mathrm{Ce}_{0.6} \mathrm{Zr}_{0.4} \mathrm{O}_{2}$ & 172 & $0.3 \% \mathrm{CH}_{4}+4.8 \% \mathrm{O}_{2}(50 \mathrm{~mL} / \mathrm{min}, 0.25 \mathrm{~g}$ sample $)$ & 380 & {$[233]$} \\
\hline $0.25 \% \mathrm{Pd} / \mathrm{Ce}_{0.25} \mathrm{Zr}_{0.75} \mathrm{O}_{2}-\mathrm{SiO}_{2}$ & - & $2.0 \% \mathrm{CH}_{4}+21 \% \mathrm{O}_{2}(10 \mathrm{~mL} / \mathrm{min}, 0.1 \mathrm{~g}$ sample $)$ & 355 & {$[229]$} \\
\hline $2.0 \% \mathrm{Pd} / \mathrm{Ce}_{0.67} \mathrm{Zr}_{0.33} \mathrm{O}_{2}$ & 77 & $2.0 \% \mathrm{CH}_{4}+20 \% \mathrm{O}_{2}(100 \mathrm{~mL} / \mathrm{min}, 0.5 \mathrm{~g}$ sample $)$ & 400 & {$[229]$} \\
\hline $2.0 \% \mathrm{Pt} / \mathrm{Ce}_{0.67} \mathrm{Zr}_{0.33} \mathrm{O}_{2}$ & 79 & $2.0 \% \mathrm{CH}_{4}+20 \% \mathrm{O}_{2}(100 \mathrm{~mL} / \mathrm{min}, 0.5 \mathrm{~g}$ sample $)$ & 417 & {$[229]$} \\
\hline $1.6 \% \mathrm{Pt} / \mathrm{Ce}_{0.67} \mathrm{Zr}_{0.33} \mathrm{O}_{2}$ & 69 & $1.0 \% \mathrm{CH}_{4}+4 \% \mathrm{O}_{2}(100 \mathrm{~mL} / \mathrm{min}, 0.5$ g sample $)$ & 335 & {$[234]$} \\
\hline $1.2 \% \mathrm{Pt} / \mathrm{Ce}_{0.6} \mathrm{Zr}_{0.3} \mathrm{Y}_{0.1} \mathrm{O}_{2}$ & 71 & $2.0 \% \mathrm{CH}_{4}+20 \% \mathrm{O}_{2}(125 \mathrm{~mL} / \mathrm{min}, 0.25 \mathrm{~g}$ sample $)$ & 558 & {$[185]$} \\
\hline 3DOM 1.1\% Pt/Ce ${ }_{0.6} \mathrm{Zr}_{0.3} \mathrm{Y}_{0.1} \mathrm{O}_{2}$ & 84 & $1.0 \% \mathrm{CH}_{4}+4 \% \mathrm{O}_{2}(125 \mathrm{~mL} / \mathrm{min}, 0.25 \mathrm{~g}$ sample $)$ & 434 & {$[185]$} \\
\hline $0.2 \% \mathrm{Au} / \mathrm{Ce}_{0.6} \mathrm{Zr}_{0.3} \mathrm{Y}_{0.1} \mathrm{O}_{2}$ & 88 & $5.0 \% \mathrm{CH}_{4}+8 \% \mathrm{O}_{2}(10 \mathrm{~mL} / \mathrm{min}, 0.1 \mathrm{~g}$ sample $)$ & 600 & {$[230]$} \\
\hline $\mathrm{Ce}_{0.75} \mathrm{Zr}_{0.25} \mathrm{O}_{2}$ & 100 & $0.6 \% \mathrm{C}_{3} \mathrm{H}_{6}+21 \% \mathrm{O}_{2}(100 \mathrm{~mL} / \mathrm{min}, 0.1 \mathrm{~g}$ sample $)$ & 330 & {$[242]$} \\
\hline $1.5 \% \mathrm{Ru} / \mathrm{Ce}_{0.75} \mathrm{Zr}_{0.25} \mathrm{O}_{2}$ & 42 & $0.6 \% \mathrm{C}_{3} \mathrm{H}_{6}+21 \% \mathrm{O}_{2}(100 \mathrm{~mL} / \mathrm{min}, 0.1 \mathrm{~g}$ sample $)$ & 212 & {$[242]$} \\
\hline $1.5 \% \mathrm{Pd} / \mathrm{Ce}_{0.33} \mathrm{Zr}_{0.67} \mathrm{O}_{2}-\mathrm{Al}_{2} \mathrm{O}_{3}$ & 60 & $0.2 \% \mathrm{C}_{3} \mathrm{H}_{8}+2 \% \mathrm{O}_{2}(500 \mathrm{~mL} / \mathrm{min}, 0.1 \mathrm{~g}$ sample $)$ & 400 & {$[235]$} \\
\hline $2 \% \mathrm{Pd} / \mathrm{Ce}_{0.2} \mathrm{Zr}_{0.78} \mathrm{Y}_{0.02} \mathrm{O}_{2}-\mathrm{Al}_{2} \mathrm{O}_{3}$ & 62 & $0.3 \% \mathrm{C}_{3} \mathrm{H}_{8}+3 \% \mathrm{O}_{2}(300 \mathrm{~mL} / \mathrm{min}, 0.6$ g sample $)$ & 324 & {$[236]$} \\
\hline $2 \% \mathrm{Pd} / \mathrm{Ce}_{0.2} \mathrm{Zr}_{0.78} \mathrm{Ca} 0.02 \mathrm{O}_{2}-\mathrm{Al}_{2} \mathrm{O}_{3}$ & 68 & $0.3 \% \mathrm{C}_{3} \mathrm{H}_{8}+3 \% \mathrm{O}_{2}(300 \mathrm{~mL} / \mathrm{min}, 0.6 \mathrm{~g}$ sample $)$ & 327 & {$[236]$} \\
\hline $2 \% \mathrm{Pd} / \mathrm{Ce}_{0.2} \mathrm{Zr}_{0.78} \mathrm{Ba}_{0.02} \mathrm{O}_{2}-\mathrm{Al}_{2} \mathrm{O}_{3}$ & 82 & $0.3 \% \mathrm{C}_{3} \mathrm{H}_{8}+3 \% \mathrm{O}_{2}(300 \mathrm{~mL} / \mathrm{min}, 0.6$ g sample $)$ & 348 & {$[236]$} \\
\hline $2 \% \mathrm{Pd} / \mathrm{Ce}_{0.2} \mathrm{Zr}_{0.75} \mathrm{Y}_{0.05} \mathrm{O}_{2}-\mathrm{Al}_{2} \mathrm{O}_{3}$ & 65 & $0.3 \% \mathrm{C}_{3} \mathrm{H}_{8}+3 \% \mathrm{O}_{2}(300 \mathrm{~mL} / \mathrm{min}, 0.6 \mathrm{~g}$ sample $)$ & 310 & {$[237]$} \\
\hline $0.5 \% \mathrm{Pt} / 3 \% \mathrm{Ni} / \mathrm{Ce}_{0.4} \mathrm{Zr}_{0.6} \mathrm{O}_{2}$ & 65 & $0.2 \% \mathrm{C}_{3} \mathrm{H}_{8}+1 \% \mathrm{O}_{2}(30 \mathrm{~mL} / \mathrm{min}, 0.1 \mathrm{~g}$ sample $)$ & 330 & {$[238]$} \\
\hline $8 \% \mathrm{CuO} / \mathrm{Ce}_{0.8} \mathrm{Zr}_{0.2} \mathrm{O}_{2}$ & 163 & $0.44 \% \mathrm{C}_{7} \mathrm{H}_{8}+21 \% \mathrm{O}_{2}(55 \mathrm{~mL} / \mathrm{min}, 0.1 \mathrm{~g}$ sample $)$ & 212 & [248] \\
\hline $1.5 \% \mathrm{Ru} / \mathrm{Ce}_{0.5} \mathrm{Zr}_{0.5} \mathrm{O}_{2}$ & 163 & $0.1 \% \mathrm{C}_{6} \mathrm{H}_{6}+2 \% \mathrm{O}_{2}(320 \mathrm{~mL} / \mathrm{min}, 0.2 \mathrm{~g}$ sample $)$ & 220 & [243] \\
\hline $1.0 \% \mathrm{Pt} / \mathrm{Ce}_{0.5} \mathrm{Zr}_{0.5} \mathrm{O}_{2}$ & 43 & $0.07 \% \mathrm{C}_{7} \mathrm{H}_{8}+2 \% \mathrm{O}_{2}(130 \mathrm{~mL} / \mathrm{min}, 0.4$ g sample $)$ & 171 & {$[244]$} \\
\hline $4.7 \% \mathrm{Au} / \mathrm{Ce}_{0.6} \mathrm{Zr}_{0.3} \mathrm{Y}_{0.1} \mathrm{O}_{2}$ & 79 & $0.1 \% \mathrm{C}_{7} \mathrm{H}_{8}+40 \% \mathrm{O}_{2}(16.7 \mathrm{~mL} / \mathrm{min}, 0.05 \mathrm{~g}$ sample $)$ & 218 & [246] \\
\hline $0.9 \% \mathrm{Au}_{1} \mathrm{Pd}_{2} / \mathrm{Ce}_{0.6} \mathrm{Zr}_{0.3} \mathrm{Y}_{0.1} \mathrm{O}_{2}$ & 76 & $0.1 \% \mathrm{C}_{7} \mathrm{H}_{8}+40 \% \mathrm{O}_{2}(16.7 \mathrm{~mL} / \mathrm{min}, 0.05 \mathrm{~g}$ sample $)$ & 190 & {$[247]$} \\
\hline $17 \% \mathrm{Pd} / \mathrm{Ce}_{0.8} \mathrm{Zr}_{0.2} \mathrm{O}_{2}$ & 113 & $40 \% \mathrm{CH}_{3} \mathrm{OH}(50 \mathrm{~mL} / \mathrm{min}, 0.3 \mathrm{~g}$ sample $)$ & 200 & {$[251]$} \\
\hline $\mathrm{Ce}_{0.6} \mathrm{Zr}_{0.3} \mathrm{Mn}_{0.1} \mathrm{O}_{\mathrm{x}}$ & 55 & $1.5 \% \mathrm{C}_{2} \mathrm{H}_{5} \mathrm{OH}+21 \% \mathrm{O}_{2}(30 \mathrm{~mL} / \mathrm{min}, 0.25$ g sample $)$ & 280 & {$[252]$} \\
\hline $\mathrm{Ce}_{0.24} \mathrm{Zr}_{0.4} \mathrm{Mn}_{0.36} \mathrm{O}_{2}$ & 163 & $0.08 \% \mathrm{C}_{4} \mathrm{H}_{9} \mathrm{OH}+21 \% \mathrm{O}_{2}(100 \mathrm{~mL} / \mathrm{min}, 0.2 \mathrm{~g}$ sample $)$ & 145 & {$[255]$} \\
\hline $5 \% \mathrm{CuO} / \mathrm{CeO}_{2}-\mathrm{ZrO}_{2}-\mathrm{TiO}_{2}$ & 16 & $0.2 \% \mathrm{C}_{4} \mathrm{H}_{8} \mathrm{O}_{2}+21 \% \mathrm{O}_{2}(100 \mathrm{~mL} / \mathrm{min}, 0.2 \mathrm{~g}$ sample $)$ & 220 & {$[257]$} \\
\hline $4 \% \mathrm{CuCe}_{0.75} \mathrm{Zr}_{0.25} \mathrm{O}_{y} / \mathrm{ZSM}-5$ & 339 & $0.2 \% \mathrm{C}_{4} \mathrm{H}_{8} \mathrm{O}_{2}+21 \% \mathrm{O}_{2}(400 \mathrm{~mL} / \mathrm{min}, 0.8 \mathrm{~g}$ sample $)$ & 200 & {$[258]$} \\
\hline $\mathrm{Ce}_{0.5} \mathrm{Zr}_{0.5} \mathrm{O}_{2}$ & 99 & $0.1 \% 1,2-\mathrm{C}_{2} \mathrm{H}_{4} \mathrm{Cl}_{2}+21 \% \mathrm{O}_{2}(500 \mathrm{~mL} / \mathrm{min}, 0.85 \mathrm{~g}$ sample $)$ & 300 & {$[260]$} \\
\hline sulphated-Ce ${ }_{0.5} \mathrm{Zr}_{0.5} \mathrm{O}_{2}$ & 98 & $0.1 \% 1,2-\mathrm{C}_{2} \mathrm{H}_{4} \mathrm{Cl}_{2}+21 \% \mathrm{O}_{2}(500 \mathrm{~mL} / \mathrm{min}, 0.85 \mathrm{~g}$ sample $)$ & 212 & {$[262]$} \\
\hline $1.5 \% \mathrm{Pt} / \mathrm{Ce}_{0.5} \mathrm{Zr}_{0.5} \mathrm{O}_{2}$ & 41 & $0.1 \% \mathrm{C}_{2} \mathrm{H}_{4} \mathrm{Cl}_{2}+21 \% \mathrm{O}_{2}(1030 \mathrm{~mL} / \mathrm{min}, 0.87 \mathrm{~g}$ sample $)$ & 412 & {$[261]$} \\
\hline $0.3 \% \mathrm{Au} / \mathrm{Ce}_{0.5} \mathrm{Zr}_{0.5} \mathrm{O}_{2}$ & 39 & $0.1 \% \mathrm{C}_{2} \mathrm{H}_{4} \mathrm{Cl}_{2}+21 \% \mathrm{O}_{2}(1030 \mathrm{~mL} / \mathrm{min}, 0.87$ g sample $)$ & 417 & {$[261]$} \\
\hline $\mathrm{Ce}_{0.15} \mathrm{Zr}_{0.85} \mathrm{O}_{2}$ & 86 & $0.1 \% \mathrm{C}_{2} \mathrm{HCl}_{3}+21 \% \mathrm{O}_{2}(500 \mathrm{~mL} / \mathrm{min}, 0.85 \mathrm{~g}$ sample $)$ & 385 & {$[265]$} \\
\hline
\end{tabular}

$T_{50}$ is denoted as temperature corresponding to $50 \%$ VOC conversion. 
and investigated the effect of $\mathrm{Ce} / \mathrm{Zr}$ ratio on the catalytic activity for $\mathrm{CH}_{4}$ oxidation [228]. $\mathrm{PdO} / \mathrm{ZrO}_{2}$ was more active than

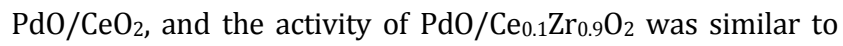
that of $\mathrm{PdO} / \mathrm{ZrO}_{2}$. However, the activity of $\mathrm{PdO} / \mathrm{Ce}_{0.2} \mathrm{Zr}_{0.8} \mathrm{O}_{2}$ catalyst decreased remarkably. As the content of Ce increased again $(x=0.3-1.0)$, the catalytic activity increased, and $\mathrm{PdO} / \mathrm{Ce}_{0.5} \mathrm{Zr}_{0.5} \mathrm{O}_{2}$ was the most active for $\mathrm{CH}_{4}$ oxidation in all catalysts. $\mathrm{Fu}$ et al. [229] reported a series of $y \%$ $\mathrm{Pd} / \mathrm{Ce}_{x} \mathrm{Zr}_{1-x} \mathrm{O}_{2} / \mathrm{SiO}_{2}(x=0-1.0, y=0.1-1.0)$ catalysts for catalytic $\mathrm{CH}_{4}$ combustion. The $\mathrm{Ce} / \mathrm{Zr}$ ratio played an important role in the catalytic activity of $\mathrm{Pd} / \mathrm{Ce}_{\mathrm{x}} \mathrm{Zr}_{1-\mathrm{x}} \mathrm{O}_{2} / \mathrm{SiO}_{2}$. $0.5 \%$ $\mathrm{Pd} / \mathrm{Ce}_{0.25} \mathrm{Zr}_{0.75} \mathrm{O}_{2} / \mathrm{SiO}_{2}$ exhibited the most active for $\mathrm{CH}_{4}$ oxidation in all catalysts, and $T_{50}$ was obviously lower than the other catalysts.

(b) Effect of CZO-supported different nobel metals

Dai et al. [230] fabricated a series of nanosize polycrystalline $y \% \mathrm{AuO}_{\mathrm{m}} / \mathrm{Ce}_{0.6} \mathrm{Zr}_{0.3} \mathrm{Y}_{0.1} \mathrm{O}_{2}(y=0.2-10.0)$ using an in-situ reduction procedure with $\mathrm{HAuCl}_{4}$ as Au source, $\mathrm{NaBH}_{4}$ as reductant, and PVP as surfactant. The redox property of $y \%$ $\mathrm{AuO}_{m} / \mathrm{CZY}$ catalysts was significantly improved by the introduction of $\mathrm{Au}$, and $\mathrm{AuOm} / \mathrm{CZY}$ catalysts with $0.2 \% \mathrm{Au}$ exhibited the highest catalytic activity for $\mathrm{CH}_{4}$ combustion, which may be ascribed to the synergistic effect between the nanosize $\mathrm{Au}$ and CZY nanocrystalline. Moreover, they reported a series of 3DOM $\mathrm{Ce}_{0.6} \mathrm{Zr}_{0.3} \mathrm{Y}_{0.1} \mathrm{O}_{2}$-supported high-dispersion Pt NPs $(y \%$ Pt/3DOM CZY, $y=0.6-1.7)$ with high surface area (84-94 $\mathrm{m}^{2} / \mathrm{g}$ ) and highly dispersed Pt NPs (2.6-4.2 nm). 1.1\% $\mathrm{Pt} / 3 \mathrm{DOM}$ CZY exhibited the best catalytic performance with $90 \% \mathrm{CH}_{4}$ conversion at $598{ }^{\circ} \mathrm{C}(\mathrm{GHSV}=30000 \mathrm{~mL} /(\mathrm{g} \cdot \mathrm{h})$ ) for $\mathrm{CH}_{4}$ combustion. The apparent activation energy $\left(E_{\mathrm{a}}\right)$ was 64 $\mathrm{kJ} / \mathrm{mol}$ for $1.1 \% \mathrm{Pt} / 3 \mathrm{DOM} \mathrm{CZY}$, which was much lower than that of $95 \mathrm{~kJ} / \mathrm{mol}$ over Bulk CZY [188]. Bozo et al. [231] prepared a $\mathrm{Ce}_{0.67} \mathrm{Zr}_{0.33} \mathrm{O}_{2}$-supported $\mathrm{Pt}$ or Pd catalyst for $\mathrm{CH}_{4}$ total oxidation. Deposition of Pt or Pd on this support resulted in a strong increase in activity, and $\mathrm{CH}_{4}$ oxidation took place at low temperature $\left(200-500{ }^{\circ} \mathrm{C}\right)$. The $\mathrm{Pd} / \mathrm{Ce}_{0.67} \mathrm{Zr}_{0.33} \mathrm{O}_{2}$ catalyst was more active than $\mathrm{Pt} / \mathrm{Ce}_{0.67} \mathrm{Zr}_{0.33} \mathrm{O}_{2}$.

(c) Effect of CZO-supported different transitional metal oxides

$\mathrm{Fe}_{2} \mathrm{O}_{3} / \mathrm{Ce}_{0.67} \mathrm{Zr}_{0.33} \mathrm{O}_{2}-\mathrm{A1}_{2} \mathrm{O}_{3}$ for $\mathrm{CH}_{4}$ combustion was reported by Gong et al. [232]. The optimal loading amount of $\mathrm{Fe}_{2} \mathrm{O}_{3}$ on $\mathrm{Ce}_{0.67} \mathrm{Zr}_{0.33} \mathrm{O}_{2}-\mathrm{A}_{2} \mathrm{O}_{3}$ for catalytic combustion of $\mathrm{CH}_{4}$ was $8 \%$, and the catalyst held the highest activity and the best thermal stability. The complete-conversion temperature of $\mathrm{CH}_{4}$ for fresh and aged samples was 515 and $565{ }^{\circ} \mathrm{C}$, respectively. Liotta et al. [233] synthesized $\mathrm{Co}_{3} \mathrm{O}_{4} / \mathrm{CZO}$ containing $30 \% \mathrm{Co}_{3} \mathrm{O}_{4}$ and investigated its catalytic activity on $\mathrm{CH}_{4}$ combustion. The results indicated that $\mathrm{Co}_{3} \mathrm{O}_{4} / \mathrm{CZO}$ exhibited a slightly lower $\mathrm{CH}_{4}$ conversion than $\mathrm{Co}_{3} \mathrm{O}_{4} / \mathrm{CeO}_{2}$.

(d) Effect of Pretreatment temperatures

Liotta et al. [233] investigated the effect of pretreatment temperature and oxygen concentration on the light-off temperature of $\mathrm{CH}_{4}$ combustion over a $\mathrm{Co}_{3} \mathrm{O}_{4} / \mathrm{CeO}_{2}-\mathrm{ZrO}_{2}$ catalyst. The thermal stability of the catalyst depended on the size of the cobalt oxide crystallites and the oxygen contents. Moreover, the ceria and ceria-zirconia played a key role in inhibiting $\mathrm{Co}_{3} \mathrm{O}_{4}$ decomposition into $\mathrm{CoO}$ and maintaining a good low-temperature combustion activity by dispersing the active phase $\mathrm{Co}_{3} \mathrm{O}_{4}$. Primet et al. [234] investigated the thermal stability of $\mathrm{Ce}_{1-x} \mathrm{Zr}_{x} \mathrm{O}_{2}(0<x<0.53)$ materials. After being aged at $1000{ }^{\circ} \mathrm{C}$ under oxygen and steam, the $\mathrm{Ce}_{0.67} \mathrm{Zr}_{0.33} \mathrm{O}_{2}$ solid solution exhibited the highest thermal stability, and the $\mathrm{Pt} / \mathrm{Ce}_{0.67} \mathrm{Zr}_{0.33} \mathrm{O}_{2}$ catalyst exhibited a higher activity for $\mathrm{CH}_{4}$ combustion than $\mathrm{Pt} / \mathrm{Al}_{2} \mathrm{O}_{3}$. However, a deactivation on stream was observed under isothermal conditions in the range of 200-500 ${ }^{\circ} \mathrm{C}$. After being aged at $1000{ }^{\circ} \mathrm{C}$, the positive effect of $\mathrm{Ce}_{0.67} \mathrm{Zr}_{0.33} \mathrm{O}_{2}$ support was no longer observed.

\subsection{Light hydrocarbons oxidation}

Cerium-zirconium-based solid solutions were also used for oxidation of other light alkanes, especially for oxidation of $\mathrm{C}_{3} \mathrm{H}_{8}$. Weng et al. [235] reported $\mathrm{C}_{3} \mathrm{H}_{8}$ oxidation over $\mathrm{Ce}_{0.33} \mathrm{Zr}_{0.67} \mathrm{O}_{2}$ and $\mathrm{Al}_{2} \mathrm{O}_{3}$ supports and investigated the effects of the supports on the catalytic performance of Pd-based catalysts for $\mathrm{C}_{3} \mathrm{H}_{8}$ oxidation. The enlargement of the interface between $\mathrm{Pd}$ and support during thermal aging might lead to different Pd-support interaction. Furthermore, the light-off temperature for $\mathrm{C}_{3} \mathrm{H}_{8}$ oxidation over co-aged $\mathrm{Pd} / \mathrm{Ce}_{0.33} \mathrm{Zr}_{0.67} \mathrm{O}_{2}$ and $\mathrm{Al}_{2} \mathrm{O}_{3}$ was lower than that over the mixture of aged $\mathrm{Pd} / \mathrm{Ce}_{0.33} \mathrm{Zr}_{0.67} \mathrm{O}_{2}$ and $\mathrm{Al}_{2} \mathrm{O}_{3}$. Meng et al. [236] prepared a series of $\mathrm{Pd} / \mathrm{CZO}-\mathrm{M} / \mathrm{Al}_{2} \mathrm{O}_{3}$ (M = Y, Ca or $\mathrm{Ba}$ ) closed-coupled catalysts by an ultrasonic-assisted successive impregnation method for the total oxidation of $\mathrm{C}_{3} \mathrm{H}_{8}$. The introduction of $\mathrm{Y}$ greatly enhanced the catalytic activity of the catalysts for $\mathrm{C}_{3} \mathrm{H}_{8}$ total oxidation because of the improved dispersion of $\mathrm{Pd}$ species and interaction between Pd species and support, which endows Pd species with higher oxidation state. They further investigated the effect of $\mathrm{Y}$ loading amounts $(0 \%, 2 \%, 5 \%, 10 \%)$ on the catalysts for $\mathrm{C}_{3} \mathrm{H}_{8}$ combustion [237]. The introduction of $5 \% \mathrm{Y}$ greatly improved the dispersion of $\mathrm{Pd}$ species and promoted the catalytic performance for $\mathrm{C}_{3} \mathrm{H}_{8}$ oxidation. However, further increasing the amount of $\mathrm{Y}$ led to the decrease of Pd-support interaction, resulting in a slight decrease of $\mathrm{Pd} 3 d_{5 / 2}$ binding energy. Therefore, the chemical state of Pd species could be influenced by $\mathrm{Y}$ and its amount, and the catalytic activity for $\mathrm{C}_{3} \mathrm{H}_{8}$ oxidation was also affected. Wei et al. [238] investigated the effect of nickel on the $\mathrm{Pt} / \mathrm{Ce}_{0.4} \mathrm{Zr}_{0.6} \mathrm{O}_{2}$ catalyst for $\mathrm{C}_{3} \mathrm{H}_{8}$ oxidation and sulfur resistance. The addition of nickel not only increased the specific surface area of the catalyst, but also enhanced its redox property. As a result, the nickel doping catalyst was more active in $\mathrm{C}_{3} \mathrm{H}_{8}$ complete oxidation. Furthermore, the introduction of nickel to the catalyst was capable of enhancing the desorption amount of sulfur species under reducing atmosphere. Thereby the sulfur resistance of the $\mathrm{Pt} / \mathrm{Ce}_{0.4} \mathrm{Zr}_{0.6} \mathrm{O}_{2}$ catalyst was improved. De Leitenburg et al. [239] reported a series of CZO doped with Mn and $\mathrm{Cu}$ solid solutions for the total oxidation of light hydrocarbons. Both $\mathrm{MnO}_{\mathrm{m}}$ and $\mathrm{CuO}$ at low loading amount were dissolved into CZO lattice, which significantly influenced the reductive behavior of the catalysts by increasing the oxygen mobility, and then the catalytic activity for the total oxidation of light HC was promoted.

\subsubsection{Alkenes}

Alkene combustion was exclusively performed with $\mathrm{C}_{3} \mathrm{H}_{6}$ as 
model compound. D'Itri et al. [240] investigated the effect of sulfation on the structural, morphological, and catalytic properties of $\mathrm{Ce}_{0.75} \mathrm{Zr}_{0.25} \mathrm{O}_{2}$ solid solution. When $\mathrm{Ce}_{0.75} \mathrm{Zr}_{0.25} \mathrm{O}_{2}$ was exposed to gaseous mixtures containing 20-40 $\mathrm{ppm} \mathrm{SO}_{2}$ at 600 ${ }^{\circ} \mathrm{C}$, the crystallite grain size grew accompanied by the loss of surface area. Additionally, the introduction of $20 \mathrm{ppm} \mathrm{SO}_{2}$ into the $1100 \mathrm{ppm} \mathrm{C}_{3} \mathrm{H}_{6}+2 \% \mathrm{O}_{2}+\mathrm{N}_{2}$ reaction mixture resulted in a promoting effect on the catalytic activity of $\mathrm{C}_{3} \mathrm{H}_{6}$ oxidation over $\mathrm{CeO}_{2}$ due to the presence of acid-base interaction between surface hydroxysulfate species and $\mathrm{C}_{3} \mathrm{H}_{6}$.

A Ce $\mathrm{Ce}_{0.25} \mathrm{Zr}_{0.75} \mathrm{O}_{2}$-supported $\mathrm{Pd}$ catalyst was prepared for $\mathrm{C}_{3} \mathrm{H}_{6}$ oxidation reaction [241]. The catalytic activity of $\mathrm{Pd} / \mathrm{CZO}$ was strongly influenced by the pretreatment conditions such as oxidative or reductive atmosphere. The initial activity of the $\mathrm{Pd} / \mathrm{CZO}$ catalyst under the insufficient oxygen condition was equivalent to the activity under the stoichiometric condition because of the property of high OSC. The CZO support promoted the dispersion of Pd oxide particles and their OSC property, which assisted the $\mathrm{C}_{3} \mathrm{H}_{6}$ oxidation reaction.

Aouad et al. [242] studied the catalytic behavior of CZO and $\mathrm{Ru} / \mathrm{CZO}$ calcined at 500 and $600{ }^{\circ} \mathrm{C}$ for $\mathrm{C}_{3} \mathrm{H}_{6}$ oxidation. The reactivity at both temperatures increased with increasing cerium content, and the introduction of Ru greatly enhanced the reactivity of the two solids. The both specific surface area and reductive behavior of the solids affected the catalytic reactivity. However, the reducibilities were the determinant factor in the catalytic behavior where easily reducible solids were more reactive. $\mathrm{Ru} / \mathrm{CeO}_{2}$ showed the optimal catalytic performance due to its high specific surface area and amount of Ru-O-Ce species. $\mathrm{RuO}_{2}$ clusters were formed with increasing $\mathrm{Zr}$ contents, leading to a decrease in their catalytic activities. When the cerium content increased in the support, a more efficient interaction was observed between cerium and ruthenium oxides. This interaction hindered the formation of $\mathrm{RuO}_{2}$ agglomerates and led to a better dispersion of ruthenium oxides and therefore a better catalytic performance.

\subsubsection{Aromatics}

Except for the report of Zhu et al. [243], which deals with benzene oxidation, all authors have chosen toluene as a model compound of aromatic hydrocarbons. The effect of Pt loading amounts $(0.09-1.00 \%)$ on the catalytic performance of CZO-supported catalysts in the total oxidation of toluene in air was investigated by Topka et al. [244]. The introduction of Pt facilitated the reduction of surface cerium and decreased the acidity of the catalysts. The catalysts with $0.59 \%$ Pt showed the best catalytic activity because of the presence of highly dispersive Pt NPs. Zhao et al. [245] investigated a $\mathrm{Pd} / \mathrm{Ce}_{0.4} \mathrm{Zr}_{0.6} \mathrm{O}_{2}$ /substrate washcoat catalyst for toluene combustion. The $\mathrm{Pd} / \mathrm{Ce}_{0.4} \mathrm{Zr}_{0.6} \mathrm{O}_{2}$ /substrate monolithic catalyst after being calcited at $400{ }^{\circ} \mathrm{C}$ displated good thermal stability and highly catalytic activity, and the conversion of toluene was up to $95 \%$ at $210{ }^{\circ} \mathrm{C}$. Dai et al. [246] prepared $y \%$ $\mathrm{Au} / \mathrm{Ce}_{0.6} \mathrm{Zr}_{0.3} \mathrm{Y}_{0.1} \mathrm{O}_{2} \quad(y \%$ Au/CZY, $y=0.4-4.7)$ using the CTAB-assisted hydrothermal and PVP-protected reduction methods for the oxidation of toluene. $4.7 \% \mathrm{Au} / \mathrm{CZY}$ exhibited the best catalytic performance at a space velocity of 20000
$\mathrm{mL} /(\mathrm{g} \cdot \mathrm{h})$, and $T_{50}$ was $32{ }^{\circ} \mathrm{C}$ for $\mathrm{CO}$ oxidation and $218{ }^{\circ} \mathrm{C}$ for toluene oxidation, respectively. It should be attributed to its higher oxygen adspecies concentration, superior low-temperature reducibility, and better Au NPs dispersion. Deactivation by water vapor addition was reversible due to the competitive adsorption of $\mathrm{H}_{2} \mathrm{O}$ and toluene as well as oxygen on the catalyst surface. $E_{\mathrm{a}}$ values $(39-53 \mathrm{~kJ} / \mathrm{mol}$ ) obtained over $y \%$ $\mathrm{Au} / \mathrm{CZY}$ were much lower than that $(88 \mathrm{~kJ} / \mathrm{mol})$ over CZY for toluene oxidation. Subsequently, they prepared CZY nanorods and supported $\mathrm{Au}$ and Pd alloy NPs [247]. 0.9\% $\mathrm{Au}_{1} \mathrm{Pd}_{2} / \mathrm{CZY}$ exhibited the best catalytic activity, and $T_{50}$ was $190{ }^{\circ} \mathrm{C}$ at a space velocity of $20000 \mathrm{~mL} /(\mathrm{g} \cdot \mathrm{h})$. The active sites might be the surface oxygen vacancies on CZY, oxidized noble metal NPs, and/or interfaces between noble metal NPs and CZY. $E_{\text {a }}$ values (37-43 kJ/mol) over $0.90 \%-0.93 \% \mathrm{AumPd} / \mathrm{CZY}$ were much lower than that $(88 \mathrm{~kJ} / \mathrm{mol})$ over CZY for toluene oxidation. Yuan et al. [248] prepared mesoporous CZO using the surfactant template-assisted method, and then it was used as support of CuO NPs for catalytic total oxidation of toluene. CuO/CZO catalysts exhibited a wormhole-like mesoporous structure with high specific surface area and uniform pore diameter, and $\mathrm{CuO}$ NPs were highly dispersive on the CZO surface. 8\% $\mathrm{CuO} / \mathrm{Ce}_{0.8} \mathrm{Zr}_{0.2} \mathrm{O}_{2}$ calcined at $400{ }^{\circ} \mathrm{C}$ showed the best catalytic activity due to the interfacial interaction between $\mathrm{CuO}$ and CZO support and highly dispersive CuO NPs as well as the nature of the support.

\subsubsection{Alcohols and other oxygenates}

Methanol combustion was investigated by Ziolek et al. [249] over $\mathrm{CeO}_{2}, \mathrm{ZrO}_{2}$, and mixed $\mathrm{CZO}$ mesoporous oxides-supported $\mathrm{Au}$ and $\mathrm{Cu}$. The electronic state of $\mathrm{Au}$ and the mobility of metals and oxygen from the support played a vital role in the combustion of methanol at low temperature. In addition, the activation temperature strongly affected the mobility of surface oxygen and the oxidation states of the cationic components, which played the role of Lewis acid sites and thereby strongly influenced the activity and selectivity of methanol oxidation. Moreover, the catalytic decomposition of methanol to $\mathrm{H}_{2}$ and $\mathrm{CO}$ was another efficient route. Chen and Liu et al. [250,251] reported catalytic decomposition of methanol to $\mathrm{CO}$ and $\mathrm{H}_{2}$ over $\mathrm{Pd} / \mathrm{Ce}_{0.65} \mathrm{Zr}_{0.30} \mathrm{La}_{0.05} \mathrm{O}_{2}$ and $\mathrm{Pd} / \mathrm{Ce}_{x} \mathrm{Zr}_{1-x} \mathrm{O}_{2} \quad(x=0-0.5)$. All $\mathrm{Pd}$-containing catalysts exhibited high selectivity to synthesis gas, among which the methanol conversion achieved 100\% at $220{ }^{\circ} \mathrm{C}$ over $\mathrm{Pd} / \mathrm{Ce}_{0.65} \mathrm{Zr}_{0.30} \mathrm{La}_{0.05} \mathrm{O}_{2}$.

The ethanol complete oxidation over $\mathrm{Mn}_{0.1} \mathrm{Ce}_{0.9} \mathrm{O}_{x}$ and $\mathrm{Mn}_{0.1} \mathrm{Ce}_{0.6} \mathrm{Zr}_{0.3} \mathrm{O}_{\mathrm{x}}$ complex compounds was studied by Wang et al. [252]. $T_{50}$ was lower over $\mathrm{Mn}_{0.1} \mathrm{Ce}_{0.9} \mathrm{O}_{x}\left(247^{\circ} \mathrm{C}\right)$ than that over $\mathrm{Mn}_{0.1} \mathrm{Ce}_{0.6} \mathrm{Zr}_{0.3 \mathrm{O}_{x}}\left(280^{\circ} \mathrm{C}\right)$ for the fresh samples. For the aged samples, however, $T_{50}$ over $\mathrm{Mn}_{0.1} \mathrm{Ce}_{0.6} \mathrm{Zr}_{0.3} \mathrm{O}_{x}$ was lower than that over $\mathrm{Mn}_{0.1} \mathrm{Ce}_{0.9} \mathrm{O}_{x}$ solid solution. The addition of $\mathrm{Zr}$ to $\mathrm{Mn}_{0.1} \mathrm{Ce}_{0.9} \mathrm{O}_{x}$ significantly improved its thermal stability, therefore, retaining its catalytic activity for the ethanol oxidation reaction. The effect of dopants $(\mathrm{M}=\mathrm{Mn}, \mathrm{Y}, \mathrm{La})$ on $\mathrm{MnO}_{\mathrm{m}} / \mathrm{Al}_{2} \mathrm{O}_{3} / \mathrm{Ce}_{0.45} \mathrm{Zr}_{0.45} \mathrm{M}_{0.10} \mathrm{O}_{y}$ for the catalytic combustion of ethanol was investigated by Chen et al. [253]. The catalytic activity of the $\mathrm{MnO}_{m} / \mathrm{Al}_{2} \mathrm{O}_{3} / \mathrm{Ce}_{0.50} \mathrm{Zr}_{0.50} \mathrm{O}_{2}$ monolithic catalyst was promoted by doping $\mathrm{Mn}, \mathrm{Y}$, and $\mathrm{La}$ into $\mathrm{Ce} 0.50 \mathrm{Zr}_{0.50} \mathrm{O}_{2}$. 
$\mathrm{MnO}_{\mathrm{m}} / \mathrm{Al}_{2} \mathrm{O}_{3} / \mathrm{Ce}_{0.45} \mathrm{Zr}_{0.45} \mathrm{Y}_{0.10} \mathrm{O}_{1.95}$ exhibited the best catalytic performance with $100 \%$ ethanol conversion temperature at $230{ }^{\circ} \mathrm{C}$. The catalytic activity of Au versus Pt on CZO in oxidation of ethanol was compared by Gaálová et al. [254]. Pt catalysts were more active in ethanol oxidation than Au catalysts due to their better reductive behavior and higher amount of basic centers. On the other hand, the Au catalysts exhibited the better selectivity in ethanol oxidation.

$\mathrm{Ce}_{0.6-\mathrm{x}} \mathrm{Zr}_{0.4} \mathrm{Mn}_{x} \mathrm{O}_{2}$ solid solutions were used for the butanol total oxidation [255]. The textural and redox properties were improved when Mn content increased in the material, especially for $x=0.36$, which was the most active in the butanol oxidation because of its high surface $\mathrm{Mn}^{4+}$ concentration and oxygen mobility.

Pagadala et al. [256] reported a versatile reusable heterogeneous $\mathrm{CZO} / \mathrm{SiO}_{2}$ catalyst synthesized by a very practical $\mathrm{C}-\mathrm{C}$ and $\mathrm{C}-\mathrm{O}$ bond forming reaction. This catalyst was superb for benzyl alcohols oxidation under the solvent-free liquid-phase condition and was reusable with no loss of catalytic activity even after multiple cycles.

Oxidations of esters were studied over non-noble metal catalysts. $\mathrm{Xu}$ et al. [257] reported a series of $\mathrm{CeO}_{2}$ and/or $\mathrm{ZrO}_{2}-\mathrm{TiO}_{2}$-supported copper oxide catalysts for catalytic ethyl acetate combustion. CZO-promoted $\mathrm{TiO}_{2}$ greatly improved the dispersion of $\mathrm{CuO}$ phase, which then enhanced the catalytic activity and prevented the formation of by-products. The complete combustion of ethyl acetate was observed at $270{ }^{\circ} \mathrm{C}$ over a $5 \% \mathrm{CuO} / \mathrm{CZO}-\mathrm{TiO}_{2}$ catalyst. A series of $\mathrm{CuCe}_{x} \mathrm{Zr}_{1-x} \mathrm{O}_{y} / \mathrm{ZSM}-5(x=$ $0-1.0$ ) catalysts were reported by Dou et al. [258], and their catalytic performance was tested for ethyl acetate abatement. The optimal performance was obtained with the $\mathrm{CuCe}_{0.75} \mathrm{Zr}_{0.25} \mathrm{O}_{y} / \mathrm{ZSM}-5$ catalyst, which achieved total combustion of ethyl acetate at $270{ }^{\circ} \mathrm{C}$ and the onset temperature as low as $110^{\circ} \mathrm{C}$. Moreover, this catalyst exhibited remarkable stability, and no deactivation phenomenon was noted after a long-term catalytic reaction for $60 \mathrm{~h}$ at $270{ }^{\circ} \mathrm{C}$. Apart from $\mathrm{Cu}$-based CZO catalysts, doping other metals (Mn, Y) into CZO affected the activity for ethyl acetate catalytic combustion [259]. The Mn doping greatly increased the OSC of the oxygen-storage materials (OSMs), whereas doping Y decreased the reduction temperature of catalysts. The doping of $\mathrm{Mn}$ and $\mathrm{Y}$ combined the advantages of $\mathrm{Mn}$ and $\mathrm{Y}$. $\mathrm{MnO}_{\mathrm{m}} / \mathrm{Ce}_{0.40} \mathrm{Zr}_{0.40} \mathrm{Mn}_{0.10} \mathrm{Y}_{0.10} \mathrm{O}_{\mathrm{y}} / \mathrm{Al}_{2} \mathrm{O}_{3}$ gave the best catalytic performance, which achieved complete conversion of ethyl acetate at $240{ }^{\circ} \mathrm{C}$, and the temperature range between the initial conversion and complete conversion was the smallest. Mn and $\mathrm{Y}$ entered the lattice of $\mathrm{CZO}$, which modified their textural properties and greatly improved the dispersion of $\mathrm{MnO}_{m}$ active phase on the support surface.

\subsubsection{Chlorinated VOC and other Cl-containing compounds}

Chlorohydrocarbon is one of the primary air pollutants, which has superior stability and toxicity and is emitted from various sources. Therefore, great efforts have been made to eliminate these compounds. Oxidation of chlorinated hydrocarbons (CHC) can produce $\mathrm{HCl}$ (Eq. (10)) or $\mathrm{Cl}_{2}$ (Eq. (11)):

$$
\begin{gathered}
\mathrm{C}_{x} \mathrm{H}_{y} \mathrm{Cl}_{z}+\left(x+\frac{y-z}{4}\right) \mathrm{O}_{2} \rightarrow x \mathrm{CO}_{2}+\frac{y-z}{2} \mathrm{H}_{2} \mathrm{O}+\mathrm{zHCl} \\
\mathrm{C}_{x} \mathrm{H}_{y} \mathrm{Cl}_{z}+\left(x+\frac{y}{4}\right) \mathrm{O}_{2} \rightarrow x \mathrm{CO}_{2}+\frac{y}{2} \mathrm{H}_{2} \mathrm{O}+\frac{z}{2} \mathrm{Cl}_{2}
\end{gathered}
$$

The ratio between $\mathrm{HCl}$ and $\mathrm{Cl}_{2}$ can be controlled by the Deacon equilibrium (Eq. (12)):

$$
2 \mathrm{HCl}+1 / 2 \mathrm{O}_{2} \rightarrow \mathrm{H}_{2} \mathrm{O}+\mathrm{Cl}_{2}
$$

This is an exothermic reaction $\left(\Delta_{r} H^{\circ}=58.4 \mathrm{~kJ} / \mathrm{mol}\right.$ at 350 $\left.{ }^{\circ} \mathrm{C}\right)$. Chlorine is produced in higher concentration at low temperature. For environmental reasons, it is preferable to orientate the reaction toward $\mathrm{HCl}$, more easily eliminated by soda washing. Whatever the product, $\mathrm{HCl}$ or $\mathrm{Cl}_{2}$, the oxidation catalyst has to work under severe conditions, generally leading to rapid deactivation. Catalyst stability is an essential parameter for VOC oxidation processes involving chlorinated hydrocarbons. CZO plays a key role in the abatement of chloroorganics.

Gutierrez-Ortiz et al. [260] studied the chlorinated hydrocarbons (1,2-dichloroethane and trichloroethylene) oxidation over a series of CZO and found that the surface acidity and lattice oxygen of the catalyst were responsible for the chlorohydrocarbons oxidation. The optimum performances were achieved over the zirconia-rich system. Matějová et al. [261] prepared $\mathrm{Ce}_{0.5} \mathrm{Zr}_{0.5} \mathrm{O}_{2}$-supported $\mathrm{Pt}$ and $\mathrm{Au}$ catalysts for the total oxidation of dichloromethane. The introduction of $\mathrm{Pt}$ and $\mathrm{Au}$ on the $\mathrm{Ce}_{0.5} \mathrm{Zr}_{0.5} \mathrm{O}_{2}$ support significantly promoted the redox behavior of surface ceria particular for Pt-based catalysts, but it led to the loss of catalyst acidity. As a result, the noble metal catalysts exhibited lower catalytic performance than $\mathrm{Ce}_{0.5} \mathrm{Zr}_{0.5} \mathrm{O}_{2}$ in dichloromethane total oxidation due to the decreases of acid sites for chlorinated compounds. Moreover, Pt-based catalysts showed considerably high $\mathrm{CO}_{2}$ selectivity compared with the $\mathrm{Ce}_{0.5} \mathrm{Zr}_{0.5} \mathrm{O}_{2}$ support.

Gutiérrez-Ortiz et al. [262] prepared a series of sulphated CZO using sulphuric acid and nitric acid for the oxidative decomposition of dichloroethane. The catalyst showed a superior catalytic activity at a reaction temperature of dichloroethane decomposition as low as $80{ }^{\circ} \mathrm{C}$. The increased acidity of CZO was responsible for its excellent activity. Li et al. [263] investigated the catalytic oxidation of 2-chlorophenol over a $\mathrm{Ru} / \mathrm{CZO}$ catalyst. The mobility of the lattice oxygen was significantly promoted by the addition of $\mathrm{Ru}$, which greatly enhanced the catalytic activity of the catalyst. González-Velasco et al. [264] studied the catalytic oxidation of dichloroethane and trichloroethylene over CZO in the presence and absence of $n$-hexane. The catalytic activity of the catalyst for the chlorinated organics oxidation was dependent on the $\mathrm{Ce} / \mathrm{Zr}$ molar ratio, surface acidity, and OSC of CZO. CZO exhibited higher activity than pure $\mathrm{CeO}_{2}$ in the elimination of chlorohydrocarbons in the absence of $n$-hexane. In the presence of $n$-hexane, however, an increase in the ignition temperature was observed over CZO. Furthermore, the introduction of $n$-hexane led to the formation of $\mathrm{H}_{2} \mathrm{O}$ in its combustion process, which was responsible for the increased selectivity to $\mathrm{HCl}$.

Rivas et al. [265] investigated trichloroethylene oxidation over CZO prepared by the CP method. The catalyst with the most acidity displayed the highest activity. A mechanism for the 
dechlorination reaction was also proposed, in which the adsorption of trichloroethylene onto catalyst surface is the rate-limiting step, in agreement with that reported by Feijen-Jeurissen et al. [266]. Gutierrez-Ortiz et al. [267] investigated 1,2-dichloroethane decomposition over $\mathrm{Cr}_{x} \mathrm{Zr}_{1-x} \mathrm{O}_{2}(x=$ $0-1.0$ ), and the catalytic activity changed with the zirconia content for the samples. $\mathrm{Ce}_{0.5} \mathrm{Zr}_{0.5} \mathrm{O}_{2}$ exhibited the best performance. A reaction mechanism was proposed based on the in-situ FT-IR spectra. It involved 1,2-dichloroethane dehydrochlorination on the acidic sites of the catalyst to form vinyl chloride and $\mathrm{HCl}$. Then the vinyl chloride got protonation from the basic species $(\mathrm{OH})$ of catalyst surface, which led to the formation of carbonium ions. Subsequently, these ions were trapped by the nucleophilic oxygen from the catalyst to form chlorinated alkoxide compound and then it decomposed to acetaldehyde. Finally, $\mathrm{CO}_{2}$ and trace amounts of $\mathrm{CO}$ were formed by the conversion of acetaldehyde.

\subsubsection{Soot combustion}

Soot emitted from diesel engine outlets is a main constituent of air pollution. It is closely related to respiratory and cardiovascular diseases as well as skin cell alterations [268]. Therefore, stringent legislation has been implemented to limit soot content from vehicles (e.g., $0.005 \mathrm{~g} / \mathrm{km}$ for soot from passenger cars in Europe since 2009, and in China since 2018). It has imposed the utilization of catalytic technologies to satisfy the required standards [269,270]. Among the different alternatives, the entrapment of particulate from exhaust gases by diesel particulate filter (DPF) has attracted much attention in recent years [271-278]. The soot particulates can be burnt off above $600{ }^{\circ} \mathrm{C}$, however, typical engine exhaust temperatures fall within the $180-400{ }^{\circ} \mathrm{C}$ range [277-279]. In order to overcome the limitation of alternative regeneration of DPF and prevent from the deposition of particles, oxidation catalysts are developed to improve the combustion activity of soot over DPF. Among which, CZO is efficiently used due to their high mobility of reactive oxygen species and thermal stability [273,280,281]. It is now accepted that it exhibits much higher soot oxidation rate in the presence of $\mathrm{O}_{2}+\mathrm{NO}_{2}$ than that in $\mathrm{O}_{2}$ alone. In this section, soot combustion over Ce-Zr-based catalysts is reviewed, as shown in Table 5.

\subsubsection{Effect of support composition}

The effects of specific surface area and OSC of CZO on soot combustion were investigated by Trovarelli et al. [280]. The surface oxygen linked to ceria played a vital role for the catalytic combustion of soot, while OSC could be important when oxidation of soot particles was carried out in the absence or

Table 5

Catalytic activities of nanosize CZO materials in soot combustion.

\begin{tabular}{|c|c|c|c|}
\hline Catalyst & Reaction conditions & $T_{50} / T_{\mathrm{m}}\left({ }^{\circ} \mathrm{C}\right)$ & Ref. \\
\hline $\mathrm{Ce}_{0.5} \mathrm{Zr}_{0.5} \mathrm{O}_{2}$ & $20 \% \mathrm{O}_{2}(100 \mathrm{~mL} / \mathrm{min}) /($ Cat. $/$ soot $=4$, tight $)$ & 522 & [285] \\
\hline $\mathrm{Ce}_{0.69} \mathrm{Zr}_{0.31} \mathrm{O}_{2}$ & $20 \% \mathrm{O}_{2}(100 \mathrm{~mL} / \mathrm{min}) /($ Cat. $/$ soot $=4$, tight $)$ & 458 & [275] \\
\hline $\mathrm{Ce}_{0.8} \mathrm{Zr}_{0.2} \mathrm{O}_{2}$ & $10 \% \mathrm{O}_{2}(100 \mathrm{~mL} / \mathrm{min}) / 50 \mathrm{mg}$ sample (Cat. $/$ soot $=9$, tight $)$ & 469 & [282] \\
\hline $\mathrm{Ce}_{0.9} \mathrm{Zr}_{0.1} \mathrm{O}_{2}-\mathrm{NP}$ & $10 \% \mathrm{O}_{2}(100 \mathrm{~mL} / \mathrm{min}) / 50 \mathrm{mg}$ sample (Cat. $/$ soot $=9$, tight $)$ & 435 & [283] \\
\hline $3 \mathrm{DOM} \mathrm{Ce} \mathrm{Ce}_{0.7} \mathrm{Zr}_{0.3} \mathrm{O}_{2}$ & $0.2 \% \mathrm{NO}+10 \% \mathrm{O}_{2}(100 \mathrm{~mL} / \mathrm{min})($ Cat. $/$ soot $=10$, loose $)$ & 388 & {$[102]$} \\
\hline $\mathrm{HP} \mathrm{Ce}_{0.5} \mathrm{Zr}_{0.5} \mathrm{O}_{2}$ & $20 \% \mathrm{O}_{2}(100 \mathrm{~mL} / \mathrm{min})($ Cat. $/$ soot $=4$, tight $)$ & 415 & [289] \\
\hline $\mathrm{K} / \mathrm{Ce}_{0.5} \mathrm{Zr}_{0.5} \mathrm{O}_{2}$ & $10 \% \mathrm{O}_{2}(500 \mathrm{~mL} / \mathrm{min}) / 110 \mathrm{mg}$ sample (Cat./soot $=10$, tight $)$ & 340 & [187] \\
\hline $\mathrm{Ru} / \mathrm{K} / \mathrm{Ce}_{0.8} \mathrm{Zr}_{0.2} \mathrm{O}_{2}$ & $10 \% \mathrm{O}_{2}(500 \mathrm{~mL} / \mathrm{min}) / 20 \mathrm{mg}$ sample (Cat./soot $=20$, loose $)$ & 385 & [306] \\
\hline $\mathrm{Ru} / \mathrm{K} / \mathrm{Ce}_{0.8} \mathrm{Zr}_{0.2} \mathrm{O}_{2}$ & $0.05 \% \mathrm{NO}+10 \% \mathrm{O}_{2}(500 \mathrm{~mL} / \mathrm{min}) / 20 \mathrm{mg}$ sample (Cat. $/ \mathrm{soot}=20$, loose $)$ & 393 & [306] \\
\hline $\mathrm{Ru} / \mathrm{Ba} / \mathrm{Ce}_{0.8} \mathrm{Zr}_{0.2} \mathrm{O}_{2}$ & $10 \% \mathrm{O}_{2}(500 \mathrm{~mL} / \mathrm{min}) / 20 \mathrm{mg}$ sample (Cat./soot = 20 , loose $)$ & 585 & [306] \\
\hline $\mathrm{Ru} / \mathrm{Ba} / \mathrm{Ce}_{0.8} \mathrm{Zr}_{0.2} \mathrm{O}_{2}$ & $0.05 \% \mathrm{NO}+10 \% \mathrm{O}_{2}(500 \mathrm{~mL} / \mathrm{min}) / 20 \mathrm{mg}$ sample (Cat. $/$ soot $=20$, loose $)$ & 495 & [306] \\
\hline $\mathrm{Ce}_{0.48} \mathrm{Zr}_{0.5} \mathrm{La}_{0.02} \mathrm{O}_{1.99}$ & $6 \% \mathrm{O}_{2}(400 \mathrm{~mL} / \mathrm{min}) / 25 \mathrm{mg}$ sample (Cat./soot $=20$, tight $)$ & 414 & [284] \\
\hline $\mathrm{Ce}_{0.84} \mathrm{Zr}_{0.15} \mathrm{Y}_{0.01} \mathrm{O}_{2}$ & $20 \% \mathrm{O}_{2}(100 \mathrm{~mL} / \mathrm{min})($ Cat. $/$ soot $=4$, tight $)$ & 456 & [405] \\
\hline $\mathrm{Ce}_{0.8} \mathrm{Zr}_{0.1} \mathrm{Pr}_{0.1} \mathrm{O}_{2}$ & $10 \% \mathrm{O}_{2}(100 \mathrm{~mL} / \mathrm{min}) / 50 \mathrm{mg}$ sample (Cat. $/$ soot $=9$, tight $)$ & 444 & [282] \\
\hline $\mathrm{Ce}_{0.4} \mathrm{Zr}_{0.5} \mathrm{Pr}_{0.1} \mathrm{O}_{2}$ & $0.2 \% \mathrm{NO}+5 \% \mathrm{O}_{2}(100 \mathrm{~mL} / \mathrm{min})($ Cat. $/$ soot $=10$, tight $)$ & 361 & {$[274]$} \\
\hline $\mathrm{Ce}_{0.48} \mathrm{Zr}_{0.5} \mathrm{Pr}_{0.02} \mathrm{O}_{1.99}$ & $6 \% \mathrm{O}_{2}(400 \mathrm{~mL} / \mathrm{min}) / 25 \mathrm{mg}$ sample (Cat. $/$ soot $=20$, tight $)$ & 410 & [284] \\
\hline $\mathrm{Ce}_{0.48} \mathrm{Zr}_{0.5} \mathrm{~Tb}_{0.02} \mathrm{O}_{1.99}$ & $6 \% \mathrm{O}_{2}(400 \mathrm{~mL} / \mathrm{min}) / 25 \mathrm{mg}$ sample (Cat. $/$ soot $=20$, tight $)$ & 414 & [284] \\
\hline $\mathrm{Ce}_{0.48} \mathrm{Zr}_{0.5} \mathrm{Sm}_{0.02} \mathrm{O}_{1.99}$ & $6 \% \mathrm{O}_{2}(400 \mathrm{~mL} / \mathrm{min}) / 25 \mathrm{mg}$ sample (Cat./soot $=20$, tight) & 411 & [284] \\
\hline $3 \mathrm{DOM} \mathrm{Ce} 0.6 \mathrm{Zr}_{0.3} \mathrm{Pr}_{0.1} \mathrm{O}_{2}$ & $0.2 \% \mathrm{NO}+5 \% \mathrm{O}_{2}(100 \mathrm{~mL} / \mathrm{min}) / 110 \mathrm{mg}$ sample (Cat. $/$ soot $=10$, loose $)$ & 361 & [103] \\
\hline $\mathrm{Ce}_{0.5} \mathrm{Zr}_{0.2} \mathrm{Fe}_{0.3} \mathrm{O}_{2}$ & $10 \% \mathrm{O}_{2}(500 \mathrm{~mL} / \mathrm{min}) / 165 \mathrm{mg}$ sample $($ Cat. $/$ soot $=10$, loose $)$ & 310 & [287] \\
\hline 3DOM Ce $0.8 \mathrm{Zr}_{0.1} \mathrm{Fe}_{0.1} \mathrm{O}_{2}$ & $0.1 \% \mathrm{NO}+0.1 \% \mathrm{NH}_{3}+3 \% \mathrm{O}_{2}(100 \mathrm{~mL} / \mathrm{min}) / 110 \mathrm{mg}$ sample (Cat. $/$ soot $=10$, loose $)$ & 375 & [182] \\
\hline 3DOM Ce $0.8 \mathrm{Zr}_{0.1} \mathrm{Mn}_{0.1} \mathrm{O}_{2}$ & $0.1 \% \mathrm{NO}+0.1 \% \mathrm{NH}_{3}+3 \% \mathrm{O}_{2}(100 \mathrm{~mL} / \mathrm{min}) / 110 \mathrm{mg}$ sample $($ Cat. $/$ soot $=10$, loose $)$ & 402 & [184] \\
\hline $3 \mathrm{DOM} \mathrm{Ce} 0.8 \mathrm{Zr}_{0.1} \mathrm{Co}_{0.1} \mathrm{O}_{2}$ & $0.1 \% \mathrm{NO}+0.1 \% \mathrm{NH}_{3}+3 \% \mathrm{O}_{2}(100 \mathrm{~mL} / \mathrm{min}) / 110 \mathrm{mg}$ sample $($ Cat. $/$ soot $=10$, loose $)$ & 433 & [184] \\
\hline $3 \mathrm{DOM} \mathrm{Ce} \mathrm{Ce}_{0.8} \mathrm{Zr}_{0.1} \mathrm{Ni}_{0.1} \mathrm{O}_{2}$ & $0.1 \% \mathrm{NO}+0.1 \% \mathrm{NH}_{3}+3 \% \mathrm{O}_{2}(100 \mathrm{~mL} / \mathrm{min}) / 110 \mathrm{mg}$ sample (Cat. $/$ soot $=10$, loose $)$ & 429 & [184] \\
\hline $\mathrm{Ru} / \mathrm{Ce}_{0.4 \mathrm{Zr}_{0.6} \mathrm{O}_{2}}$ & $20 \% \mathrm{O}_{2}(75 \mathrm{~mL} / \mathrm{min}) / 11.67 \mathrm{mg}$ sample (Cat./soot $=9$, loose) & 360 & [294] \\
\hline $3 \mathrm{DOM} \mathrm{Au} / \mathrm{Ce}_{0.7} \mathrm{Zr}_{0.3} \mathrm{O}_{2}$ & $0.2 \% \mathrm{NO}+5 \% \mathrm{O}_{2}(50 \mathrm{~mL} / \mathrm{min}) / 110 \mathrm{mg}$ sample (Cat./soot $=10$, loose $)$ & 375 & [101] \\
\hline $\mathrm{Cu} / \mathrm{Ce}_{0.55} \mathrm{Zr}_{0.45} \mathrm{O}_{2}$ & $9.5 \% \mathrm{O}_{2}(500 \mathrm{~mL} / \mathrm{min}) / 110 \mathrm{mg}$ sample$($ Cat. $/$ soot $=10$, tight $)$ & 365 & [296] \\
\hline $\mathrm{Co} / \mathrm{Ce}_{0.5} \mathrm{Zr}_{0.5} \mathrm{O}_{2}$ & $15 \% \mathrm{O}_{2}(35 \mathrm{~mL} / \mathrm{min}) / 100 \mathrm{mg}$ sample(Cat. $/$ soot = 10 , tight $)$ & 386 & [298] \\
\hline $\mathrm{Ni} / \mathrm{Ce}_{0.5} \mathrm{Zr}_{0.5} \mathrm{O}_{2}$ & $20 \% \mathrm{O}_{2}(60 \mathrm{~mL} / \mathrm{min}) / 100 \mathrm{mg}$ sample (Cat. $/$ soot $=4$, tight $)$ & 463 & [299] \\
\hline $\mathrm{Ag} / \mathrm{Ce}_{0.75} \mathrm{Zr}_{0.25} \mathrm{O}_{2}$ & $5 \% \mathrm{H}_{2} \mathrm{O}+4.8 \% \mathrm{O}_{2}(50 \mathrm{~mL} / \mathrm{min}) / 200 \mathrm{mg}$ sample (Cat. $/$ soot $=19$, loose) & 286 & [295] \\
\hline $\mathrm{Ag} / \mathrm{Ce}_{0.75} \mathrm{Zr}_{0.25} \mathrm{O}_{2}$ & $5 \% \mathrm{H}_{2} \mathrm{O}+0.1 \% \mathrm{NO}+4.8 \% \mathrm{O}_{2}(50 \mathrm{~mL} / \mathrm{min}) / 200 \mathrm{mg}$ sample $($ Cat. $/$ soot $=19$, loose $)$ & 279 & [295] \\
\hline $\mathrm{CuO}-\mathrm{CoO} / \mathrm{Ce}_{0.5} \mathrm{Zr}_{0.5} \mathrm{O}_{2}$ & $20 \% \mathrm{O}_{2}(60 \mathrm{~mL} / \mathrm{min}) / 100 \mathrm{mg}$ sample (Cat./soot = 4, tight) & 363 & [299] \\
\hline $\mathrm{CuO}-\mathrm{NiO} / \mathrm{Ce}_{0.5} \mathrm{Zr}_{0.5} \mathrm{O}_{2}$ & $20 \% \mathrm{O}_{2}(60 \mathrm{~mL} / \mathrm{min}) / 100 \mathrm{mg}$ sample (Cat./soot $=4$, tight $)$ & 388 & [299] \\
\hline
\end{tabular}

$T_{50}$ and $T_{\mathrm{m}}$ are denoted as temperature corresponding to $50 \%$ soot conversion and temperature at the maximum $\mathrm{CO}_{2}$ concentration in the process of soot combustion, respectively. Loose or tight is referred to that the contact condition between catalyst and soot is loose contact or tight contact. 
defect of gaseous oxygen. The effects of $\mathrm{Ce} / \mathrm{Zr}$ ratios on the phase composition and catalytic activities of CZO and Pr/CZO samples for soot combustion were investigated by Bensaid et al. [282], as displayed in Table 5. The role of $\mathrm{Zr}$ in stabilizing surface area of ceria was also important when evaluating the effect of composition on soot combustion activity. Fino et al. [283] prepared a series of nanostructured CZO with different $\mathrm{Zr}$ contents and structural features for soot combustion. The optimally catalytic performance was obtained for the nano-polyhedra $\mathrm{Ce}_{0.9} \mathrm{Zr}_{0.1} \mathrm{O}_{2}$ catalyst due to its higher mobility of the lattice oxygen and easier reducibility compared with other catalysts. The substitution of some $\mathrm{Zr}^{4+}$ ions into $\mathrm{Ce}^{4+}$ was favorable for the generation of defects in the ceria lattice, thereby leading to a distortion of the oxygen sublattice. Nevertheless, the amount of redox Ce species decreased with increasing $\mathrm{Zr}$ contents. Therefore, it seemed that the substitution of $\mathrm{Zr}$ for Ce did not have a direct promotion effect on the oxidation activity of catalysts.

The effect of the rare earth elements-modified CZO on the catalytic combustion of soot was investigated. Aneggi et al. [284] studied the effect of rare earth elements ( $\mathrm{La}, \mathrm{Pr}, \mathrm{Sm}, \mathrm{Tb}$ ) on the textural and structural characteristics of $\mathrm{CeO}_{2}$ and $\mathrm{CZO}$ for soot combustion. $\mathrm{CeO}_{2}$ doped with these rare earth elements exhibited more active activities due to the increased oxygen storage, which could provide an alternative route for the oxidation of big soot particles in contact with ceria. However, CZO modified with rare earth elements did not achieve lower combustion temperature, which was comparable to $\mathrm{CeO}_{2}$ and CZO. The role of Pr as dopant for ceria-based catalysts was studied in CO and soot oxidation by Zhao et al. [103]. It appeared that the incorporation of Pr species into CZO framework improved the oxidation activity for $\mathrm{CO}$, while this positive effect was less prominent for soot combustion due to the effect of catalyst morphology. The phase compositions of Pr-modified CZO were similar to those of corresponding CZO samples, and cubic and tetragonal phases coexisted in the samples with moderate zirconia content, which was beneficial to soot combustion. Additionally, the effects of thermal and hydrothermal treatments on the catalytic activities of $3 \mathrm{DOM} \mathrm{CeO}_{2}, \mathrm{Ce}_{0.7} \mathrm{Zr}_{0.3} \mathrm{O}_{2}$, and $\mathrm{Ce}_{0.6} \mathrm{Zr}_{0.3} \mathrm{Pr}_{0.1} \mathrm{O}_{2}$ for soot oxidation were comparatively studied. Compared with 3DOM $\mathrm{CeO}_{2}$, 3DOM Ce-Zr-based solid solutions, especially $\mathrm{Pr}$-modified $\mathrm{Ce}_{0.6} \mathrm{Zr}_{0.3} \mathrm{Pr}_{0.1} \mathrm{O}_{2}$ solid solution, showed the highest stability due to its lowest lattice oxygen mobility among the three samples. The relative efficacy of the La promoter in CZO was investigated systematically for soot oxidation at low temperature [285]. The addition of $\mathrm{La}^{3+}$ to ceria promoted the oxidation rate of soot compared with pure ceria and $\mathrm{Zr}^{4+}$-doped ceria. This should be due to the more active oxygen provoked by defective structure of ceria, which was induced by the presence of $\mathrm{La}^{3+}$. The effect of $\mathrm{Y}$ doping and loading on the physicochemical properties and soot combustion activity of CZO was investigated by Bueno-López et al. [286]. In tight contact, $\mathrm{Ce}_{0.85-\mathrm{x}} \mathrm{Zr}_{0.15} \mathrm{Y}_{\mathrm{x}} \mathrm{O}_{2}$ mixed oxides on the catalytic activity with respect to yttrium. And in loose contact, the catalytic activity was dependent on their specific surface area, and catalysts $\mathrm{Ce}_{0.85-\mathrm{x}} \mathrm{Zr}_{0.15} \mathrm{Y}_{\mathrm{x}} \mathrm{O}_{2}\left(10-13 \mathrm{~m}^{2} / \mathrm{g}\right)$ were more active than $\mathrm{Ce}_{1-\mathrm{x}} \mathrm{Y}_{\mathrm{x}} \mathrm{O}_{2}\left(2-3 \mathrm{~m}^{2} / \mathrm{g}\right)$. In this loose contact condi- tion, the yttrium doping and loading had a minor or null effect on the activity, and the stabilizing effect of the specific surface area due to zirconium doping prevailed.

\subsubsection{Effect of preparation method}

The catalytic performances of CZO-based materials for soot combustion were influenced by the preparation method. Sang et al. [287] reported a series of $\mathrm{Ce}_{0.5} \mathrm{Fe}_{0.30} \mathrm{Zr}_{0.20} \mathrm{O}_{2}$ catalysts prepared by different methods (CP, SG, physical mixed, impregnation, and hydrothermal method). $\mathrm{Fe}^{3+}$ and $\mathrm{Zr}^{4+}$ were incorporated into ceria lattice to form a homogeneous Ce-Fe-Zr-O solid solution by the CP method, but two kinds of Fe phases existed in $\mathrm{Ce}-\mathrm{Fe}-\mathrm{Zr}-\mathrm{O}$ catalysts prepared by other methods: dispersed $\mathrm{Fe}_{2} \mathrm{O}_{3}$ clusters and $\mathrm{Fe}^{3+}$ incorporated into $\mathrm{CeO}_{2}$ lattice. The free $\mathrm{Fe}_{2} \mathrm{O}_{3}$ clusters could promote the activity of catalysts for soot combustion comparing with $\mathrm{Ce}-\mathrm{Fe}-\mathrm{Zr}-\mathrm{O}$ solid solution owing to the synergetic effect between free $\mathrm{Fe}_{2} \mathrm{O}_{3}$ and surface oxygen vacancies. In addition, the activity of catalysts considerably relied on the surface reducibility of free $\mathrm{Fe}_{2} \mathrm{O}_{3}$ particles. The hydrothermal $\mathrm{Ce}_{0.5} \mathrm{Fe}_{0.3} \mathrm{Zr}_{0.2} \mathrm{O}_{2}$ catalyst displayed the minimum ignition temperature $\left(251{ }^{\circ} \mathrm{C}\right)$ and maximum oxidation rate temperature $\left(T_{m}=310^{\circ} \mathrm{C}\right)$ for the combustion of soot in tight contact between soot and catalysts. This was due to the both abundant free $\mathrm{Fe}_{2} \mathrm{O}_{3}$ particles and high oxygen vacancy concentration. Even after being aged at $800{ }^{\circ} \mathrm{C}$ for $10 \mathrm{~h}, T_{\mathrm{m}}$ still displayed a low value at $361^{\circ} \mathrm{C}$.

\subsubsection{Effect of pore structure}

It is well known that the conventional ceria-zirconium-based catalysts have smaller pore sizes $(<10$ $\mathrm{nm}$ ) than soot particles (>20 nm). Therefore, soot particles are difficult to enter the inner pores of these catalysts to access active sites. So how to effectively make use of the inner surface for increasing the contact area between catalysts and soot particles is a key factor to enhance the catalytic activity for the removal of soot. Fino et al. [283] investigated the soot combustion over microporous and mesoporous $\mathrm{Ce}_{0.9} \mathrm{Zr}_{0.1} \mathrm{O}_{2}$ oxides. Lower soot conversion was achieved for both microporous and mesoporous $\mathrm{Ce}_{0.9} \mathrm{Zr}_{0.1} \mathrm{O}_{2}$ with similar $\mathrm{Ce} / \mathrm{Zr}$ ratio. $\mathrm{Ce}_{0.9} \mathrm{Zr}_{0.1} \mathrm{O}_{2}$ particle catalyst showed the worse activity than the porous materials, which confirmed the important role of the textural properties for soot combustion. 3DOM CZO contains periodic arrays of interconnected macropores [102]. The open, interconnected macroporous structure is a desirable feature for diesel soot combustion. Compared with that of disordered macroporous (DM) catalysts, 3DOM samples facilitate the contact between soot and catalysts and promote the catalytic activity for soot combustion. $T_{50}$ of 3DOM samples could be lowered by $51{ }^{\circ} \mathrm{C}$ at most, as shown in Fig. 16. Then, 3DOM CZO-supported Au NPs catalysts were prepared via the gas bubbling-assisted membrane reduction method [288]. This kind of catalysts combined both advantages of good contact between diesel soot and catalyst by 3DOM supports and the highly active sites for the activation of $\mathrm{O}_{2}$ by Au clusters with suitable nanosize, and they exhibited good catalytic performances for the oxidation of soot. $3 \mathrm{DOM} \mathrm{Au} / \mathrm{Ce}_{0.7} \mathrm{Zr}_{0.3} \mathrm{O}_{2}$ catalyst showed $T_{50}$ as low as $375^{\circ} \mathrm{C}$. In addition, Pr-modified 3DOM 


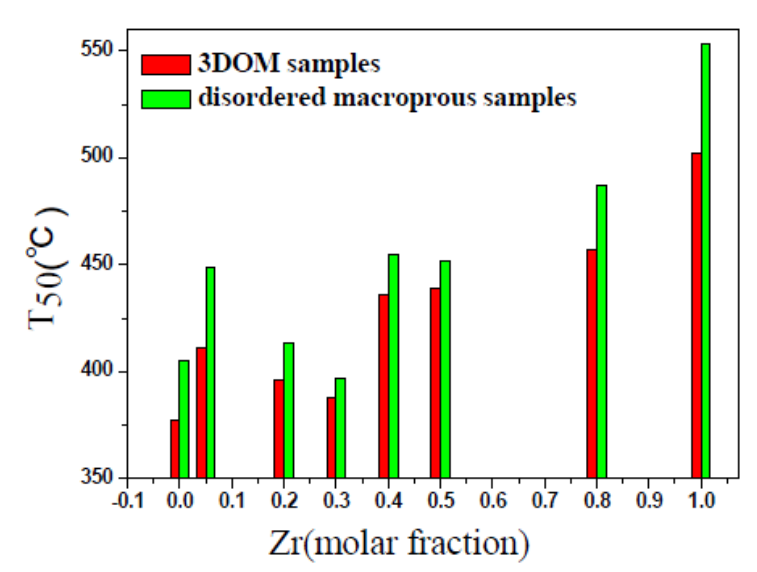

Fig. 16. $T_{50}$ of $\mathrm{Ce}_{1-\mathrm{x}} \mathrm{Zr}_{\mathrm{x}} \mathrm{O}_{2}$ catalysts with different macroporous structures versus $\mathrm{Zr}$ molar fraction for soot combustion. Reprinted from [102] with permission.

CZO was prepared by a CCT method [103]. It was used for the removal of soot and exhibited higher catalytic activities compared with DM ones. This was due to the improved contact efficiency between soot and ordered macroporous structure.

Zaletova et al. [289] reported that hierarchical porous (HP) CZO was prepared using small-size fraction of wood as template for oxidation of diesel soot particulate. HP CZO exhibited higher soot conversion over regular CZO due to its larger surface area, higher amount of mobile lattice oxygen and lower temperature of oxygen release.

\subsubsection{Effect of active phase}

$\mathrm{Ru}$ is established as a successful catalytic system in oxidation reactions [290-293]. Nascimento et al. [294] reported the soot combustion over $\mathrm{Ru}$-doped $\mathrm{Ce}_{0.4} \mathrm{Zr}_{0.6} \mathrm{O}_{2}$ nanopowders in the temperature range of $220-500{ }^{\circ} \mathrm{C}$. $\mathrm{Ce}_{0.4} \mathrm{Zr}_{0.6} \mathrm{O}_{2}$ showed good tolerance to water as well as excellent thermal stability. The addition of $\mathrm{Ru} N$ Ns $(8-10 \mathrm{~nm})$ to $\mathrm{Ce}_{0.4} \mathrm{Zr}_{0.6} \mathrm{O}_{2}$ greatly boosted the reactivity of the mixed binary catalyst due to the increased active oxygen species. Chen and Zheng [295] prepared a mesoporous $\mathrm{Ag} / \mathrm{CZO}$ catalyst with $\mathrm{Ag} / \mathrm{Ce}$ structure by the $\mathrm{CP}$ method using a mixture of $\mathrm{NH}_{3} \cdot \mathrm{H}_{2} \mathrm{O}$ and $\mathrm{KOH}$ as precipitant. The Ag-Ce interaction led to the increase of $\mathrm{Ag}^{+}$species, which was favorable for the activation of oxygen species. In addition, it was found that $\mathrm{Ag}^{0}$ species surrounding with $\mathrm{Ag}^{+}$species was more beneficial to activating the oxygen. While Ag-Ce interface brought about $\mathrm{Ag}^{+}$species, which would be more effective in transferring the activated oxygen species. Thus, the Ag-based catalyst with optimal Ag-Ce interaction exhibited excellent performance for soot oxidation even in the loose contact mode and in the absence of $\mathrm{NO}_{x}$. And its activity could keep stable for several runs, which was attributed to Ag-Ce interaction along with different distribution of Ag species.

Transition metals, such as $\mathrm{Co}, \mathrm{Cu}$ and, $\mathrm{Mn}$, are widely used in commercial soot removal systems. Wu et al. [296] investigated the soot catalytic oxidation over $\mathrm{Cu}$ doping $\mathrm{CeO}_{2} / \mathrm{CZO}$ catalysts. $\mathrm{Cu}$ modification improved the activity and selectivity of $\mathrm{CeO}_{2}$ and CZO for the catalytic oxidation of soot attributing to the well dispersed copper oxide species strongly interacting with the ceria surface, which might lower the activation energy of soot combustion. Reddy et al. [297] reported CZO-supported Cu catalysts for soot combustion. The introduction of $\mathrm{Cu}^{2+}$ into CZO was benefited to the formation of more structural defects, which accelerated the oxygen diffusion and induced the production of more surface-active oxygen species. It was responsible for the improved low-temperature activity of soot combustion. Chen et al. [298] investigated the effect of Co addition on catalytic performance of $\mathrm{Ce}_{0.5} \mathrm{Zr}_{0.5} \mathrm{O}_{2}$ mixed oxide for soot combustion. The catalytic activity of the catalyst was effectively improved by the addition of Co with soot due to the existence of synergistic effect between Co and Ce. CZO-based monometallic (CoO/CZO and $\mathrm{NiO} / \mathrm{CZO})$ and bimetallic (CuO-CoO/CZO and CuO-NiO/CZO) catalysts were prepared by Reddy et al. [299] and used for soot oxidation. The bimetallic CuO-CoO/CZO catalyst exhibited the best catalytic activity $\left(T_{50}=363{ }^{\circ} \mathrm{C}\right)$ and nearly $100 \% \mathrm{CO}_{2}$ selectivity due to the formation of facile reduction and abundant oxygen vacancies as well as the small size of the metal particles and the high specific surface area. Escribano et al. [300] found that the Mn/CZO catalyst showed high activity for soot combustion, producing $\mathrm{CO}_{2}$ and $\mathrm{CO}$ as a by-product in the temperature range of $152-452{ }^{\circ} \mathrm{C}$, and the amount of $\mathrm{CO}$ decreased significantly with increasing $\mathrm{O}_{2}$ concentration in the feed gases.

Adding low melting point metal salts can improve the catalytic activity [301], and alkali metals have been reported as a molten salt to promote catalyst-soot contact by increasing surface mobility [102,302,303]. Neyertz et al. [279] reported that the introduction of $\mathrm{K}$ promoted the catalytic performances of $\mathrm{K} / \mathrm{CeO}_{2}$ /cordierite and $\mathrm{K} / \mathrm{Ce} 0.65 \mathrm{Zr}_{0.35} \mathrm{O}_{2}$ /cordierite for soot combustion. However, the $\mathrm{K} / \mathrm{CeO}_{2} /$ cordierite catalyst was more active due to the distribution of $\mathrm{Zr}$ on the surface of $\mathrm{Ce}_{0.65} \mathrm{Zr}_{0.35} \mathrm{O}_{2}$, which decreased the catalytic activity. Zhu et al. [304] investigated the effect of $\mathrm{KNO}_{3}$ loading on $\mathrm{Ce}_{0.5} \mathrm{Zr}_{0.5} \mathrm{O}_{2}$ for catalytic soot combustion. $\mathrm{KNO}_{3}$ loading on $\mathrm{Ce}_{0.5} \mathrm{Zr}_{0.5} \mathrm{O}_{2}$ resulted in an distinct enhancement in the catalytic activity due to that $\mathrm{KNO}_{3}$ favored the formation of chemisorbed oxygen and carbonate species $(\mathrm{C}-\mathrm{O}-\mathrm{K})$, which could react with soot to yield $\mathrm{CO}_{2}$, and the reduced state $\mathrm{C}-\mathrm{M}$ was reoxidized by $\mathrm{O}^{*}$ to reform C-O-K. In addition, Wu and Weng et al. [305] studied the role of CZO in diesel soot oxidation and thermal stability of a potassium catalyst, and they believed $\mathrm{KNO}_{3}$ to be the key factor affecting soot catalytic combustion due to that the nitrate can act as an oxidant of soot being transformed into reduced nitrite species.

Castoldi et al. [306] investigated K- and Ba-doped Ru supported catalysts for the removal of soot in the presence of $\mathrm{NO}_{x}$. $1 \mathrm{wt} \% \mathrm{Ru}-10 \mathrm{wt} \% \mathrm{AM} / \mathrm{MO}\left(\mathrm{AM}=\mathrm{Ba}\right.$ or $\mathrm{K} ; \mathrm{MO}=\mathrm{Ce}_{0.8} \mathrm{Zr}_{0.2} \mathrm{O}_{2}$, $\mathrm{ZrO}_{2}, \mathrm{Al}_{2} \mathrm{O}_{3}$ ) catalysts promoted the soot particulate combustion in the presence of $\mathrm{NO} / \mathrm{O}_{2}$. The promotion effect for K-based catalysts seemed to be not dependent on the nature of the support, and it appeared to be closely related to the synergic interaction between $\mathrm{Ru}$ and $\mathrm{K}$ that boosted the combustion of soot at low temperature. K-containing catalysts exhibited very low onset temperature, in the range $220-235^{\circ} \mathrm{C}$. In addition, all $\mathrm{Ru}$-based samples were able to simultaneously remove $\mathrm{NO}_{x}$ and soot when operating under isothermal cycling conditions, i.e., 
alternating lean-rich phases based on the typical diesel engine $\mathrm{NO}_{x}$ reduction strategy. In particular, the materials showed a $\mathrm{NO}_{x}$ storage capacity comparable to that of model Pt-based catalysts. $\mathrm{NO}_{x}$ storage capacity increased over Ru-based systems in the presence of soot particulate, while for model Pt-containing catalysts a detrimental effect of soot was found. Among all the developed formulations, K-based materials exhibited higher $\mathrm{NO}_{x}$ storage capacity and higher soot oxidation activity compared to Ba-containing samples.

\subsubsection{Mechanisms of soot combustion over nanosize ceria-zirconium-based solid solutions}

The combustion of soot over ceria mainly relies on the redox couple. $\mathrm{Ce}^{3+} / \mathrm{Ce}^{4+}$ with its ability shifts between $\mathrm{Ce}_{2} \mathrm{O}_{3}$ and $\mathrm{CeO}_{2}$, which is associated with the OSC of ceria. The surface oxygen of pure ceria is used for the soot oxidation and the consecutive vacant site is quickly refilled by gaseous/subsurface oxygen. Doped ceria can create more structural defects compared to pure ceria. So, these defects facilitate either more gaseous oxygen to adsorb onto the surface or diffusion of subsurface lattice oxygen onto the surface, thereby enhancing the formation of active oxygen species. It was reported that the rate of this active oxygen transfer to soot is much faster than that of both gas phase oxygen transfer to soot. It is self recombination to give $\mathrm{O}_{2}$, hence plays a crucial role in the soot oxidation. The reaction mechanism for soot combustion in the presence of $\mathrm{O}_{2} / \mathrm{NO}$ over $3 \mathrm{DOM} \mathrm{Au} / \mathrm{Ce}_{1-\mathrm{x}} \mathrm{Zr}_{\mathrm{x}} \mathrm{O}_{2}$ catalysts was investigated by Zhao et al. [101], and they proposed a reaction pathway for soot combustion, as shown in Fig. 17. The synergic effect between $\mathrm{Au}$ particle and $\mathrm{Ce}_{1-\mathrm{x}} \mathrm{Zr}_{\mathrm{x}} \mathrm{O}_{2}$ support played an important role for soot combustion. So far, the accepted mechanism $[285,307,308]$ for the catalytic oxidation of soot over cerium-zirconium-based solid solutions involved the following steps:

$$
\begin{aligned}
& \mathrm{M}_{\text {red }}+\text { gas }-\mathrm{O} \rightarrow \mathrm{M}_{\text {ox }}-\mathrm{O} \\
& \mathrm{M}_{\mathrm{ox}}-\mathrm{O}+\mathrm{C}_{\mathrm{f}} \rightarrow \mathrm{M}_{\text {red }}+\mathrm{SOC} \\
& \mathrm{SOC} \rightarrow \mathrm{CO} \text { or } \mathrm{CO}_{2}
\end{aligned}
$$

where $\mathrm{M}_{\mathrm{red}}$ and $\mathrm{M}_{\mathrm{ox}} \mathrm{O} \mathrm{O}$ represented the reduced and oxidized states of the catalyst, respectively. Gas- 0 stood for the oxidant gas $\left(\mathrm{O}_{2}, \mathrm{CO}_{2}, \mathrm{H}_{2} \mathrm{O}\right.$, etc.), $\mathrm{C}$ denoted a carbon active site or free site on the soot surface, and SOC represented a surface carbon-oxygen complex. In the first step, the catalyst "captured" oxygen from the gas-phase molecules and was itself oxidized. In the second step, the active oxygen on the catalyst trans-

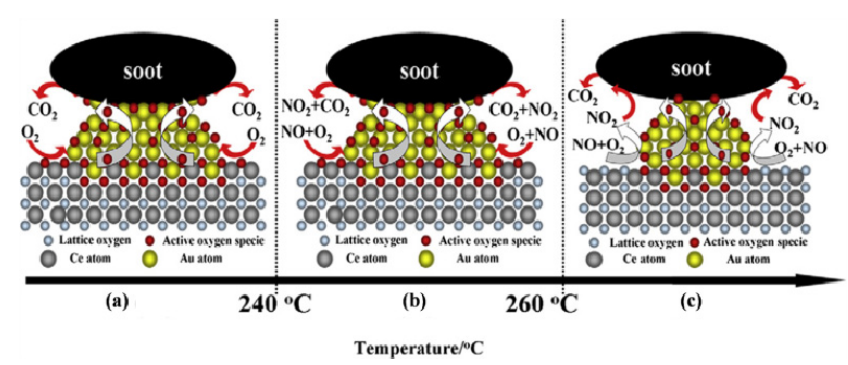

Fig. 17. Mechanism illustration of soot combustion over 3DOM $\mathrm{Au} / \mathrm{Ce}_{1-\mathrm{x}} \mathrm{Zr}_{\mathrm{x}} \mathrm{O}_{2}$ catalysts at different temperatures in the presence of $\mathrm{O}_{2}$ and NO. Reprinted from [101] with permission. fered/spilled over to the soot and the catalyst was reduced. In the third step, the SOC decomposed to yield $\mathrm{CO}$ or $\mathrm{CO}_{2}$.

\subsection{Nanosize cerium-zirconium-based solid solutions for selec- tive oxidation of $\mathrm{NH}_{3}$}

The removal of $\mathrm{NH}_{3}$ from waste streams is becoming an important issue due to ever increasing environmental concerns [309]. In order to control the $\mathrm{NH}_{3}$ slip, several different techniques have been used for the elimination of $\mathrm{NH}_{3}$, such as adsorption, chemical treatment, catalytic decomposition, and selective catalytic oxidation (SCO) [310-314]. Among which, $\mathrm{SCO}$ of $\mathrm{NH}_{3}$ to $\mathrm{N}_{2}$ from oxygen-containing waste gases over CZO is becoming a hot issue in recent years.

\subsubsection{Effect of material composition}

$\mathrm{Qu}$ et al. [315] investigated SCO over $\mathrm{Ce}_{1-x} \mathrm{Zr}_{x} \mathrm{O}_{2}(0.2 \leq x \leq$ 0.8 ) mixed oxides. Compared with pure $\mathrm{CeO}_{2}$ and $\mathrm{ZrO}_{2}, \mathrm{CZO}$ exhibited more acid sites and higher catalytic activity. Especially, the $\mathrm{Ce}_{0.4} \mathrm{Zr}_{0.6} \mathrm{O}_{2}$ catalyst displayed the highest $\mathrm{NH}_{3}$ conversion and the lowest total conversion temperature up to 360 ${ }^{\circ} \mathrm{C}$, which was associated with the partial phase segregations of $\mathrm{ZrO}_{2}$ in $\mathrm{Ce}_{0.2} \mathrm{Zr}_{0.8} \mathrm{O}_{2}$. Additionally, zirconium-rich samples $(x>$ 0.4 ) showed the higher $\mathrm{N}_{2}$ selectivity $(\sim 100 \%)$, and the formation of $\mathrm{N}_{2} \mathrm{O}$ was the main reason resulting in the low $\mathrm{N}_{2}$ selectivity for these catalysts $(x \leq 0.4)$. They further studied

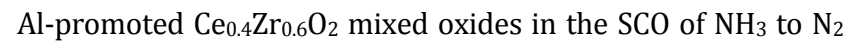
[316]. The addition of $\mathrm{Al}$ to $\mathrm{Ce}_{0.4} \mathrm{Zr}_{0.6} \mathrm{O}_{2}$ greatly improved the oxidation activity of $\mathrm{NH}_{3}$. Particularly, the $3 \% \mathrm{Al}-\mathrm{Ce}_{0.4} \mathrm{Zr}_{0.6} \mathrm{O}_{2}$ catalyst exhibited higher $\mathrm{NH}_{3}$ conversion $(12.7 \%)$ than the $\mathrm{Ce}_{0.4} \mathrm{Zr}_{0.6} \mathrm{O}_{2}$ catalyst due to the improved oxygen mobility, reducibility, and oxygen vacancies. Among these, oxygen vacancy was thought to be the essential oxygen adsorption and activation sites. Therefore, more oxygen vacancies facilitated $\mathrm{NH}_{3}$ oxidation reaction.

\subsubsection{Effect of active phase types and reaction condition}

$\mathrm{Qu}$ and Wang et al. [317] prepared a series of $\mathrm{Cu} / \mathrm{CZO}$ materials by the incipient-wetness impregnation, CA-SG, and homogeneous precipitation methods. $\mathrm{Cu} / \mathrm{CZO}$ prepared by the CA-SG method exhibited the best $\mathrm{NH}_{3}$-SCO activity owing to its better adsorption capacity, more isolated $\mathrm{Cu}^{2+}$, and active oxygen adspecies. The influence of $\mathrm{Ni}$ loading $(0,5 \%$, and $10 \%)$, oxygen amounts $(\lambda=0.25,0.5)$, and gas hourly space velocity (50000, 100000 , and $150000 \mathrm{~h}^{-1}$ ) on catalysts for $\mathrm{NH}_{3}-\mathrm{SCO}$ was investigated by Nassos et al. [318]. $10 \% \mathrm{Ni} / \mathrm{Ce}_{0.9} \mathrm{La}_{0.1} \mathrm{O}_{2}$ showed the optimally catalytic activity with $65 \%$ and $97 \% \mathrm{~N}_{2}$ yield at 500 and $750{ }^{\circ} \mathrm{C}$, respectively. Increasing $\lambda$ and lowering the gas hourly space velocity led to considerably improved $\mathrm{N}_{2}$ yield at $500{ }^{\circ} \mathrm{C}$. Qu and Yan et al. [319] synthesized Ru-modified $\mathrm{Ce}_{1-\mathrm{x}} \mathrm{Zr}_{\mathrm{x}} \mathrm{O}_{2}$ for $\mathrm{NH}_{3}-\mathrm{SCO}$. The $0.2 \% \mathrm{Ru}$-modified $\mathrm{Ce}_{0.6} \mathrm{Zr}_{0.4} \mathrm{O}_{2}$ catalyst displayed excellent performance for the $\mathrm{SCO}$ of slip $\mathrm{NH}_{3}$, and $\mathrm{SO}_{2}$ could enhance the removal of slip $\mathrm{NH}_{3}$ in the presence of $\mathrm{NO}_{x}$ but also slightly supressed $\mathrm{NH}_{3}$ oxidation and significantly improved $\mathrm{N}_{2}$ selectivity to $100 \%$ in the absence of $\mathrm{NO}_{x}$, as shown in Fig. 18. 

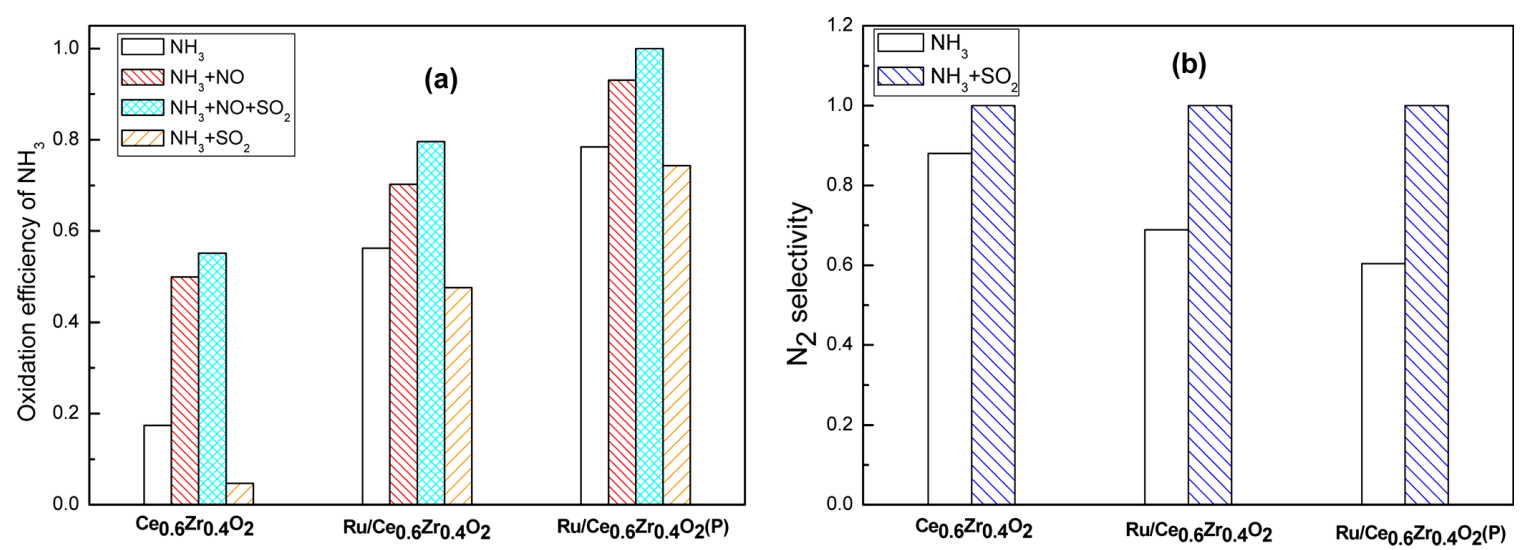

Fig. 18. (a) $\mathrm{NH}_{3}-\mathrm{SCO}$ efficiency over various catalysts at $350{ }^{\circ} \mathrm{C}$; (b) $\mathrm{N}_{2}$ selectivity of $\mathrm{NH}_{3}-\mathrm{SCO}$ with or without $\mathrm{SO}_{2}$ over various catalysts. GHSV $=\sim 3 \times$ $10^{5} \mathrm{~h}^{-1}$, temperature $=350{ }^{\circ} \mathrm{C}, 30 \mathrm{ppm}$ of $\mathrm{NH}_{3}, 30 \mathrm{ppm}$ of $\mathrm{NO}, 500 \mathrm{ppm}$ of $\mathrm{SO}_{2}$, the other gas including $4 \% \mathrm{O}_{2}$ and $\mathrm{N}_{2}$. Reprinted from [319] with permission.

\subsubsection{Mechanisms of $\mathrm{NH}_{3}$ oxidation over nanosize ceria-zirconium-based solid solutions}

$\mathrm{Qu}$ and co-worker [317] proposed that the mechanism of $\mathrm{NH}_{3}$-SCO with lattice oxygen was different from that of gaseous oxygen, which was much less active than gaseous oxygen at low temperature. They suggested that the reaction mechanism of $\mathrm{NH}_{3}$-SCO over $\mathrm{Ru} / \mathrm{Ce}_{0.6} \mathrm{Zr}_{0.4} \mathrm{O}_{2}$ should follow an internal SCR mechanism [319], as shown in Fig. 19, which was in accordance with the results of Breen et al. [320] The adsorbed $\mathrm{NH}_{3}$ was first activated and reacted with lattice oxygen to form a - HNO intermediate. Subsequently, $-\mathrm{HNO}$ reacted with $\mathrm{O}_{2}$ to generate NO. Meanwhile, the formed NO interacted with $-\mathrm{NH}_{2}$ to produce $\mathrm{N}_{2}$, and $\mathrm{N}_{2} \mathrm{O}$ as the byproduct.

$$
\begin{gathered}
\mathrm{NH}_{3} \rightarrow \mathrm{NH}_{2}+\mathrm{H} \\
\mathrm{NH}_{2} \rightarrow \mathrm{NH}+\mathrm{H} \\
\mathrm{NH}+\mathrm{O} \rightarrow \mathrm{HNO} \\
\mathrm{O}_{2} \rightarrow 2 \mathrm{O} \\
\mathrm{HNO}+\mathrm{O} \rightarrow \mathrm{NO}+\mathrm{OH} \\
\mathrm{NH}_{2}+\mathrm{NO} \rightarrow \mathrm{N}_{2}+\mathrm{H}_{2} \mathrm{O} \\
\mathrm{NH}+\mathrm{NO} \rightarrow \mathrm{N}_{2} \mathrm{O}+\mathrm{H} \\
\mathrm{H}+\mathrm{OH} \rightarrow \mathrm{H}_{2} \mathrm{O} \\
4 \mathrm{NH}_{3}+3 \mathrm{O}_{2} \rightarrow 2 \mathrm{~N}_{2}+6 \mathrm{H}_{2} \mathrm{O}
\end{gathered}
$$

4.3. Nanosize cerium-zirconium-based solid solutions for selective reduction of $\mathrm{NO}_{x}$

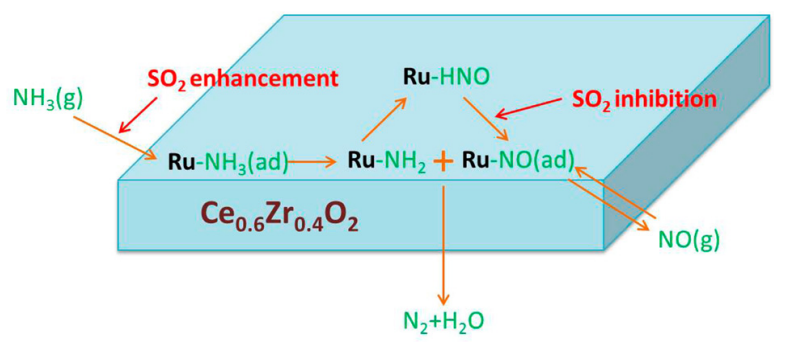

Fig. 19. Mechanism of $\mathrm{NH}_{3}-\mathrm{SCO}$ and the effect of $\mathrm{SO}_{2}$. Reprinted from [319] with permission.
$\mathrm{NO}_{x}$ produced from the combustion of fossil fuels such as coke in the electrical power plants or petroleum in the engines of vehicles brought about ecological and health hazards [321]. The nitrous oxide $\mathrm{N}_{2} \mathrm{O}$, not submitted to drastic regulations as $\mathrm{NO}_{x}$, is considered as a nontoxic greenhouse gas. However, its global warming potential is 310 times as that of $\mathrm{CO}_{2}$, and its abatement is often considered as a priority to avoid erratic climate changes in the next decades [322,323]. Therefore, great efforts were devoted to the development of highly efficient catalysts for the elimination of $\mathrm{NO}_{x}$ including $\mathrm{N}_{2} \mathrm{O}$ [324-326]. CZO has drawn ever increasing attention due to its specific properties. $\mathrm{NO}_{x}$ can be reduced or decomposed to $\mathrm{N}_{2}$ by direct decomposition or by chemical reduction using reductants such as $\mathrm{NH}_{3}, \mathrm{H}_{2}$, $\mathrm{HC}$, etc.

\subsection{1. $\mathrm{NH}_{3}-\mathrm{SCR}$}

$\mathrm{NH}_{3}$-SCR is regarded as an effective method for the removal of $\mathrm{NO}_{x}$ from stationary and mobile sources, and the catalytic efficiency of this technique is significantly affected by the composition of CZO supported catalysts, as show in Table 6 .

\subsubsection{Effect of support composition}

Zhang et al. [327] studied the catalytic activity of the 3DOM CZO catalyst doped by metal $\mathrm{M}\left(\mathrm{Mn}, \mathrm{Fe}, \mathrm{Cu}\right.$ and $\mathrm{Co}$ ) for $\mathrm{NH}_{3}-\mathrm{SCR}$ of $\mathrm{NO}_{x}$. Those dopants were well incorporated into Ce lattice, except for $\mathrm{Cu}$, and the introduction of those additives to CZO enhanced the active oxygen species, surface reducibility and acidity of the catalysts. Therefore, these doped catalysts displayed better catalytic activity than CZO at low temperature. Among them, the Co-modified catalyst showed the optimum catalytic activity attributed to its highest $\mathrm{O}_{\alpha} /\left(\mathrm{O}_{\alpha}+\mathrm{O}_{\beta}\right)$ ratio and reducibility, as well as the strongest $\mathrm{NH}_{3}$ adsorption ability. In addition, Fe and Mn dopants effectively broadened the activation temperature window.

The effect of nickel- and sulfate- modified CZO for $\mathrm{NH}_{3}-\mathrm{SCR}$ of NO in the presence of excess $\mathrm{O}_{2}$ was investigated by Weng et al. [328]. The addition of $\mathrm{Ni}$ increased the strength of Lewis acid sites of the catalyst, which was viewed as the essential active sites for low-temperature $\mathrm{NH}_{3}$-SCR reaction. Additionally, the sulfate modification induced the formation of Brønsted 
Table 6

Catalytic activities of nanosize $\mathrm{CZO}$ materials in $\mathrm{NH}_{3}-\mathrm{SCR}$ of $\mathrm{NO}_{x}$.

\begin{tabular}{|c|c|c|c|c|c|}
\hline Catalyst & Reaction conditions & $X_{\text {NO }}(\%)$ & $T_{\mathrm{r}}\left({ }^{\circ} \mathrm{C}\right)$ & $S_{\mathrm{N} 2}(\%)$ & Ref. \\
\hline $\mathrm{Ce}_{0.75} \mathrm{Zr}_{0.25} \mathrm{O}_{2}$ & $\mathrm{NO} / \mathrm{NH}_{3} / \mathrm{H}_{2} \mathrm{O} / \mathrm{O}_{2}=0.05: 0.05: 5: 5 / 300000 \mathrm{~h}^{-1}$ & 77 & $300-350$ & - & [346] \\
\hline $3 \mathrm{DOM} \mathrm{Ce} \mathrm{C}_{0.8} \mathrm{Zr}_{0.2} \mathrm{O}_{2}$ & $\mathrm{NO} / \mathrm{NH}_{3} / \mathrm{SO}_{2} / \mathrm{O}_{2}=0.05: 0.05: 0.02: 3 / 20000 \mathrm{~h}^{-1}$ & $>90$ & $275-425$ & - & [327] \\
\hline $3 \mathrm{DOM} \mathrm{Ce}_{0.75} \mathrm{Zr}_{0.2} \mathrm{M}_{0.05} \mathrm{O}_{2-\delta}(\mathrm{M}=\mathrm{Fe}, \mathrm{Cu}, \mathrm{Mn}, \mathrm{Co})$ & $\mathrm{NO} / \mathrm{NH}_{3} / \mathrm{SO}_{2} / \mathrm{O}_{2}=0.05: 0.05: 0.02: 3 / 20000 \mathrm{~h}^{-1}$ & $>90$ & $225-450$ & - & [327] \\
\hline $\mathrm{Ni}_{0.04} \mathrm{Ce}_{0.81} \mathrm{Zr}_{0.15} \mathrm{O}_{2}$ & $\mathrm{NO} / \mathrm{NH}_{3} / \mathrm{H}_{2} \mathrm{O} / \mathrm{CO}_{2} / \mathrm{O}_{2}=0.05: 0.05: 10: 14: 14 / 160000 \mathrm{~h}^{-1}$ & $40-50$ & $275-375$ & 81 & [328] \\
\hline $\mathrm{Ni}_{0.04} \mathrm{Ce}_{0.81} \mathrm{Zr}_{0.09} \mathrm{~S}_{0.06} \mathrm{O}_{2}$ & $\mathrm{NO} / \mathrm{NH}_{3} / \mathrm{H}_{2} \mathrm{O} / \mathrm{CO}_{2} / \mathrm{O}_{2}=0.05: 0.05: 10: 14: 14 / 160000 \mathrm{~h}^{-1}$ & $>80$ & $275-425$ & - & [328] \\
\hline $\mathrm{Mo}_{0.5} \mathrm{CeZr}_{2} \mathrm{O}_{x}$ & $\mathrm{NO} / \mathrm{NH}_{3} / \mathrm{O}_{2}=0.05: 0.05: 5 / 50000 \mathrm{~h}^{-1}$ & $>90$ & $220-425$ & - & {$[338]$} \\
\hline $10 \% \mathrm{P} / \mathrm{Ce}_{0.75} \mathrm{Zr}_{0.25} \mathrm{O}_{2}$ & $\mathrm{NO} / \mathrm{NH}_{3} / \mathrm{H}_{2} \mathrm{O} / \mathrm{O}_{2}=0.05: 0.05: 5: 5 / 300000 \mathrm{~h}^{-1}$ & $>80$ & $300-500$ & - & [346] \\
\hline $10 \% \mathrm{P} / \mathrm{Ce}_{0.75} \mathrm{Zr}_{0.25} \mathrm{O}_{2}$ & $\mathrm{NO} / \mathrm{NH}_{3} / \mathrm{O}_{2}=0.05: 0.05: 5 / 30000 \mathrm{~h}^{-1}$ & $>80$ & $250-450$ & - & [347] \\
\hline $\mathrm{ZP} / \mathrm{Ce}_{0.75} \mathrm{Zr}_{0.25} \mathrm{O}_{2}$ & $\mathrm{NO} / \mathrm{NH}_{3} / \mathrm{H}_{2} \mathrm{O} / \mathrm{O}_{2}=0.05: 0.05: 5: 5 / 300000 \mathrm{~h}^{-1}$ & $>80$ & $240-470$ & - & [346] \\
\hline $\mathrm{F} / \mathrm{Ce}_{0.5} \mathrm{Zr}_{0.5} \mathrm{O}_{2} / \mathrm{TiO}_{2}$ & $\mathrm{NO} / \mathrm{NH}_{3} / \mathrm{O}_{2}=0.06: 0.06: 6 / 71400 \mathrm{~h}^{-1}$ & $>80$ & $290-450$ & - & [330] \\
\hline $9.1 \% \mathrm{WO}_{3} / \mathrm{Ce}_{x} \mathrm{Zr}_{1-x} \mathrm{O}_{2}(x=0.58,0.4)$ & $\mathrm{NO} / \mathrm{NH}_{3} / \mathrm{H}_{2} \mathrm{O} / \mathrm{CO}_{2} / \mathrm{O}_{2}=0.05: 0.05: 10: 10: 10 / 160000 \mathrm{~h}^{-1}$ & $>90$ & $275-500$ & 100 & [335] \\
\hline $5 \% \mathrm{Mo} / \mathrm{Ce}-\mathrm{ZrO}_{2}$ & $\mathrm{NO} / \mathrm{NH}_{3} / \mathrm{O}_{2}=0.05: 0.05: 5 / 98000 \mathrm{~h}^{-1}$ & $>90$ & $250-400$ & - & [338] \\
\hline $10 \% \mathrm{WO}_{3} / \mathrm{Ce}_{0.68} \mathrm{Zr}_{0.32} \mathrm{O}_{2}$ & $\mathrm{NO} / \mathrm{NH}_{3} / \mathrm{O}_{2}=0.05: 0.05: 5 / 30000 \mathrm{~h}^{-1}$ & $>80$ & $213-470$ & $>97$ & [331] \\
\hline $10 \% \mathrm{WO}_{3} / 20 \% \mathrm{Ti}^{-\mathrm{Ce}_{0.68} \mathrm{Zr}_{0.32} \mathrm{O}_{2}}$ & $\mathrm{NO} / \mathrm{NH}_{3} / \mathrm{O}_{2}=0.05: 0.05: 5 / 30000 \mathrm{~h}^{-1}$ & $>80$ & $190-500$ & $>99$ & [331] \\
\hline $15 \% \mathrm{WO}_{3} / \mathrm{ZrO}_{2}-\mathrm{Ce}_{0.6} \mathrm{Zr}_{0.4} \mathrm{O}_{2}$ & $\mathrm{NO} / \mathrm{NH}_{3} / \mathrm{H}_{2} \mathrm{O} / \mathrm{O}_{2}=0.1: 0.1: 5: 10 / 50000 \mathrm{~h}^{-1}$ & $>80$ & $275-500$ & 87 & [334] \\
\hline $\mathrm{Ce}_{1-x} \mathrm{Zr}_{x} \mathrm{VO}_{4}(x=0.1-0.8)$ & $\mathrm{NO} / \mathrm{NH}_{3} / \mathrm{O}_{2}=0.05: 0.05: 5 / 26000 \mathrm{~h}^{-1}$ & $>80$ & $150-390$ & 100 & [333] \\
\hline $5 \% \mathrm{~V}_{2} \mathrm{O}_{5} / \mathrm{Ce}_{0.7} \mathrm{Zr}_{0.3} \mathrm{O}_{2}$ & $\mathrm{NO} / \mathrm{NH}_{3} / \mathrm{O}_{2}=0.1: 0.1: 5 / 70000 \mathrm{~h}^{-1}$ & 90 & 200 & $\sim 100$ & [342] \\
\hline $\mathrm{FeW}_{1.1} / \mathrm{Ce}_{0.68} \mathrm{Zr}_{0.32} \mathrm{O}_{2}$ & $\mathrm{NO} / \mathrm{NH}_{3} / \mathrm{O}_{2}=0.1: 0.1: 5 / 30000 \mathrm{~h}^{-1}$ & $>90$ & $245-455$ & $\sim 100$ & [337] \\
\hline $\mathrm{MnO}_{\mathrm{m}} / \mathrm{Ce}_{0.5} \mathrm{Zr}_{0.5} \mathrm{O}_{2}$ & $\mathrm{NO} / \mathrm{NH}_{3} / \mathrm{H}_{2} \mathrm{O} / \mathrm{SO}_{2} / \mathrm{O}_{2}=0.06: 0.06: 3: 0.01: 3 / 30000 \mathrm{~h}^{-1}$ & $>90$ & $100-220$ & $>85$ & [340] \\
\hline $\mathrm{MnO}_{\mathrm{m}}(0.4) / \mathrm{Co}_{0.1} \mathrm{Ce}_{0.45} \mathrm{Zr}_{0.45} \mathrm{O}_{2}$ & $\mathrm{NO} / \mathrm{NH}_{3} / \mathrm{H}_{2} \mathrm{O} / \mathrm{SO}_{2} / \mathrm{O}_{2}=0.06: 0.066: 3: 0.01: 6 / 45000 \mathrm{~h}^{-1}$ & $>90$ & $110-250$ & $>85$ & {$[341]$} \\
\hline $15 \% \mathrm{Nb}_{2} \mathrm{O}_{5} / \mathrm{Ce}_{0.75} \mathrm{Zr}_{0.25} \mathrm{O}_{2}$ & $\mathrm{NO} / \mathrm{NH}_{3} / \mathrm{H}_{2} \mathrm{O} / \mathrm{CO}_{2} / \mathrm{O}_{2}=0.05: 0.05: 5: 12: 5 / 300000 \mathrm{~h}^{-1}$ & $>90$ & $300-500$ & $\sim 100$ & [344] \\
\hline
\end{tabular}

$X_{\mathrm{NOx}}, S_{\mathrm{N} 2}$ and $T_{\mathrm{r}}$ are denoted as $\mathrm{NO}_{x}$ conversion, $\mathrm{N}_{2}$ selectivity, and reaction temperature range of NO complete conversion, respectively.

acid sites, which weakened the strong oxidation of $\mathrm{NH}_{3}$ but enhanced the $\mathrm{NH}_{3}$ adsorption capacity of catalyst. Therefore, the catalytic activity of the catalysts at high temperature was improved. Moreover, the introduction of sulfates to $\mathrm{NiO} / \mathrm{CZO}$ led to high $\mathrm{NH}_{3}-\mathrm{SCR}$ activity and $\mathrm{N}_{2}$ selectivity. The addition of sulfates not only promoted the mobility of lattice oxygen by the formation of $\mathrm{Ni}^{\mathrm{n}+}-\mathrm{O}-\mathrm{S}^{n+}$ bond in $\mathrm{CZO}$, but also inhibited $\mathrm{NH}_{3}$ oxidation by reducing the amount of surface active oxygen [329].

Shen and Zhu et al. [330] studied the effect of fluorine additive on $\mathrm{CeO}_{2}-\mathrm{ZrO}_{2}-\mathrm{TiO}_{2}$ (CZT) for $\mathrm{NH}_{3}-\mathrm{SCR}$. A series of CZT catalysts with different fluorine additives were synthesized by an impregnation method. The (001) facets were exposed on the catalyst surface with the modulation of HF. The grain size of $\mathrm{TiO}_{2}$ increased and the specific surface area reduced after adding HF. However, the OSC of catalyst could be also enhanced with the modulation of HF. In addition, the synergy of (101) and (001) facets and the increase of surface chemisorbed oxygen and $\mathrm{Ce}^{3+}$ concentrations were beneficial to the improvement of catalytic activity. CZT-10F exhibited excellent catalytic performance for $\mathrm{NH}_{3}$-SCR and more than $96 \%$ NO conversion at $360{ }^{\circ} \mathrm{C}$ under GHSV of $71400 \mathrm{~h}^{-1}$.

Wang and Chen et al. [331,332] investigated the effect of titanium additive on a W/CZO monolithic catalyst for $\mathrm{NH}_{3}$-SCR of $\mathrm{NO}_{x}$. The doping of $\mathrm{TiO}_{2}$ led to the formation of cerium-zirconium-titanium solid solution with large surface area. The interactions among metal oxides promoted the reductive behavior of the catalyst, which was helpful to enhance the $\mathrm{NH}_{3}$-SCR activity at low temperature. Moreover, the addition of $\mathrm{TiO}_{2}$ to $\mathrm{CZO}$ improved the adsorption and activation of $\mathrm{NH}_{3}$ and increased the reactivity of adsorbed nitrate species with $\mathrm{NH}_{3}$ species, and $\mathrm{WO}_{3} / \mathrm{CZT}$ with $20 \% \mathrm{TiO}_{2}$ showed better deNO $\mathrm{N}_{x}$ activity and sulfur/water vapor tolerance than W/CZO.

Zhang and Huang et al. [333] developed a series of $\mathrm{Ce}_{1-\mathrm{x}} \mathrm{Zr}_{\mathrm{x}} \mathrm{VO}_{4}$ solid solutions for $\mathrm{NH}_{3}-\mathrm{SCR}$ of $\mathrm{NO}_{x}$. The introduction of $\mathrm{Zr}$ into $\mathrm{CeVO}_{4}$ considerably enhanced the specific surface area, redox property, active oxygen species as well as surface acidity of the catalysts, which were favorable for the improvement of SCR performance. The catalyst $\mathrm{Ce}_{0.85} \mathrm{Zr}_{0.15} \mathrm{VO}_{4}$ exhibited the best low-temperature $\mathrm{NH}_{3}$-SCR performance. $T_{50}$ was as low as $125^{\circ} \mathrm{C}$ for above $80 \%$ NO conversion, and almost $100 \% \mathrm{~N}_{2}$ selectivity was obtained in the range of $150-375{ }^{\circ} \mathrm{C}$. Furthermore, the catalysts also showed excellent $\mathrm{H}_{2} \mathrm{O} / \mathrm{SO}_{2}$ durability and good performance at high GHSV of $400000 \mathrm{~h}^{-1}$.

\subsubsection{Effect of active phase types}

Kröcher et al. [334] prepared a $15 \% \mathrm{WO}_{3} / \mathrm{ZrO}_{2}-\mathrm{Ce}_{0.6} \mathrm{Zr}_{0.4} \mathrm{O}_{2}$ catalyst by the SC method. The catalyst showed more than $90 \%$ $\mathrm{NO}_{x}$ reduction efficiency between 300 and $500{ }^{\circ} \mathrm{C}$, and it remained almost unchange over the entire temperature range even after being aged at $700{ }^{\circ} \mathrm{C}$. In addition, sulfur poisoning promoted the reduction efficiency of $\mathrm{NO}_{x}$ at high temperatures at the cost of a decreased low-temperature activity, but the catalyst could be fully recovered by heating in $\mathrm{O}_{2}$ at $650^{\circ} \mathrm{C}$. Can et al. [335] investigated the catalytic performance of CZO-supported $\mathrm{WO}_{3}$ catalysts for $\mathrm{NH}_{3}$-SCR of $\mathrm{NO}_{x}$. The addition of $\mathrm{WO}_{3}$ on $\mathrm{CZO}$ induced a loss of the basic properties, the oxygen mobility, and the oxidation capacity of $\mathrm{NO}$ to $\mathrm{NO}_{2}$, but it also led to a significant enhancement of $\mathrm{NH}_{3}$ storage capacity, which seemed to play a significant role in $\mathrm{NH}_{3}$-SCR reaction at high temperatures [336]. The changes in acid-base properties resulted in the enhancement of $\mathrm{NH}_{3}$-SCR performance. All $\mathrm{WO}_{3} / \mathrm{CZO}$ materials exhibited more than $80 \% \mathrm{NO}_{x}$ reduction efficiency for $\mathrm{NH}_{3}-\mathrm{SCR}$ at $350{ }^{\circ} \mathrm{C}$ in the presence of $\mathrm{H}_{2} \mathrm{O}$ and $\mathrm{CO}_{2}$ 
in feed gas. Xu and Chen et al. [337] reported that W/Fe ratio of $\mathrm{FeW}_{\mathrm{m}} / \mathrm{Ce}_{0.68} \mathrm{Zr}_{0.32} \mathrm{O}_{2}(m=0-1.38)$ monolithic catalysts strongly affected the catalytic performance of the catalysts for $\mathrm{NH}_{3}-\mathrm{SCR}$ of $\mathrm{NO}_{x}$. The $\mathrm{FeW}_{1.03} / \mathrm{Ce}_{0.68} \mathrm{Zr}_{0.32} \mathrm{O}_{2}$ catalyst displayed the best catalytic performance, which exhibited 95\% $\mathrm{NO}_{x}$ conversion and nearly $100 \% \mathrm{~N}_{2}$ selectivity ranging from 250 to $435{ }^{\circ} \mathrm{C}$. This should be due to the more chemically adsorbed oxygen species and $\mathrm{Fe}^{3+}$ active species as well as surface acid sites, which together contributed to the excellent catalytic activity of the $\mathrm{FeW}_{1.03} / \mathrm{Ce}_{0.68} \mathrm{Zr}_{0.32} \mathrm{O}_{2}$ catalyst.

The effect of Mo addition on CZO catalysts for $\mathrm{NH}_{3}$-SCR of $\mathrm{NO}_{x}$ was studied by Liu and He et al. [338]. The addition of Mo inhibited the growth of $\mathrm{CeO}_{2}$ particles, improved the redox ability, and increased the amount of surface acidity, especially the Lewis acidity. All of the characteristics were responsible for the excellent $\mathrm{NH}_{3}$-SCR performance. Among these, the CeMo ${ }_{0.5} \mathrm{Zr}_{2} \mathrm{O}_{x}$ catalyst showed the best SCR activity, $\mathrm{SO}_{2} / \mathrm{H}_{2} \mathrm{O}$ durability, and thermal stability. Interestingly, Liu and Li et al. [339] further confirmed the professional effect of Mo additive and proposed that the highly dispersed $\mathrm{MoO}_{3}$ not only induced the formation of more Brønsted acid and Lewis acid sites on the catalyst surface, but also promoted the redox property of the catalyst. They should be accounted for the enhanced SCR activity.

A series of $\mathrm{Mn} / \mathrm{CZO}$ catalysts with different Mn loading amounts were prepared to investigate the $\mathrm{NH}_{3}$-SCR performance of $\mathrm{NO}$ at low temperature. When Mn loading amounts increased, $\mathrm{NO}$ conversion on $\mathrm{MnO}_{\mathrm{m}} / \mathrm{Ce}_{0.5} \mathrm{Zr}_{0.5} \mathrm{O}_{2}$ first increased and then decreased. When $\mathrm{Mn} /(\mathrm{Ce}+\mathrm{Zr})=0.6$, the activity reached the best. The $E_{a}$ value of $\mathrm{MnO}_{\mathrm{m}} / \mathrm{Ce}_{0.5} \mathrm{Zr}_{0.5} \mathrm{O}_{2}$ catalyst was $18.1 \mathrm{~kJ} / \mathrm{mol}$, which was lower than that of $\mathrm{MnO}_{m} / \mathrm{TiO}_{2}$ (38 $\mathrm{kJ} / \mathrm{mol}$ ) [340]. Zhang and Shi et al. [155] combined the experiment and theory to investigate $\mathrm{MnO}_{\mathrm{m}} / \mathrm{CZO}$ nanorods for low-temperature $\mathrm{NH}_{3}$-SCR of NO. $\mathrm{MnO}_{m}$ on the surface of na-

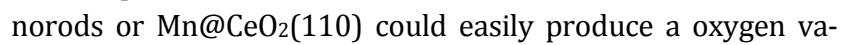
cancy distortion. Moreover, the $\mathrm{Mn} @ \mathrm{CeO}_{2}(110)$ model in the DFT analysis showed a prominent effect on $\mathrm{NO}$ and $\mathrm{NH}_{3}$ adsorption, which resulted in a stronger nitrite intermediate (NOO*) formation and more attractive interaction with $\mathrm{NH}_{3}$ gas compared with those observed in the $\mathrm{CeO}_{2}(110)$ model. A contrastive study on the difference between the introduction of cobalt in the active component and the support of Mn/CZO was made by Shen et al. [341]. Mn/Co-CZO exhibited a higher catalytic activity compared with $\mathrm{Mn} / \mathrm{CZO}$ and $\mathrm{Mn}-\mathrm{Co} / \mathrm{CZO}$ because of the highly dispersed manganese oxides, good redox properties, more surface acid sites, and surface adsorbed oxygen species as well as more $\mathrm{Mn}^{4+}$ ion. Furthermore, Mn/Co-CZO also exhibited an outstanding $\mathrm{SO}_{2}$ and $\mathrm{H}_{2} \mathrm{O}$-resistance.

Brückner et al. [342] investigated $\mathrm{NH}_{3}$-SCR of $\mathrm{NO}$ at low temperature over $\mathrm{VO}_{m} / \mathrm{Ce}_{x} \mathrm{Zr}_{1-x} \mathrm{O}_{2}(x=0-1.0)$ catalysts. $5 \%$ $\mathrm{VO}_{\mathrm{m}} / \mathrm{Cex}_{\mathrm{Xr}} \mathrm{Zr}_{\mathrm{x}} \mathrm{O}_{2}$ catalysts with $x=0.7-0.9$ seemed to be promising catalysts, which exhibited almost $100 \%$ of both NO conversion and $\mathrm{N}_{2}$ selectivity at $220{ }^{\circ} \mathrm{C}$, and no deactivation took place during at least $190 \mathrm{~h}$ under a space velocity of $70000 \mathrm{~h}^{-1}$. Reddy et al. [343] studied the effect of acidic and redox properties of a $\mathrm{V}_{2} \mathrm{O}_{5} / \mathrm{CZO}$ catalyst in $\mathrm{NH}_{3}$-SCR of NO. SCR activity of $\mathrm{V}_{2} \mathrm{O}_{5} / \mathrm{ZrO}_{2}$ was related to the support crystallinity, acidity, and redox behavior. The $\mathrm{V}_{2} \mathrm{O}_{5} / \mathrm{CZO}$ catalyst exhibited high activity and selectivity for $\mathrm{NH}_{3}-\mathrm{SCR}$ of $\mathrm{NO}$ and was less prone to unselective oxidation of $\mathrm{NH}_{3}$ to $\mathrm{N}_{2} \mathrm{O}$. The effect of $\mathrm{Nb}$ loading amounts on the active sites and surface acidity of $\mathrm{NbO}_{\mathrm{m}} / \mathrm{CZO}$ for $\mathrm{NH}_{3}-\mathrm{SCR}$ of $\mathrm{NO}_{x}$ was studied by Wu et al. [344]. The catalyst with $15 \% \mathrm{Nb}_{2} \mathrm{O}_{5}$ showed the best $\mathrm{NH}_{3}$-SCR activity and almost $100 \% \mathrm{~N}_{2}$ selectivity in the temperature range of $190-460{ }^{\circ} \mathrm{C}$ at a high space velocity of $300000 \mathrm{~h}^{-1}$. Altering the $\mathrm{Nb}$ loading amount would lead to the change in the structure and distribution of surface supported $\mathrm{NbO}_{m}$ species and evolution of electronic interaction between $\mathrm{Nb}$ species and CZO support. The electron transfer effect from $\mathrm{Nb}^{n+}$ to $\mathrm{Ce}^{n+}$ would result in the increase of $\mathrm{Ce}^{3+}$, oxygen vacancies, and active oxygen. Moreover, the total surface acidity of the catalyst was remarkably enhanced after $\mathrm{Nb}$ loading, which could promote $\mathrm{NH}_{3}$ adsorption and suppress the $\mathrm{NH}_{3}$ unselective oxidation and be especially beneficial to SCR of $\mathrm{NO}_{x}$ at high temperatures $\left(>300{ }^{\circ} \mathrm{C}\right)$. Furthermore, the increased cerium sites with adjacent active oxygen contributed to the highly catalytic activity of the $\mathrm{NbO}_{\mathrm{m}} / \mathrm{CZO}$ catalyst at low temperatures. The effect of $\mathrm{Nb}$ introduction on the catalytic activity and hydrothermal stability of CZO catalyst for $\mathrm{NH}_{3}-\mathrm{SCR}$ of $\mathrm{NO}_{x}$ was reported by Liu and $\mathrm{He}$ et al. [345]. $\mathrm{Nb}$ additive to CZO not only increased the specific surface area and enhanced redox property, but also boosted the $\mathrm{NH}_{3}$ adsorption and activation and promoted the reactivity of adsorbed nitrate together with $\mathrm{NH}_{3}$ species. All of the above characteristics were responsible for the excellent $\mathrm{NH}_{3}$-SCR performance. The $\mathrm{CeNb}_{3} \mathrm{Zr}_{2} \mathrm{O}_{x}$ catalyst exhibited superior SCR activity, high $\mathrm{N}_{2}$ selectivity, and excellent hydrothermal durability, which still possessed high reductivity and abundant acid sites after being aged at $800{ }^{\circ} \mathrm{C}$.

Si et al. [346] investigated the effect of zirconium phosphate addition to $\mathrm{Ce}_{0.75} \mathrm{Zr}_{0.25} \mathrm{O}_{2}$ (ZP/CZO) on $\mathrm{NH}_{3}$-SCR of NO. The $\mathrm{ZP} / \mathrm{CZO}$ catalyst showed superior catalytic activity and good $\mathrm{N}_{2}$ selectivity at $250-450{ }^{\circ} \mathrm{C}$ under high space velocity of 300000 $\mathrm{h}^{-1}$ owing to the following two main factors. First, the zirconium phosphate provided adsorption sites for $\mathrm{NH}_{3}$ on the catalyst surface, and the cerium sites acted as the redox sites for NO oxidation. The two distinct adsorption sites for $\mathrm{NH}_{3}$ and $\mathrm{NO}_{x}$ resulted in a close contact between ads- $\mathrm{NH}_{3} / \mathrm{NH}^{4+}$ and ads- $\mathrm{NO}_{3}{ }^{-} / \mathrm{NO}_{2}{ }^{-}$species on the $\mathrm{ZP} / \mathrm{CZO}$ catalyst (as illustrated in Fig. 20), which could rapidly react with NO together with active surface lattice oxygen. Second, the pre-combination of zirconium and phosphate could lower the interactions between phosphates and cerium ions. Thereby the mobility of surface lattice oxygen on the $\mathrm{Ce}_{0.75} \mathrm{Zr}_{0.25} \mathrm{O}_{2}$ catalyst was maintained, which was beneficial to obtaining a catalyst with high $\mathrm{NH}_{3}$-SCR activity at low temperatures. Subsequently, the modification of $\mathrm{Ce}_{0.75} \mathrm{Zr}_{0.25} \mathrm{O}_{2}$ by phosphate could enhance the hydrothermal stability and sulfur resistance of the catalyst [347].

\subsubsection{Effect of preparation condition}

Effect of calcination temperature on the structure and catalytic performance of the $\mathrm{WO}_{3} / \mathrm{CZO}$ monolithic catalyst for $\mathrm{NH}_{3}$-SCR of $\mathrm{NO}_{x}$ was studied by Wang and Chen et al. [348]. SCR catalytic activity of $\mathrm{WO}_{3} / \mathrm{CZO}$ was greatly enhanced by modestly rising the calcined temperature. $\mathrm{WO}_{3} / \mathrm{CZO}$ calcination at 


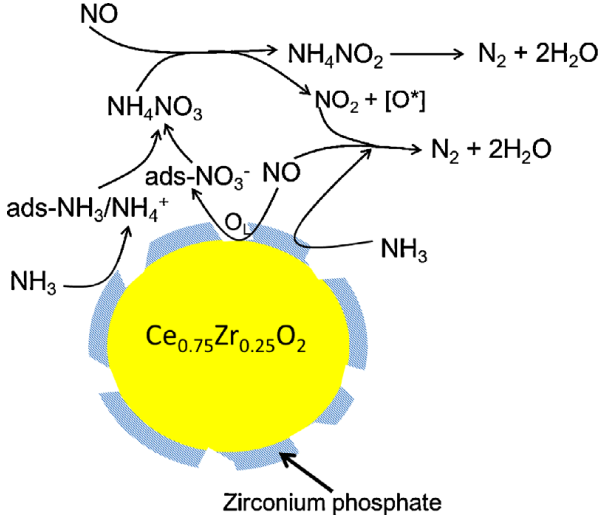

Fig. 20. Illustration of $\mathrm{NH}_{3}-\mathrm{SCR}$ reaction route on zirconium phosphate-CZO. Reprinted from [346] with permission.

$500{ }^{\circ} \mathrm{C}$ exhibited the lowest light-off temperature of $173^{\circ} \mathrm{C}$ and total conversion temperature of $205{ }^{\circ} \mathrm{C}$, while $\mathrm{WO}_{3} / \mathrm{CZO}$ calcination at $600{ }^{\circ} \mathrm{C}$ showed a broader temperature range $\left(220-455^{\circ} \mathrm{C}\right)$ with more than $90 \% \mathrm{NO}_{x}$ conversion. The calcination temperature at $500{ }^{\circ} \mathrm{C}$ for $\mathrm{WO}_{3} / \mathrm{CZO}$ was favorable for stabilizing the structure, increasing the amount of acid sites, $\mathrm{Ce}^{3+}$, and surface active oxygen species, as well as enhancing reductivity of the catalyst. All of these together contributed to its better $\operatorname{deNO}_{x}$ activity at low temperatures. Zhang et al. [349] investigated the catalytic properties of $\mathrm{CeO}_{2}-\mathrm{ZrO}_{2}-\mathrm{WO}_{3}$ (CZW) catalysts synthesized by various methods for $\mathrm{NH}_{3}-\mathrm{SCR}$ of $\mathrm{NO}_{x}$. The CZW catalyst prepared by a hydrothermal method exhibited the optimal performance in the range of $175-450{ }^{\circ} \mathrm{C}$ due to the high specific surface area, the good redox behavior, the large amount of $\mathrm{Ce}^{3+}$, and the chemisorbed oxygen species. Moreover, the highly dispersed $\mathrm{WO}_{3}$ species over CZO and the abundant Brønsted acid sites were also responsible for the excellent SCR activity.

\subsubsection{Mechanisms of $\mathrm{NH}_{3}$-SCR of $\mathrm{NO}_{x}$ over nanosize} ceria-zirconium-based solid solutions

According to the studies of Gong et al. [350], Cai et al. [351], Brückner et al. [352], and Lee et al. [353], the mechanism of $\mathrm{NH}_{3}$-SCR of $\mathrm{NO}_{x}$ over CZO followed two distinct reaction pathways, the $\mathrm{L}-\mathrm{H}$ mechanism at low temperature $\left(<200{ }^{\circ} \mathrm{C}\right)$ and the E-R mechanism at high temperature $\left(>200^{\circ} \mathrm{C}\right)$ :

$$
\begin{gathered}
\mathrm{O}_{2(\mathrm{~g})}+2 * \rightarrow 2 \mathrm{O}^{-} * \\
\mathrm{NO}_{(\mathrm{g})}+\mathrm{O}^{-} * \rightarrow \mathrm{NO}_{2(\mathrm{a})} \\
2 \mathrm{NH}_{3(\mathrm{~g})}+2 \mathrm{H}^{+} \rightarrow 2 \mathrm{NH}_{4(\mathrm{a})}^{+}(\mathrm{Br} \phi \text { nsted acid site }) \\
2 \mathrm{NH}_{4}^{+}+\mathrm{NO}_{2(\mathrm{a})} \rightarrow \mathrm{NO}_{2}\left(\mathrm{NH}_{4}^{+}\right)_{2} \\
\mathrm{NO}_{2}\left(\mathrm{NH}_{4}^{+}\right)_{2}+\mathrm{NO} \rightarrow \cdots \rightarrow 2 \mathrm{~N}_{2}+3 \mathrm{H}_{2} \mathrm{O}+2 \mathrm{H}^{+}\left(<200^{\circ} \mathrm{C}\right) \\
\mathrm{NH}_{3(\mathrm{~g})} \rightarrow \mathrm{NH}_{3(\mathrm{a})}(\text { Lewis acid site }) \\
\mathrm{NH}_{3(\mathrm{a})} \rightarrow \mathrm{NH}_{2(\mathrm{a})}+\mathrm{H}^{+}+\mathrm{e}^{-} \\
\mathrm{NH}_{2(\mathrm{a})}+\mathrm{NO}_{(\mathrm{g})} \rightarrow \mathrm{NH}_{2} \mathrm{NO}_{(\mathrm{a})} \rightarrow \mathrm{N}_{2}+\mathrm{H}_{2} \mathrm{O}
\end{gathered}
$$

In this $\mathrm{SCR}$ reaction, gaseous $\mathrm{NH}_{3}$ molecules were first adsorbed on the Brønsted acid sites to generate $\mathrm{NH}_{4}{ }^{+}$ions. Meanwhile, NO molecules were also adsorbed on the catalyst surface and were oxidized to $\mathrm{NO}_{2}$ adspecies. Then one molecule of $\mathrm{NO}_{2}$ reacted with two adjacent $\mathrm{NH}_{4}^{+}$to generate active complex $\mathrm{NO}_{2}\left(\mathrm{NH}_{4}^{+}\right)_{2}$. $\mathrm{NO}_{2}\left(\mathrm{NH}_{4}{ }^{+}\right)_{2}$ finally reacted with one molecule of $\mathrm{NO}$ to produce $\mathrm{N}_{2}$ and $\mathrm{H}_{2} \mathrm{O}$ and thus finished the catalytic cycle.

\subsection{2. $\mathrm{H}_{2}-\mathrm{SCR}$}

Until the full transition to the hydrogen economy and zero emissions of greenhouse gases are realized, $\mathrm{H}_{2}$-SCR might be considered as a breakthrough $\mathrm{NO}_{x}$ control technology in favor of the current popular $\mathrm{NH}_{3}$-SCR. In 2014, Efstathiou et al. [354] for the first time reported the catalytic activity of $\mathrm{W}$-promoted CZO (Ce-rich or Zr-rich) solids towards $\mathrm{H}_{2}$-SCR of $\mathrm{NO}_{x}$. In the range of $250-350{ }^{\circ} \mathrm{C}$ and at GHSV $=51000 \mathrm{~h}^{-1}, \mathrm{NO}_{x}$ conversions were in the $30 \%-55 \%$ range with $85 \%-92 \% \mathrm{~N}_{2}$ selectivity (Fig. 21). A good stability of both Zr-rich and Ce-rich W/CZO catalysts was also obtained at 300 or $250{ }^{\circ} \mathrm{C}$ even after $66 \mathrm{~h}$ on-line reaction. The introduction of about 7 vol\% $\mathrm{H}_{2} \mathrm{O}$ in the feed stream resulted in a $10 \%-15 \%$ drop in $\mathrm{NO}_{x}$ conversions in the range of $250 \%-300{ }^{\circ} \mathrm{C}$, but an improvement in $\mathrm{N}_{2}$ selectivity by about 5\%. Moreover, the specific integral reaction rate of Zr-rich W/CZO towards $\mathrm{H}_{2}$-SCR in the range of $250-350{ }^{\circ} \mathrm{C}$ was as 2-3 times as that on Ce-rich W/CZO solid. Recently, Li et al. [355] prepared a Pd catalyst with highly dispersed $\mathrm{Pd}$ nanoclusters on an Al-doped CZO mixed oxide for low-temperature $\mathrm{H}_{2}$-SCR of $\mathrm{NO}_{x}$ with excess $\mathrm{O}_{2}$. The introduction of $\mathrm{Al}$ into $\mathrm{CZO}$ could effectively reduce the crystallite size and enhance the specific surface as well as increase the surficial $\mathrm{Ce}^{3+}$ concentrations and adsorbed oxygen species. As a result, a remarkable hydrogen spillover ability was achieved. The supported Pd nanoclusters showed $84 \% \mathrm{NO}_{x}$ conversion in the temperature range of $100-300^{\circ} \mathrm{C}$.

Liotta et al. [356] investigated the effect of the strong metal-support interaction (SMSI) on the catalytic activity of a $\mathrm{Pt} / \mathrm{Ce}_{0.6} \mathrm{Zr}_{0.4} \mathrm{O}_{2}$ catalyst for $\mathrm{H}_{2}$-SCR of $\mathrm{NO}_{x}$. The catalytic activity was enhanced for the catalyst pre-treated in $\mathrm{H}_{2}$ at $350{ }^{\circ} \mathrm{C} \mathrm{com-}$ pared with the samples performed at 800 and $1050{ }^{\circ} \mathrm{C}$. Moreover, transient reactivity tests of $\mathrm{NO}$ reduction by $\mathrm{H}_{2}$ were also conducted. As expected, the sample pre-reduced at $350{ }^{\circ} \mathrm{C}$ showed higher activity. The pretreatments had no effect on the $\mathrm{N}_{2}$ selectivity at the temperature of the maximum $\mathrm{NO}_{x}$ conversion. Therefore, it demonstrated the presence of SMSI effect between Pt and ceria and the important role of Pt in promoting the CZO structural reorganization. Such type of interaction determined a decrease of $\mathrm{Pt}$ and ceria reduction temperature and a stabilization of Pt oxide even in reducing atmosphere at high temperature. Efstathiou et al. [357] reported a series of $\mathrm{Pt} / \mathrm{Ce}_{x} \mathrm{Zr}_{1-x} \mathrm{O}_{2}(x=0.4-0.6)$ solids to be used for the SCR of NO under lean burn conditions $\left(2.5 \% \mathrm{O}_{2}\right)$ using $\mathrm{C}_{3} \mathrm{H}_{6}$ and $\mathrm{H}_{2}$ as reducing agents. These $\mathrm{Pt} / \mathrm{Ce}_{\mathrm{x}} \mathrm{Zr}_{1-\mathrm{x}} \mathrm{O}_{2}$ catalysts showed significant differences for $\mathrm{H}_{2}$-SCR performance in the range of $120-180{ }^{\circ} \mathrm{C}$ but practically exhibited the same catalytic behavior at higher temperatures. It was proved that the active $\mathrm{NO}_{x}$ of $\mathrm{H}_{2}$-SCR path resided within a reactive zone around each Pt nanoparticle, which extended to less than one lattice constant on the support surface. In addition, a remarkable activity and $\mathrm{N}_{2}$ selectivity enhancement was observed at temperature above $400{ }^{\circ} \mathrm{C}$ when both $\mathrm{H}_{2}$ and $\mathrm{C}_{3} \mathrm{H}_{6}$ reducing agents were used 

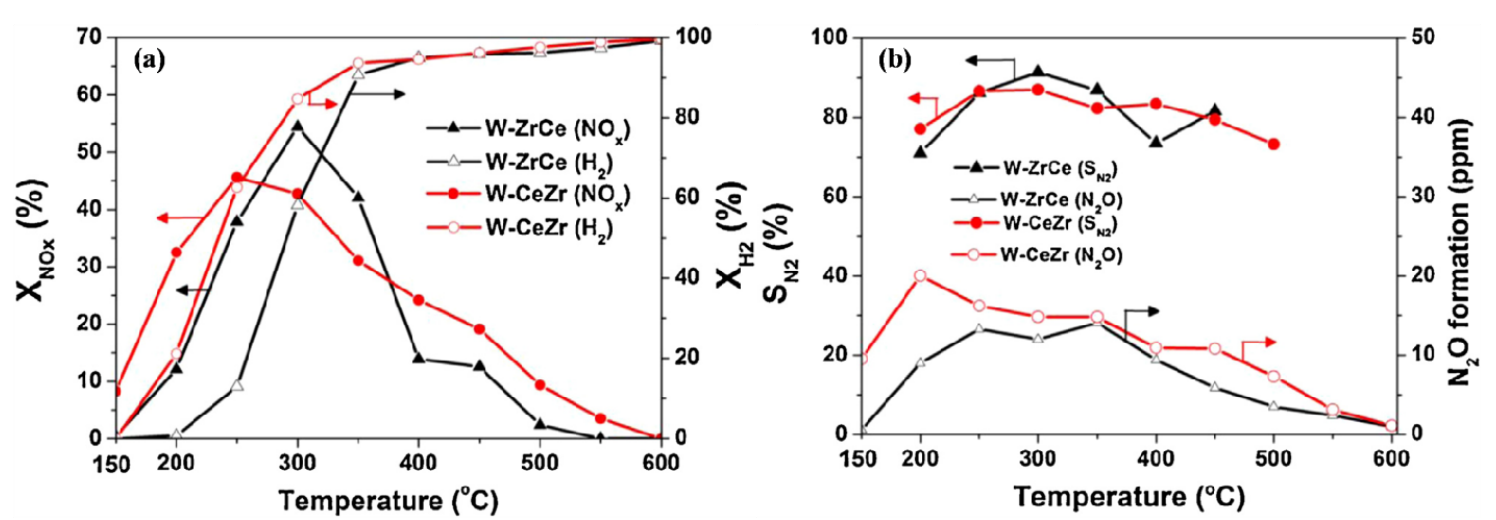

Fig. 21. (a) $\mathrm{NO}_{x}$ conversion $\left(X_{\mathrm{NOx}}, \%\right), \mathrm{H}_{2}$ conversion $\left(X_{\mathrm{H} 2}, \%\right)$, (b) $\mathrm{N}_{2}$ selectivity $\left(\mathrm{S}_{\mathrm{N} 2}\right)$ and $\mathrm{N}_{2} \mathrm{O}$ formation (ppm) in $\mathrm{H}_{2}$-SCR as a function of temperature over W-CeZr catalysts. Reaction conditions: 520 ppm NO $\mathrm{NO}_{x}\left(\mathrm{NO}: \mathrm{NO}_{2}=9: 1\right), 1.0 \% \mathrm{H}_{2}, 5 \% \mathrm{O}_{2}, 10 \% \mathrm{CO}_{2}$ and $\mathrm{He}$ as balance gas, GHSV $=51000$ h-1. Reprinted from [354] with permission.

compared to $\mathrm{H}_{2}$-SCR or $\mathrm{C}_{3} \mathrm{H}_{6}$-SCR alone. This synergy effect was explained to arise mainly because of the increase of $\theta_{\mathrm{H}}$ in the presence of $-\mathrm{CH}_{x}$ species derived from adsorbed $\mathrm{C}_{3} \mathrm{H}_{6}$ decomposition on $\mathrm{Pt}$, which blocked sites of oxygen chemisorption. The increase of surface oxygen vacancies promoted the formation of a more reactive chelating nitrite $\left(\mathrm{NO}_{2}{ }^{-}\right)$species compared to the case of $\mathrm{H}_{2}$-SCR.

\subsection{3. $H C-S C R$}

Although SCR of $\mathrm{NO}_{x}$ by $\mathrm{NH}_{3}$ or urea has proven to be an effective method for reducing $\mathrm{NO}_{x}$ emissions, there are several problems inevitably existing in the present $\mathrm{NH}_{3}$-SCR technology, such as $\mathrm{NH}_{3}$ slip, air-heaters fouling storage hazards, ash odor, equipment corrosion, and high running cost. Thus, a very significant market potential exists for an improved technology in this area. As a result, SCR of NO by HC derived from on-board fuel has attracted a lot of attention in the past years [320,358-361], as displayed in Table 7.

\subsubsection{1. $\mathrm{CH}_{4}-\mathrm{SCR}$}

As the main component of natural gas, $\mathrm{CH}_{4}$ is an attractive reductant of $\mathrm{NO}_{x}$ for a number of power sources. Nevertheless, the chemical stability of $\mathrm{CH}_{4}$ implies high activation temperature and, usually, a poor selectivity towards the reduction of NO by $\mathrm{CH}_{4}$ is obtained. Therefore, only a limited number of noble metals can act as the active component, such as $\mathrm{Pd}$ [355,362-365]. In 2004, Granger et al. [366] explored $\mathrm{CH}_{4}$ as alternative in SCR of NO in the presence of oxygen over Pd/CZO under lean conditions. The activation procedure under $\mathrm{O}_{2}$ or $\mathrm{H}_{2}$ drastically influenced the catalytic performance of the catalyst. $\mathrm{Pd} / \mathrm{Ce}_{0.52} \mathrm{Zr}_{0.48} \mathrm{O}_{2}$ showed a higher activity and a better $\mathrm{N}_{2}$ selectivity under $\mathrm{O}_{2}$ than that under $\mathrm{H}_{2}$, indicating that oxygen could enhance the activity. Moreover, the stabilization of a metallic or oxidic Pd phase led to poor activity in the conversion of NO in the absence of oxygen. Azambre et al. [367] reported Pd supported on sulfated CZO catalysts for $\mathrm{CH}_{4}-\mathrm{SCR}$ of $\mathrm{NO}_{x}$ and investigated the correlation between catalytic performance and nature of active Pd species. The catalytic activity was mainly dependent on the Pd loading amount. At low Pd loadings, Brönsted acidity of the sulfated support was beneficial to stabilizing Pd to form highly dispersed Pd species, which existed as $\left[(\mathrm{PdO})_{m-\mathrm{H}}\right]^{n+}$ adducts located in the vicinity of sulfate species. The corresponding $0.24 \%-0.53 \% \mathrm{Pd} /$ sulfated-CZO catalysts exhibited $30 \%-35 \% \mathrm{NO}_{x}$ conversion to $\mathrm{N}_{2}$ around $370{ }^{\circ} \mathrm{C}$. By

Table 7

Catalytic activity of nanosize CZO materials in HC-SCR of $\mathrm{NO}_{x}$.

\begin{tabular}{|c|c|c|c|c|c|}
\hline Catalyst & Reaction conditions & $X_{\mathrm{NO}}(\%)$ & $T_{\mathrm{r}}\left({ }^{\circ} \mathrm{C}\right)$ & $S_{\mathrm{N} 2}(\%)$ & Ref. \\
\hline $\mathrm{Ce}_{0.7} \mathrm{Zr}_{0.3} \mathrm{O}_{2}$ & $\mathrm{NO} / \mathrm{HC} / \mathrm{O}_{2}=0.0247: 0.025: 5 / 30000 \mathrm{~h}^{-1}$ & $9-27$ & $180-430$ & - & [373] \\
\hline $3 \% \mathrm{~W}-\mathrm{CZO}$ & $\mathrm{NO} / \mathrm{NO}_{2} / \mathrm{H}_{2} / \mathrm{O}_{2} / \mathrm{CO}_{2} / \mathrm{H}_{2} \mathrm{O}=0.0468: 0.0052: 1 / 5 / 10 / 7 / 51000 \mathrm{~h}^{-1}$ & 56 & 300 & 77-92 & [354] \\
\hline $1 \% \mathrm{Ni} / \mathrm{Al}-\mathrm{Ce}_{\mathrm{x}} \mathrm{Zr}_{1-\mathrm{x}} \mathrm{O}_{2}$ & $\mathrm{NO} / \mathrm{NO}_{2} / \mathrm{H}_{2} / \mathrm{O}_{2}=0.09: 0.01: 1: 5 / 60000 \mathrm{~h}^{-1}$ & $10-12$ & $100-300$ & - & [355] \\
\hline $4 \% \mathrm{Cu}-1 \% \mathrm{Ag} / \mathrm{Ce}_{0.75} \mathrm{Zr}_{0.25} \mathrm{O}_{2}$ & $\mathrm{NO} / \mathrm{HC} / \mathrm{O}_{2}=0.2: 0.2: 10 / 30000 \mathrm{~h}^{-1}$ & $56-89$ & $335-550$ & - & [372] \\
\hline $0.1 \% \mathrm{Pt} / \mathrm{Ce}_{0.5} \mathrm{Zr}_{0.5} \mathrm{O}_{2}$ & $\mathrm{NO} / \mathrm{H}_{2} / \mathrm{O}_{2}=0.015: 0.8: 2.5 / 33000 \mathrm{~h}^{-1}$ & $60-92$ & $170-300$ & $70-82$ & [357] \\
\hline $0.1 \% \mathrm{Pt} / \mathrm{Ce}_{0.5 \mathrm{Z}} \mathrm{Zr}_{0.5} \mathrm{O}_{2}$ & $\mathrm{NO} / \mathrm{HC} / \mathrm{O}_{2}=0.015: 0.5: 2.5 / 33000 \mathrm{~h}^{-1}$ & 50 & 350 & 78 & [357] \\
\hline $0.1 \% \mathrm{Pt} / \mathrm{Ce}_{0.5} \mathrm{Zr}_{0.5} \mathrm{O}_{2}$ & $\mathrm{NO} / \mathrm{H}_{2} / \mathrm{HC} / \mathrm{O}_{2}=0.015: 0.8: 0.5: 2.5 / 33000 \mathrm{~h}^{-1}$ & 100 & $450-600$ & $95-98$ & [357] \\
\hline $1 \% \mathrm{Pt} / \mathrm{Ce}_{0.5} \mathrm{Zr}_{0.5} \mathrm{O}_{2}$ & $\mathrm{NO} / \mathrm{HC} / \mathrm{O}_{2}=1: 3: 3 / 40000 \mathrm{~h}^{-1}$ & 80 & 500 & - & [375] \\
\hline $1 \% \mathrm{Pt} / \mathrm{Ce}_{0.6} \mathrm{Zr}_{0.4} \mathrm{O}_{2}$ & $\mathrm{NO} / \mathrm{HC} / \mathrm{O}_{2}=0.1: 0.1: 5 / 60000 \mathrm{~h}^{-1}$ & 60 & 250 & 74 & [356] \\
\hline $1 \% \mathrm{Pd} / \mathrm{Al}-\mathrm{Ce}_{\mathrm{x}} \mathrm{Zr}_{1-\mathrm{x}} \mathrm{O}_{2}$ & $\mathrm{NO} / \mathrm{NO}_{2} / \mathrm{H}_{2} / \mathrm{O}_{2}=0.09: 0.01: 1: 5 / 60000 \mathrm{~h}^{-1}$ & $>84$ & $100-300$ & - & [355] \\
\hline $0.89 \% \mathrm{Pd} / \mathrm{Ce}_{0.68} \mathrm{Zr}_{0.32} \mathrm{O}_{2}$ & $\mathrm{NO} / \mathrm{HC} / \mathrm{O}_{2}=0.034: 0.19: 8 / 112500 \mathrm{~h}^{-1}$ & 29 & 243 & 87 & [369] \\
\hline $1 \% \mathrm{Pd} / \mathrm{Ce}_{0.2} \mathrm{Zr}_{0.8} \mathrm{O}_{2}$ & $\mathrm{NO}_{2} / \mathrm{CH}_{4}=1: 1 / 4200 \mathrm{~h}^{-1}$ & 100 & $495-700$ & 100 & [368] \\
\hline Sulfated $1 \% \mathrm{Pd} / \mathrm{Ce}_{0.52} \mathrm{Zr}_{0.48} \mathrm{O}_{2}$ & $\mathrm{NO} / \mathrm{CH}_{4} / \mathrm{O}_{2}=0.015: 0.15: 7 / 40000 \mathrm{~h}^{-1}$ & $5-15$ & $250-500$ & - & [367] \\
\hline $0.52 \% \mathrm{Rh} / \mathrm{Ce}_{0.62} \mathrm{Zr}_{0.38} \mathrm{O}_{2}$ & $\mathrm{NO} / \mathrm{HC} / \mathrm{O}_{2}=0.0247: 0.025: 5 / 30000 \mathrm{~h}^{-1}$ & 52 & 360 & 一 & [374] \\
\hline $0.4 \% \mathrm{Rh} / \mathrm{Ce}_{0.5} \mathrm{Zr}_{0.5} \mathrm{O}_{2}$ & $\mathrm{NO} / \mathrm{HC} / \mathrm{O}_{2} / \mathrm{H}_{2} \mathrm{O}=0.05: 0.1167: 0.5 / 500000 \mathrm{~h}^{-1}$ & 100 & $400-600$ & - & [370] \\
\hline 0.44\% Rh-0.54\%Pd/Ce.68 $\mathrm{Zr}_{0.32} \mathrm{O}_{2}$ & $\mathrm{NO} / \mathrm{HC} / \mathrm{O}_{2}=0.034: 0.19: 8 / 112500 \mathrm{~h}^{-1}$ & 28 & 288 & 81 & [371] \\
\hline $0.44 \% \mathrm{Rh}-0.91 \% \mathrm{Pt} / \mathrm{Ce}_{0.68} \mathrm{Zr}_{0.32} \mathrm{O}_{2}$ & $\mathrm{NO} / \mathrm{HC} / \mathrm{O}_{2}=0.034: 0.19: 8 / 112500 \mathrm{~h}^{-1}$ & 16 & 289 & 85 & [371] \\
\hline
\end{tabular}

$X_{\mathrm{NO} x}, S_{\mathrm{N} 2}$ and $T_{\mathrm{r}}$ denote $\mathrm{NO}_{x}$ conversion, $\mathrm{N}_{2}$ selectivity, and reaction temperature range of $\mathrm{NO}$ complete conversion, respectively. 
contrast, higher Pd loading amounts were detrimental for the SCR reaction due to the promoted formation of $\mathrm{PdO}_{m}$ clusters, which showed more active in the selective oxidation of $\mathrm{CH}_{4}$. In addition, the introduction of $\mathrm{H}_{2} \mathrm{O}$ to the feed was unfavorable due to the prevention of $\mathrm{NO}_{x}$ and $\mathrm{CH}_{4}$ sorption at low-medium temperatures. The reaction intermediates involved in $\mathrm{CH}_{4}-\mathrm{SCR}$ and the factors controlling the reactivity of $\mathrm{Pd} / \mathrm{CZO}$ catalyst were studied by Azambre et al. [368]. By DRIFTS of adsorbed $\mathrm{CO}$, it was found that $\mathrm{Pd}$ species on $\mathrm{Ce}_{0.2} \mathrm{Zr}_{0.8} \mathrm{O}_{2}$ were mainly present in $\mathrm{Pd}^{x+}$ ionic form surrounded by surface oxygens or small $\mathrm{PdO}_{m}$ clusters cationic form. The investigation of temperature-programmed surface reaction in $\mathrm{CH}_{4}+\mathrm{NO}_{2}$ atmosphere indicated that $\mathrm{CH}_{4}$-SCR reaction on $\mathrm{Pd} / \mathrm{Ce}_{0.2} \mathrm{Zr}_{0.8} \mathrm{O}_{2}$ was initiated at $280{ }^{\circ} \mathrm{C}$ and yielded almost $100 \% \quad \mathrm{~N}_{2}$ above $500{ }^{\circ} \mathrm{C}$. DRIFTS-MS and TGA experiments showed that deNO $\mathrm{O}_{x}$ activity was due to a surface reaction between adsorbed $\mathrm{CO}_{x}$ species, which were generated by $\mathrm{CH}_{4}$ activation on reduced Pd sites with ad- $\mathrm{N}_{x} \mathrm{O}_{y}$ species presumably located on the support. The detrimental effect of $\mathrm{O}_{2}$ on deNO $\mathrm{N}_{x}$ was due to the promotion of the complete combustion of $\mathrm{CH}_{4}$ assisted by the ceria-zirconia component at the expense of SCR reaction above $320^{\circ} \mathrm{C}$.

\subsubsection{2. $\mathrm{C}_{3} \mathrm{H}_{6}-\mathrm{SCR}$}

Compared to $\mathrm{H}_{2}, \mathrm{CH}_{4}$, much more efforts have been made to improve NO removal using $\mathrm{C}_{3} \mathrm{H}_{6}$ as reductant. Thomas et al. [369] investigated $\mathrm{C}_{3} \mathrm{H}_{6}-\mathrm{SCR}$ of $\mathrm{NO}_{x}$ on $\mathrm{Pd} / \mathrm{Ce}_{0.68} \mathrm{Zr}_{0.32} \mathrm{O}_{2}$ catalysts (Pd/CZO). The addition of Pd to CZO significantly promoted the reduction of $\mathrm{NO}$ by $\mathrm{C}_{3} \mathrm{H}_{6}$, and the catalyst still exhibited relative high deNO ${ }_{x}$ activity even in the presence of $1.7 \%$ $\mathrm{H}_{2} \mathrm{O}$. Pd/CZO displayed much higher $\mathrm{N}_{2}$ selectivity than $\mathrm{Pd} 0 / \mathrm{SiO}_{2}$, indicating that the lean $\operatorname{deNO}_{x}$ mechanism occurring on these catalysts should be different from that of $\mathrm{Pd}^{0} / \mathrm{SiO}_{2}$.

Haneda et al. [370] studied the catalytic performance of Rh supported on $\mathrm{CZO}$ for $\mathrm{C}_{3} \mathrm{H}_{6}$-SCR of NO. The catalytic activity of $\mathrm{Rh} / \mathrm{CZO}$ strongly depended on the $\mathrm{Ce} / \mathrm{Zr}$ ratio. $\mathrm{Rh} / \mathrm{Ce}_{0.50} \mathrm{Zr}_{0.50} \mathrm{O}_{2}$ showed the best activity. Moreover, the activity of Rh/CZO for $\mathrm{C}_{3} \mathrm{H}_{6}$-SCR of $\mathrm{NO}$ also depended on the reaction gas conditions. The presence of $\mathrm{O}_{2}$ could inhibit $\mathrm{NO}$ reduction by $\mathrm{C}_{3} \mathrm{H}_{6}$, especially for $\mathrm{Rh} / \mathrm{Ce}_{0.74} \mathrm{Z}_{0.26} \mathrm{O}_{2}$. The effect of the nature of platinum group metals (PGMs: $\mathrm{Pd}, \mathrm{Rh}, \mathrm{Pt}$ ) on the lean $\mathrm{C}_{3} \mathrm{H}_{6}$-assisted removal of $\mathrm{NO}$ on $\mathrm{Ce}_{0.68} \mathrm{Zr}_{0.32} \mathrm{O}_{2}$-supported catalysts was investigated by Thomas et al. [371]. The order of reactivity of CZO-supported PGMs was Pd $\geq \mathrm{Pt} \geq \mathrm{Rh}$, and CZO-supported catalysts exhibited higher $\mathrm{N}_{2}$ selectivity than those supported on $\mathrm{SiO}_{2}$ or $\mathrm{Al}_{2} \mathrm{O}_{3}$. The higher catalytic activity of Pd-based catalysts for $\mathrm{C}_{3} \mathrm{H}_{6}-\mathrm{SCR}$ of $\mathrm{NO}_{x}$ might be associated with the greater ability of the $\mathrm{PdO}_{x}$ phase to adsorb $\mathrm{NO}_{2}$.

Amin et al. [372] studied the catalytic activity of CZO-supported $\mathrm{Cu}$ and $\mathrm{Ag}$ for $\mathrm{C}_{3} \mathrm{H}_{6}$-SCR of NO. Compared to $\mathrm{Cu}(4) / \mathrm{Ag}(1) / \mathrm{CeO}_{2}, \mathrm{Cu}(4) / \mathrm{Ag}(1) / \mathrm{Ce}_{0.75} \mathrm{Zr}_{0.25} \mathrm{O}_{2}$ displayed higher deNO ${ }_{x}$ activity in the range of $250-350{ }^{\circ} \mathrm{C}$. The SMSI and high redox property of the support exhibited by the $\mathrm{Cu}(4) / \mathrm{Ag}(1) / \mathrm{Ce}_{0.75} \mathrm{Zr}_{0.25} \mathrm{O}_{2}$ catalyst were considered to be the main reasons of the improvement of $\mathrm{C}_{3} \mathrm{H}_{6}-\mathrm{SCR}$ performance. In addition, reaction temperature was found to affect NO reduction activity more significantly than $\mathrm{NO}$ and $\mathrm{C}_{3} \mathrm{H}_{6}$ concentrations. The optimum conditions were estimated to be $415.4{ }^{\circ} \mathrm{C}$,
1827.2 ppm of NO, and 1908.1 ppm of $\mathrm{C}_{3} \mathrm{H}_{6}$ concentration corresponding to NO conversion of $82.9 \%$.

\subsubsection{Other $\mathrm{C}_{x} \mathrm{H}_{y}$-SCR}

Compared with $\mathrm{CH}_{4}-\mathrm{SCR}$ and $\mathrm{C}_{3} \mathrm{H}_{6}$-SCR, more research has been performed on SCR of $\mathrm{NO}_{x}$ with a mixture of $\mathrm{HC}$ representative of the exhaust gas from fossil fuel combustion $\left(\mathrm{C}_{3} \mathrm{H}_{8}\right.$, $\mathrm{C}_{3} \mathrm{H}_{6}$, and $\mathrm{C}_{7} \mathrm{H}_{8}$ ) over CZO catalysts. Costa et al. [373] studied the relationship between the surface properties and $\operatorname{deNO}_{x}$ activity of CZO. $\mathrm{Ce}_{x} \mathrm{Zr}_{1-x} \mathrm{O}_{2}(x=0.17-0.8)$ were active in deNO reaction, and their catalytic activities varied with the different cerium amounts and reached the maximum for $x=0.62$ with $27 \% \mathrm{NO}_{x}$ transformation to $\mathrm{N}_{2}$ at $322^{\circ} \mathrm{C}$. Subsequently, Costa et al. [374] investigated CZO-supported rhodium catalyst for $\mathrm{NO}_{x}$ reduction, and the catalytic activities were evaluated by isothermal steady-state experiments using a mixture of exhaust gases of HC. The addition of $\mathrm{Rh}$ on $\mathrm{Ce}_{0.62} \mathrm{Zr}_{0.38} \mathrm{O}_{2}$ considerably improved the catalytic activity during the $\operatorname{deNO}_{x}$ process assisted by $\mathrm{HC}$, and decreased by about $34^{\circ} \mathrm{C}$ for the temperature of $\mathrm{NO}_{x}$ conversion to $\mathrm{N}_{2}$, which went up to $57 \%$. The effect of support on the three-way catalytic $\mathrm{HC}-\mathrm{NO}-\mathrm{O}_{2}$ reaction over $\mathrm{Pt} / \mathrm{CZO}$ catalysts under reducing conditions was investigated by means of operando X-ray absorption near edge structure [375]. The formation of active metallic $\mathrm{Pt}$ sites and the self-poisoning effect of adsorbed carbonaceous species on metallic Pt should determine the start-up behavior of catalytic reaction over supported Pt catalysts. The oxygen reactivity in the support oxide was also important for reducing the catalytic start-up temperature in addition to the suitable Pt reduction temperature.

\subsubsection{Mechanisms of HC-SCR of $\mathrm{NO}_{x}$ over nanosize ceria-zirconium-based solid solutions}

The reduction mechanism of $\mathrm{NO}_{x}$ by $\mathrm{HC}$ over CZO is very complex [376-381]. According to the mechanism proposed by Djéga-Mariadassou et al. [379] (as shown in Fig. 22), the first step of this catalyst is to oxidize $\mathrm{NO}$ to $\mathrm{NO}_{2}$. The second step is the mild oxidation of $\mathrm{HC}$ by $\mathrm{NO}_{2}$ to form oxygenate species, which plays an important role in the catalyst regeneration process. The release of $\mathrm{N}_{2}$ occurs in step 3. It involved $\mathrm{NO}_{x}$ dissociation and followed by the formation of $\mathrm{N}_{2}$ and scavenging of the adsorbed oxygen species left from NO dissociation. The removal of the adsorbed oxygen was due to the total oxidation of an activated reductant $\left(\mathrm{C}_{x} \mathrm{H}_{y} \mathrm{O}_{z}\right)$. In addition, both steps 2 and 3 have to turn over simultaneously. However, at the molecular level, the both steps were not in the same catalytic cycle.

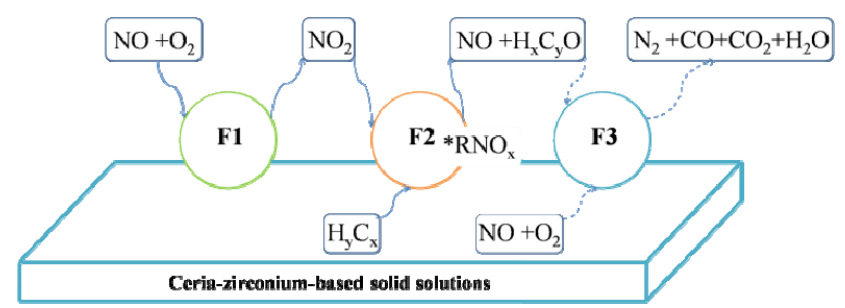

Fig. 22. Catalys-assisted de $\mathrm{NO}_{x}$ reaction: each cycle corresponds to one function (F1, F2, and F3). 


\subsection{4. $\mathrm{C}_{\mathrm{X}} \mathrm{H}_{2 \mathrm{x}+1} \mathrm{OH}-\mathrm{SCR}$}

For $\operatorname{deNO}_{x}$ reaction, it has been reported that when a hydrocarbon is able to catalytically reduce $\mathrm{NO}_{x}$, its corresponding alcohol must also be useful for such a process [382]. The role of $\mathrm{CH}_{3} \mathrm{OH}$ in the reduction of $\mathrm{NO}_{x}$ to $\mathrm{N}_{2}$ was investigated over $\mathrm{H}_{3} \mathrm{PW}_{12} \mathrm{O}_{40}$-Pt/CZO [383]. The reduction of $\mathrm{NO}_{x}$ went through two stages. First, during the lean mode for $2 \mathrm{~min}, \mathrm{NO}_{x}\left(\mathrm{NO} / \mathrm{NO}_{2}\right.$ $=1$ ) were stored in the catalyst; second, they were reduced into $\mathrm{N}_{2}$ during the rich period $\left(\mathrm{CH}_{3} \mathrm{OH}\right.$ injection $\left.1 \mathrm{~min}\right)$. With $\mathrm{CH}_{3} \mathrm{OH}$, $\mathrm{NO}_{x}$ storage efficiency of $\mathrm{H}_{3} \mathrm{PW}_{12} \mathrm{O}_{40}-\mathrm{Pt} / \mathrm{CZO}$ was stable and high (ca. $100 \%$ ), and about $55 \%$ of stored $\mathrm{NO}_{x}$ were reduced into $\mathrm{N}_{2}$ by alternative lean/rich cycles. $\mathrm{C}_{x} \mathrm{H}_{y} \mathrm{O}_{z}$ intermediate species derived from methanol were thought to be the intermediate reductants for $\mathrm{NO}_{x}$.

Azambre et al. [384] studied the catalytic performance of sulfated CZO catalysts for SCR of $\mathrm{NO}_{x}$ by ethanol. The sulfated CZO catalysts were prepared by direct sulfation of the crystallized CZO nanopowders with $0.5 \mathrm{~mol} / \mathrm{L} \mathrm{H}_{2} \mathrm{SO}_{4}$. The sulfation treatment enhanced the SCR activity via the promotion of alternative pathways for the formation of $\mathrm{N}_{2}$ and the prevention of combustion reactions at medium temperatures. Moreover, $\mathrm{NO}_{x}$ conversion was shown to exceed $30 \%$ on most of SCR catalysts in the range of $250-400{ }^{\circ} \mathrm{C}$. Above $350-400{ }^{\circ} \mathrm{C}$, the $\mathrm{N}_{2}$ selectivity was close to $100 \%$ and an optimum deNO $\mathrm{N}_{x}$ yield of $48 \%$ was achieved for a sulfated catalyst with a Ce molar fraction of 0.5. Azambre and his coworkers [385] further studied the effect of $\mathrm{Ag}, \mathrm{Pd}$ and $\mathrm{Co}$ additive on the $\mathrm{SCR}$ of $\mathrm{NO}_{x}$ by ethanol over sulfated CZO catalysts. The metal promoters have a discrete effect on $\mathrm{C}_{2} \mathrm{H}_{5} \mathrm{OH}-\mathrm{SCR}$ activity, often negative and sometimes positive. Positive effects essentially arised from the formation of acetaldehyde, which was the most effective reductant of the system. It occurred mostly in the presence of $\mathrm{Ag}$ species in the +1 oxidation state. By contrast, the Pd catalyst was not effective for $\mathrm{C}_{2} \mathrm{H}_{5} \mathrm{OH}$-SCR because it induced a depletion of the organics needed for $\mathrm{NO}_{x}$ reduction by promoting total oxidation reactions. Another negative effect was the inhibition of the most active cerium sites of the support, which led to a decrease of the SCR activity at low temperatures and the shift of deNO window towards the high temperatures.

Djéga-Mariadassou et al. [386] investigated the catalytic performance of 1-propanol-assisted reduction of $\mathrm{NO}_{x}$ over a $\mathrm{Ir} / \mathrm{Ce}_{0.6} \mathrm{Zr}_{0.4} \mathrm{O}_{2}$ catalyst. This catalytic material showed a promotional effect of iridium on the conversion of $\mathrm{NO}_{x}$. $\mathrm{Ir} / \mathrm{Ce}_{0.6} \mathrm{Zr}_{0.4} \mathrm{O}_{2}$ exhibited a higher $\mathrm{NO}_{x}$ reduction $(25 \%$ at 225 ${ }^{\circ} \mathrm{C}$ ) than $\mathrm{Ce}_{0.6 \mathrm{Zr}_{0.4} \mathrm{O}_{2}}$ (19\% at $260{ }^{\circ} \mathrm{C}$ ). 1-Propanol was activated at lower temperatures over the Ir catalyst. Moreover, $\mathrm{R}^{-\mathrm{NO}_{x}}$ species were found to be the intermediates of the $\operatorname{deNO}_{x}$ process, which provided the partially oxidized species required by the deNO ${ }_{x}$ model.

\subsection{Nanosize ceria-zirconium-based solid solutions for $\mathrm{NO}_{\mathrm{x}}$ direct decomposition}

\subsubsection{NO direct decomposition}

Although several methods exist to eliminate NO, direct decomposition of $\mathrm{NO}$ to $\mathrm{N}_{2}$ and $\mathrm{O}_{2}\left(\mathrm{NO} \rightarrow 1 / 2 \mathrm{~N}_{2}+1 / 2 \mathrm{O}_{2}\right.$ ) is recognized to be one of the most attractive methods because it does not need any reductants and is simple and economical. NO is thermodynamically unstable. However, it does not decompose easily due to its high $E_{\text {a value }}(364 \mathrm{~kJ} / \mathrm{mol})$. Therefore, a

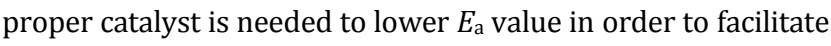
the decomposition. Research in this domain has been extensively performed on noble metal-supported catalysts [387,388], metal oxides [389-394], carbon [395-397], and zeolite-based catalysts [398-404]. Whereas, little research was reported on the direct decomposition of $\mathrm{NO}_{x}$ over CZO-based catalysts. Cheng et al. [405] prepared nanosize CZO-supported $\mathrm{H}_{3} \mathrm{PW}_{12} \mathrm{O}_{40}$ (HPW) for NO capture and decomposition. CZO exhibited remarkable promotion effect on the capture of $\mathrm{NO}_{x}$. For HPW/CZO prepared by a mechanical grinding method, $\mathrm{NO}_{x}$ adsorption efficiency was considerably enhanced with increasing HPW loading amounts in the range of $20 \%-70 \%$. However, the deNO ${ }_{x}$ efficiency decreased with increasing loading of HPW (>70\%). Subsequent to the adsorption process, the adsorbed $\mathrm{NO}_{x}$ decomposed to $\mathrm{N}_{2}$ upon heating from 150 to $450{ }^{\circ} \mathrm{C}$, with a $\mathrm{N}_{2}$ yield of $27.3 \%$. Yang et al. [406] reported a Ce-Cu-Zr/ZSM-5 catalyst prepared by an ion-exchange method showing high catalytic activity for NO decomposition in the presence of $\mathrm{O}_{2}$, and the highest NO conversion was up to $75 \%$. This indicated that the introduction of CZO could promote the formation of a new highly active site, which facilitated oxygen mobilization and desorption, thereby enhanced the activity of catalysts.

\subsection{2. $\mathrm{N}_{2} \mathrm{O}$ direct decomposition}

Besides NO, nitrous oxide $\left(\mathrm{N}_{2} \mathrm{O}\right)$ has drawn ever increasing attention in the past decades because of its detrimental green house effect and ozone-depleting action [322,407-410]. Thus, the development of highly active catalysts to purify $\mathrm{N}_{2} \mathrm{O}$ is becoming an important issue. Imamura et al. [411] investigated the effects of structural composition and calcination temperature of the catalysts on the catalytic performance of $\mathrm{Rh} / \mathrm{CZO}$ for $\mathrm{N}_{2} \mathrm{O}$ decomposition. The incorporation of $\mathrm{Zr}$ into ceria significantly enhanced its thermal stability to retain high specific surface area even at the calcination temperature of $900{ }^{\circ} \mathrm{C}$. $\mathrm{Rh} / \mathrm{Ce}_{0.7} \mathrm{Zr}_{0.3} \mathrm{O}_{2}$ exhibited the optimal catalytic activity due to the highly dispersed $\mathrm{Rh}$ species exposed to the support surface. Nevertheless, too high calcination temperature $\left(1200^{\circ} \mathrm{C}\right)$ led to the remarkable decrease of catalyst surface area and the aggregation of Rh.

So far, $\mathrm{NO}_{x}$ direct decomposition over metal surfaces, oxides, or zeolites is faced to some serious practical difficulties. $\mathrm{NO}_{x}$ decomposition process is a high-temperature reaction, which is undesirable. $\mathrm{NO}_{x}$ dissociation over single crystal metal easily reoxidizes the metal surface, which in turn hinders the $\mathrm{NO}_{x}$ dissociation process. So, a reducing agent is needed to scavenge the dissociated oxygen. From an exhaust catalysis view, it is not sufficient to dissociate $\mathrm{NO}_{x}$, and other pollutants like $\mathrm{CO}$ and $\mathrm{HC}$ should also be oxidized. Therefore, $\mathrm{NO}_{x}$ reduction by $\mathrm{H}_{2}, \mathrm{HC}$, and $\mathrm{NH}_{3}$ is more attractive for $\mathrm{NO}_{x}$ abatement.

\subsubsection{Mechanisms of $\mathrm{NO}_{x}$ direct decomposition over nanosize ceria-zirconium-based solid solutions}

It is widely accepted that $\mathrm{N}_{2} \mathrm{O}$ decomposition is a sensitive reaction to oxygen mobility. 


$$
\begin{aligned}
\mathrm{N}_{2} \mathrm{O}+* & \rightarrow \mathrm{N}_{2} \mathrm{O}^{*} \\
\mathrm{~N}_{2} \mathrm{O}^{*} & \rightarrow \mathrm{N}_{2}+\mathrm{O}^{*} \\
2 \mathrm{O}^{*} & \rightarrow \mathrm{O}_{2}+2^{*}
\end{aligned}
$$

In this mechanism, the asterisk $\left(^{*}\right)$ is a coordinatively unsaturated site of oxidic transition for $\mathrm{N}_{2} \mathrm{O}$ adsorption. The first step for $\mathrm{N}_{2} \mathrm{O}$ decomposition was the adsorption of $\mathrm{N}_{2} \mathrm{O}$ followed by its decomposition, leading to $\mathrm{N}_{2}$ formation in association with surface oxygen. In this classical model, oxygen formation occurred through recombination of two adsorbed atomic oxygen species $\left(\mathrm{O}^{*}\right)$ or through reaction of $\mathrm{N}_{2} \mathrm{O}$ with adsorbed atomic oxygen species.

\subsection{Nanosize cerium-zirconium-based solid solutions for simultaneous removal of $\mathrm{CO}$ and $\mathrm{NO}_{\mathrm{x}}$}

The simultaneous removal of $\mathrm{CO}$ and $\mathrm{NO}_{x}$ in the presence or absence of $\mathrm{O}_{2}, \mathrm{CO}_{2}$, and $\mathrm{H}_{2} \mathrm{O}$ is a proper model reaction, which is different from real automobile exhaust emission. However, the fundamental studies using the supported noble and non-noble metal catalysts were performed to get more insight into the nature of this reaction [412-416], as shown in Table 8.

\subsubsection{Pt-based ceria-zirconium catalysts}

Rao et al. [417] reported CZO-supported Rh catalysts for NO + CO reaction. The activation of the reductant was difficult on the bare support, and the presence of Rh was necessary to activate and spill it over to the support. Moreover, the bulk oxygen vacancy played an important role in promoting NO conversion over Rh/CZO catalysts, and oxygen vacancy gradient was indicated as the main driving force for NO dissociation. Ihm et al. [418] investigated the catalytic activities of $\mathrm{Pt} / \mathrm{WO}_{3} / \mathrm{CZO}$ catalysts for $\mathrm{NO}+\mathrm{CO}$ reaction with or without oxygen. $\mathrm{Pt} / \mathrm{CeO}_{2}$ and $\mathrm{Pt} / \mathrm{CZO}$ could be readily reduced by $\mathrm{CO}$, while the reduction was significantly inhibited with the introduction of $\mathrm{WO}_{3}$ for $\mathrm{Pt} / \mathrm{WO}_{3} / \mathrm{CZO}$. It was due to that $\mathrm{WO}_{3}$ addition suppressed the formation of the active sites for $\mathrm{NO}$ reduction. $\mathrm{Pt} / \mathrm{WO}_{3} / \mathrm{ZrO}_{2}$ showed a slightly higher activity than $\mathrm{Pt} / \mathrm{ZrO}_{2}$. As reported by Regalbuto and Wolf [419], Pt- $\mathrm{WO}_{3}$ adlineation sites exhibited very high NO dissociation activity and increased the activity toward NO + CO reaction. However, based on the results displayed in Fig. 23, there was no obvious correlation between acidity and catalytic activity for $\mathrm{NO}+\mathrm{CO}$ reaction over $\mathrm{Pt} / \mathrm{WO}_{3} / \mathrm{CeO}_{2} / \mathrm{ZrO}_{2}$ catalysts in the absence of oxygen. With excess oxygen, $\mathrm{Pt} / \mathrm{WO}_{3} / \mathrm{CZO}$ and $\mathrm{Pt} / \mathrm{WO}_{3} / \mathrm{ZrO}_{2}$ catalysts showed higher $\mathrm{NO}$ conversion to $\mathrm{N}_{2}$ and $\mathrm{N}_{2} \mathrm{O}$ particularly at low temperature. This was attributed to the enhanced acidity from $\mathrm{ZrO}_{2}$ and $\mathrm{WO}_{3}$ in the $\mathrm{Pt} / \mathrm{WO}_{3} / \mathrm{CeO}_{2} / \mathrm{ZrO}_{2}$ catalysts in the presence of excess oxygen.

\subsubsection{Pd-based ceria-zirconium catalysts}

Wang et al. [420] prepared a series of mesoporous $\mathrm{Ce}_{0.6} \mathrm{Zr}_{0.4} \mathrm{O}_{2}$ solid solutions with cationic defects by a surfactant-controlled synthesis method, and the pore size of $\mathrm{Ce}_{0.6} \mathrm{Zr}_{0.4} \mathrm{O}_{2}$ could be governed by the incorporation of the surfactant into solid network and the calcination temperature. In the cold start of reaction, NO reduction by $\mathrm{CO}$ with excess oxygen over the $3 \% \mathrm{Pd} / \mathrm{Ce}_{0.6} \mathrm{Zr}_{0.4} \mathrm{O}_{2}$ catalyst presented $100 \%$ selectivity to $\mathrm{N}_{2}$. At reaction temperatures below $200{ }^{\circ} \mathrm{C}$, NO restrained the oxidation of $\mathrm{CO}$. However, above $200^{\circ} \mathrm{C}$, CO oxidation showed an inhibition effect on NO conversion, and there was a reaction competition between $\mathrm{NO}$ reduction by $\mathrm{CO}$ and $\mathrm{CO}$ oxidation by $\mathrm{O}_{2}$. The key factor of the reaction competition was the concentration of $\mathrm{CO}$ and $\mathrm{O}_{2}$. The different oxygen concentration also influenced Pd state. High coverage of Pd surface by oxygen was favorable for $\mathrm{NO}$ oxidation to $\mathrm{NO}_{2}$ but suppressed NO decomposition to $\mathrm{N}^{*}$ and $\mathrm{O}^{*}$. Fernández-García et al. [421] investigated the light-off behavior for $\mathrm{CO}+\mathrm{NO}$ reaction over $\mathrm{Pd} / \mathrm{CZO} / \mathrm{Al}_{2} \mathrm{O}_{3}$ catalysts prepared by the ME method. The promoting effect of CZO was present in both $\mathrm{CO}$ oxidation and NO reduction reactions, and it was dependent on the characteristics of the promoter and the nature of the reaction. CO oxidation activity was greatly enhanced by contact between $\mathrm{Pd}$ and the 3-D aggregated promoter, and the catalytic activity increased with increasing CZO content. Fernández-Garcıa and co-workers [422] further studied the catalytic activity of a series of $\mathrm{Pd}-\mathrm{Cr}$ bimetallic catalysts supported on a $\mathrm{CZO} / \mathrm{Al}_{2} \mathrm{O}_{3}$ mixed support for $\mathrm{CO}+\mathrm{NO}+\mathrm{O}_{2}$ reaction. The catalytic activities of these bimetallic catalysts were strongly influenced by the nature of the support. For the $\mathrm{Al}_{2} \mathrm{O}_{3}$ support, an interaction

\begin{tabular}{|c|c|c|c|c|c|}
\hline $\begin{array}{l}\text { Catalyst } \\
\end{array}$ & Reaction conditions & $T\left({ }^{\circ} \mathrm{C}\right)$ & $X_{\mathrm{NO}}(\%)$ & $X_{\mathrm{CO}}(\%)$ & Ref. \\
\hline $1.23 \mathrm{CuO} / \mathrm{Ce}_{0.67} \mathrm{Zr}_{0.33} \mathrm{O}_{2}$ & $0.05 \mathrm{~g} / \mathrm{NO}: \mathrm{CO} / \mathrm{He}=1: 2: 17 / 12000 \mathrm{~h}^{-1}$ & 400 & 100 & - & [416] \\
\hline $4 \% \mathrm{Cu} / \mathrm{Ce}_{\mathrm{x}} \mathrm{Zr}_{1-\mathrm{x}} \mathrm{O}_{2}$ & $0.1 \mathrm{~g} / \mathrm{NO}: \mathrm{CO} / \mathrm{He}=0.3: 0.3: 99.4 / 50000 \mathrm{~h}^{-1}$ & 400 & 100 & $92 \sim 96$ & [425] \\
\hline $0.4 \mathrm{CuO} / \mathrm{Ce}_{\mathrm{x}} \mathrm{Zr}_{1-\mathrm{x}} \mathrm{O}_{2} / \gamma-\mathrm{Al}_{2} \mathrm{O}_{3}$ & $0.05 \mathrm{~g} / \mathrm{NO}: \mathrm{CO} / \mathrm{He}=1: 2: 17 / 12000 \mathrm{~h}^{-1}$ & 400 & 100 & - & [426] \\
\hline $\mathrm{yCuO} / \mathrm{Ce}_{\mathrm{x}} \mathrm{Zr}_{1-\mathrm{x}} \mathrm{O}_{2}(y=0.3,0.6,0.9,1.2,1.5)$ & $0.05 \mathrm{~g} / \mathrm{NO}: \mathrm{CO} / \mathrm{He}=1: 2: 17 / 12000 \mathrm{~h}^{-1}$ & 400 & 100 & - & [429] \\
\hline$y \mathrm{Co}-0.5 \mathrm{Cu} / \mathrm{Ce}_{0.67} \mathrm{Zr}_{0.33} \mathrm{O}_{2}(y=0.08,0.16,0.32)$ & $0.05 \mathrm{~g} / \mathrm{NO}: \mathrm{CO} / \mathrm{He}=1: 2: 17 / 24000 \mathrm{~h}^{-1}$ & 400 & $100(y=0.08)$ & 90 & [428] \\
\hline $0.08 \mathrm{Mn}-0.5 \mathrm{Cu} / \mathrm{Ce}_{0.67} \mathrm{Zr}_{0.33} \mathrm{O}_{2}$ & $0.05 \mathrm{~g} / \mathrm{NO}: \mathrm{CO} / \mathrm{He}=1: 2: 17 / 24000 \mathrm{~h}^{-1}$ & 400 & 100 & 90 & [429] \\
\hline $0.5 \% \mathrm{M} / \mathrm{Ce}_{0.6} \mathrm{Zr}_{0.4} \mathrm{O}_{2}(\mathrm{M}=\mathrm{Rh}, \mathrm{Pt})$ & $0.04-0.008 \mathrm{~g} / \mathrm{NO}: \mathrm{CO} / \mathrm{He}=1: 3: 96 / 12000-50000 \mathrm{~h}^{-1}$ & 400 & $100(M=\mathrm{Pt})$ & - & [417] \\
\hline $1 \% \mathrm{Pt} / 15 \% \mathrm{WO}_{3}-\mathrm{Ce}_{0.65} \mathrm{Zr}_{0.35} \mathrm{O}_{2}$ & $0.5 \mathrm{~g} / \mathrm{NO}: \mathrm{CO} / \mathrm{He}=0.5: 0.5: 99 / 40000 \mathrm{~h}^{-1}$ & 400 & 90 & 73 & [418] \\
\hline$y \% \mathrm{Rh} / \mathrm{Ce}_{0.65} \mathrm{Zr}_{0.35} \mathrm{O}_{2}(y=0.05 \sim 1)$ & $0.5 \mathrm{~g} / \mathrm{NO}: \mathrm{CO} / \mathrm{O}_{2} / \mathrm{He}=0.1: 1: 0.45: 98.45 / 40000 \mathrm{~h}^{-1}$ & 400 & 100 & 100 & [424] \\
\hline $1 \% \mathrm{Pd} / \mathrm{Ce}_{0.5} \mathrm{Zr}_{0.5} \mathrm{O}_{2}$ & $3.4 \mathrm{~g} / \mathrm{NO}: \mathrm{CO} / \mathrm{O}_{2} / \mathrm{He}=1: 1: 0.45: 97.55 / 30000 \mathrm{~h}^{-1}$ & 400 & 18 & 100 & [421] \\
\hline $3 \% \mathrm{Pd} / \mathrm{Ce}_{0.6} \mathrm{Zr}_{0.4} \mathrm{O}_{2}$ & $0.05 \mathrm{~g} / \mathrm{NO}: \mathrm{CO} / \mathrm{O}_{2} / \mathrm{He}=0.023: 0.0685: 1: 98.908 / 70000 \mathrm{~h}^{-1}$ & 400 & 70 & 100 & [420] \\
\hline $1 \% \mathrm{PdNi} / \mathrm{Ce}_{0.5} \mathrm{Zr}_{0.5} \mathrm{O}_{2}$ & $\mathrm{NO}: \mathrm{CO} / \mathrm{O}_{2} / \mathrm{He}=0.1: 1: 0.45: 98.45 / 30000 \mathrm{~h}^{-1}$ & 400 & 30 & 100 & [423] \\
\hline $1 \% \mathrm{PdCr} / \mathrm{Ce}_{0.5} \mathrm{Zr}_{0.5} \mathrm{O}_{2} / \mathrm{Al}_{2} \mathrm{O}_{3}$ & $3.4 \mathrm{~g} / \mathrm{NO}: \mathrm{CO} / \mathrm{O}_{2} / \mathrm{He}=0.1: 1: 0.45: 98.45 / 30000 \mathrm{~h}^{-1}$ & 400 & 6 & 68 & [422] \\
\hline
\end{tabular}

\section{Table 8}

Catalytic Activity of nanosize CZO materials in simultaneous removal of $\mathrm{CO}$ and $\mathrm{NO}_{x}$.

$X_{\mathrm{NOx}}, X_{\mathrm{CO}}$ and $T$ are denoted as $\mathrm{NO}_{x}$ conversion, $\mathrm{CO}$ conversion and reaction temperature, respectively. 

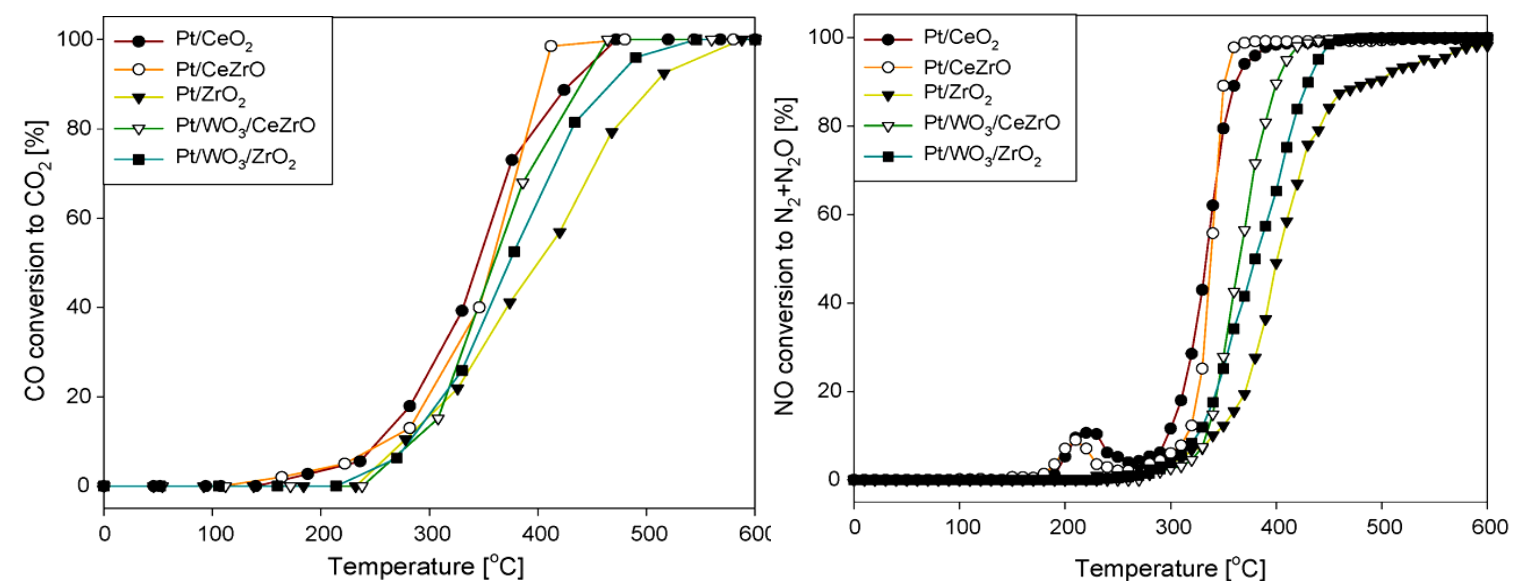

Fig. 23. Catalytic activities for the removal of NO + CO over various catalysts (CO: 0.5\%, NO: 0.5\%). Reprinted from [419] with permission.

between $\mathrm{Pd}$ and $\mathrm{Cr}$ existed in the calcination state, and the mixed oxide phase containing $\mathrm{Pd}^{+}$and $\mathrm{Cr}^{3+}$ appeared to be the main factor leading to the enhancement in $\mathrm{CO}$ oxidation and the decrease in NO reduction compared with the monometallic system. In the case of the $\mathrm{CZO} / \mathrm{Al}_{2} \mathrm{O}_{3}$ mixed support, the introduction of $\mathrm{Cr}$ was less influential for catalytic activity. The effect of $\mathrm{Ni}$ on the catalytic activity of $\mathrm{Pd}-\mathrm{Ni} / \mathrm{CZO} / \mathrm{Al}_{2} \mathrm{O}_{3}$ catalysts for stoichiometric $\mathrm{CO}$ and NO elimination was investigated by Martínez-Arias et al. [423]. A significant dependence on the support nature in terms of catalytic changes was produced by $\mathrm{Ni}$. The introduction of $\mathrm{Ni}$ considerably promoted the $\mathrm{CO}$ oxidation activity over the $\mathrm{CZO} / \mathrm{Al}_{2} \mathrm{O}_{3}$-supported catalyst. This was due to the changes of Pd distribution over the support, which favored the formation of active Pd-CZO interfaces. The significant extent of such a promoting effect revealed an important role of the particle size of CZO component on such catalytic processes.

\subsubsection{Rh-based ceria-zirconium catalysts}

Compared with Pt- and Pd-based CZO catalysts, Rh-based CZO catalysts get relatively less attention. In 2009, Ihm et al. [424] prepared CZO by supercritical synthesis and CP methods as support for a Rh catalyst. The catalytic activities of the catalysts were investigated for $\mathrm{NO}+\mathrm{CO}$ reaction. $\mathrm{Rh} / \mathrm{CZO}$ prepared by a supercritical synthesis method exhibited better reducibility and higher thermal stability as well as better performance for the catalytic reduction of NO by CO than that prepared by a CP method. CZO prepared by the supercritical synthesis method showed more potential applications as catalyst support due to its sparsely-agglomerated morphology and higher thermal stability.

\subsubsection{Cu-based ceria-zirconium catalysts}

In addition to CZO-supported noble metals (Pt, Pd, Rh) catalysts, considerable efforts have been devoted to developing promising Cu-based catalysts for $\mathrm{NO}+\mathrm{CO}$ reaction. Zhang et al. [425] investigated the catalytic activity of $4 \% \mathrm{Cu} / \mathrm{Ce}_{x} \mathrm{Zr}_{1-x} \mathrm{O}_{2}(x$ $=0-1.0$ ) catalysts for the reduction of NO by CO. The incorporation of $\mathrm{Zr}^{4+}$ into $\mathrm{CeO}_{2}$ could stabilize $\mathrm{Cu}^{+}$species, which was favorable for the initial reductive chemisorption of NO to $\mathrm{N}_{2} \mathrm{O}$. $\mathrm{Cu} / \mathrm{Ce}_{0.75} \mathrm{Zr}_{0.25} \mathrm{O}_{2}$ showed an excellent low temperature activity with $40 \% \mathrm{~N}_{2}$ yield at $150{ }^{\circ} \mathrm{C}$ due to its abundant surface reactive oxygen sites and high reducibility, and $\mathrm{N}_{2}$ yield $>85 \%$ was obtained for all $\mathrm{Zr}$-containing catalysts at $250{ }^{\circ} \mathrm{C}$ and above. Gao et al. [426] studied the effects of $\mathrm{Ce} / \mathrm{Zr}$ molar ratios on the physicochemical properties of $\mathrm{CuO} / \mathrm{Ce}_{x} \mathrm{Zr}_{1-x} \mathrm{O}_{2} / \gamma-\mathrm{Al}_{2} \mathrm{O}_{3}$ catalysts for $\mathrm{NO}+\mathrm{CO}$ reaction. The ceria-rich catalyst showed higher activity and TOF value towards NO reduction compared with the pure ceria and zirconia-rich ones due to the difference in the interaction among $\mathrm{Cu}, \mathrm{Ce}_{x} \mathrm{Zr}_{1-\mathrm{x}} \mathrm{O}_{2}$, and $\gamma-\mathrm{Al}_{2} \mathrm{O}_{3}$ support. Dong et al. [427] prepared a series of $\mathrm{CuO} / \mathrm{Ce}_{x} \mathrm{Zr}_{1-x} \mathrm{O}_{2}$ catalysts with different $\mathrm{Cu}$ loading amounts and $\mathrm{Ce} / \mathrm{Zr}$ molar ratios and studied the correlation of structural characteristics with catalytic performance for NO reduction by CO. The ceria-rich (pseudocubic $t^{\prime}$ ) phase could disperse and stabilize the copper species more effectively and resulted in stronger interaction with copper than the zirconia-rich $(t)$ phase. Furthermore, compared with the zirconia-rich phase, the synergistic interaction of $\mathrm{Cu}$ with ceria-rich phase easily promoted the reduction of copper species and surface oxygen as well as the activation of adsorbed NO species. Therefore, the $\mathrm{CuO} / \mathrm{Ce}_{0.8} \mathrm{Zr}_{0.2} \mathrm{O}_{2}$ catalyst exhibited the higher activity for NO reduction than $\mathrm{CuO} / \mathrm{Ce}_{0.5} \mathrm{Zr}_{0.5} \mathrm{O}_{2}$ and the $\mathrm{CuO} / \mathrm{Ce}_{0.2} \mathrm{Zr}_{0.8} \mathrm{O}_{2}$ catalysts.

Compared with CZO-supported mono-metal catalysts, binary metal oxides possess more active species, which may be more favorable for the catalytic reaction of $\mathrm{NO}+\mathrm{CO}$. Dong and co-workers [428] investigated the activity of binary metal oxides $\mathrm{Ce}_{0.67} \mathrm{Zr}_{0.33} \mathrm{O}_{2}$ supported $\mathrm{CuO}-\mathrm{CoO}_{m}$ catalysts for the removal of NO and CO. The addition of cobalt species significantly improved the activity of $\mathrm{NO}+\mathrm{CO}$ by promoting the reduction of dispersed copper oxide. FT-IR results further revealed that the addition of cobalt oxide changed the adsorption type of $\mathrm{NO}$ and $\mathrm{CO}$ on the catalysts, and oxidized $\mathrm{NO}$ dimers into ionic $\mathrm{NO}_{3}^{-}$, and then these partial surface active species might be reduced into low-valence state above $300{ }^{\circ} \mathrm{C}$. Subsequently, they investigated the effect of $\mathrm{MnO}_{m}$ modification on the activity of the $\mathrm{CuO} / \mathrm{Ce}_{0.67} \mathrm{Zr}_{0.33} \mathrm{O}_{2}$ catalyst for NO reduction by $\mathrm{CO}$ [429]. The introduction of $\mathrm{Cu}$ and $\mathrm{Mn}$ species induced the expansion of lattice and the decrease of microstrain of CZO, thereby promoting the formation of oxygen vacancies. The addition of $\mathrm{Mn}$ species could promote the reduction of the catalysts and assist 
copper oxide in changing the valence and supplying oxygen. These reduction behavior was dependent on the loading amounts of $\mathrm{MnO}_{m}$ and the impregnation procedure. In addition, the introduction of $\mathrm{MnO}_{m}$ could not change the adsorption type of NO, but readily facilitated the activation of the adsorbed NO species. As a result, these factors were responsible for the enhancement of activity and selectivity through $\mathrm{MnO}_{m}$ modification.

\subsubsection{Mechanisms of simultaneous removal CO and NO reaction} over nanosize ceria-zirconium-based solid solutions

There are two mechanisms related to simultaneous removal CO and NO, the redox mechanism and the organonitrogen mechanism. The redox mechanism involves an initial dissociation-chemisorption of $\mathrm{NO}$, which forms a $\mathrm{N}_{2} \mathrm{O}$ intermediate and an oxidized surface, and then $\mathrm{CO}$ further reduces $\mathrm{N}_{2} \mathrm{O}$ into $\mathrm{N}_{2}$ and restores the original catalytic surface $[237,430]$. By contrast, the organonitrogen mechanism includes the generation of isocyanate compounds as an intermediate [431,432]. In the catalytic reduction of $\mathrm{NO}_{x}$, the two reaction mechanisms may occur simultaneously, and the contribution of each mechanism may depend on the reductant type, catalyst nature, and reaction conditions (temperature, space velocity, concentration, etc.) $[433,434]$. Zhang and Kaliaguine et al. [430] proposed that $\mathrm{CO}+\mathrm{NO}$ reaction mechanism on $\mathrm{Cu} / \mathrm{CZO}$ involved the dissociation and reduction of chemisorbed $\mathrm{NO}_{x}$.

At the $50-250^{\circ} \mathrm{C}$ low-temperature region:

$$
\mathrm{Cu}^{+}+\mathrm{NO} \rightarrow \mathrm{Cu}^{2+} \mathrm{NO}^{-}
$$$$
\mathrm{Cu}^{2+} \mathrm{NO}^{-}+\mathrm{Ce}^{4+}-\mathrm{O} \leftrightarrow \mathrm{Cu}^{2+}-\mathrm{NO}_{2}^{-} \text {(nitrite) }+\mathrm{Ce}^{3+}
$$$$
\mathrm{Cu}^{2+} \mathrm{NO}_{2}^{-}+\mathrm{Ce}^{4+}-\mathrm{O} \leftrightarrow \mathrm{Cu}^{2+}-\mathrm{NO}_{3}^{-} \text {(nitrate) }+\mathrm{Ce}^{3+}
$$$$
2 \mathrm{Cu}^{2+} \mathrm{NO}^{-}+\mathrm{Ce}^{3+} \leftrightarrow \mathrm{Cu}^{2+} \ldots \mathrm{NO}^{-} \ldots \mathrm{Cu}^{2+}+\mathrm{Ce}^{3+} \rightarrow
$$$$
\mathrm{Cu}^{2+} \mathrm{N}_{2} \mathrm{O}^{2-} \mathrm{Cu}^{2+}+\mathrm{Ce}^{4+}-\mathrm{O} \rightarrow 2 \mathrm{Cu}^{+}+\mathrm{N}_{2} \mathrm{O}+\mathrm{Ce}^{4+}-\mathrm{O}^{-}
$$$$
\mathrm{Cu}^{2+} \mathrm{N}_{2} \mathrm{O}^{2-} \mathrm{Cu}^{2+}+\mathrm{Ce}^{3+}-\mathrm{O} \rightarrow 2 \mathrm{Cu}^{+}+\mathrm{N}_{2}+\mathrm{Ce}^{4+}-\mathrm{O}^{-}
$$

At the high-temperature range above $250{ }^{\circ} \mathrm{C}$ :

$$
\begin{gathered}
\mathrm{Cu}^{+} \mathrm{NO}+\mathrm{CO}+\mathrm{Ce}^{3+} \rightarrow \mathrm{Cu}^{+} \mathrm{NCO}+\mathrm{Ce}^{4+} \mathrm{O}^{-} \\
\mathrm{Cu}^{+} \mathrm{NCO}+\mathrm{Cu}^{+}-\mathrm{NO} \rightarrow 2 \mathrm{Cu}^{+}+\mathrm{N}_{2}+\mathrm{CO}_{2} \\
\mathrm{Cu}^{+} \mathrm{NCO}+\mathrm{Ce}^{4+} \mathrm{O}^{-} \rightarrow \mathrm{Cu}^{+}+\mathrm{Ce}^{3+}+1 / 2 \mathrm{~N}_{2}+\mathrm{CO}_{2}
\end{gathered}
$$

Oxidation of intermediate carbonaceous species:

$$
\begin{gathered}
\mathrm{Ce}^{4+}-\mathrm{O}^{-}+\mathrm{CO} \rightarrow \mathrm{Ce}^{4+}-\mathrm{COO}^{-} \rightarrow \mathrm{CO}_{2}+\mathrm{Ce}^{3+} \\
\mathrm{Ce}^{4+}-\mathrm{O}^{-}+\mathrm{CO}_{2} \rightarrow \mathrm{Ce}^{3+}+\text { carbonate }
\end{gathered}
$$

Sun and Dong et al. [428] reported a possible reaction mechanism over $\mathrm{CuCo} / \mathrm{CZO}$ catalysts for $\mathrm{NO}+\mathrm{CO}$ reaction:

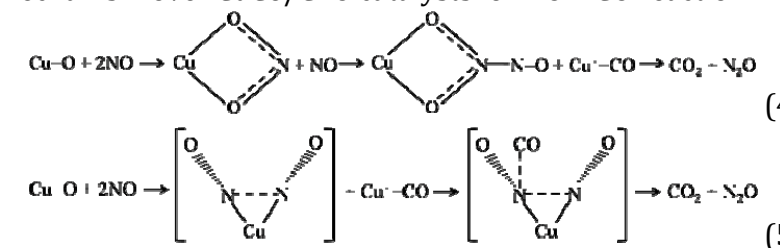

$\mathrm{Cu}^{+}+\mathrm{N}_{2} \mathrm{O} \rightarrow \mathrm{Cu}^{2+}-\mathrm{N}_{2} \mathrm{O}^{-} \rightarrow \mathrm{N}_{2}+\mathrm{Cu}^{2+} \mathrm{O}^{-} \stackrel{\mathrm{Cu}^{+}-\mathrm{CO}}{\longrightarrow} \mathrm{Cu}^{+}+\mathrm{CO}_{2}$

$\mathrm{Co}^{2+}+\mathrm{N}_{2} \mathrm{O} \rightarrow \mathrm{Co}^{3+}-\mathrm{N}_{2} \mathrm{O}^{-} \rightarrow \mathrm{N}_{2}+\mathrm{Co}^{3+} \mathrm{O}^{-} \rightarrow \mathrm{Co}^{2+}+\mathrm{O}_{2} \stackrel{\mathrm{CO}}{\longrightarrow} \mathrm{CO}_{2}$

NO was assumed to preferentially adsorb over dispersed copper oxide or oxygen vacancy sites of CZO to form chelating nitrite and cis- $\mathrm{N}_{2} \mathrm{O}_{2}{ }^{2-}$ below $300{ }^{\circ} \mathrm{C}$ (Eqs. (49) and (50)). These adsorbed $\mathrm{NO}_{x}$ species reacted with $\mathrm{CO}$ activated by $\mathrm{Cu}^{+}$species, and then $\mathrm{N}_{2} \mathrm{O}$ and $\mathrm{CO}_{2}$ were produced. When the temperature was over $300{ }^{\circ} \mathrm{C}$, the catalyst could be reduced by $\mathrm{CO}$ to $\mathrm{Cu}^{+}$and $\mathrm{Co}^{2+}$ ions. The catalytic reduction of $\mathrm{NO}$ to $\mathrm{N}_{2}$ was generated by CO. The main $\mathrm{Cu}^{+}$species contributed to $\mathrm{N}_{2} \mathrm{O}$ reduction by $\mathrm{CO}$, while the dispersed cobalt oxides played an important role in $\mathrm{N}_{2} \mathrm{O}$ decomposition and reduction by $\mathrm{CO}$, as shown in Eqs. (51) and (52).

\subsection{Nanosize cerium-zirconium-based solid solutions for simultaneous removal of $\mathrm{NO}_{x}$ and soot}

The simultaneous removal of $\mathrm{NO}_{x}$ and soot using one catalytic material was proposed for the first time by Yoshida et al. [435], which seems to be one of the most effective and economic after-treatment techniques. The key challenge is to find a catalyst that can achieve a high rate of soot oxidation in combination with substantial $\mathrm{NO}_{x}$ reduction at sufficiently low temperature. Several kinds of catalysts such as precious metals [436-439], transition metal oxides [440], alkaline metal oxides [441], perovskite-like type oxides [442-446], and ceria-based oxides $[285,447,448]$ have shown good catalytic activities for simultaneous removal of $\mathrm{NO}_{x}$ and soot. Especially, CZO is one of the key components owing to its excellent OSC property and robust stability [156,214].

\subsubsection{Effect of preparation conditions}

The key features of CZO that exhibited the catalytic performance of the simultaneous removal of $\mathrm{NO}_{x}$ and soot were investigated by Bueno-Lopez et al. [449]. The catalytic activity of the catalyst for soot combustion was dependent on both specific surface area and Ce/Zr molar ratio, which closely depended on the preparation procedures, but $\mathrm{NO}_{x}$ conversion was very low. The surface distribution of cations was associated with the homogeneity of CZO according to the different synthesis procedure. The specific surface area of CZO was usually lower than $90 \mathrm{~m}^{2} / \mathrm{g}$. Nevertheless, constant $T_{50}$ could be obtained for the catalysts with specific surface areas above this value, i.e., there was a minimum temperature that could be lowered by increasing the surface area of the catalyst (Fig. 24).

The effect of the cerium precursor salt on the catalytic activity of CZO for the removal of $\mathrm{NO}_{x}$ and soot was reported by García-García et al. [450]. CZO prepared with $\left(\mathrm{NH}_{4}\right)_{2} \mathrm{Ce}\left(\mathrm{NO}_{3}\right)_{6}$ showed higher catalytic activity than the counterpart catalysts prepared with a $\mathrm{Ce}\left(\mathrm{NO}_{3}\right)_{3} \cdot 6 \mathrm{H}_{2} \mathrm{O}$ precursor, and ceria-rich catalysts with ceria-rich exhibited better catalytic performance than the corresponding zirconia-rich ones.

\subsubsection{Effect of rare earth doping}

The property of CZO can be adjusted by dopants, and thus their catalytic activity for the elimination of $\mathrm{NO}_{x}$ and soot is enhanced. Dulgheru et al. [451] studied the effects of rare earth (La, Nd, Pr)-modified CZO for catalytic removal of $\mathrm{NO}_{x}$ and soot. The rare earth dopants increased the activity of CZO. Especially, the doping of La and $\operatorname{Pr}$ significantly enhanced the low-temperature activity due to the increased formation of $\mathrm{NO}_{2}$. Whereas, the effect was less pronounced for a $\mathrm{Nd}$-doped sample. Bueno-López et al. [452] investigated the effect of $\mathrm{Nd}$ 


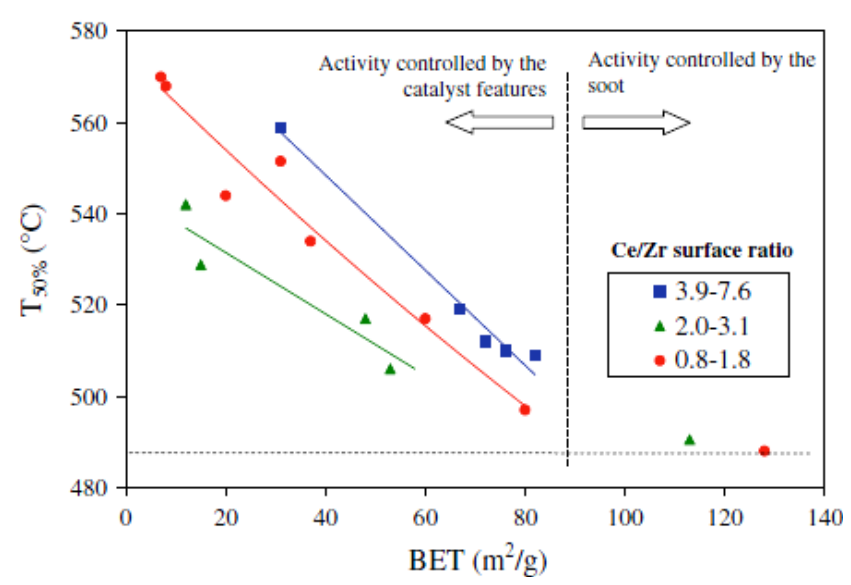

Fig. 24. $T_{50}$ versus BET surface area of the catalysts for the removal of $\mathrm{NO}_{x}$ and soot. Reprinted from [449] with permission.

doping on the physicochemical properties and catalytic activity for the elimination of $\mathrm{NO}_{x}$ and soot over CZO. Four oxides including $\mathrm{CeO}_{2}$, $\mathrm{Ce}_{0.9} \mathrm{Ndd}_{0.1} \mathrm{O}_{2}, \mathrm{Ce}_{0.73} \mathrm{Zr}_{0.27} \mathrm{O}_{2}$, and $\mathrm{Ce}_{0.64} \mathrm{Zr}_{0.27} \mathrm{Nd}_{0.09} \mathrm{O}_{2}$ were prepared by a $\mathrm{CP}$ method. $\mathrm{Ce}_{0.64} \mathrm{Zr}_{0.27} \mathrm{Nd}_{0.09} \mathrm{O}_{2}$ showed the best catalytic activity due to the improved thermal stability and redox properties. Moreover, it was confirmed that the higher activity of $\mathrm{Ce}_{0.64} \mathrm{Zr}_{0.27} \mathrm{Nd}_{0.09} \mathrm{O}_{2}$ was closely related to the formation of less stable surface nitrates and nitrites species. Thus, it provided alternative and faster $\mathrm{NO}_{2}$ production pathways.

\subsubsection{Effect of transitional metal doping}

It is generally accepted that reaction pathways for the combustion of soot over CZO-supported active metal catalysts can be divided into two sections according to different temperatures. At low temperatures, soot is directly oxidized by active oxygen species that are migrated from the surface of CZO-supported catalysts. At high temperatures, both $\mathrm{NO}_{2}$ and active oxygen species promote soot oxidation, and especially $\mathrm{NO}_{2}$ as an intermediate reactant plays a dominant role. In this process, $\mathrm{NO}_{2}$ serving as the oxidizer is reduced, and soot acting as the reducer is oxidized. Thus, the simultaneous removal of soot and $\mathrm{NO}_{x}$ is realized. However, it is noted that only a part of
NO can be oxidized to $\mathrm{NO}_{2}$ by the catalyst owing to the thermal equilibrium compositions. Therefore, most of NO is not reduced and directly emitted to atmosphere, which can result in great harmful to human health. Thus, an additional reductant needs to be added into this reaction process. Based on this consideration, Cheng et al. [181,182,184] prepared a Fe-doped 3DOM CZO material that could simultaneously remove soot and $\mathrm{NO}_{x}$ from diesel engine exhausts. Ammonia was used as a reductant for $\mathrm{NO}_{x}$ removal. 3DOM Ce-Zr-based mixed oxides were synthesized by a carbon-template method and varied Fe content in the mixed oxide. Those materials showed high efficiency in simultaneous removal of $\mathrm{NO}_{x}$ and soot in intermediate temperatures $\left(285-420{ }^{\circ} \mathrm{C}\right.$ with $100 \% \mathrm{NO}_{x}$ conversion), which essentially meets the demand of diesel engine exhaust emissions. Moreover, the addition of Fe to Ce-Zr lowered the temperature of soot combustion to a level that was typically achieved by more expensive Pt catalysts (Fig. 25). The importance of the open 3DOM texture in soot capture and combustion was demonstrated by comparison to a mesopore or particle mixed oxide of the same composition. Furthermore, DFT calculation was used to understand the surface reducibility of the mixed oxides and gain insight into the role of $\mathrm{Fe}$ and surface oxygen vacancies in the reaction mechanism of $\mathrm{NO}_{x}$ reduction and soot oxidation. It showed that substitution of Fe in CZO increased the number of oxygen vacancies (Fig. 26), thereby enhancing the catalytic performance of simultaneous removal of $\mathrm{NO}_{x}$ and soot. Ce/Zr ratios affected the catalytic activity [181]. A 3DOM $\mathrm{Ce}_{0.85} \mathrm{Fe}_{0.1} \mathrm{Zr}_{0.05} \mathrm{O}_{2}$ sample exhibited the optimal catalytic activity with a maximum concentration of $\mathrm{CO}_{2}$ at $415^{\circ} \mathrm{C}$ and nearly a $100 \%$ NO conversion in the range of $365-503^{\circ} \mathrm{C}$. In addition, 3DOM Ce ${ }_{0.8} \mathrm{M}_{0.1} \mathrm{Zr}_{0.1} \mathrm{O}_{2}$ ( $\mathrm{M}=\mathrm{Mn}, \mathrm{Co}, \mathrm{Ni}$ ) catalysts were also prepared, and the $3 \mathrm{DOM} \mathrm{Ce}_{0.8} \mathrm{Mn}_{0.1} \mathrm{Zr}_{0.1} \mathrm{O}_{2}$ catalyst displayed the maximum concentration of $\mathrm{CO}_{2}$ at $402{ }^{\circ} \mathrm{C}$ for soot combustion and excellent $\mathrm{NH}_{3}$-SCR performance at $374-512{ }^{\circ} \mathrm{C}$ [183]. The specific 3DOM architecture, high $\mathrm{Ce}^{3+} / \mathrm{Ce}^{4+}$ ratio and amount of chemisorbed oxygen species, good low-temperature reductive property, and the abundant of acid sites should be responsible for the excellent catalytic efficiency of $\mathrm{Ce}_{0.8} \mathrm{M}_{0.1} \mathrm{Zr}_{0.1} \mathrm{O}_{2}(\mathrm{M}=\mathrm{Fe}$, $\mathrm{Mn}, \mathrm{Co}, \mathrm{Ni}$ ) for the simultaneous elimination of $\mathrm{NO}_{x}$ and soot.
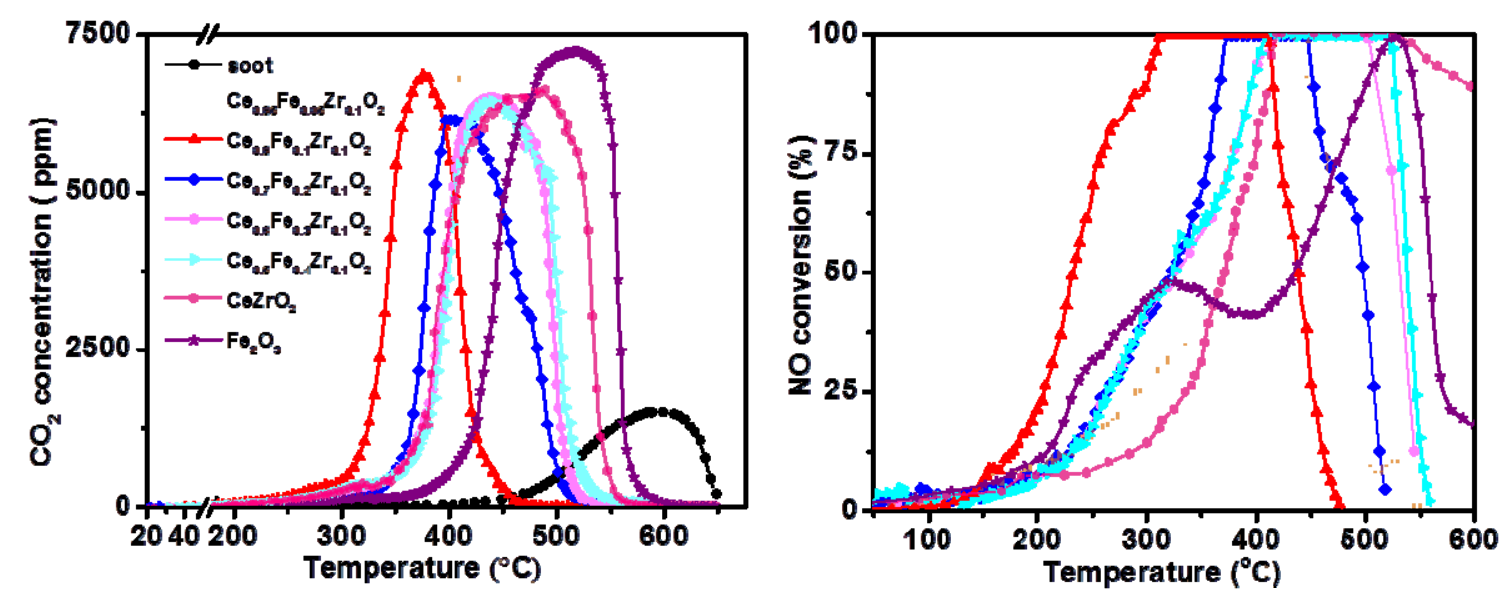

Fig. 25. $\mathrm{CO}_{2}$ concentration (left) and $\mathrm{NO}$ conversion (right) as a function of temperature upon exposure of $3 \mathrm{DOM}^{\mathrm{C}} \mathrm{Ce}_{0.9-\mathrm{x}} \mathrm{Fe}_{\mathrm{x}} \mathrm{Zr}_{0.1} \mathrm{O}_{2}$ catalysts loosely mixed with model soot. Reaction conditions: 1000 ppm of $\mathrm{NH}_{3}, 1000 \mathrm{ppm}$ of NO, $3 \% \mathrm{O}_{2}$ and balance $\mathrm{N}_{2}$, GHSV = 25000 h-1. Reprinted from [182] with permission. 

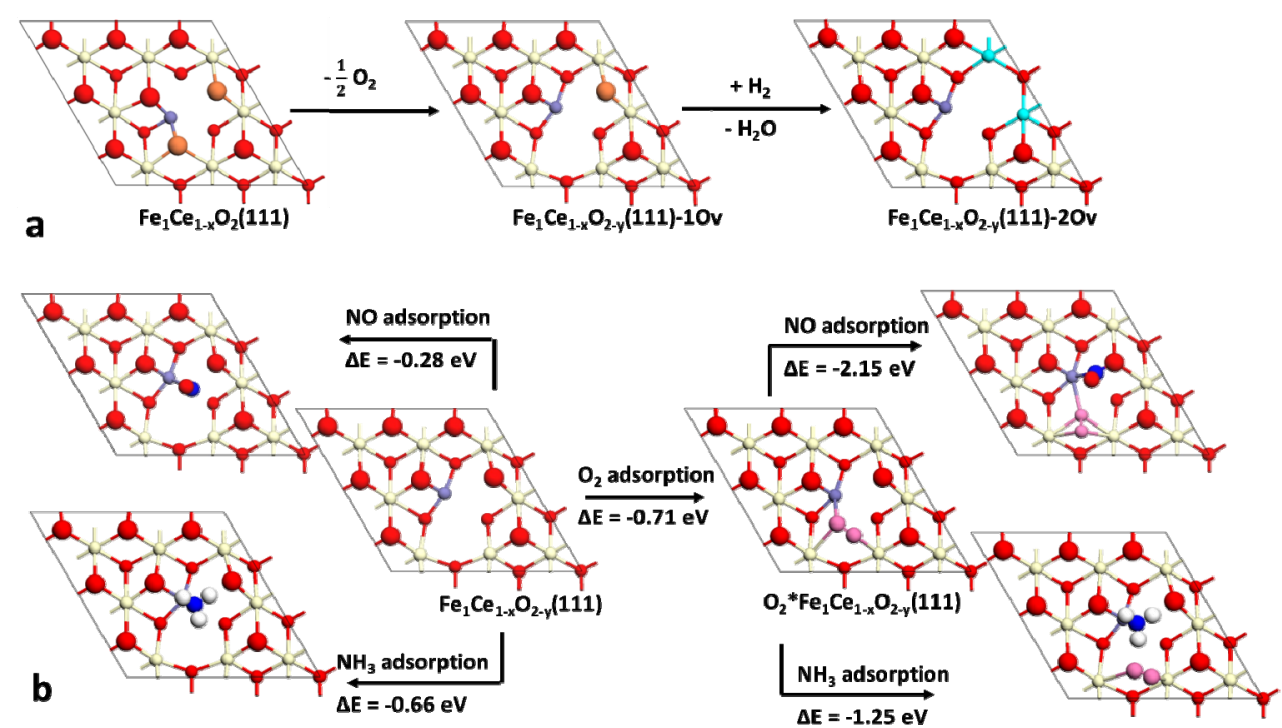

Fig. 26. (a) Structure of Fe-doped $\mathrm{CeO}_{2}(111)$ as the stoichiometric surface and with one and two oxygen vacancies; (b) Adsorption of $\mathrm{NH}_{3}$ and $\mathrm{NO}$ on Fe-doped $\mathrm{CeO}_{2}(111)$ with one oxygen vacancy $\left(\mathrm{Fe}_{1} \mathrm{Ce}_{1-\mathrm{x}} \mathrm{O}_{2-\mathrm{y}}(111)\right.$ ); Fe-doped $\mathrm{CeO}_{2}(111)$ with the oxygen vacancy preadsorbed by $\mathrm{O}_{2}$ $\left(\mathrm{O}_{2}{ }^{*} \mathrm{Fe}_{1} \mathrm{Ce}_{1-\mathrm{x}} \mathrm{O}_{2-\mathrm{y}}(111)\right)$. Color scheme: white, $\mathrm{Ce}^{4+}$; green, $\mathrm{Ce}^{3+}$; red, $\mathrm{O}$; orange, $\mathrm{O}$ to be removed; purple, $\mathrm{Fe}$; blue, $\mathrm{N}$; bright white, $\mathrm{H}$. Reprinted from [182] with permission.

\subsection{Three-way catalytic removal for the exhausts from gasoline engines}

Nowadays, three-way catalysts consisted of noble metals (Pt, Rh, Pd), sub-catalysts $\left(\mathrm{CeO}_{2}, \mathrm{CeO}_{2}-\mathrm{ZrO}_{2}\right.$, etc.), and monolithic ceramic supports (alumina, $2 \mathrm{MgO} \cdot 2 \mathrm{Al}_{2} \mathrm{O}_{3} \cdot 5 \mathrm{SiO}_{2}$, etc.) comprise the state-of-the-art gas after-treatment technology, which are installed in gasoline-powered vehicle emission control systems for simultaneous conversion of $\mathrm{CO}, \mathrm{NO}_{x}$ and unburnt HC [453]. Improving performance of catalysts for vehicle exhaust is the key issue to meet the increasing standard of emission regulations. Many research groups have pioneeringly and deeply studied the properties of CZO and its important role in three-way catalysis [454-459]. It has been found that the preparation process [460-462] and material composition [463-466] can significantly influence the concentration of active $\mathrm{Ce}^{4+}$ species and structural properties in the solid solution, as shown in Table 9.

\subsubsection{Effect of preparation conditions}

Zhou et al. [467] investigated the effect of synthesis conditions ( $\mathrm{pH}$ values of the solution of metal precursors and aging temperature) on properties of $\mathrm{Ce}_{0.67} \mathrm{Zr}_{0.33} \mathrm{O}_{2}$ prepared by a $\mathrm{CP}$ method and its application in Pd-based TWCs. The crystallite size of CZO increased significantly with increasing aging temperature during precipitation, while OSC dropped and no notable effect on porosity of CZO was observed. Moreover, the structural properties of CZO were affected by the $\mathrm{pH}$ value during precipitation. Pd-based TWCs supported on this CZO support showed the best catalytic activity. Chen et al. [468] investigated the effect of synthesis methods (CP, mechanical mixing, and modified $\mathrm{CP}$ method) on the structural properties and catalytic performance of $\mathrm{Pd} / \mathrm{Ce}_{0.5} \mathrm{Zr}_{0.5} \mathrm{O}_{2}-\mathrm{Al}_{2} \mathrm{O}_{3}$ TWCs. The different preparation methods gave rise to the different inter- actions between $\mathrm{CZO}$ and $\mathrm{Al}_{2} \mathrm{O}_{3}$, thereby leading to various atom rearrangements during the aging process. The catalyst prepared by the modified CP method maintained superior textural and structural properties as well as reductive behavior after being aged, which exhibited high catalytic performance with $10 \%$ conversion temperatures of $\mathrm{C}_{3} \mathrm{H}_{8}, \mathrm{CO}$, and $\mathrm{NO}$ of 327 , 164 , and $208{ }^{\circ} \mathrm{C}$, respectively. These were obviously lower than that of the catalysts synthesized by the conventional CP method and mechanical mixing route. Hu et al. [7] synthesized nanosize CZY using a hydrothermal method. TWCs-containing CZY displayed a higher catalytic activity. Zhang et al. [469] prepared $\mathrm{Ce}_{1-\mathrm{x}} \mathrm{Zr}_{x} \mathrm{O}_{2}(x=0-0.8)$ nanoparticle powders by a mild urea hydrolysis hydrothermal method. $\mathrm{Ce}_{1-x} \mathrm{Zr}_{x} \mathrm{O}_{2}(x=0.4-0.6)$ powders preferred a metastable $t^{\prime \prime}$ phase to $t^{\prime}$ phase due to small crystallite size effect. The stabilization of pseudocubic $t^{\prime \prime}$ structure led to the high strain level in $\mathrm{Ce}_{1-\mathrm{x}} \mathrm{Zr}_{\mathrm{x}} \mathrm{O}_{2}(x=0.4-0.6)$ crystal lattice. Moreover, a linear relationship between the lattice strain and OSC value of the $\mathrm{CeO}_{2}-\mathrm{ZrO}_{2}$ catalyst was observed, and this correlation could be used as a tool to evaluate its OSC and help to fabricate new $\mathrm{CeO}_{2}-\mathrm{ZrO}_{2}$ catalysts with higher OSC and better redox performance. Zhou and co-workers [470] reported the effect of mechanical mixing and CP methods on the redox behavior and catalytic performance of the three-way CZA catalysts. CZA prepared by the CP method exhibited better thermal stability than that prepared by mechanical mixing due to the presence of stronger interaction between $\mathrm{CZO}$ and $\mathrm{Al}_{2} \mathrm{O}_{3}$, which was helpful for maintaining large surface area and small particle size and inhibiting the formation of $\alpha$-alumina phase under the high-temperature condition. Moreover, it could also improve the thermal stability of Pd/CZA catalysts. They further studied the preparation methods (CP, homogeneous precipitation, ME and hydrothermal method) on the catalytic performance of $\mathrm{Ce}_{0.67} \mathrm{Zr}_{0.33} \mathrm{O}_{2}$-supported Pd TWCs [471]. The preparation methods significantly influenced the physicochemical properties of $\mathrm{Ce}_{0.67} \mathrm{Zr}_{0.33} \mathrm{O}_{2}$ mixed oxides. The catalyst prepared 
Table 9

Catalytic activities of nanosize CZO materials in three-way catalytic removal.

\begin{tabular}{|c|c|c|c|c|c|c|}
\hline \multirow{2}{*}{ Three-way catalyst } & \multirow{2}{*}{ Reaction conditions } & \multicolumn{4}{|c|}{$T_{50}\left({ }^{\circ} \mathrm{C}\right)$} & \multirow{2}{*}{ Ref. } \\
\hline & & $\mathrm{HC}$ & $\mathrm{CO}$ & NO & $\mathrm{NO}_{2}$ & \\
\hline $\mathrm{Ce}_{0.68} \mathrm{Zr}_{0.27} \mathrm{Nd}_{0.05} \mathrm{O}_{2}$ & $\mathrm{NO} / \mathrm{C}_{3} \mathrm{H}_{6} / \mathrm{C}_{6} \mathrm{H}_{6} / \mathrm{CO} / \mathrm{O}_{2} / \mathrm{CO}_{2} / \mathrm{H}_{2} \mathrm{O} / \mathrm{GHSV}=0.1: 0.012: 0.018: 0.03: 5: 3 / 2 / 42000 \mathrm{~h}^{-1}$ & 520 & - & - & - & [492] \\
\hline $\mathrm{Pd} / \mathrm{Ce}_{0.2} \mathrm{Zr}_{0.8} \mathrm{O}_{2}$ & $\mathrm{NO} / \mathrm{NO}_{2} / \mathrm{C}_{3} \mathrm{H}_{6} / \mathrm{C}_{3} \mathrm{H}_{8} / \mathrm{CO} / \mathrm{O}_{2} / \mathrm{GHSV}=1: 0.3: 0.67: 0.33: 7.5: 7.45 / 43000 \mathrm{~h}^{-1}$ & 230 & 160 & 232 & 180 & [489] \\
\hline $\mathrm{Pd} / 5 \% \mathrm{La}-\mathrm{Ce}_{0.2} \mathrm{Zr}_{0.8} \mathrm{O}_{2}$ & $\mathrm{NO} / \mathrm{NO}_{2} / \mathrm{C}_{3} \mathrm{H}_{6} / \mathrm{C}_{3} \mathrm{H}_{8} / \mathrm{CO} / \mathrm{O}_{2} / \mathrm{GHSV}=1: 0.3: 0.67: 0.33: 7.5: 7.45 / 43000 \mathrm{~h}^{-1}$ & 215 & 181 & 213 & 187 & [485] \\
\hline $\mathrm{Pt} / \mathrm{La}_{0.1} \mathrm{Ce}_{0.4} \mathrm{Zr}_{0.5} \mathrm{O}_{1.9}-\mathrm{Al}_{2} \mathrm{O}_{3}$ & $\mathrm{NO} / \mathrm{C}_{3} \mathrm{H}_{6} / \mathrm{CO} / \mathrm{O}_{2} / \mathrm{GHSV}=1: 1.067: 7: 7.8 / 50,500 \mathrm{~h}^{-1}$ & 350 & 333 & 370 & - & [487] \\
\hline $\mathrm{Pt}-\mathrm{Rh} / \mathrm{Y}_{0.075} \mathrm{La}_{0.075} \mathrm{Ce}_{0.35} \mathrm{Zr}_{0.50} \mathrm{O}_{2}-\mathrm{Al}_{2} \mathrm{O}_{3}$ & $\mathrm{NO} / \mathrm{C}_{3} \mathrm{H}_{8} / \mathrm{CO} / \mathrm{O}_{2} / \mathrm{CO}_{2} / \mathrm{H}_{2} \mathrm{O} / \mathrm{GHSV}=0.1: 0.05: 0.72: 6.21: 10: 8.33 / 34000 \mathrm{~h}^{-1}$ & 222 & 170 & 189 & - & [488] \\
\hline $\mathrm{Pd} / 10 \% \operatorname{Pr}-\mathrm{Ce}_{0.2} \mathrm{Zr}_{0.8} \mathrm{O}_{2}$ & $\mathrm{NO} / \mathrm{NO}_{2} / \mathrm{C}_{3} \mathrm{H}_{6} / \mathrm{C}_{3} \mathrm{H}_{8} / \mathrm{CO} / \mathrm{O}_{2} / \mathrm{GHSV}=1: 0.3: 0.67: 0.33: 7.5: 7.45 / 43000 \mathrm{~h}^{-1}$ & 200 & 148 & 173 & 156 & [489] \\
\hline $\mathrm{Pd} / 8 \% \mathrm{Pr}-\mathrm{Ce}_{0.33} \mathrm{Zr}_{0.67} \mathrm{O}_{2}$ & $\mathrm{NO} / \mathrm{NO}_{2} / \mathrm{C}_{3} \mathrm{H}_{6} / \mathrm{C}_{3} \mathrm{H}_{8} / \mathrm{CO} / \mathrm{O}_{2} / \mathrm{GHSV}=1: 0.25: 0.55: 0.275: 5: 6.21 / 43000 \mathrm{~h}^{-1}$ & 250 & 209 & 261 & 212 & [490] \\
\hline $\mathrm{Pd} / 5 \% \operatorname{Pr}-\mathrm{Ce}_{0.2} \mathrm{Zr}_{0.8} \mathrm{O}_{2}$ & $\mathrm{NO} / \mathrm{NO}_{2} / \mathrm{C}_{3} \mathrm{H}_{6} / \mathrm{C}_{3} \mathrm{H}_{8} / \mathrm{CO} / \mathrm{O}_{2} / \mathrm{GHSV}=1: 0.3: 0.67: 0.33: 7.5: 7.45 / 43000 \mathrm{~h}^{-1}$ & 212 & 155 & 178 & 158 & [489] \\
\hline $\mathrm{Pd} / 5 \% \mathrm{Nd}-\mathrm{Ce}_{0.2} \mathrm{Zr}_{0.8} \mathrm{O}_{2}$ & $\mathrm{NO} / \mathrm{NO}_{2} / \mathrm{C}_{3} \mathrm{H}_{6} / \mathrm{C}_{3} \mathrm{H}_{8} / \mathrm{CO} / \mathrm{O}_{2} / \mathrm{GHSV}=1: 0.3: 0.67: 0.33: 7.5: 7.45 / 43000 \mathrm{~h}^{-1}$ & 218 & 184 & 206 & 170 & [491] \\
\hline $\mathrm{Pt}-\mathrm{Rh} / \mathrm{Nd}_{\mathrm{x}} \mathrm{Ce}_{0.35} \mathrm{Zr}_{0.55} \mathrm{O}_{1.95}-\mathrm{Al}_{2} \mathrm{O}_{3}$ & $\mathrm{NO} / \mathrm{C}_{3} \mathrm{H}_{8} / \mathrm{CO} / \mathrm{O}_{2} / \mathrm{CO}_{2} / \mathrm{H}_{2} \mathrm{O} / \mathrm{GHSV}=0.1: 0.081: 0.646: 6.21: 12: 10 / 34000 \mathrm{~h}^{-1}$ & 259 & 160 & 211 & - & [493] \\
\hline $\mathrm{Pd} / 5 \% \mathrm{Sm}-\mathrm{Ce}_{0.2} \mathrm{Zr}_{0.8} \mathrm{O}_{2}$ & $\mathrm{NO} / \mathrm{NO}_{2} / \mathrm{C}_{3} \mathrm{H}_{6} / \mathrm{C}_{3} \mathrm{H}_{8} / \mathrm{CO} / \mathrm{O}_{2} / \mathrm{GHSV}=1: 0.3: 0.67: 0.33: 7.5: 7.45 / 43000 \mathrm{~h}^{-1}$ & 220 & 178 & 183 & 180 & [495] \\
\hline $\mathrm{Pd} / 5 \% \mathrm{Y}-\mathrm{Ce}_{0.2} \mathrm{Zr}_{0.8} \mathrm{O}_{2}$ & $\mathrm{NO} / \mathrm{NO}_{2} / \mathrm{C}_{3} \mathrm{H}_{6} / \mathrm{C}_{3} \mathrm{H}_{8} / \mathrm{CO} / \mathrm{O}_{2} / \mathrm{GHSV}=1: 0.3: 0.67: 0.33: 7.5: 7.45 / 43000 \mathrm{~h}^{-1}$ & 233 & 181 & 207 & 181 & [495] \\
\hline $\mathrm{Pd} / 5 \% \mathrm{Cr}-\mathrm{Ce}_{0.67} \mathrm{Zr}_{0.33} \mathrm{O}_{2}$ & $\mathrm{NO} / \mathrm{NO}_{2} / \mathrm{C}_{3} \mathrm{H}_{6} / \mathrm{C}_{3} \mathrm{H}_{8} / \mathrm{CO} / \mathrm{O}_{2} / \mathrm{GHSV}=1: 0.3: 0.67: 0.33: 7.5: 7.45 / 43000 \mathrm{~h}^{-1}$ & 280 & 203 & 305 & 235 & [502] \\
\hline $\mathrm{Pd} / 5 \% \mathrm{Mn}-\mathrm{Ce}_{0.67} \mathrm{Zr}_{0.33} \mathrm{O}_{2}$ & $\mathrm{NO} / \mathrm{NO}_{2} / \mathrm{C}_{3} \mathrm{H}_{6} / \mathrm{C}_{3} \mathrm{H}_{8} / \mathrm{CO} / \mathrm{O}_{2} / \mathrm{GHSV}=1: 0.3: 0.67: 0.33: 7.5: 7.45 / 43000 \mathrm{~h}^{-1}$ & 279 & 130 & 258 & 182 & [502] \\
\hline $\mathrm{Pd} / 1 \% \mathrm{Fe}-\mathrm{Ce}_{0.67} \mathrm{Zr}_{0.33} \mathrm{O}_{2}$ & $\mathrm{NO} / \mathrm{NO}_{2} / \mathrm{C}_{3} \mathrm{H}_{6} / \mathrm{C}_{3} \mathrm{H}_{8} / \mathrm{CO} / \mathrm{O}_{2} / \mathrm{GHSV}=1: 0.3: 0.67: 0.33: 7.5: 7.45 / 43000 \mathrm{~h}^{-1}$ & 252 & 115 & 240 & 126 & [496] \\
\hline $\mathrm{Pd} / 5 \%$ Co- $\mathrm{Ce}_{0.67} \mathrm{Zr}_{0.33} \mathrm{O}_{2}$ & $\mathrm{NO} / \mathrm{NO}_{2} / \mathrm{C}_{3} \mathrm{H}_{6} / \mathrm{C}_{3} \mathrm{H}_{8} / \mathrm{CO} / \mathrm{O}_{2} / \mathrm{GHSV}=1: 0.3: 0.67: 0.33: 7.5: 7.45 / 43000 \mathrm{~h}^{-1}$ & 245 & 161 & 210 & 167 & [497] \\
\hline $\mathrm{Pd} / 5 \% \mathrm{Ni}-\mathrm{Ce}_{0.67} \mathrm{Zr}_{0.33} \mathrm{O}_{2}$ & $\mathrm{NO} / \mathrm{NO}_{2} / \mathrm{C}_{3} \mathrm{H}_{6} / \mathrm{C}_{3} \mathrm{H}_{8} / \mathrm{CO} / \mathrm{O}_{2} / \mathrm{GHSV}=1: 0.3: 0.67: 0.33: 7.5: 7.45 / 43000 \mathrm{~h}^{-1}$ & 264 & 161 & 184 & 184 & [498] \\
\hline
\end{tabular}

$T_{50}$ is denoted as $50 \%$ conversion temperatures of $\mathrm{HC}, \mathrm{CO}, \mathrm{NO}$ and $\mathrm{NO}_{2}$.

by the CP method amplified the stoichiometric window for the fresh and aged catalyst due to suitable pore distribution, better OSC value, good redox property, and textural stability.

\subsubsection{Effect of pretreatment conditions}

Liotta et al. [472] investigated the effect of redox pretreatment on the structural composition of CZO for three-way catalysis. The changes of structure resulted from different calcination treatments were brought back by the redox cycles. The reductive behavior of CZO was not changed by repeated cycles, and the loss of surface area did not affect the total OSC. In addition, the alternative reductive and oxidative treatments led to reversible change of the solid solution composition around the nominal value of $\mathrm{Ce}_{0.6} \mathrm{Zr}_{0.4} \mathrm{O}_{2}$. $\mathrm{Zhou}$ et al. [473] found that the catalytic activities of $\mathrm{Pd} / \mathrm{CZO}-\mathrm{Al}_{2} \mathrm{O}_{3}$ catalysts were affected by thermal treatment. The surface oxygen desorption capacity and lattice oxygen mobility decreased due to the sintering of supports after being calcined at high temperature, which was unfavorable for the dispersion of active species, leading to the loss of three-way catalytic activities. Anderson et al. [474] invesigated the effect of oxychlorination treatments on the redox and oxygen storage and release properties of $\mathrm{Pd}-\mathrm{Rh} / \mathrm{CZO} / \mathrm{Al}_{2} \mathrm{O}_{3}$ model TWCs. Thermal aging could not only lead to the decrease of metal dispersion, but also result in a loss of OSC as oxygen storage component. A series of complex feed-streams were performed on $\mathrm{Ce}_{0.68} \mathrm{Zr}_{0.32} \mathrm{O}_{2}$ mixed oxide to investigate its performance as TWCs by González-Velasco et al. [475]. The pre-reducing treatment could greatly enhance both low-temperature NO reduction activity and $\mathrm{N}_{2}$ selectivity. Although a remarkable decrease in the specific surface area of the mixed oxide took place after being aged at $900{ }^{\circ} \mathrm{C}$, the catalytic activity of the aged sample remained similar or even better than the fresh one due to the increased OSC value. Therefore, $\mathrm{CO}$ and $\mathrm{HC}$ emissions during cold-start state could be reduced by placing the catalytic converter nearer the outlet to the engine exhaust, where the CZO-based catalyst would be heated faster.

\subsubsection{Effect of alkali or alkali-earth metals doping}

$\mathrm{Ba}$ and $\mathrm{Sr}$ are reported to be two excellent promoters for $\mathrm{Al}_{2} \mathrm{O}_{3}$, which can effectively suppress the decrease of specific specific surface area and inhibit the transformation of the $\mathrm{Al}_{2} \mathrm{O}_{3}$ phase at high temperature in the three-way catalytic reaction [476-479]. Zhou's group [480] reported the effect of $\mathrm{BaO}$ doping on the structure and catalytic performance of $\mathrm{Pd} / \mathrm{Ce}_{\mathrm{x}} \mathrm{Zr}_{1-\mathrm{x}} \mathrm{O}_{2}$ $(x=0.2-0.8)$ catalysts for automobile emission control. BaO addition significantly promoted the catalytic activity of $\mathrm{HC}$ and $\mathrm{NO}_{x}$ conversions due to promoting the formation of oxygen vacancy and improving active oxygen mobility resulting from electronic and structural modifications. After thermal aging treatment, $\mathrm{Zr}$-rich catalysts $\left(\mathrm{CeO}_{2} / \mathrm{ZrO}_{2}<1\right)$ underwent less severe deterioration of the catalytic activity compared with Ce-rich catalysts $\left(\mathrm{CeO}_{2} / \mathrm{ZrO}_{2} \geq 1\right)$ due to better thermal stability, and $\mathrm{Pd} / \mathrm{Ce}_{0.5} \mathrm{Zr}_{0.5} \mathrm{O}_{2} \mathrm{BaO}$ presented the optimally catalytic performance. Subsequently, they probed the role of Ba in TWCs $\mathrm{Pd} / \mathrm{Ce}_{0.5} \mathrm{Zr}_{0.5} \mathrm{O}_{2}$ using in-situ DRIFTS [481]. The introduction of Ba weakened the strong adsorption of $\mathrm{HC}$ reactants on the catalyst surface and accelerated NO dissociation. It facilitated the formation of intermediates ( $\mathrm{CN}$ and NCO) due to the excellent electron-donating ability of $\mathrm{Ba}$. Thereby Ba-modified catalysts exhibited much higher catalytic activity for $\mathrm{HC}$ and $\mathrm{NO}_{x}$ conversions than the unmodified one. However, the introduction of $\mathrm{Ba}$ led to the loss of active sites, thus it inhibited CO oxidation at low temperatures. Wang et al. [482] investigated the effect of different amounts of Sr doping on the catalytic performance of $\mathrm{Pd} / \mathrm{Ce}_{0.67} \mathrm{Zr}_{0.33} \mathrm{O}_{2}$ catalysts for automobile emission control. $\mathrm{Sr}$ doping enhanced the low-temperature activity and the thermal stability of the Pd phase owing to the improved oxygen mobility and OSC. Pd-based TWCs supported on $\mathrm{Ce}_{0.67} \mathrm{Zr}_{0.33} \mathrm{Sr}_{0.03} \mathrm{O}_{2.03}$ support exhibited the optimal activity for $\mathrm{C}_{3} \mathrm{H}_{8}$ and NO conversion as well as broadened activation temperature window. Shi et al. [483] conducted a comparative study of the catalytic performance over $\mathrm{SrO}$ and $\mathrm{BaO}$ doping $\mathrm{CeO}_{2}-\mathrm{ZrO}_{2}$ for TWCs. $\mathrm{Ce}_{0.35} \mathrm{Zr}_{0.55} \mathrm{Sr}_{0.10} \mathrm{O}_{1.9}$ (CZS) and $\mathrm{Ce}_{0.35} \mathrm{Zr}_{0.55} \mathrm{Ba}_{0.10} \mathrm{O}_{1.9}$ (CZB) were 
prepared by an oxidation-CP method with $\mathrm{H}_{2} \mathrm{O}_{2}$ as oxidizing agent, and then they were used for preparing TWCs with a low loading amount of $\mathrm{Pt}$ and $\mathrm{Rh}$. The incorporation of $\mathrm{Sr}^{2+}$ ions into CZO could retain a higher OSC value than the introduction of $\mathrm{Ba}^{2+}$ ions. Moreover, the introduction of $\mathrm{Sr}^{2+}$ ions favored the formation of homogeneously face-centered cubic phases and maintained the stability of lattice cell units. Therefore, the catalyst modified by $\mathrm{Sr}^{2+}$ exhibited a better catalytic activity and wider activation temperature window.

\subsubsection{Effect of rare earth doping}

With ever increasingly rigorous emission regulations are being implemented, taking into account that a significant portion of toxic emissions is produced during cold start, it is necessary to place TWCs closer to the engine in order to attain their light-off activity immediately after the start up of the engine. Consequently, the catalysts should be capable of tolerating high temperature. Therefore, better thermal stability and higher OSC are urgent for the development of new-generation TWCs. A great amount of research has demonstrated that the doping rare earth metal can improve the three-way catalytic activity and temperature operation window, as shown in Table 9 [484-498].

\subsubsection{Effect of transition metal doping}

Effect of different amounts of Fe-modified $\mathrm{CeO}_{2}-\mathrm{ZrO}_{2}$ on the physicochemical properties and catalytic behavior of TWCs for automotive emission control was investigated by Zhou et al. $[496,497]$. The Pd/CZFe(1\%) catalyst exhibited optimal catalytic performance for $\mathrm{CO}, \mathrm{HC}, \mathrm{NO}$, and $\mathrm{NO}_{2}$ eliminations. The doping of $1 \%$ iron oxide promoted the formation of homogeneous Ce-Zr-Fe-O ternary solid solution, which not only facilitated the reduction of $\mathrm{Ce}^{4+} \rightarrow \mathrm{Ce}^{3+}$ and the generation of oxygen vacancy and then improved the interaction between $\mathrm{Fe}$ and Ce-Zr, but also enhanced Ce redox behavior. The introduction of cobalt oxide by the CP method considerably enhanced the catalytic activity of Pd-based TWCs with $T_{50}$ for $\mathrm{HC}$ at $245^{\circ} \mathrm{C}$, for $\mathrm{CO}$ at $161{ }^{\circ} \mathrm{C}$, for $\mathrm{NO}$ at $210{ }^{\circ} \mathrm{C}$, and for $\mathrm{NO}_{2}$ at $167{ }^{\circ} \mathrm{C}$. It should be due to the formation of more homogeneous ternary solid solution, which improved OSC and the interaction between CZO and cobalt metal. In addition, Zhou et al. [498-500] also reported the introduction of $\mathrm{Ni}$ promoted the redox behavior of Pd/CZO catalysts, leading to the increase of OSC of samples, and $\mathrm{Pd} / \mathrm{CZNi}(3 \%)$ exhibited the optimal catalytic performance compared with other catalysts. Zhou et al. [501,502] investigated the behavior of $\mathrm{Pd}$ supported on transition metals ( $\mathrm{M}=\mathrm{Cr}, \mathrm{Mn}, \mathrm{Fe}, \mathrm{Co}, \mathrm{Ni}$ ) modified $\mathrm{Ce}_{0.67} \mathrm{Zr}_{0.33} \mathrm{O}_{2}$ oxides under stoichiometric $\mathrm{CO}+\mathrm{HC}+\mathrm{NO}_{x}+\mathrm{O}_{2}$ reaction conditions. The incorporation of transition metals especially $\mathrm{Fe}$ and Co strongly improved the oxygen mobility and greatly enhanced the OSC of CZO and the corresponding catalysts. The introduction of Fe and Co into CZO was more beneficial to forming homogeneous Ce-Zr-M-O ternary solid solution and therefore promoting the reduction of $\mathrm{Pd} / \mathrm{CZO}$. As a result, the catalytic activities of the catalysts were significantly enhanced (Fig. 27).

\subsubsection{Mechanisms of three-way catalytic removal for the}

\section{exhausts from gasoline engines over nanosize} ceria-zirconium-based solid solutions

Shi et al. [483] proposed that the mechanisms of three-way catalytic removal for the exhausts from gasoline engines on $\mathrm{Pt}-\mathrm{Rh} / \mathrm{Ce}_{0.35} \mathrm{Zr}_{0.55} \mathrm{Sr}_{0.10} \mathrm{O}_{1.9} /$ La-stabilized $\mathrm{Al}_{2} \mathrm{O}_{3} \quad$ (LA) and $\mathrm{Pt}-\mathrm{Rh} / \mathrm{Ce} 0.35 \mathrm{Zr} 0.55 \mathrm{Ba} 0.10 \mathrm{O}_{1.9} / \mathrm{LA}$ were as follows:

$$
\begin{gathered}
\mathrm{CO}+\mathrm{O}_{2} \rightarrow \mathrm{CO}_{2} \\
\mathrm{C}_{3} \mathrm{H}_{8}+\mathrm{O}_{2} \rightarrow \mathrm{CO}_{2}+\mathrm{H}_{2} \mathrm{O} \\
\mathrm{CO}+\mathrm{NO} \rightarrow \mathrm{CO}_{2}+\mathrm{N}_{2} \\
\mathrm{O}_{2}+\mathrm{Ce}_{2} \mathrm{O}_{3} \rightarrow \mathrm{CeO}_{2} \\
\mathrm{NO}+\mathrm{Ce}_{2} \mathrm{O}_{3} \rightarrow \mathrm{CeO}_{2}+\mathrm{N}_{2}
\end{gathered}
$$

The first three steps (Eqs. (53)-(55)) were involved in the elimination of pollutants over TWCs. The fourth step (Eq. (56)) played a role in adjusting the ratio of oxidant/reductant. The last step referred to the reduction of $\mathrm{NO}_{x}$ in TWCs at $\lambda<1$. Steam-reforming and water-gas shift reactions would take place when $\mathrm{H}_{2} \mathrm{O}$ was present in exhaust gas. $\mathrm{H}_{2}$ would be produced to react with NO. CZO could supply active oxygen species resulting from the cerium charge transformation $\mathrm{CeO}_{2} \leftrightarrow \mathrm{Ce}_{2} \mathrm{O}_{3}$ when alkaline-earth metal oxides were incorporated to $\mathrm{CZO}$ lattice. They would react with the adsorbed NO on the catalyst:

$$
\mathrm{NO}+\mathrm{O}_{2} \rightarrow \mathrm{NO}_{2}
$$

Subsequently, $\mathrm{NO}_{2}$ reacted with alkaline-earth metal oxides, for example $\mathrm{SrO}$ and $\mathrm{BaO}$ :

$$
\mathrm{NO}_{2}+\mathrm{BaO} \rightarrow \mathrm{BaO}-\mathrm{NO}_{2}
$$

Then $\mathrm{BaO}-\mathrm{NO}_{2}$ reacted with $\mathrm{NO}$ and produced nitrite:

$$
\mathrm{BaO}-\mathrm{NO}_{2}+\mathrm{NO} \rightarrow \mathrm{BaO}\left(\mathrm{NO}_{2}\right)_{2}
$$

Furthermore, nitrite further reacted with $\mathrm{NO}_{2}$ and produced nitrate:

$$
\mathrm{BaO}\left(\mathrm{NO}_{2}\right)_{2}+\mathrm{NO}_{2} \rightarrow \mathrm{BaO}\left(\mathrm{NO}_{3}\right)_{2}
$$

Excess oxygen was stored in CZO materials (Eq. (56)) at $\lambda>$ 1 based on the former step. Meanwhile, $\mathrm{NO}_{x}$ was also stored in CZO materials, and then released at $\lambda<1$ and reduced on the noble metal sites, leading to the enhancement of $\mathrm{NO}_{x}$ conversion under wider air/fuel ratios.

\subsubsection{Summary of cerium-zirconium-based material for} three-way catalytic removal of exhausts from gasoline engines

$$
\begin{gathered}
2 \mathrm{C}_{\mathrm{Ce}}^{\mathrm{x}}+\mathrm{O}_{\mathrm{o}} \rightarrow 2 \mathrm{Ce}_{\mathrm{Ce}}^{\prime}+\mathrm{V}_{\mathrm{O}}^{*}+1 / 2 \mathrm{O}_{2} \\
\mathrm{MO} \stackrel{\mathrm{CeO}_{2}}{\longrightarrow} \mathrm{M}_{\mathrm{Ce}}^{\prime}+\mathrm{V}_{\mathrm{O}}^{*}+1 / 2 \mathrm{O}_{2} \\
\mathrm{M}_{2} \mathrm{O}_{3} \stackrel{\mathrm{CeO}_{2}}{\longrightarrow} 2 \mathrm{M}_{\mathrm{Ce}}^{\prime}+2 \mathrm{O}_{\mathrm{O}}^{\mathrm{x}}+\mathrm{V}_{\mathrm{O}}^{*}+1 / 2 \mathrm{O}_{2}
\end{gathered}
$$

There are two kinds of oxygen vacancies in cerium-base materials. One is produced by the revivification of $\mathrm{Ce}^{4+}$ through Eq. (62), and the other is produced by doping ions through Eqs. (63) and (64) [503-505]. The OSC and redox properties of a cerium-based oxygen storage material are closely related to the oxygen vacancy concentration, migration rate of oxygen vacancy, surface area, and the formation of anion defects [506,507]. The lattice defects formed in the bulk of CZO can make the bulk lattice oxygen and oxygen vacancies to be used in catalytic reaction, but the OSC and thermal stability still can not meet the ever increasingly stringent emission standards. Thus, it urgently needs to further improve oxygen vacancy, lattice defect, OSC, and thermal stability of CZO. The introduc- 

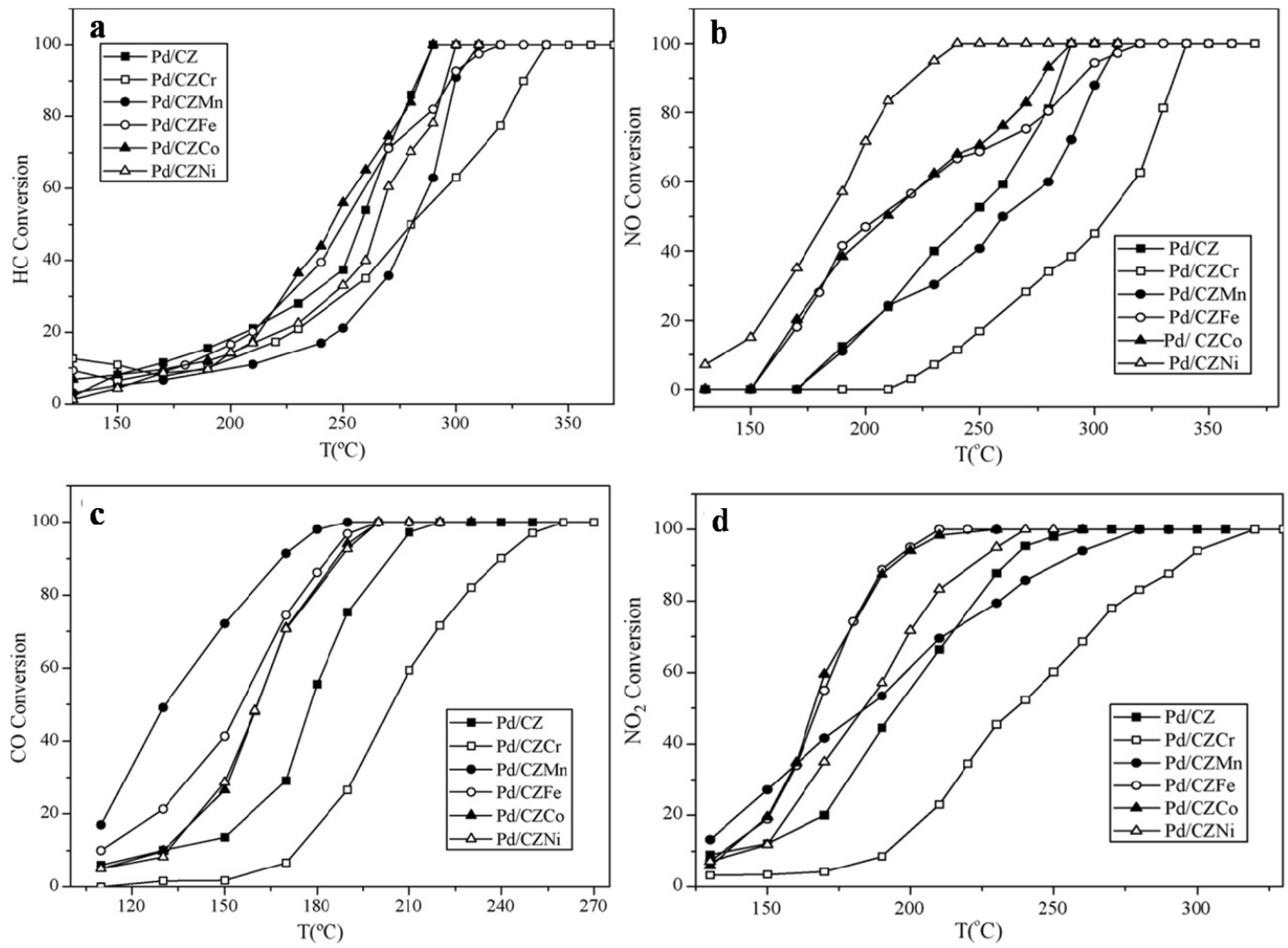

Fig. 27. Conversion of (a) $\mathrm{HC}$, (b) $\mathrm{NO}$, (c) $\mathrm{CO}$, and (d) $\mathrm{NO}_{2}$ over various catalysts as a function of reaction temperature under stoichiometric $\mathrm{CO}+\mathrm{HC}+$ $\mathrm{NO}_{x}+\mathrm{O}_{2}$. Reaction condition: $\mathrm{NO}(0.1 \%)-\mathrm{NO}_{2}(0.03 \%)-\mathrm{C}_{3} \mathrm{H}_{6}(0.067 \%)-\mathrm{C}_{3} \mathrm{H}_{8}(0.033 \%)-\mathrm{CO}(0.75 \%)-\mathrm{O}_{2}(0.745 \%)$ in Ar. Reprinted from [502] with permission.

tion of a third metal to the CZO material may be a feasible way. The influence of extra metal doping mainly includes the following two aspects. One way is to change the radius of dopant ions to make the lattice atoms rearrangement and crystal structure producing different degrees of distortion, which can effectively reduce the diffusion resistance of oxygen in crystal lattice. The other way is to introduce a valence state lower than $\mathrm{Ce}^{4+}$ and $\mathrm{Zr}^{4+}$ cation and by the charge balance of crystal lattice to form oxygen vacancy and then improve the diffusion rate of bulk oxygen.

\subsection{Nanosize cerium-zirconium-based solid solutions for $\mathrm{CO}_{2}$ transformation}

The emission of $\mathrm{CO}_{2}$ originated from human activity is a significant factor resulting in the rapid global warming. The catalytic transformation of $\mathrm{CO}_{2}$ into useful stuffs is recognized to be one of the economic and effective ways to mitigate $\mathrm{CO}_{2}$ buildup [508]. The key challenge is to develop an effective catalyst that can achieve a high $\mathrm{CO}_{2}$ conversion at low temperature. Among the catalysts, CZO is one of the key components owing to its excellent OSC property and robust stability. And this part mainly focuses on three $\mathrm{CO}_{2}$ transformation reactions over CZO: methanation, reforming and chemical transformations.

\subsection{1. $\mathrm{CO}_{2}$ methanation}

$\mathrm{CO}_{2}$ methanation is a green and promising method for the atmospheric $\mathrm{CO}_{2}$ reduction. This process is a catalytic hydrogenation reaction (Sabatier reaction):

$$
\mathrm{CO}_{2}+4 \mathrm{H}_{2} \rightarrow \mathrm{CH}_{4}+2 \mathrm{H}_{2} \mathrm{O} \quad \Delta H_{298 \mathrm{~K}}=-252.9 \mathrm{~kJ} / \mathrm{mol}
$$

Much research has been devoted to this particular reaction over Ni-based CZO catalysts. Roger and co-workers [509,510] reported that the $\mathrm{Ce} / \mathrm{Zr}$ ratio and Ni loading distinctly affected the catalytic performance of $\mathrm{Ni} / \mathrm{CZO}$ catalysts for $\mathrm{CO}_{2}$ methanation. The catalyst with $\mathrm{Ce} / \mathrm{Zr}$ mole ratio of $72 / 28$ and $10 \% \mathrm{Ni}$ exhibited the best activity. Kawi et al. [511] proposed that the preparation methods can influence the catalytic activity of $\mathrm{CO}_{2}$ methanation over $\mathrm{Ni} / \mathrm{CZO}$ catalysts. The catalyst prepared by ammonia evaporation showed a higher activity than the counterpart catalysts synthesized by impregnation and deposition precipitation methods due to stronger metal-support interactions between Ce and Ni species. Roger et al. [509] also found that noble metals $(\mathrm{Rh}, \mathrm{Ru})$ dopping significantly enhanced the catalytic performance of $\mathrm{Ni} / \mathrm{CZO}$ catalysts for $\mathrm{CO}_{2}$ methanation due to the higher dispersion of Ni species. Wang et al. [512] investigated the effect of $\mathrm{Ru}$ dopping amount on $\mathrm{Ni} / \mathrm{CZO}$ catalysts for $\mathrm{CO}_{2}$ methanation. Ru promoted the catalytic activity of catalyst for $\mathrm{CO}_{2}$ conversion and the catalyst with $3 \mathrm{wt} \% \mathrm{Ru}$ showed the optimal activity with $\mathrm{CO}_{2}$ conversion and methane selectivity of $98.2 \%$ and $100 \%$, respectively. Zhang et al. [513] proposed that the addition of $5 \mathrm{wt} \%$ Co can increase the oxygen vacancy and defect of $\mathrm{Ni} / \mathrm{CZO}$ catalysts, and thereby promote the catalytic activity for $\mathrm{CO}_{2}$ methanation.

Although the reaction of $\mathrm{CO}_{2}$ methanation is a simple pro- 
cess, it appears to be difficult to reach a consensus on the reaction mechanism. The main controversy concentrates on the nature of intermediate compound and the formation scheme of methane. Kawi et al. [511] proposed that the mechanism of $\mathrm{CO}_{2}$ methanation on $\mathrm{Ni} / \mathrm{CZO}$ catalyst was as follows. At temperature below $150{ }^{\circ} \mathrm{C}, \mathrm{CO}_{2}$ first adsorbs on the surface of $\mathrm{Ni} / \mathrm{CZO}$ as mono- and/or bi-dentate carbonate, and then these carbonate species react with dissociated hydrogen to form hydrogenated carbonates. When the temperature is above $250{ }^{\circ} \mathrm{C}$, these hydrogenated carbonate species further react with dissociated hydrogen to generate monodentate carbonate. These intermediate species convert into formaldehyde-like and methoxy species followed by dissociating to $\mathrm{CH}_{4}$. The methanation of $\mathrm{CO}_{2}$ proceeds by $\mathrm{CO}_{2}$ direct hydrogenation to form methane without the formation of $\mathrm{CO}$ as intermediate.

\subsubsection{Reforming with $\mathrm{CO}_{2}$ and methane}

$\mathrm{CO}_{2}$ reforming of $\mathrm{CH}_{4}$ to synthesis gas is considered to be an efficient and attractive approach to eliminate green house gases. This process is called dry reforming of methane reaction:

$$
\mathrm{CO}_{2}+\mathrm{CH}_{4} \rightleftarrows 2 \mathrm{CO}+2 \mathrm{H}_{2} \quad \Delta H_{298 \mathrm{~K}}=247 \mathrm{~kJ} / \mathrm{mol}
$$

Idem et al. [514] investigated the catalytic activity of Ni-based CZO catalysts for $\mathrm{CO}_{2}$ reforming of $\mathrm{CH}_{4}$. Compared with $\mathrm{Ni} / \mathrm{ZrO}_{2}$ and $\mathrm{Ni} / \mathrm{Ce}$-doped $\mathrm{ZrO}_{2}$ catalysts, $\mathrm{Ni} / \mathrm{CZO}$ showed higher resistance to carbon deposition due to its enhanced low-temperature reducibility. It is well known that the deactivation of catalyst induced by active metal sintering is a thorny and challenging subject in this reaction. Wang and co-workers [515] prepared a series of mesoporous CZO-supported Ni catalysts by a CTAB-assisted method. The catalyst exhibited outstanding stability and initial activity for $\mathrm{CO}_{2}$ reforming of $\mathrm{CH}_{4}$ reaction. It should be attributed to its large specific surface area and high dispersion of NiO. Liu et al. [516] synthesized a $\mathrm{Ni} / \mathrm{CZO} / \mathrm{MSU}-\mathrm{H}$ catalyst by a hydrothermal method for $\mathrm{CO}_{2}$ reforming of $\mathrm{CH}_{4}$. Owing to the enhanced OSC for the synergistic effect between MSU-H and CZO, Ni/CZO/MSU-H presented high resistance to coke. In addition, the property of CZO could be adjusted by dopants, thus their catalytic activity for $\mathrm{CO}_{2}$ reforming of $\mathrm{CH}_{4}$ was improved. Noronha et al. [517] reported that the introduction of $\mathrm{Al}$ to $\mathrm{CZO}$ could significantly promote the oxygen mobility of the $\mathrm{Ni} / \mathrm{CZO} / \mathrm{Al}_{2} \mathrm{O}_{3}$ catalyst, and thereafter it inhibited the formation of carbon from blocking metallic particle. Idem and co-workers [518] studied the effect of metals dopping ( $\mathrm{M}=\mathrm{Al}, \mathrm{Ba}, \mathrm{Ca}, \mathrm{Hf}, \mathrm{La}, \mathrm{Pr}, \mathrm{Sm}, \mathrm{Sr}, \mathrm{Tb}$, and $\mathrm{Y}$ ) on $\mathrm{Ni} / \mathrm{CZMO}$ catalysts for $\mathrm{CO}_{2}$ reforming of $\mathrm{CH}_{4}$. The results showed that the dopants increased the activity of Ni/CZMO. Especially, the doping of $\mathrm{Ca}$, La, and Y considerably boosted the low-temperature activity because of the increased Ni dispersion, OSC, and reducibility. Meanwhile, the introduction of a second active metal is another important method to improve the catalytic activity of the $\mathrm{Ni} / \mathrm{CZO}$ catalyst for $\mathrm{CO}_{2}$ reforming of $\mathrm{CH}_{4}$. Lee et al. [519] investigated the effect of $\mathrm{Mg}$ doping on the physicochemical properties and catalytic activity for $\mathrm{CO}_{2}$ reforming of $\mathrm{CH}_{4}$ over Ni/CZO Ni-Mg/CZO showed better catalytic activity than $\mathrm{Ni} / \mathrm{CZO}$ due to the improved thermal stability. Moreover, Kiennemann et al. [520] studied the influence of the introduction of the second metal ( $\mathrm{M}=\mathrm{Co}, \mathrm{Fe}$, and $\mathrm{Rh})$ on
$\mathrm{Ni}-\mathrm{M} / \mathrm{CZO}$ catalyst activity for $\mathrm{CO}_{2}$ reforming of $\mathrm{CH}_{4}$. The addition of Rh distinctly enhanced the activity and stability of the catalyst. In addition to $\mathrm{Ni}$ as active species, other metals such as $\mathrm{Pt}$ and Co were also supported on CZO and investigated for $\mathrm{CO}_{2}$ reforming of $\mathrm{CH}_{4}$ reaction. Resasco et al. [521] prepared a series of Pt-based CZO catalysts with different $\mathrm{Ce} / \mathrm{Zr}$ ratios for $\mathrm{CO}_{2}$ reforming of $\mathrm{CH}_{4}$. It was found that $\mathrm{Pt} / \mathrm{Ce}_{0.5} \mathrm{Zr}_{0.5} \mathrm{O}_{2}$ exhibited an optimal activity and a good correlation between catalytic activity and reducibility. Su et al. [52] reported Co-based CZO catalysts with two $\mathrm{Ce} / \mathrm{Zr}$ ratios $(0.33 / 0.67,0.6 / 0.4)$ for $\mathrm{CO}_{2}$ reforming of $\mathrm{CH}_{4}$. The catalyst with the $\mathrm{Ce} / \mathrm{Zr}$ ratio of $0.6 / 0.4$ showed a better activity due to its better reducibility, higher Co dispersion, and alkalescence of $\mathrm{Co} / \mathrm{Ce}_{0.6} \mathrm{Zr}_{0.4} \mathrm{O}_{2}$ surface. Meanwhile, it should be noted that Pt- and Co-based CZO catalysts possess a lower activity than $\mathrm{Ni} / \mathrm{CZO}$ for $\mathrm{CO}_{2}$ reforming of $\mathrm{CH}_{4}$. However, the Ni-based catalyst readily induced deactivation due to coke deposition. Thus, the introduction of a second active metal should be necessary.

Idem et al. [514,522] proposed that the mechanism of $\mathrm{CO}_{2}$ reforming of $\mathrm{CH}_{4}$ on $\mathrm{Ni} / \mathrm{CZO}$ was as follows:

$$
\mathrm{CH}_{4}+2 \mathrm{~S} \leftrightarrow \mathrm{CH}_{\mathrm{x}}+(4-\mathrm{x}) \mathrm{H}_{(\mathrm{s})}
$$

where, (s) represents the active sites on $\mathrm{Ni} / \mathrm{CZO}$ surface. $\mathrm{CH}_{4}$ first adsorbs on $\mathrm{S}$ and then dissociates to $\mathrm{CH}_{x}$ fragments. The adsorbed $\mathrm{H}$ atoms reacts to produce $\mathrm{H}_{2}$ :

$$
(4-\mathrm{x}) \mathrm{H}_{(\mathrm{s})} \leftrightarrow(4-\mathrm{x} / 2) \mathrm{H}_{2}+\mathrm{S}
$$

$\mathrm{CH}_{x}$ fragments were oxidated on $\mathrm{Ni} / \mathrm{CZO}$ surface to form $\mathrm{CO}$ and $\mathrm{H}_{2}$ :

$$
\mathrm{CH}_{\mathrm{x}}+2(\mathrm{Ce}-\mathrm{Zr}) \mathrm{O}_{2} \leftrightarrow \mathrm{CO}+(\mathrm{x} / 2) \mathrm{H}_{2}+(\mathrm{Ce}-\mathrm{Zr})_{2} \mathrm{O}_{3}+\mathrm{S}
$$

Eq. (70) represents the oxidation of reduced sites on $\mathrm{Ni} / \mathrm{CZO}$ surface by $\mathrm{CO}_{2}$ to generate $\mathrm{CO}$ and initial Ni/CZO. Therefore, the reaction can readily proceed forward by the highly mobile oxygen species supplied by the high OSC and reducibility of $\mathrm{Ni} / \mathrm{CZO}$.

$$
\mathrm{CO}_{2}+(\mathrm{Ce}-\mathrm{Zr})_{2} \mathrm{O}_{3} \leftrightarrow \mathrm{CO}+2(\mathrm{Ce}-\mathrm{Zr}) \mathrm{O}_{2}
$$

\subsection{3. $\mathrm{CO}_{2}$ for the synthesis of dimethyl carbonate}

It is generally accepted that dimethyl carbonate (DMC) is an important chemical intermediate in chemical industry and direct synthesis of $\mathrm{DMC}$ from $\mathrm{CO}_{2}$ and methanol is an environmentally friendly chemical process [523]. Tomishige et al. [524] employed CZO as a catalyst for the synthesis of DMC from $\mathrm{CO}_{2}$ and methanol reaction. They found that the catalytic activity of catalyst is closely related to the calcination temperature, and the higher calcination temperature can induce more active surface and thereby enhance the activity. Kim et al. [525-527] reported that the catalytic activity of the catalyst for this reaction was dependent on the preparation method and the catalyst prepared by a decomposition method using adipic acid exhibited the highest specific surface area $\left(170 \mathrm{~m}^{2} / \mathrm{g}\right)$ and best catalytic performance. Saha et al. [528] synthesized a highly active and stable $\mathrm{CZO} /$ graphene catalyst for direct synthesis of DMC from $\mathrm{CO}_{2}$ and methanol. They proposed that the introduction of grapheme significantly promoted the formation of highly crystalline nanostructures and thereby improved its activity. Jung et al. [529] prepared a series of $\mathrm{Ga}_{2} \mathrm{O}_{3}$-modified $\mathrm{CZO}$ catalysts and investigated their catalytic activity for direct synthesis of 
DMC from $\mathrm{CO}_{2}$ and methanol. $5 \mathrm{wt} \% \mathrm{Ga}_{2} \mathrm{O}_{3} / \mathrm{CZO}$ showed the best activity. Jung and co-workers [530] further studied the effect of acidity of catalyst on the catalytic performance for synthesis of DMC from $\mathrm{CO}_{2}$ and methanol. They prepared $\mathrm{PW}_{12} \mathrm{O}_{40}$-modified CZO catalysts for this reaction. The results revealed that the modification of CZO by $\mathrm{PW}_{12} \mathrm{O}_{40}$ greatly improved the activity of catalyst for synthesis of DMC from $\mathrm{CO}_{2}$ and methanol because of the enhancement of Brønsted acid sites provided by $\mathrm{PW}_{12} \mathrm{O}_{40}$ and that the acidity played a key role in influencing the catalyst activity. Liu et al. [531] for the first time prepared ionic liquid 1-ethyl-3-methylimidazolium bromide ([EMIM]Br)-modified CZO catalyst for synthesis of DMC from $\mathrm{CO}_{2}$ and methanol. The catalytic performance of [EMIM] Br/CZO increased for DMC production, and it provided a promising alternative for the selective production of DMC from methanol and $\mathrm{CO}_{2}$.

Kumar et al. [532,533] proposed that the mechanism of synthesis of DMC from $\mathrm{CO}_{2}$ and methanol on $\mathrm{CZO}$ was as follows.

$\mathrm{CH}_{3} \mathrm{OH}$ first adsorbs on acidic and basic sites of $\mathrm{CZO}$ surface and then dissociates to $\mathrm{CH}_{3}{ }^{+}, \mathrm{OH}^{-}, \mathrm{CH}_{3} \mathrm{O}^{-}$, and $\mathrm{H}^{+}$, respectively:

$$
\mathrm{CH}_{3} \mathrm{OH} \rightarrow \mathrm{CH}_{3}^{+}+\mathrm{OH}^{-} \text {Acidic sites of the catalyst }
$$$$
\mathrm{CH}_{3} \mathrm{OH} \rightarrow \mathrm{CH}_{3} \mathrm{O}^{-}+\mathrm{H}^{+} \text {Basic sites of the catalyst }
$$

Then, $\mathrm{CH}_{3} \mathrm{O}^{-}$reacts with $\mathrm{CO}_{2}$ to form $\mathrm{CH}_{3} \mathrm{OCO}_{2}-$ on the basic sites of CZO:

$\mathrm{CH}_{3} \mathrm{O}^{-}+\mathrm{CO}_{2} \rightarrow \mathrm{CH}_{3} \mathrm{OCO}_{2}^{-}$Basic sites of the catalyst

Finally, $\mathrm{CH}_{3} \mathrm{OCO}_{2}-$ reacts with $\mathrm{CH}_{3}{ }^{+}$to form $\mathrm{DMC}$, and $\mathrm{H}^{+}$reacts with $\mathrm{OH}^{-}$to generate $\mathrm{H}_{2} \mathrm{O}$ :

$$
\begin{gathered}
\mathrm{CH}_{3} \mathrm{OCO}_{2}^{-}+\mathrm{CH}_{3}^{+} \rightarrow \mathrm{DMC} \\
\mathrm{H}^{+}+\mathrm{OH}^{-} \rightarrow \mathrm{H}_{2} \mathrm{O}
\end{gathered}
$$

\subsection{Summary of nanosize cerium-zirconium-based materials for environmental catalysis}

Environmental catalysis, which can transform pollutants into harmless substances or valuable stuff, is now recognized as one of the most useful methods to reduce environmental pollution in the world [534,535]. CZO is used as the active component, support, or oxygen storage material, and it is indispensable to purify pollutants in environmental catalysis. The main characteristics of environmental catalysts are as follows.

(a) High activity. The catalysts should be extremely efficient to remove the hazardous substances. Because the concentration of the harmful substances in exhausts is usually low, it is only the catalysts with high activity that can efficiently remove them.

(b) High selectivity. The exhaust gas compositions to be disposed are often complex, and the catalysts should possess high selectivity.

(c) High stability. The gases to be treated often contain some toxic ingredients. Therefore, the catalysts should have strong toxicity resistance, high chemical stability, and long lifetime. Moreover, the catalysts should have high thermal stability and wide operation temperature window.

(d) High adaptability. The reaction conditions for the re- moval of harmful substances vary dramatically. For example, the space velocity of automobile exhausts could be as high as hundreds of thousands, and the changes of the exhaust temperature vary from dozens of Celsius degrees when cold starting to seven or eight hundred Celsius degrees when speeding up.

In addition, the environmental catalysts should also possess high mechanical strength, because the amount of gases to be treated is often large. The catalysts ought to withstand the pressure of fluid flushing. Moreover, the catalysts should be easy to be prepared, cheap and wear-resisting, and low pressure drop.

CZO materials possess good redox and OSC. They are excellent environmental catalysts or acted as the assistant of precious metal catalysts. Although the lattice defects forming in CZO can be helpful to the catalytic reaction, the OSC and thermal stability should be further improved to meet the requirements of environmental catalysts for high activity, high selectivity, high stability and high adaptability. From the typical catalytic reactions described above, it can be deduced that the methods to improve the properties of CZO catalysts are as follows: (1) adopting a suitable preparation method to design and improve the microstructure texture and physicochemical properties of $\mathrm{CZO}$; (2) supporting active metals to enhance catalytic performance of CZO; (3) introduction of additional components into CZO to further increase the degree of lattice oxygen deficiency, improve OSC, and then enhance the catalytic activity, selectivity, and adaptability of environmental catalysts. The addition of additional components including rare earth, transition and alkaline earth or other metals can also inhibit the transformation of crystal phase of CZO and then improve the thermal stability of environmental catalysts.

Doping rare earth oxides with variable state into CZO can not only enhance their lattice defects and improve the redox property of catalyst, but also significantly enhance lattice defects such as the number of oxygen vacancies. Additionally, doping rare earth elements into CZO can also form a ternary solid solution, which may improve the thermal stability of CZO [536].

Transition metals have unfilled valence orbit, and their properties are quite different from other elements. There are many single electrons in the electron configuration of the element in this part, which are readily to lose, so these metals have a variable valence state. The unique electron configuration of transition metals determines their good low-temperature redox properties. The previous reviews show that the introduction of transition metals into CZO can form a solid solution structure and the modified CZO exhibits good low-temperature redox properties. The transition metals supported catalysts possess a low ignition temperature, which realize the purification treatment of automobile exhaust under cold start condition. The common transition metals used for doping $\mathrm{CZO}$ are $\mathrm{Mn}, \mathrm{Cu}, \mathrm{Fe}, \mathrm{Co}, \mathrm{Ni}$, and $\mathrm{Cr}$, etc.

Alkaline earth metals can form ternary solid solution with CZO to some extent, but the solid solubility varies greatly with the change of ion radius of alkaline earth metals. The ion radii of $\mathrm{Mg}^{2+}, \mathrm{Ca}^{2+}, \mathrm{Sr}^{2+}$ and $\mathrm{Ba}^{2+}$ are $0.66,1.12,1.25$, and $1.42 \AA$, re- 
spectively $[537,538]$. Among them, $\mathrm{Ca}^{2+}$ and $\mathrm{Sr}^{2+}$ exhibit higher solid solubility with CZO because of their appropriate ion radii, but $\mathrm{Mg}^{2+}$ and $\mathrm{Ba}^{2+}$ show lower solid solubility with CZO. The effect of doping different alkali earth metals on the catalytic properties of CZO is different. Ca and Sr are easily distributed in the lattice of CZO to form ternary solid solution structure, which can improve the thermal stability and OSC performance of $\mathrm{CZO}$ based catalysts.

The oxides of $\mathrm{Al}_{2} \mathrm{O}_{3}$ and $\mathrm{SiO}_{2}$ can remarkably affect the catalytic performance of CZO. Although they can not be soluble with cerium and zirconium, they can interact with each other to generate new dispersive phase, which can inhibit catalyst from sintering at high temperature and improve its stability, redox and OSC performance.

\section{General conclusions and perspectives}

Different from the other rare earth oxides, cerium-zirconium-based solid solutions and related oxides are excellent candidate catalysts for heterogeneous catalysis due to the unique textural and structural properties, controllable composition, and good redox and OSC properties derived from the facile shift of $\mathrm{Ce}^{3+} / \mathrm{Ce}^{4+}$. By partial substitution of ions $\mathrm{Ce}^{4+}$ or $\mathrm{Zr}^{4+}$, the amount of nonstoichiometric oxygen and redox behavior of the materials can be changed, which would remarkably enhance the catalytic performance of these materials. Thus, cerium-zirconium-based oxides are widely applied in heterogeneous catalysis especially for environmental catalysis, such as the purification of $\mathrm{CO}, \mathrm{NO}_{x}, \mathrm{NH}_{3}, \mathrm{VOC}, \mathrm{CO}_{2}$, soot, etc. In addition, the cerium-zirconium-based oxides were also widely used for fuel cells, solar energy materials, and so on.

CZO-based materials are interesting for catalysis applications, and some work should be further attempted to improve the performance of CZO-based catalysts. The basic strategies according the above description include:

(a) Adopting a suitable preparation method to improve the microstructure texture and physicochemical properties of nanosize CZO;

(b) Adjusting the $\mathrm{Ce} / \mathrm{Zr}$ ratio to promote the redox properties of CZO-based materials;

(c) Supporting active metals, e.g. noble metals Pt, Rh, and Pd or transitional metals $\mathrm{Mn}, \mathrm{Co}$, and $\mathrm{Cu}$, etc., to enhance catalytic performance of CZO-based materials;

(d) Introducing additional components to CZO to further increase lattice oxygen deficiency, improve OSC, and enhance the catalytic activity, selectivity, and adaptability of catalysts. The addition of the third component including rare earth, transition and alkaline earth or other metals can also inhibit the transformation of crystal phase of CZO and then improve the thermal stability of catalysts.

Historically, the inventors of CZO materials in the 1970s focused on their application for removal of exhaust gases to substitute the noble metal catalysts. However, this impetus has declined mainly owing to their lower OSC and thermal stability. This weakness certainly warrants further research on the subject. The correlation between catalytic performance and solid state properties is crucial for the design and tailoring of effi- cient catalysts. CZO materials should be further improved to meet the requirements of environmental catalysts for the high activity, the high selectivity, the high stability, and the high adaptability. It is anticipated that further investigations will expand the understanding for their structure and physicochemical properties and contribute to the development in the practical processes for more widely fields such as catalysis and separation, energy storage and utilization, and optical or aerospace materials.

\section{Conflicts of interest}

There are no conflicts to declare.

\section{Acknowledgments}

This work was financially supported by the National Natural Science Foundation of China (21673290, U1662103).

\section{References}

[1] J. Lelieveld, J. S. Evans, M. Fnais, D. Giannadaki, A. Pozzer, Nature, 2015, 525, 367-371.

[2] B. J. Finlayson-Pitts, J. N. Pitts Jr, Science, 1997, 276, 1045-1051.

[3] D. Devaiah, L. H. Reddy, S. E. Park, B. M. Reddy, Catal. Rev., 2018, $60,177-277$

[4] P. Gao, Z. Kang, W. Fu, W. Wang, X. Bai, E. Wang, J. Am. Chem. Soc., 2010, 132, 4197-4201.

[5] C. Misra, C. Ruehl, J. Collins, D. Chernich, J. Herner, Environ. Sci. Technol., 2017, 51, 6981-6989.

[6] H. Matsui, N. Ishiguro, K. Enomoto, O. Sekizawa, T. Uruga, M. Tada, Angew. Chem. Int. Ed., 2016, 55, 12022-12025.

[7] Y. Hu, J. Am. Chem. Soc., 2006, 89, 2949-2951.

[8] C. Larese, F. C. Galisteo, M. L. Granados, R. Mariscal, J. L. G. Fierro, P. S. Lambrou, A. M. Efstathiou, J. Catal., 2004, 226, 443-456.

[9] C. Larese, M. L. Granados, F. C. Galisteo, R. Mariscal, J. L. G. Fierro, Appl. Catal. B, 2006, 62, 132-143.

[10] T. Montini, M. Melchionna, M. Monai, P. Fornasiero, Chem. Rev., 2016, 116, 5987-6041.

[11] M. Cargnello, J. J. D. Jaen, J. C. H. Garrido, K. Bakhmutsky, T. Montini, J. J. C. Gamez, R. J. Gorte, P. Fornasiero, Science, 2012, 337, 713-717.

[12] Z. Liu, D. C. Grinter, P. G. Lustemberg, T. D. Nguyen-Phan, Y. Zhou, S. Luo, I. Waluyo, E. J. Crumlin, D. J. Stacchiola, J. Zhou, J. Carrasco, H. F. Busnengo, M. V. Ganduglia-Pirovano, S. D. Senanayake, J. A. Rodriguez, Angew. Chem. Int. Ed., 2016, 55, 7455-7459.

[13] R. Carrasquillo-Flores, I. Ro, M. D. Kumbhalkar, S. Burt, C. A. Carrero, A. C. Alba-Rubio, J. T. Miller, I. Hermans, G. W. Huber, J. A. Dumesic, J. Am. Chem. Soc., 2015, 137, 10317-10325.

[14] J. Carrasco, D. Lopez-Duran, Z. Liu, T. Duchon, J. Evans, S. D. Senanayake, E. J. Crumlin, V. Matolin, J. A. Rodriguez, M. Veronica Ganduglia-Pirovano, Angew. Chem. Int. Ed., 2015, 54, 3917-3921.

[15] X. Yao, R. Zhao, L. Chen, J. Du, C. Tao, F. Yang, L. Dong, Appl. Catal. B-Environ., 2017, 208, 82-93.

[16] W. Xu, Z. Liu, A. C. Johnston-Peck, S. D. Senanayake, G. Zhou, D. Stacchiola, E. A. Stach, J. A. Rodriguez, ACS Catal., 2013, 3, 975-984.

[17] C. Sun, H. Li, L. Chen, Energy Environ. Sci., 2012, 5, 8475-8505.

[18] H. Y. Kim, H. M. Lee, G. Henkelman, J. Am. Chem. Soc., 2012, 134, 1560-1570. 


\section{Graphical Abstract}

Chin. J. Catal., 2019, 40: 1438-1487 doi: S1872-2067(19)63400-5

Structure, synthesis, and catalytic properties of nanosize cerium-zirconium-based solid solutions in environmental catalysis

Jixing Liu, Zhen Zhao, Chunming Xu, Jian Liu *

China University of Petroleum; Shenyang Normal University

Cerium-zirconium-based solid solutions have been widely used in environmental catalysis, such as the purification for nitrogen oxides $\left(\mathrm{NO}_{\mathrm{x}}\right)$, $\mathrm{CO}$, hydrocarbon ( $\mathrm{HC}), \mathrm{CO}_{2}$ and solid particulate matters (PM).

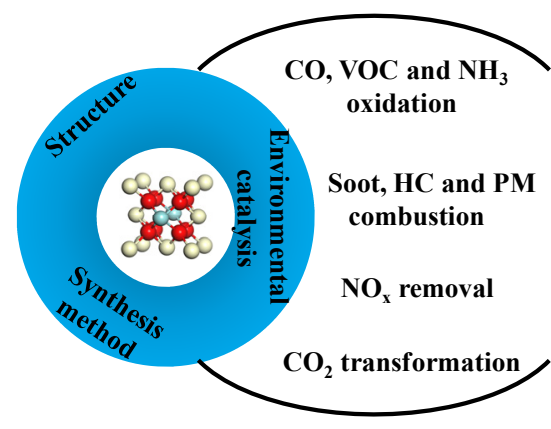

[19] J. Buckeridge, D. O. Scanlon, A. Walsh, C. R. A. Catlow, A. A. Sokol, Phys. Rev. B, 2013, 87, 214304.

[20] J. C. Hernández, A. B. Hungría, J. A. Pérez-Omil, S. Trasobares, S. Bernal, P. A. Midgley, A. Alavi, J. J. Calvino, J. Phys. Chem. C, 2007, 111, 9001-9004.

[21] C. M. Kalamaras, D. D. Dionysiou, A. M. Efstathiou, ACS Catal., 2012, 2, 2729-2742.

[22] M. Li, U. Tumuluri, Z. Wu, S. Dai, ChemSusChem, 2015, 8, 3651-3660.

[23] D. Mukherjee, B. G. Rao, B. M. Reddy, Appl. Catal. B, 2016, 197, 105-115.

[24] J. Ouyang, H. Yang, J. Phys. Chem. C, 2009, 113, 6921-6928.

[25] B. M. Reddy, P. Bharali, P. Saikia, S. E. Park, M. W. E. van den Berg, M. Muhler, W. Grünert, J. Phys. Chem. C, 2008, 112, 11729-11737.

[26] B. M. Reddy, A. Khan, Y. Yamada, T. Kobayashi, S. Loridant, J. C. Volta, J. Phys. Chem. B, 2003, 107, 11475-11484.

[27] R. Sharan, A. Dutta, J. Alloys Compd., 2017, 693, 936-944.

[28] R. Si, Y. W. Zhang, L. M. Wang, S. J. Li, B. X. Lin, W. S. Chu, Z. Y. Wu, C. H. Yan, J. Phys. Chem. C, 2007, 111, 787-794.

[29] A. Trovarelli, Comment. Inorg. Chem., 1999, 20, 263-284.

[30] K. Yin, R. J. Davis, S. Mahamulkar, C. W. Jones, P. Agrawal, H. Shibata, A. Malek, AIChE J., 2017, 63, 725-738.

[31] T. Andana, M. Piumetti, S. Bensaid, N. Russo, D. Fino, R. Pirone, Appl. Catal. B, 2016, 197, 125-137.

[32] H. Borchert, Y. Borchert, V. V. Kaichev, I. P. Prosvirin, G. M. Alikina, A. I. Lukashevich, V. I. Zaikovskii, E. M. Moroz, E. A. Paukshtis, V. I. Bukhtiyarov, J. Phys. Chem. B, 2005, 109, 20077-20086.

[33] A. V. Egranov, T. Y. Sizova, R. Y. Shendrik, N. A. Smirnova, J. Phys. Chem. Solids, 2016, 90, 7-15.

[34] S. J. Hong, A. V. Virkar, J. Am. Ceram. Soc., 1995, 78, 433-439.

[35] K. Michel, J. P. Eufinger, G. Ulbrich, M. Lerch, J. Janek, M. T. Elm, Phys. Chem. Chem. Phys., 2017, 19, 17661-17669.

[36] E. Mamontov, T. Egami, R. Brezny, M. Koranne, S. Tyagi, J. Phys. Chem. B, 2000, 104, 11110-11116.

[37] C. Loschen, A. Migani, S. T. Bromley, F. Illas, K. M. Neyman, Phys. Chem. Chem. Phys., 2008, 10, 5730-5738.

[38] P. Fornasiero, G. R. Rao, J. Kašpar, F. L'erario, M. Graziani, J. Catal., 1998, 175, 269-279.

[39] P. Fornasiero, A. Speghini, R. Di Monte, M. Bettinelli, J. Kašpar, A. Bigotto, V. Sergo, M. Graziani, Chem. Mater., 2004, 16, 1938-1944.

[40] M. Kuhn, S. Bishop, J. Rupp, H. Tuller, Acta Mater., 2013, 61, 4277-4288.

[41] A. Gupta, U. Waghmare, M. Hegde, Chem. Mater., 2010, 22, 5184-5198.
[42] A. D. Mayernick, M. J. Janik, J. Phys. Chem. C, 2008, 112, 14955-14964.

[43] M. Nolan, J. Phys. Chem. C, 2011, 115, 6671-6681.

[44] Z. Fei, X. Xie, Y. Dai, H. Liu, X. Chen, J. Tang, M. Cui, X. Qiao, Ind. Eng. Chem. Res., 2014, 53, 19438-19445.

[45] E. Rohart, O. Larcher, S. Deutsch, C. Hedouin, H. Aimin, F. Fajardie, M. Allain, P. Macaudiere, Top. Catal., 2004, 30/31, 417-423.

[46] S. Yang, M. Besson, C. Descorme, Appl. Catal. B, 2015, 165, 1-9.

[47] J. A. Anderson, R. A. Daley, S. Y. Christou, A. M. Efstathiou, Appl. Catal. B, 2006, 64, 189-200.

[48] M. Monai, T. Montini, M. Melchionna, T. Duchon, P. Kus, C. Chen, N. Tsud, L. Nasi, K. C. Prince, K. Veltruska, V. Matolin, M. M. Khader, R. J. Gorte, P. Fornasiero, Appl. Catal. B, 2017, 202, 72-83.

[49] K. A. Pokrovski, A. T. Bell, J. Catal., 2006, 241, 276-286.

[50] R. Hu, D. Li, H. Xue, N. Zhang, Z. Liu, Z. Liu, Int. J. Hydrogen Energy, 2017, 42, 7786-7797.

[51] P. S. Lambrou, S. Y. Christou, A. P. Fotopoulos, F. K. Foti, T. N. Angelidis, A. M. Efstathiou, Appl. Catal. B, 2005, 59, 1-11.

[52] S. Zeng, X. Zhang, X. Fu, L. Zhang, H. Su, H. Pan, Appl. Catal. B, 2013, $136,308-316$.

[53] J. A. Rodriguez, J. C. Hanson, J. Y. Kim, G. Liu, A. Iglesias-Juez, M. Fernández-García, J. Phys. Chem. B, 2003, 107, 3535-3543.

[54] M. Yashima, H. Arashi, M. Kakihana, M. Yoshimura, J. Am. Ceram. Soc., 1994, 77, 1067-1071.

[55] M. Yashima, K. Ohtake, M. Kakihana, M. Yoshimura, J. Am. Ceram. Soc., 1994, 77, 2773-2776.

[56] M. Yashima, H. Takashina, M. Kakihana, M. Yoshimura, J. Am. Ceram. Soc., 1994, 77, 1869-1874.

[57] F. Zhang, C. H. Chen, J. C. Hanson, R. D. Robinson, I. P. Herman, S. W. Chan, J. Am. Ceram. Soc., 2006, 89, 1028-1036.

[58] H. Tomaszewski, J. Strzeszewski, L. Adamowicz, V. Sergo, J. Am. Chem. Soc., 2002, 85, 2855-2857.

[59] M. Yashima, S. Sasaki, Y. Yamaguchi, M. Kakihana, M. Yoshimura, T. Mori, Appl. Phys. Lett., 1998, 72, 182-184.

[60] I. O. Fábregas, R. O. Fuentes, D. G. Lamas, M. E. F. De Rapp, N. E. W. de Reca, M. C. Fantini, A. F. Craievich, R. J. Prado, R. P. Millen, M. L. Temperini, J. Phys. Condens. Matter, 2006, 18, 7863-7881.

[61] M. Yashima, K. Morimoto, N. Ishizawa, M. Yoshimura, J. Am. Chem. Soc., 1993, 76, 2865-2868.

[62] V. R. Mastelaro, V. Briois, D. P. F. de Souza, C. L. Silva, J. Eur. Ceram. Soc., 2003, 23, 273-282.

[63] P. Fornasiero, E. Fonda, R. Di Monte, G. Vlaic, J. Kašpar, M. Graziani, J. Catal., 1999, 187, 177-185.

[64] G. Vlaic, P. Fornasiero, S. Geremia, J. Kašpar, M. Graziani, J. Catal., 
1997, 168, 386-392.

[65] G. Vlaic, R. Di Monte, P. Fornasiero, E. Fonda, J. Kašpar, M. Graziani, J. Catal., 1999, 182, 378-389.

[66] T. Montini, A. Speghini, L. De Rogatis, B. Lorenzut, M. Bettinelli, M. Graziani, P. Fornasiero, J. Am. Chem. Soc., 2009, 131, 13155-13160.

[67] P. Fornasiero, T. Montini, M. Graziani, J. Kašpar, A. B. Hungria, A. Martinez-Arias, J. C. Conesa, Phys. Chem. Chem. Phys., 2002, 4, 149-159.

[68] T. Montini, M. A. Banares, N. Hickey, R. Di Monte, P. Fornasiero, J. Kašpar, M. Graziani, Phys. Chem. Chem. Phys., 2004, 6, 1-3.

[69] S. Otsuka-Yao-Matsuo, T. Omata, N. Izu, H. Kishimoto, J. Solid State Chem., 1998, 138, 47-54.

[70] J. C. Conesa, J. Phys. Chem. B, 2003, 107, 8840-8853.

[71] Z. Hui, G. Nicolas, V. Françoise, P. Michèle, Solid State Ionics, 2003, 160, 317-326.

[72] S. Lemaux, A. Bensaddik, A. M. J. Van der Eerden, J. H. Bitter, D. C. Koningsberger, J. Phys. Chem. B, 2001, 105, 4810-4815.

[73] P. Fornasiero, G. Balducci, R. Di Monte, J. Kašpar, V. Sergo, G. Gubitosa, A. Ferrero, M. Graziani, J. Catal., 1996, 164, 173-183.

[74] J. Kašpar, P. Fornasiero, J. Solid State Chem., 2003, 171, 19-29.

[75] R. Di Monte, J. Kašpar, Catal. Today, 2005, 100, 27-35.

[76] A. I. Kozlov, D. H. Kim, A. Yezerets, P. Andersen, H. H. Kung, M. C. Kung, J. Catal., 2002, 209, 417-426.

[77] X. Liu, K. Zhou, L. Wang, B. Wang, Y. Li, J. Am. Chem. Soc., 2009, 131, 3140-3141.

[78] D. R. Sellick, A. Aranda, T. Garcia, J. M. Lopez, B. Solsona, A. M. Mastral, D. J. Morgan, A. F. Carley, S. H. Taylor, Appl. Catal. B-Environ., 2013, 132-132, 98-106.

[79] X. D. Wu, J. Fan, R. Ran, D. Weng, Chem. Eng. J., 2005, 109, 133-139.

[80] N. N. Gavrilova, V. V. Nazarov, Inorg. Mater., 2018, 54, 831-839.

[81] M. Ozawa, M. Kimura, A. Isogai, J. Alloys Compd., 1993, 193, 73-75.

[82] T. Murota, T. Hasegawa, S. Aozasa, H. Matsui, M. Motoyama, J. Alloys Compd., 1993, 193, 298-299.

[83] C. Bozo, F. Gaillard, N. Guilhaume, Appl. Catal. A, 2001, 220, 69-77.

[84] O. A. Kirichenko, G. W. Graham, W. Chun, R. W. McCabe, Stud. Surf. Sci. Catal., 1998, 118, 411-420.

[85] C. E. Hori, A. Brenner, K.Y. S. Ng, K. M. Rahmoellerc, D. Belton, Catal. Today, 1999, 50, 299-308.

[86] A. Cabanas, J. A. Darr, M. Poliakoff, E. Lester, Chem. Commun., 2000, 901-902.

[87] M. Hirano, T. Miwa, M. Inagaki, J. Am. Ceram. Soc., 2001, 84, 1728-1732.

[88] A. P. Oliveira, M. L. Torem, Powder Technol., 2001, 119, 181-193.

[89] D. Terribile, A. Trovarelli, J. Llorca, C. de Leitenburg, G. Dolcetti, Catal. Today, 1998, 43, 79-88.

[90] M. P. Kapoor, A. Raj, Y. Matsumura, Microporous Mesoporous Mater., 2001, 44-45, 565-572.

[91] L. Yin, Y. Wang, G. Pang, Y. Koltypin, A. Gedanken, J. Colloid Interface Sci., 2002, 246, 78-84.

[92] C. C. Chuang, H. I. Hsiang, F. S. Yen, C. C. Chen, S. J. Yang, Ceram. Int., 2013, 39, 1717-1722.

[93] Y. Zhou, L. Lan, M. Gong, Y. Chen, J. Mater. Sci., 2016, 51, 4283-4295.

[94] M. Thammachart, V. Meeyoo, T. Rirksomboon, S. Osuwan, Catal. Today, 2001, 68, 53-61.

[95] H. Liang, S. Wu, Y. Hong, S. Li, Y. Chen, X. Yu, D. Ye, Catal. Lett., 2014, 144, 685-690.

[96] M. Chen, P. Z. Zheng, Z. B. Hang, X. M. Zheng, J. Inorg. Mater., 2004, 19, 661-665.

[97] Q. Yuan, Q. Liu, W. G. Song, W. Feng, W. L. Pu, L. D. Sun, Y. W. Zhang,
C. H. Yan, J. Am. Chem. Soc., 2007, 129, 6698-6699.

[98] S. Abdollahzadeh-Ghom, C. Zamani, T. Andreu, M. Epifani, J. R. Morante, Appl. Catal. B, 2011, 108-109, 32-38.

[99] Y. Wei, J. Liu, Z. Zhao, A. Duan, G. Jiang, C. Xu, J. Gao, H. He, X. Wang, Energy Environ. Sci., 2011, 4, 2959-2970.

[100] Y. Wei, J. Jiao, X. Zhang, B. Jin, Z. Zhao, J. Xiong, Y. Li, J. Liu, J. Li, Nanoscale, 2017, 9, 4558-4571.

[101] Y. Wei, J. Liu, Z. Zhao, A. Duan, G. Jiang, J. Catal., 2012, 287, 13-29.

[102] G. Zhang, Z. Zhao, J. Liu, G. Jiang, A. Duan, J. Zheng, S. Chen, R. Zhou, Chem. Commun., 2010, 46, 457-459.

[103] G. Zhang, Z. Zhao, J. Xu, J. Zheng, J. Liu, G. Jiang, A. Duan, H. He, Appl. Catal. B, 2011, 107, 302-315.

[104] Y. Wei, J. Liu, Z. Zhao, G. Jiang, A. Duan, H. He, X. Wang, Chin. J. Catal., 2010, 31, 283-288.

[105] E. Matijevic, W. P. Hsu, J. Colloid Interface Sci., 1987, 118, 506-523.

[106] C. S. Wright, R. I. Walton, D. Thompsett, J. Fisher, S. E. Ashbrook, Adv. Mater., 2007, 19, 4500-4504.

[107] J. R. Kim, W. J. Myeong, S. K. Ihm, Appl. Catal. B, 2007, 71, 57-63.

[108] D. Rangappa, T. Naka, A. Kondo, M. Ishii, T. Kobayashi, T. Adschiri, J. Am. Chem. Soc., 2007, 129, 11061-11066.

[109] D. Rangappa, S. Ohara, T. Naka, A. Kondo, M. Ishii, T. Adschiri, J. Mater. Chem., 2007, 17, 4426-4429.

[110] M. K. Devaraju, X. Liu, K. Yusuke, S. Yin, T. Sato, Nanotechnology, 2009, 20, 405606.

[111] B. M. Reddy, G. K. Reddy, I. Ganesh, J. M. F. Ferreira, J. Mater. Sci., 2009, 44, 2743-2751.

[112] W. Chen, F. Li, J. Yu, L. Liu, H. Gao, Mater. Res. Bull., 2006, 41, 2318-2324.

[113] Z. Zhang, Y. Zhang, Z. Mu, P. Yu, X. Ni, S. Wang, L. Zheng, Appl. Catal. $B, 2007,76,335-347$.

[114] S. N. Mlondo, P. J. Thomos, P. O’Brien, J. Am. Chem. Soc., 2009 , 131, 6072-6073.

[115] J. Gong, X. Bao, Chem. Soc. Rev., 2017, 46, 1770-1771.

[116] Q. Wang, Z. Li, B. Zhao, G. Li, R. Zhou, J. Mol. Catal. A, 2011, 344, 132-137.

[117] M. Sanchez-Dominguez, M. Boutonnet, C. Solans, J. Nanopart. Res., 2009, 11, 1823-1829.

[118] H. Yang, C. Du, W. Yang, C. Huang, X. Zhang, Mater. Rev., 2004, 18, 25-28.

[119] J. Y. Chane-Ching, F. Cobo, D. Aubert, H. G. Harvey, M. Airiau, A. Corma, Chem. Eur. J., 2005, 11, 979-987.

[120] L. Xu, H. Song, L. Chou, Int. J. Hydrogen Energy, 2012, 37, 18001-18020.

[121] K. S. Suslick, M. M. Fang, T. Hyeon, M. M. Mdleleni, in: L. A. Crum, T. J. Mason, J. L. Reisse, K. S. Suslick eds, Sonochemistry and Sonoluminescence, Kluwer Academic Publishers, 1999, NATO ASI Series C, Vol. 524, 291-320.

[122] A. Gurav, T. Kodas, T. Pluym, Y. Xiong, Aerosol Sci. Technol., 1993, 19, 411-452.

[123] J. Guo, X. Xin, X. Zhang, S. Zhang, J. Nanopart. Res., 2009, 11, 737-741.

[124] C. Cau, Y. Guari, T. Chave, J. Larionova, P. Pochon, S. I. Nikitenko, J. Phys. Chem. C, 2013, 117, 22827-22833.

[125] A. Trovarelli, F. Zamar, J. Llorca, C. De Leitenburg, G. Dolcetti, J. T. Kiss, J. Catal., 1997, 169, 490-502.

[126] E. Aneggi, V. Rico-Perez, C. de Leitenburg, S. Maschio, L. Soler, J. Llorca, A. Trovarelli, Angew. Chem. Int. Ed., 2015, 54, 14010-14043.

[127] W. T. Gibbons, L. J. Venstrom, R. M. De Smith, J. H. Davidson, G. S. Jackson, Phys. Chem. Chem. Phys., 2014, 16, 14271-14280. 
[128] M. Kim, R. M. Laine, J. Am. Chem. Soc., 2009, 131, 9220-9229.

[129] J. C. Yu, L. Zhang, J. Lin, J. Colloid Interface Sci., 2003, 260, 240-243.

[130] R. Strobel, H. J. Metz, S. E. Pratsinis, Chem. Mater., 2008, 20, 6346-6351.

[131] Y. Zhang, D. Kang, C. Saquing, M. Aindow, C. Erkey, Ind. Eng. Chem. Res., 2005, 44, 4161-4164.

[132] S. A. Kondrat, S. H. Taylor, Catalysis, 2014, 26, 218-248.

[133] D. Das, G. Thrimurthulu, K. Lakshmi, B. M. Reddy, Int. J. Nanotechnol., 2010, 7, 1166-1177.

[134] B. M. Reddy, P. Bharali, Y. H. Seo, E. A. Prasetyanto, S. E. Park, Catal. Lett., 2008, 126, 125-133.

[135] B. M. Reddy, G. K. Reddy, I. Ganesh, J. M. F. Ferreira, Catal. Lett., 2009, 130, 227-234.

[136] B. M. Reddy, G. K. Reddy, L. Katta, J. Mol. Catal. A, 2010, 319, 52-57.

[137] G. R. Li, D. L. Qu, Y. X. Tong, J. Phys. Chem. C, 2009, 113, 2704-2709.

[138] I. Avramova, D. Stoychev, T. Marinova, Appl. Surf. Sci., 2006, 253, 1365-1370.

[139] L. M. Toscani, M. G. Zimicz, J. R. Casanova, S. A. Larrondo, Int. J. Hydrogen Energy, 2014, 39, 8759-8766.

[140] S. Manjunatha, M. S. Dharmaprakash, Mater. Res. Express, 2018, $5,035043$.

[141] I. I. Soykal, H. Sohn, D. Singh, J. T. Miller, U. S. Ozkan, ACS Catal., 2014, 4, 585-592.

[142] R. Di Monte, P. Fornasiero, S. Desinan, J. Kašpar, J. M. Gatica, J. J. Calvino, E. Fonda, Chem. Mater., 2004, 16, 4273-4285.

[143] X. Weng, B. Perston, X. Z. Wang, I. Abrahams, T. Lin, S. Yang, J. R. G. Evans, D. J. Morgan, A. F. Carley, M. Bowker, J. C. Knowles, I. Rehman, J. A. Darr, Appl. Catal. B, 2009, 90, 405-415.

[144] M. Soh, D. W. Kang, H. G. Jeong, D. Kim, D. Y. Kim, W. Yang, C. Song, S. Baik, I. Y. Choi, S. K. Ki, H. J. Kwon, T. Kim, C. K. Kim, S. H. Lee, T. Hyeon, Angew. Chem. Int. Ed., 2017, 56, 11399-11403.

[145] R. Si, Y. W. Zhang, L. P. You, C. H. Yan, J. Phys. Chem. B, 2006, 110, 5994-6000.

[146] Y. Du, J. Zhang, H. He, J. Chin. Rare Earth Soc., 2003, 21(S2), 44-47.

[147] J. Liu, Z. Zhao, C. Xu, A. Duan, L. Wang, S. Zhang, Catal. Commun., 2007, 8, 220-224.

[148] C. Chen, Y. Yu, W. Li, C. Cao, P. Li, Z. Dou, W. Song, J. Mater. Chem., 2011, 21, 12836-12841.

[149] G. R. Li, D. L. Qu, Y. X. Tong, Electrochem. Commun., 2008, 10, 80-84.

[150] T. Y. Yu, J. Joo, Y. I. Park, T. Hyeon, Angew. Chem. Int. Ed., 2005, 44, 7411-7414.

[151] Y. Du, S. Shi, H. He, H. Dai, Particuology, 2011, 9, 63-68.

[152] A. Chen, Y. Zhou, N. Ta, Y. Li, W. Shen, Catal. Sci. Technol., 2015, 5, 4184-4192.

[153] W. T. Chen, K. B. Chen, M. F. Wang, S. F. Weng, C. S. Lee, M. C. Lin, Chem. Commun., 2010, 46, 3286-3288.

[154] R. Gao, D. Zhang, P. Maitarad, L. Shi, T. Rungrotmongkol, H. Li, J. Zhang, W. Cao, J. Phys. Chem. C, 2013, 117, 10502-10511.

[155] P. Maitarad, D. Zhang, R. Gao, L. Shi, H. Li, L. Huang, T. Rungrotmongkol, J. Zhang, J. Phys. Chem. C, 2013, 117, 9999-10006.

[156] Y. Zhang, L. Zhang, J. Deng, H. Dai, H. He, Inorg. Chem., 2009, 48, 2181-2192.

[157] L. Yan, X. Xing, R. Yu, L. Qiao, J. Chen, J. Deng, G. Liu, Scripta Mater., 2007, 56, 301-304.

[158] W. Q. Han, L. J. Wu, Y. M. Zhu, J. Am. Chem. Soc., 2005, 127, 12814-12815.

[159] N. Karousis, I. Suarez-Martinez, C. P. Ewels, N. Tagmatarchis,
Chem. Rev., 2016, 116, 4850-4883.

[160] M. Prato, Nature, 2010, 465, 172-173.

[161] R. O. Fuentes, L. M. Acuna, M. G. Zimic, D. G. Lamas, J. G. Sacanell, A. G. Leyva, R. T. Baker, Chem. Mater., 2008, 20, 7356-7363.

[162] Y. C. Chen, K. B. Chen, C. S. Lee, M. Lin, J. Phys. Chem. C, 2009, 113, 5031-5034.

[163] E. L. Crepaldi, G. J. de A. A. Soler-Illia, A. Bouchara, D. Grosso, D. Durand, C. Sanchez, Angew. Chem. Int. Ed., 2003, 42, 347-351.

[164] X. Luo, B. Zhu, C. Xia, G. Niklasson, C. Granqvist, Sol. Energy Mater. Sol. Cells, 1998, 53, 341-347.

[165] M. Veszelei, L. Kullman, A. Azens, C. G. Granqvist, B. Hjörvarsson, J. Appl. Phys., 1997, 81, 2024-2026.

[166] T. Brezesinski, M. Antonietti, M. Groenewolt, N. Pinna, B. Smarsly, New J. Chem., 2005, 29, 237-242.

[167] I. L. Violi, A. Zelcer, M. M. Bruno, V. Luca, G. J. A. A. Soler-Illia, ACS Appl. Mater. Interfaces, 2015, 7, 1114-1121.

[168] P. Hartmann, T. Brezesinski, J. Sann, A. Lotnyk, J. P. Eufinger, L. Kienle, J. Janek, ACS Nano, 2013, 7, 2999-3013.

[169] X. Liang, X. Wang, Y. Zhuang, B. Xu, S. Kuang, Y. Li, J. Am. Chem. Soc., 2008, 130, 2736-2737.

[170] J. Wang, W. Xu, L. Chen, Y. Jia, L. Wang, X. J. Huang, J. Liu, Chem. Eng. J., 2013, 231, 198-205.

[171] D. Terribile, A. Trovarelli, J. Llorca, C. de Leitenburg, G. Dolcetti, J. Catal., 1998, 178, 299-308.

[172] A. S. Deshpande, N. Pinna, B. Smarsly, M. Antonietti, M. Niederberger, Small, 2005, 1, 313-316.

[173] R. Si, Y. W. Zhang, C. X. Xiao, S. J. Li, B. X. Lin, Y. Kou, C. H. Yan, Phys. Chem. Chem. Phys., 2004, 6, 1056-1063.

[174] M. Crocker, U. M. Graham, R. Gonzalez, G. Jacobs, E. Morris, A. M. Rubel, R. Andrews, J. Mater. Sci., 2007, 42, 3454-3464.

[175] Y. Gu, S. Feng, J. Li, X. Gu, M. Wang, J. Rare Earths, 2007, 25, 710-714.

[176] A. S. Deshpande, M. Niederberger, Microporous Mesoporous Mater., 2007, 101, 413-418.

[177] B. Puertolas, B. Solsona, S. Agouram, R. Murillo, A. M. Mastral, A. Aranda, S. H. Taylor, T. Garcia, Appl. Catal. B, 2010, 93, 395-405.

[178] C. Li, X. Gu, Y. Wang, Y. Wang, Y. Wang, X. Liu, G. Lu, J. Rare Earths, 2009, 27, 211-215.

[179] S. Li, J. Zheng, W. Yang, Y. Zhao, Y. Liu, J. Porous Mater., 2008, 15, 589-592.

[180] S. Li, J. Zheng, Y. Zhao, Y. Liu, J. Porous Mater., 2009, 16, 553-556.

[181] Y. Cheng, J. Liu, Z. Zhao, Y. Wei, W. Song, C. Xu, Environ. Sci. Nano, 2017, 4, 1168-1177.

[182] Y. Cheng, W. Song, J. Liu, H. Zheng, Z. Zhao, C. Xu, Y. Wei, E. J. M. Hensen, ACS Catal., 2017, 7, 3883-3892.

[183] Y. Wei, J. Liu, Z. Zhao, C. Xu, A. Duan, G. Jiang, Appl. Catal. A, 2013, 453, 250-261.

[184] Y. Cheng, J. Liu, Z. Zhao, W. Song, Y. Wei, Chem. Eng. Sci., 2017, 167, 219-228.

[185] H. Arandiyan, H. Dai, K. Ji, H. Sun, J. Li, ACS Catal., 2015, 5, 1781-1793.

[186] W. Xu, J. Wang, L. Wang, G. Sheng, J. Liu, H. Yu, X. J. Huang, J. Hazard. Mater., 2013, 260, 498-507.

[187] C. M. Ho, J. C. Yu, X. C. Wang, S. Y. Lai, Y. F. Qiu, J. Mater. Chem., 2005, 15, 2193-2201.

[188] J. Xiong, Q. Wu, X. Mei, J. Liu, Y. Wei, Z. Zhao, D. Wu, J. Li, ACS Catal., 2018, 8, 7915-7930.

[189] G. R. Li, D. L. Qu, Y. X. Tong, J. Phys. Chem. C., 2009, 113, 2704-2709.

[190] B. Li, X. Wei, W. Pan, J. Power Sources, 2009, 193, 598-601.

[191] M. Ozawa, M. Takahashi-Morita, K. Kobayashi, M. Haneda, Catal. Today, 2017, 281, 482-489. 
[192] S. I. Matsumoto, Catal. Today, 2004, 90, 183-190.

[193] S. Bernal, G. Blanco, J. J. Calvino, J. C. Hernandez, J. A. Perez-Omil, J. M. Pintado, M. R. Yeste, J. Alloys Compd., 2008, 451, 521-525.

[194] M. Sugiura, Catal. Surv. Asia, 2003, 7, 77-87.

[195] J. Wang, H. Chen, Z. Hu, M. Yao, Y. Li, Catal. Rev.-Sci. Eng., 2015, 57, 79-144.

[196] K. Wu, L. D. Sun, C. H. Yan, Adv. Energy Mater., 2016, 6, 1600501.

[197] A. Arango-Diaz, J. A. Cecilia, E. Moretti, A. Talon, P. Nunez, J. Marrero-Jerez, J. Jimenez-Jimenez, A. Jimenez-Lopez, E. Rodriguez-Castellon, Int. J. Hydrogen Energy, 2014, 39, 4102-4108.

[198] K. Liu, A. Wang, T. Zhang, ACS Catal., 2012, 2, 1165-1178.

[199] E. Moretti, L. Storaro, A. Talon, P. Riello, A. I. Molina, E. Rodriguez-Castellon, Appl. Catal. B, 2015, 168-169, 385-395.

[200] H. Choi, J. Kim, S. J. Choung, J. Kim, M. R. Othman, Chem. Eng. Sci., 2017, 172, 688-693.

[201] M. Boaro, C. De Leitenburg, G. Dolcetti, A. Trovarelli, J. Catal., 2000, 193, 338-347.

[202] Z. Zhao, X. Lin, R. Jin, Y. Dai, G. Wang, Catal. Sci. Technol., 2012, 2, 554-563.

[203] P. Bharali, P. Saikia, L. Katta, B. M. Reddy, J. Ind. Eng. Chem., 2013, 19, 327-336.

[204] J. L. Ayastuy, A. Gurbani, M. P. González-Marcos, M. A. Gutiérrez-Ortiz, Appl. Catal. A, 2010, 387, 119-128.

[205] Y. Z. Chen, B. J. Liaw, H. C. Chen, Int. J. Hydrogen Energy, 2006, 31, 427-435.

[206] B. M. Reddy, P. Lakshmanan, P. Bharali, P. Saikia, G. Thrimurthulu, M. Muhler, W. Grünert, J. Phys. Chem C, 2007, 111, 10478-10483.

[207] M. Teng, L. Luo, X. Yang, Microporous Mesoporous Mater., 2009, $119,158-164$.

[208] Z. Zhao, R. Jin, T. Bao, X. Lin, G. Wang, Appl. Catal. B, 2011, 110, 154-163.

[209] J. Liu, B. Liu, Y. Fang, Z. Zhao, Y. Wei, X. Q. Gong, C. Xu, A. Duan, G. Jiang, Environ. Sci. Technol., 2014, 48, 12403-12410.

[210] Z. Yang, T. K. Woo, K. Hermansson, J. Chem. Phys., 2006, 124, 224704.

[211] Y. Tang, H. Zhang, L. Cui, C. Ouyang, S. Shi, W. Tang, H. Li, J. S. Lee, L. Chen, Phys. Rev. B, 2010, 82, 125104.

[212] M. Boaro, F. Giordano, S. Recchia, V. Dal Santo, M. Giona, A. Trovarelli, Appl. Catal. B, 2004, 52, 225-237.

[213] W. S. Epling, L. E. Campbell, A. Yezerets, N. W. Currier, J. E. Parks, Catal. Rev.-Sci. Eng., 2004, 46, 163-245.

[214] I. Atribak, A. Bueno-López, A. Garcia-Garcia, J. Catal., 2008, 259, 123-132.

[215] A. Bueno-López, D. Lozano-Castelló, I. Such-Basáñez, J. M. García-Cortés, M. J. Illán-Gómez, C. S. M. de Lecea, Appl. Catal. B, 2005, 58, 1-7.

[216] I. Atribak, N. Guillen-Hurtado, A. Bueno-Lopez, A. Garcia-Garcia, Appl. Surf. Sci., 2010, 256, 7706-7712.

[217] W. Cai, Q. Zhong, S. Zhang, W. Zhao, Chem. Eng. J., 2014, 236, 223-232.

[218] W. Cai, Q. Zhong, W. Zhao, Y. Bu, Appl. Catal. B, 2014, 158-159, 258-268.

[219] W. Cai, Q. Zhong, W. Zhao, Chem. Eng. J., 2014, 246, 328-336.

[220] W. Cai, Q. Zhong, J. Ding, Y. Bu, Chem. Eng. J., 2015, 270, 1-8.

[221] D. Shang, Q. Zhong, W. Cai, J. Mol. Catal. A, 2015, 399, 18-24.

[222] M. Ehn, J. A. Thornton, E. Kleist, M. Sipila, H. Junninen, I. Pullinen, M. Springer, F. Rubach, R. Tillmann, B. Lee, F. Lopez-Hilfiker, S. Andres, I. H. Acir, M. Rissanen, T. Jokinen, S. Schobesberger, J. Kangasluoma, J. Kontkanen, T. Nieminen, T. Kurten, L. B. Nielsen, S. Jorgensen, H. G. Kjaergaard, M. Canagaratna, M. Dal Maso, T. Berndt, T. Petaja, A. Wahner, V. M. Kerminen, M. Kulmala, D. R.
Worsnop, J. Wildt, T. F. Mentel, Nature, 2014, 506, 476-479.

[223] M. S. Kamal, S. A. Razzak, M. M. Hossain, Atmos. Environ., 2016, 140, 117-134.

[224] I. Ben Said, K. Sadouki, S. Masse, T. Coradin, L. S. Smiri, S. Fessi, Microporous Mesoporous Mater., 2018, 260, 93-101.

[225] K. Eguchi, H. Arai, Catal. Today, 1996, 29, 379-386.

[226] Z. Zhang, Q. Yang, H. Chen, K. Chen, X. Lu, P. Ouyang, J. Fu, J. G. Chen, Green Chem., 2018, 20, 197-205.

[227] S. Pengpanich, V. Meeyoo, T. Rirksomboon, K. Bunyakiat, Appl. Catal. A, 2002, 234, 221-233.

[228] L. Ma, M. F. Luo, L. F. Han, S. Y. Chen, React. Kinet. Catal. Lett., 2000, 70, 357-362.

[229] Z. Zhou, S. Ji, F. Yin, Z. Lu, C. Li, J. Fuel Chem. Technol., 2007, 35, 583-588.

[230] Y. Zhang, J. Deng, L. Zhang, W. Qiu, H. Dai, H. He, Catal. Today, 2008, 139, 29-36.

[231] C. Bozo, N. Guilhaume, J. M. Herrmann, J. Catal., 2001, 203, 393-406.

[232] Z. M. Liu, Y. Q. Chen, J. B. Zhong, J. L. Wang, S. H. Yan, M. C. Gong, J. Rare Earths, 2007, 25, 585-589.

[233] L. F. Liotta, G. Di Carlo, G. Pantaleo, G. Deganello, Appl. Catal. B, 2007, 70, 314-322.

[234] C. Bozo, N. Guilhaume, E. Garbowski, M. Primet, Catal. Today, 2000, 59, 33-45.

[235] M. Li, X. Wu, J. Wan, S. Liu, R. Ran, D. Weng, Catal. Today, 2015, 242, 322-328.

[236] G. Wang, M. Meng, Y. Zha, T. Ding, Fuel, 2010, 89, 2244-2251.

[237] G. Wang, R. You, M. Meng, Fuel, 2013, 103, 799-804.

[238] Y. Zheng, Y. Zheng, Y. Xiao, G. Cai, K. Wei, Catal. Commun., 2013, 39, 1-4.

[239] D. Terribile, A. Trovarelli, C. de Leitenburg, A. Primavera, G. Dolcetti, Catal. Today, 1999, 47, 133-140.

[240] S. S. Deshmukh, M. Zhang, V. I. Kovalchuk, J. L. D’Itri, Appl. Catal. $B, \mathbf{2 0 0 3}, 45,135-145$.

[241] N. Kamiuchi, M. Haneda, M. Ozawa, Catal. Today, 2015, 241, 100-106.

[242] D. Homsi, S. Aouad, J. El Nakat, B. El Khoury, P. Obeid, E. Abi-Aad, A. Aboukaïs, Catal. Commun., 2011, 12, 776-780.

[243] C. Hu, Q. Zhu, Z. Jiang, Powder Technol., 2009, 194, 109-114.

[244] P. Topka, L. Kaluža, J. Gaálová, Chem. Pap., 2016, 70, 898-906.

[245] L. Zhao, Q. Zhang, M. Luo, B. Teng, Yu. Xie, J. Rare Earths, 2007, 25, 715-720.

[246] W. Tan, G. Guo, J. Deng, S. Xie, H. Yang, Y. Jiang, H. Dai, Ind. Eng. Chem. Res., 2014, 53, 18452-18461.

[247] W. Tan, J. Deng, S. Xie, H. Yang, Y. Jiang, G. Guo, H. Dai, Nanoscale, 2015, 7, 8510-8523.

[248] Q. F. Deng, T. Z. Ren, A. Bao, Y. Liu, Z. Y. Yuan, J. Ind. Eng. Chem., 2014, 20, 3303-3312.

[249] P. Kaminski, M. Ziolek, Appl. Catal. B, 2016, 187, 328-341.

[250] M. Zhao, X. Li, L. Zhang, C. Zhang, M. Gong, Y. Chen, Catal. Today, 2011, 175, 430-434.

[251] Y. Y. Liu, T. Hayakawa, T. Ishii, M. Kumagai, H. Yasuda, K. Suzuki, S. Hamakawa, K. Murata, Appl. Catal. A, 2001, 210, 301-314.

[252] T. Rao, M. Shen, L. Jia, J. Hao, J. Wang, Catal. Commun., 2007, 8, 1743-1747.

[253] H. Cao, W. Song, M. Gong, J. Wang, S. Yan, Z. Liu, Y. Chen, J. Nat. Gas Chem., 2009, 18, 83-87.

[254] J. Gaálová, P. Topka, L. Kaluža, O. Šolcová, Catal. Today, 2011, 175, 231-237.

[255] S. Azalim, M. Franco, R. Brahmi, J. M. Giraudon, J. F. Lamonier, J. Hazard. Mater., 2011, 188, 422-427.

[256] R. Pagadala, S. Maddila, S. Rana, S. B. Jonnalagadda, RSC Adv., 
2014, 4, 6602-6607.

[257] Y. Yang, X. Xu, K. Sun, J. Hazard. Mater., 2007, 139, 140-145.

[258] S. Li, Q. Hao, R. Zhao, D. Liu, H. Duan, B. Dou, Chem. Eng. J., 2016, 285, 536-543.

[259] H. Y. Cao, J. L. Wang, S. H. Yan, Z. M. Liu, M. C. Gong, Y. Q. Chen, Acta Phys.-Chim. Sin., 2012, 28, 1936-1942.

[260] B. de Rivas, R. Lopez-Fonseca, C. Sampedro, J. I. Gutierez-Ortiz, Appl. Catal. B, 2009, 90, 545-555.

[261] L. Matejova, P. Topka, L. Kaluza, S. Pitkaaho, S. Ojala, J. Gaalova, R. L. Keiski, Appl. Catal. B, 2013, 142, 54-64.

[262] B. de Rivas, C. Sampedro, M. Garcia-Real, R. Lopez-Fonseca, J. I. Gutierrez-Ortiz, Appl. Catal. B, 2013, 129, 225-235.

[263] N. Li, C. Descorme, M. Besson, Catal. Commun., 2007, 8, 1815-1819.

[264] J. I. Gutiérrez-Ortiz, B. de Rivas, R. López-Fonseca, J. R. González-Velasco, Catal. Today, 2005, 107-108, 933-941.

[265] B. de Rivas, R. López-Fonseca, J. R. González-Velasco, J. I. Gutiérrez-Ortiz, Catal. Commun., 2008, 9, 2018-2021.

[266] M. M. R. Feijen-Jeurissen, J. J. Jorna, B. E. Nieuwenhuys, G. Sinquin, C. Petit, J. P. Hindermann, Catal. Today, 1999, 54, 65-79.

[267] B. de Rivas, J. I. Gutierrez-Ortiz, R. Lopez-Fonseca, J. R. Gonzalez-Velasco, Appl. Catal. A, 2006, 314, 54-63.

[268] A. Bueno-López, Appl. Catal. B, 2014, 146, 1-11.

[269] E. Aneggi, C. de Leitenburg, A. Trovarelli, in: A. Trovarelli, P. Fornasiero eds, Catalysis by Ceria and Related Materials, 2nd ed., Imperial College Press, London, 2013, 565-621.

[270] K. Kochloefl, in: G. Ertl, H. Knözinger, J. Weitkamp eds.,, Handbook of Heterogeneous Catalysis, Vol. 4, Wiley-VCH, Weinheim, 1997, 1831.

[271] J. A. Sullivan, P. Dulgheru, I. Atribak, A. Bueno-Lopez, A. Garcia-Garcia, Appl. Catal. B, 2011, 108-109, 134-139.

[272] B. M. Reddy, P. Bharali, G. Thrimurthulu, P. Saikia, L. Katta, S. E. Park, Catal. Lett., 2008, 123, 327-333.

[273] S. Liu, X. Wu, D. Weng, R. Ran, J. Rare Earths, 2015, 33, 567-590.

[274] C. Lee, Y. Jeon, T. Kim, A. Tou, J. I. Park, H. Einaga, Y. G. Shul, Fuel, 2018, 212, 395-404.

[275] S. Bensaid, M. Piumetti, C. Novara, F. Giorgis, A. Chiodoni, N. Russo, D. Fino, Nanoscale Res. Lett., 2016, 11, 494-508.

[276] I. Atribak, A. Bueno-Lopez, A. Garcia-Garcia, Catal. Commun., 2008, 9, 250-255.

[277] E. Aneggi, D. Wiater, C. de Leitenburg, J. Llorca, A. Trovarelli, ACS Catal., 2014, 4, 172-181.

[278] J. Oi-Uchisawa, A. Obuchi, S. Wang, T. Nanba, A. Ohi, Appl. Catal. B-Environ., 2003, 43, 117-129.

[279] C. A. Neyertz, E. D. Banús, E. E. Miró, C. A. Querini, Chem. Eng. J., 2014, 248, 394-405.

[280] E. Aneggi, C. de Leitenburg, J. Llorca, A. Trovarelli, Catal. Today, 2012, 197, 119-126.

[281] E. D. Banús, V. G. Milt, E. E. Miró, M. A. Ulla, Appl. Catal. A, 2009, $362,129-138$.

[282] T. Andana, M. Piumetti, S. Bensaid, N. Russo, D. Fino, R. Pirone, Nanoscale Res. Lett., 2016, 11, 278.

[283] M. Piumetti, S. Bensaid, N. Russo, D. Fino, Appl. Catal. B, 2016, $180,271-282$.

[284] E. Aneggi, C. de Leitenburg, G. Dolcetti, A. Trovarelli, Catal. Today, 2006, 114, 40-47.

[285] L. Katta, P. Sudarsanam, G. Thrimurthulu, B. M. Reddy, Appl. Catal. B, 2010, 101, 101-108.

[286] I. Atribak, A. Bueno-López, A. García-García, J. Mol. Catal. A, 2009, 300, 103-110.

[287] Z. Gu, X. Sang, H. Wang, K. Li, J. Rare Earths, 2014, 32, 817-823.

[288] Y. Wei, J. Liu, Z. Zhao, Y. Chen, C. Xu, A. Duan, G. Jiang, H. He, An- gew. Chem. Int. Ed., 2011, 50, 2326-2329.

[289] N. V. Zaletova, A. O. Turakulova, V. V. Lunin, Stud. Surf. Sci. Catal., 2010, 175, 305-309.

[290] J. Barbier Jr., F. Delanoë, F. Jabouille, D. Duprez, G. Blanchard, P. Isnard, J. Catal., 1998, 177, 378-385.

[291] M. Nishiumi, H. Miura, K. Wada, S. Hosokawa, M. Inoue, ACS Catal., 2012, 2, 1753-1759.

[292] Y. Y. Gorbanev, S. Kegnæs, C. W. Hanning, T. W. Hansen, A. Riisager, ACS Catal., 2012, 2, 604-612.

[293] S. Aouad, E. Abi-Aad, A. Aboukaïs, Appl. Catal. B, 2009, 88, 249-256.

[294] L. Nascimento, R. Martins, R. Silva, P. de Sousa Filho, O. Serra, React. Kinet. Mech. Catal., 2014, 111, 149-165.

[295] X. Deng, M. Li, J. Zhang, X. Hu, J. Zheng, N. Zhang, B. H. Chen, Chem. Eng. J., 2017, 313, 544-555.

[296] Q. Liang, X. Wu, D. Weng, Z. Lu, Catal. Commun., 2008, 9, 202-206.

[297] K. N. Rao, P. Venkataswamy, B. M. Reddy, Ind. Eng. Chem. Res., 2011, 50, 11960-11969.

[298] Y. H. Zhang, H. L. Zhang, Y. Cao, Y. Yang, B. Q. Xu, M. Zhao, M. C. Gong, H. D. Xu, Y. Q. Chen, Chem. Pap., 2016, 70, 1370-1379.

[299] B. M. Reddy, K. N. Rao, Catal. Commun., 2009, 10, 1350-1353.

[300] V. S. Escribano, E. F. López, J. M. Gallardo-Amores, C. del Hoyo Martínez, C. Pistarino, M. Panizza, C. Resini, G. Busca, Combust. Flame, 2008, 153, 97-104.

[301] A. Alinezhadchamazketi, A. A. Khodadadi, Y. Mortazavi, A. Nemati, J. Environ. Sci., 2013, 25, 2498-2506.

[302] M. Peralta, V. Milt, L. Cornaglia, C. Querini, J. Catal., 2006, 242, 118-130.

[303] E. Miró, F. Ravelli, M. Ulla, L. Cornaglia, C. Querini, Catal. Today, 1999, 53, 631-638.

[304] L. Zhu, X. Wang, React. Kinet. Mech. Catal., 2014, 112, 383-395.

[305] X. Wu, D. Liu, K. Li, J. Li, D. Weng, Catal. Commun., 2007, 8, 1274-1278.

[306] R. Matarrese, E. Aneggi, L. Castoldi, J. Llorca, A. Trovarelli, L. Lietti, Catal. Today, 2016, 267, 119-129.

[307] A. Bueno-López, K. Krishna, M. Makkee, J. Moulijn, J. Catal., 2005, 230, 237-248.

[308] J. A. Moulijn, F. Kapteijn, Carbon, 1995, 33, 1155-1165.

[309] J. Phillips, VIGYAN, Inc., Vienna, VA, 1995.

[310] M. A. Wojtowicz, F. P. Miknis, R. Grimes, W. W. Smith, M. A. Serio, J. Hazard. Mater., 2000, 74, 81-89.

[311] F. E. Spokoyny, US Patent 6264905, 2001.

[312] E. Ito, R. Hultermans, P. Lugt, M. Burgers, H. Van Bekkum, C. Van den Bleek, Stud. Surf. Sci. Catal., 1995, 96, 661-673.

[313] T. V. Johnson, SAE Technical paper, 2002-01-0285, 2002.

[314] G. Olofsson, L. R. Wallenberg, A. Andersson, J. Catal., 2005, 230, 1-13.

[315] Z. Wang, Z. Qu, X. Quan, H. Wang, Appl. Catal. A, 2012, 411-412, 131-138.

[316] Z. Wang, Z. Qu, R. Fan, Sep. Purif. Technol., 2015, 147, 24-31.

[317] Z. Qu, Z. Wang, X. Zhang, H. Wang, Catal. Sci. Technol., 2016, 6, 4491-4502.

[318] S. Nassos, E. E. Svensson, M. Boutonnet, S. G. Jaras, Appl. Catal. B, 2007, 74, 92-102.

[319] W. Chen, Y. Ma, Z. Qu, Q. Liu, W. Huang, X. Hu, N. Yan, Environ. Sci. Technol., 2014, 48, 12199-12205.

[320] J. Breen, R. Burch, C. Hardacre, C. Hill, C. Rioche, J. Catal., 2007, 246, 1-9.

[321] S. Morin, J. Savarino, M. M. Frey, N. Yan, S. Bekki, J. W. Bottenheim, J. M. F. Martins, Science, 2008, 322, 730-732.

[322] J. X. Liu, L. Wang, W. Y. Song, M. J. Zhao, J. Liu, H. Wang, Z. Zhao, C. 
M. Xu, Z. C. Duan, ACS Sustain. Chem. Eng., 2019, 7, 2811-2820.

[323] A. Schilt, E. J. Brook, T. K. Bauska, D. Baggenstos, H. Fischer, F. Joos, V. V. Petrenko, H. Schaefer, J. Schmitt, J. P. Severinghaus, R. Spahni, T. F. Stocker, Nature, 2014, 516, 234-237.

[324] A. M. Beale, F. Gao, I. Lezcano-Gonzalez, C. H. F. Peden, J. Szanyi, Chem. Soc. Rev., 2015, 44, 7371.

[325] P. Granger, V. I. Parvulescu, Chem. Rev., 2011, 111, 3155-3207.

[326] L. Wang, J. X. Liu, W. Y. Song, H. Wang, Y. Li, J. Liu, Z. Zhao, J. B. Tan, Z. C. Duan, J. L. Deng, Chem. Eng. J., 2019, 366, 504-513.

[327] S. Cai, D. Zhang, L. Zhang, L. Huang, H. Li, R. Gao, L. Shi, J. Zhang, Catal. Sci. Technol., 2014, 4, 93-101.

[328] Z. Si, D. Weng, X. Wu, J. Yang, B. Wang, Catal. Commun., 2010, 11, 1045-1048.

[329] Z. Si, D. Weng, X. Wu, Z. Ma, J. Ma, R. Ran, Catal. Today, 2013, 201, 122-130.

[330] Q. Jin, Y. Shen, S. Zhu, J. Colloid Interface Sci., 2017, 487, 401-409.

[331] H. Xu, X. Feng, S. Liu, Y. Wang, M. Sun, J. Wang, Y. Chen, Appl. Surf. Sci., 2017, 419, 697-707.

[332] H. D. Xu, S. Liu, Y. Wang, Q. J. Lin, C. L. Lin, L. Lan, Q. Wang, Y. Q. Chen, Appl. Surf. Sci., 2018, 427, 656-669.

[333] X. Zhao, L. Huang, H. Li, H. Hu, X. Hu, L. Shi, D. Zhang, Appl. Catal. B-Environ., 2016, 183, 269-281.

[334] T. Baidya, A. Bernhard, M. Elsener, O. Kröcher, Top. Catal., 2013, $56,23-28$.

[335] F. Can, S. Berland, S. Royer, X. Courtois, D. Duprez, ACS Catal., 2013, 3, 1120-1132.

[336] L. Lietti, Appl. Catal. B, 1996, 10, 281-297.

[337] H. Xu, Y. Li, B. Xu, Y. Cao, X. Feng, M. Sun, M. Gong, Y. Chen, J. Ind. Eng. Chem., 2016, 36, 334-345.

[338] S. Ding, F. Liu, X. Shi, K. Liu, Z. Lian, L. Xie, H. He, ACS Appl. Mater. Interfaces, 2015, 7, 9497-9506.

[339] Z. Liu, H. Su, J. Li, Y. Li, Catal. Commun., 2015, 65, 51-54.

[340] B. Shen, Y. Wang, F. Wang, T. Liu, Chem. Eng. J., 2014, 236, 171-180.

[341] X. Zhang, B. Shen, K. Wang, J. Chen, J. Ind. Eng. Chem., 2013, 19, 1272-1279.

[342] T. H. Vuong, J. Radnik, E. Kondratenko, M. Schneider, U. Armbruster, A. Brückner, Appl. Catal. B, 2016, 197, 159-167.

[343] S. S. R. Putluru, A. Riisager, R. Fehrmann, Catal. Lett., 2009, 133, 370-375.

[344] Z. Ma, X. Wu, Z. Si, D. Weng, J. Ma, T. Xu, Appl. Catal. B, 2015, 179, 380-394.

[345] S. Ding, F. Liu, X. Shi, H. He, Appl. Catal. B, 2016, 180, 766-774

[346] J. Yu, Z. Si, L. Chen, X. Wu, D. Weng, Appl. Catal. B, 2015, 163, 223-232.

[347] Z. Si, D. Weng, X. Wu, R. Ran, Z. Ma, Catal. Commun., 2012, 17, 146-149.

[348] H. Xu, M. Sun, S. Liu, Y. Li, J. Wang, Y. Chen, RSC Adv., 2017, 7, 24177-24187.

[349] P. Ning, Z. Song, H. Li, Q. Zhang, X. Liu, J. Zhang, X. Tang, Z. Huang, Appl. Surf. Sci., 2015, 332, 130-137.

[350] X. Chen, X. Sun, C. Gong, G. Lv, C. Song, Front. Mater. Sci., 2016, $10,211-223$.

[351] W. Cai, Q. Zhong, D. Wang, Y. Zhao, M. Chen, Y. Bu, ACS Appl Nano Mater, 2018, 1, 1150-1163.

[352] T. H. Vuong, J. Radnik, J. Rabeah, U. Bentrup, M. Schneider, H. Atia, U. Armbruster, W. Grünert, A. Brückner, ACS Catal., 2017, 7, 1693-1705.

[353] S. H. Jo, I. Lee, H. Park, H. Lee, Ceram. Int., 2017, 43, 5182-5188.

[354] A. Väliheikki, K. C. Petallidou, C. M. Kalamaras, T. Kolli, M. Huuhtanen, T. Maunula, R. L. Keiski, A. M. Efstathiou, Appl. Catal. $B$, 2014, 156-157, 72-83.
[355] Z. Peng, Z. Li, Y. Q. Liu, S. Yan, J. Tong, D. Wang, Y. Y. Ye, S. Li, Chem. Commun., 2017, 53, 5958-5961.

[356] L. Liotta, A. Longo, A. Macaluso, A. Martorana, G. Pantaleo, A. Venezia, G. Deganello, Appl. Catal. B, 2004, 48, 133-149.

[357] C. M. Kalamaras, G. G. Olympiou, V. I. Pârvulescu, B. Cojocaru, A. M. Efstathiou, Appl. Catal. B, 2017, 206, 308-318.

[358] R. Burch, P. J. Millington, A. Walker, Appl. Catal. B, 1994, 4, 65-94.

[359] M. D. Amiridis, T. Zhang, R. J. Farrauto, Appl. Catal. B, 1996, 10 203-227.

[360] R. Burch, J. P. Breen, F. C. Meunier, Appl. Catal. B, 2002, 39, 283-303.

[361] Z. Hu, X. Liu, D. Meng, Y. Guo, Y. Guo, G. Lu, ACS Catal., 2016, 6, 2265-2279.

[362] R. Burch, A. Ramli, Appl. Catal. B, 1998, 15, 49-62.

[363] Y. Li, J. N. Armor, Appl. Catal. B, 1993, 2, 239-256.

[364] K. Shimizu, F. Okada, Y. Nakamura, A. Satsuma, T. Hattori, J. Catal., 2000, 195, 151-160.

[365] T. J. Lee, I. S. Nam, S. W. Ham, Y. S. Baek, K. H. Shin, Appl. Catal. B, 2003, 41, 115-127.

[366] M. Pirez-Engelmann, P. Granger, L. Leclercq, G. Leclercq, Top Catal., 2004, 30-31, 59-64.

[367] B. Azambre, L. Zenboury, P. Da Costa, S. Capela, S. Carpentier, A. Westermann, Catal. Today, 2011, 176, 242-249.

[368] L. Zenboury, B. Azambre, J. Weber, Catal. Today, 2008, 137, 167-173.

[369] C. Thomas, O. Gorce, C. Fontaine, J.-M. Krafft, F. Villain, G. Djéga-Mariadassou, Appl. Catal. B, 2006, 63, 201-214.

[370] M. Haneda, K. Shinoda, A. Nagane, O. Houshito, H. Takagi, Y. Nakahara, K. Hiroe, T. Fujitani, H. Hamada, J. Catal., 2008, 259, 223-231.

[371] C. Thomas, O. Gorce, F. Villain, G. Djéga-Mariadassou, J. Mol. Catal. A, 2006, 249, 71-79.

[372] N. A. S. Amin, C. M. Chong, Chem. Eng. J., 2005, 113, 13-25.

[373] M. Adamowska, S. Muller, P. Da Costa, A. Krzton, P. Burg, Appl. Catal. B, 2007, 74, 278-289.

[374] M. Adamowska, A. Krztoń, M. Najbar, J. Camra, G. Djéga-Mariadassou, P. Da Costa, Appl. Catal. B, 2009, 90, 535-544.

[375] T. Tanabe, Y. Nagai, K. Dohmae, N. Takagi, N. Takahashi, H. Shinjoh, Appl. Catal. B, 2011, 105, 41-49.

[376] O. Gorce, F. Baudin, C. Thomas, P. Da Costa, G. Djéga-Mariadassou, Appl. Catal. B, 2004, 54, 69-84.

[377] M. Adamowska-Teyssier, A. Krzton, P. Da Costa, G. Djega-Mariadassou, Fuel, 2015, 150, 21-28.

[378] M. Adamowska, A. Krzton, M. Najbar, P. Da Costa, G. Djega-Mariadassou, Catal. Today, 2008, 137, 288-291.

[379] G. Djéga-Mariadassou, M. Berger, O. Gorce, J. W. Park, H. Pernot, C. Potvin, C. Thomas, P. Da Costa, Stud. Surf. Sci. Catal., 2007, 171, 145-173.

[380] R. Strobel, F. Krumeich, S. E. Pratsinis, A. Baiker, J. Catal, 2006 243, 229-238.

[381] C. M. Kalamaras, G. G. Olympiou, V. I. Parvulescu, B. Cojocaru, A M. Efstathiou, Appl. Catal. B, 2017, 206, 308-318.

[382] G. Djéga-Mariadassou, Catal. Today, 2004, 90, 27-34.

[383] M. A. Gómez-García, S. Libs, P. Bernhardt, V. Pitchon, A. Kiennemann, Ind. Eng. Chem. Res., 2007, 46, 7045-7049.

[384] A. Westermann, B. Azambre, Catal. Today, 2011, 176, 441-448.

[385] A. Westermann, B. Azambre, A. Koch, Catal. Today, 2012, 191, 65-74.

[386] F. Baudin, P. Da Costa, C. Thomas, S. Calvo, Y. Lendresse, S. Schneider, F. Delacroix, G. Plassat, G. Djéga-Mariadassoua, Top. Catal., 2004, 30-31, 97-101. 
[387] M. S. Li, K. Seshan, L. Lefferts, Appl. Catal. B, 2004, 50, 143-151.

[388] X. Q. Wang, S. A. Sigmon, J. J. Spivey, H. H. Lamb, Catal. Today, 2004, 96, 11-20.

[389] H. Iwakuni, Y. Shinmyou, H. Yano, H. Matsumoto, T. Ishihara, Appl. Catal. B, 2007, 74, 299-306.

[390] C. Tofan, D. Klvana, J. Kirchnerova, Appl. Catal. B, 2002, 36, 311-323.

[391] H. J. Hwang, M. Awano, J. Eur. Ceram. Soc., 2001, 21, 2103-2107.

[392] Z. Zhao, X. Yang, Y. Wu, Appl. Catal. B, 1996, 8, 281-297.

[393] Y. Zhu, D. Wang, F. Yuan, G. Zhang, H. Fu, Appl. Catal. B, 2008, 82, 255-263.

[394] Z. Liu, J. Hao, L. Fu, T. Zhu, Appl. Catal. B, 2003, 44, 355-370.

[395] J. Zawadzki, M. Wiśniewski, Carbon, 2002, 40, 119-124.

[396] K. Almusaiteer, R. Krishnamurthy, S. Chuang, Catal. Today, 2000, 55, 291-299.

[397] J. Zhu, Y. Wei, W. Chen, Z. Zhao, A. Thomas, Chem. Commun., 2010, 46, 6965-6967.

[398] M. Y. Kustova, S. B. Rasmussen, A. L. Kustov, C. H. Christensen, Appl. Catal. B, 2006, 67, 60-67.

[399] L. D. Li, Q. Shen, J. J. Yu, Z. P. Hao, Z. P. Xu, G. Q. Max Lu, Environ. Sci. Technol., 2007, 41, 7901-7906.

[400] B. M. Abu-Zied, W. Schwieger, A. Unger, Appl. Catal. B, 2008, 84, 277-288.

[401] P. K. Sajith, Y. Shiota, K. Yoshizawa, ACS Catal., 2014, 4, 2075-2085.

[402] W. Xu, J. Zhou, Z. You, Y. Luo, Y. Ou, ChemCatchem, 2015, 7, 450-458.

[403] K. M. Valkaj, V. Tomasic, A. Katovic, E. Bielanska, Mater. Sci. Poland, 2016, 34, 177-184.

[404] T. Ohnishi, K. Kawakami, M. Nishioka, M. Ogura, Catal. Today, 2017, 281, 566-574.

[405] L. Cheng, R. Wang, Mater. Sci. Forum., 2013, 745-746, 485-490.

[406] P. F. Yang, J. C. Zhou, Z. Wang, Adv. Mater. Res., 2010, 113-116, 1735-1739.

[407] B. A. Hungate, J. S. Dukes, M. R. Shaw, Y. Luo, C. B. Field, Science, 2003, 302, 1512-1513.

[408] L. Li, J. Xu, J. Hu, J. Han, Environ. Sci. Technol., 2014, 48, 5290-5297.

[409] E. A. Davidson, D. Kanter, Environ. Res. Lett., 2014, 9, 105012.

[410] J. W. Erisman, J. Galloway, S. Seitzinger, A. Bleeker, K. Butterbach-Bahl, Curr. Opin. Enviro. Sustain., 2011, 3, 281-290.

[411] S. Imamura, R. Hamada, Y. Saito, K. Hashimoto, H. Jindai, J. Mol. Catal. A, 1999, 139, 55-62.

[412] J. Novakova, Appl. Catal. B, 2001, 30, 445-457.

[413] A. Gupta, A. Kumar, U. V. Waghmare, M. S. Hegde, Chem. Mater., 2009, 21, 4880-4891.

[414] M. Haneda, H. Hamada, J. Catal., 2010, 273, 39-49.

[415] X. Wang, N. Maeda, A. Baiker, ACS Catal., 2016, 6, 7898-7906.

[416] L. Liu, B. Liu, L. Dong, J. Zhu, H. Wan, K. Sun, B. Zhao, H. Zhu, L. Dong, Y. Chen, Appl. Catal. B, 2009, 90, 578-586.

[417] G. R. Rao, P. Fornasiero, R. Di Monte, J. Kašpar, G. Vlaic, G. Balducci, S. Meriani, G. Gubitosa, A. Cremona, M. Graziani, J. Catal., 1996, 162, 1-9.

[418] H. O. Zhu, J. R. Kim, S. K. Ihm, React. Kinet. Catal. Lett., 2009, 97, 207-215.

[419] J. R. Regalbuto, E. E. Wolf, J. Catal., 1988, 109, 12-24.

[420] L. F. Chen, G. Gonzalez, J. A. Wang, L. E. Norena, A. Toledo, S. Castillo, M. Moran-Pineda, Appl. Surf. Sci., 2005, 243, 319-328.

[421] A. Martınez-Arias, M. Fernández-Garcia, A. Iglesias-Juez, A. Hungria, J. Anderson, J. Conesa, J. Soria, Appl. Catal. B, 2001, 31, 51-60.

[422] M. Fernández-Garcia, A. Martınez-Arias, A. Iglesias-Juez, A. Hun- gria, J. A. Anderson, J. C. Conesa, J. Soria, J. Catal., 2003, 214, 220-233.

[423] A. B. Hungría, M. Fernández-García, J. A. Anderson, A. Martínez-Arias, J. Catal., 2005, 235, 262-271.

[424] J. R. Kim, W. J. Myeong, S. K. Ihm, J. Catal., 2009, 263, 123-133.

[425] R. Zhang, W. Y. Teoh, R. Amal, B. Chen, S. Kaliaguine, J. Catal., 2010, 272, 210-219.

[426] Q. Yu, L. Liu, L. Dong, D. Li, B. Liu, F. Gao, K. Sun, L. Dong, Y. Chen, Appl. Catal. B, 2010, 96, 350-360.

[427] L. Liu, Z. Yao, B. Liu, L. Dong, J. Catal., 2010, 275, 45-60.

[428] L. Liu, Y. Chen, L. Dong, J. Zhu, H. Wan, B. Liu, B. Zhao, H. Zhu, K. Sun, L. Dong, Y. Chen, Appl. Catal. B, 2009, 90, 105-114.

[429] L. Liu, Q. Yu, J. Zhu, H. Wan, K. Sun, B. Liu, H. Zhu, F. Gao, L. Dong, Y. Chen, J. Colloid Interface Sci., 2010, 349, 246-255.

[430] R. Zhang, H. Alamdari, S. Kaliaguine, J. Catal., 2006, 242, 241-253.

[431] F. Solymosi, T. Bansagi, J. Catal., 2001, 202, 205-206.

[432] W. C. Hecker, A. T. Bell, J. Catal., 1984, 85, 389-397.

[433] R. H. H. Smits, Y. Iwasawa, Appl. Catal. B, 1995, 6, L201-L207.

[434] V. I. Pârvulescu, P. Grange, B. Delmon, Catal. Today, 1998, 46, 233-316.

[435] K. Yoshida, S. Makino, S. Sumiya, G. Muramatsu, R. Helferich, SAE Technical Paper, 892046, 1989.

[436] J. Oi-Uchisawa, S. Wang, T. Nanba, A. Ohi, A. Obuchi, Appl. Catal. $B, \mathbf{2 0 0 3}, 44,207-215$.

[437] A. Datta, H. I. Khwaja, R. Y. Kelkar, A. R. Saple, M. Datta, Chem. Commun., 1996, 851-852.

[438] B. S. Sanchez, C. A. Querini, E. E. Miro, Appl. Catal. A, 2009, 366, 166-175.

[439] R. Matarrese, S. Morandi, L. Castoldi, P. Villa, L. Lietti, Appl. Catal. $B, 2017,201,318-330$.

[440] G. Mul, F. Kapteijn, C. Doornkamp, J. A. Moulijn, J. Catal., 1998, 179, 258-266.

[441] L. Castoldi, R. Matarrese, L. Lietti, P. Forzatti, Appl. Catal. B, 2009, 90, 278-285.

[442] J. Liu, Z. Zhao, C. Xu, A. Duan, Appl. Catal. B, 2008, 78, 61-72.

[443] J. Liu, Z. Zhao, C. Xu, A. Duan, G. Jiang, J. Phys. Chem. C, 2008, 112, 5930-5941.

[444] Y. Wu, T. Yu, B. S. Dou, C. X. Wang, X. F. Xie, Z. L. Yu, S. R. Fan, Z. R. Fan, L. C. Wang, J. Catal., 1989, 120, 88-107.

[445] Z. Li, M. Meng, Q. Li, Y. Xie, T. Hu, J. Zhang, Chem. Eng. J., 2010, 164, 98-105.

[446] J. Xu, J. Liu, Z. Zhao, C. Xu, J. Zheng, A. Duan, G. Jiang, J. Catal., 2011, 282, 1-12.

[447] S. B. Simonsen, S. Dahl, E. Johnson, S. Helveg, J. Catal., 2008, 255, $1-5$.

[448] K. Krishna, A. Bueno-López, M. Makkee, J. A. Moulijn, Appl. Catal. $B, \mathbf{2 0 0 7}, 75,189-200$.

[449] I. Atribak, A. Bueno-Lopez, A. Garcia-Garcia, Top. Catal., 2009, 52, 2088-2091.

[450] N. Guillen-Hurtado, A. Bueno-Lopez, A. Garcia-Garcia, Appl. Catal. A, 2012, 437-438, 166-172.

[451] P. Dulgheru, J. A. Sullivan, Top. Catal., 2013, 56, 504-510.

[452] A. M. Hernandez-Gimenez, L. P. dos Santos Xavier, A. Bueno-Lopez, Appl. Catal. A, 2013, 462-463, 100-106.

[453] K. C. Taylor, in: J. R. Anderson, M. Boudart, eds, Catalysis: Science and Technology, Vol. 5 Springer-verlag, Berlin, 1984, 5, 119-170

[454] P. Fornasiero, R. Di Monte, G. R. Rao, J. Kaspar, S. Meriani, A. Trovarelli, M. Graziani, J. Catal., 1995, 151, 168-177.

[455] Z. Zhang, Y. Fan, Y. Xin, Q. Li, R. Li, J. A. Anderson, Z. Zhang, Environ. Sci. Technol., 2015, 49, 7989-7995.

[456] C. E. Hori, H. Permana, K. Y. Si. Ng, A. Brenner, K. More, K. M. 
Rahmoeller, D. Belton, Appl. Catal. B, 1998, 16, 105-117.

[457] M. Zhao, M. Shen, J. Wang, J. Catal., 2007, 248, 258-267.

[458] H. He, H. X. Dai, L. H. Ng, K. W. Wong, C. T. Au, J. Catal., 2002, 206, $1-13$.

[459] P. S. Lambrou, C. N. Costa, S. Y. Christou, A. M. Efstathiou, Appl. Catal. B, 2004, 54, 237-250.

[460] L. Lan, S. Chen, Y. Cao, M. Zhao, M. Gong, Y. Chen, J. Colloid Interface Sci., 2015, 450, 404-416.

[461] Y. Zhou, J. Deng, L. Lan, J. Wang, S. Yuan, M. Gong, Y. Chen, J. Mater. Sci., 2017, 52, 5894-5907.

[462] A. Papavasiliou, A. Tsetsekou, V. Matsouka, M. Konsolakis, I. V. Yentekakis, N. Boukos, Appl. Catal. B, 2009, 90, 162-174.

[463] T. Masui, T. Ozaki, K. Machida, G. Adachi, J. Alloys Compd., 2000, 303-304, 49-55.

[464] T. Nakatani, T. Wakita, R. Ota, K. Tanaka, T. Wakasugi, J. Ceram. Soc.Jpn., 2003, 111, 137-141.

[465] L. Lan, S. H. Chen, H. M. Li, H. M. Li, W. X. Wu, J. Deng, Y. Q. Chen, J. Ind. Eng. Chem., 2018, 58, 246-257.

[466] H. M. Li, L. Lan, S. H. Chen, D. Y. Liu, W. Wang, Y. Q. Chen, J. Inorg. Mater., 2018, 33, 798-804.

[467] B. Zhao, Q. Wang, G. Li, R. Zhou, J. Alloys Compd., 2010, 508, 500-506.

[468] L. Lan, S. Chen, M. Zhao, M. Gong, Y. Chen, J. Mol. Catal. A, 2014, $394,10-21$.

[469] R. Si, Y. W. Zhang, S. J. Li, B. X. Lin, C. H. Yan, J. Phys. Chem. B, 2004, 108, 12481-12488

[470] S. Lin, L. Yang, X. Yang, R. Zhou, Chem. Eng. J., 2014, 247, 42-49.

[471] B. Zhao, G. Li, C. Ge, Q. Wang, R. Zhou, Appl. Catal. B, 2010, 96, 338-349.

[472] L. F. Liotta, A. Macaluso, A. Longo, G. Pantaleo, A. Martorana, G. Deganello, Appl. Catal. A, 2003, 240, 295-307.

[473] B. Zhao, C. Yang, Q. Wang, G. Li, R. Zhou, J. Alloys Compd., 2010, 494, 340-346.

[474] R. Daley, S. Christou, A. Efstathiou, J. Anderson, Appl. Catal. B-Environ., 2005, 60, 117-127.

[475] J. R. Gonzalez-Velasco, M. A. Gutierrez-Ortiz, J. L. Marc, M. P. Gonzalez-Marcos, G. Blanchard, Appl. Catal. B, 2001, 33, 303-314.

[476] J. Kaspar, P. Fornasiero, N. Hickey, Catal. Today, 2003, 77, 419-449.

[477] R. J. Farrauto, R. M. Heck, Catal. Today, 1999, 51, 351-360.

[478] L. Lan, S. Chen, Y. Cao, S. Wang, Q. Wu, Y. Zhou, M. Huang, M. Gong, Y. Chen, J. Mol. Catal. A, 2015, 410, 100-109.

[479] J. Wang, M. Shen, Y. An, J. Wang, Catal. Commun., 2008, 10, 103-107.

[480] L. Yang, X. Yang, R. Zhou, J. Phys. Chem. C, 2016, 120, 2712-2723.

[481] L. Yang, X. Yang, S. Lin, R. Zhou, Catal. Sci. Technol,, 2015, 5, 2688-2695.

[482] M. Shen, J. Wang, J. Shang, Y. An, J. Wang, W. Wang, J. Phys. Chem. C, 2009, 113, 1543-1551.

[483] J. Guo, Z. Shi, D. Wu, H. Yin, M. Gong, Y. Chen, Mater. Res. Bull., 2013, 48, 495-503.

[484] M. Ozawa, J. Alloys Compd., 2006, 408-412, 1090-1095.

[485] Q. Wang, G. Li, B. Zhao, M. Shen, R. Zhou, Appl. Catal. B, 2010, 101, 150-159.

[486] Q. Wang, G. Li, B. Zhao, R. Zhou, Appl. Catal. B, 2010, 100, 516-528.

[487] A. Papavasiliou, A. Tsetsekou, V. Matsouka, M. Konsolakis, I. V. Yentekakis, Appl. Catal. A, 2010, 382, 73-84.

[488] J. Guo, Z. Shi, D. Wu, H. Yin, M. Gong, Y. Chen, Appl. Surf. Sci., 2013, 273, 527-535.

[489] Q. Wang, G. Li, B. Zhao, R. Zhou, Fuel, 2011, 90, 3047-3055.
[490] X. Yang, L. Yang, S. Lin, R. Zhou, J. Phys. Chem. C, 2015, 119 6065-6074.

[491] Q. Wang, G. Li, B. Zhao, R. Zhou, J. Hazard. Mater., 2011, 189, 150-157.

[492] L. P. dos Santos Xavier, V. Rico-Perez, A. M. Hernandez-Gimenez, D. Lozano-Castello, A. Bueno-Lopez, Appl. Catal. B, 2015, 162, 412-419.

[493] J. Guo, Z. Shi, D. Wu, H. Yin, M. Gong, Y. Chen, J. Alloys Compd., 2015, 621, 104-115.

[494] Q. Wang, G. Li, B. Zhao, R. Zhou, J. Mol. Catal. A, 2011, 339, 52-60.

[495] Q. Wang, B. Zhao, G. Li, R. Zhou, Environ. Sci. Technol, 2010, 44, 3870-3875.

[496] G. Li, Q. Wang, B. Zhao, M. Shen, R. Zhou, J. Hazard. Mater., 2011, 186, 911-920.

[497] G. Li, Q. Wang, B. Zhao, R. Zhou, J. Mol. Catal. A, 2010, 326, 69-74.

[498] G. Li, B. Zhao, Q. Wang, R. Zhou, Appl. Catal. B, 2010, 97, 41-48.

[499] G. Li, Q. Wang, B. Zhao, R. Zhou, Catal. Today, 2011, 175, 40-47.

[500] G. Li, Q. Wang, B. Zhao, R. Zhou, Appl. Catal. B, 2011, 105, 151-162.

[501] G. Li, Q. Wang, B. Zhao, R. Zhou, Fuel, 2012, 92, 360-368.

[502] G. Li, Q. Wang, B. Zhao, R. Zhou, Catal. Today, 2010, 158, 385-392.

[503] H. F. Wang, H. Y. Li, X. Q. Gong, Y. L. Guo, G. Z. Lu, P. Hu, Phys. Chem. Chem. Phys., 2012, 14, 16521-16535.

[504] E. Aneggi, C. de Leitenburg, A. Trovarelli, Catal. Today, 2012, 181, 108-115.

[505] H. F. Wang, X. Q. Gong, Y. L. Guo, Y. Guo, G. Z. Lu, P. Hu, J. Phys Chem. C, 2009, 113, 10229-10232.

[506] L. Lan, S. Chen, Y. Cao, M. Gong, Y. Chen, Catal. Sci. Technol., 2015 5, 4488-4500.

[507] T. Hou, B. Yu, S. Zhang, J. Zhang, D. Wang, T. Xu, L. Cui, W. Cai, Appl. Catal. B, 2015, 168-169, 524-530.

[508] W. Wang, J. Gong, Front. Chem. Sci. Eng., 2010, 5, 2-10.

[509] F. Ocampo, B. Louis, L. Kiwi-Minsker, A. C. Roger, Appl. Catal. A, 2011, 392, 36-44.

[510] F. Ocampo, B. Louis, A. C. Roger, Appl. Catal. A, 2009, 369, 90-96.

[511] J. Ashok, M. L. Ang, S. Kawi, Catal. Today, 2017, 281, 304-311.

[512] X. Shang, D. Deng, X. Wang, W. Xuan, X. Zou, W. Ding, X. Lu, Int. J. Hydrogen Energy, 2018, 43, 7179-7189.

[513] H. W. Zhu, R. Razzaq, C. S. Li, Y. Muhmmad, S. J. Zhang, AIChE J., 2013, 59, 2567-2576.

[514] P. Kumar, Y. Sun, R. O. Idem, Energy Fuels, 2007, 21, 3113-3123.

[515] W. Yuan, Y. Wang, Y. Zou, W. Tan, W. Hou, L. Zheng, F. Wu, L. Zhou, Catal. Lett., 2016, 146, 1663-1673.

[516] X. Chang, B. Liu, H. Xia, R. Amin, Appl. Surf. Sci., 2018, 442, 342-351.

[517] E. C. Faria, R. C. R. Neto, R. C. Colman, F. B. Noronha, Catal. Today, 2014, 228, 138-144.

[518] A. Khan, T. Sukonket, B. Saha, R. Idem, Energy Fuels, 2012, 26, 365-379.

[519] W. J. Jang, D. W. Jeong, J. O. Shim, H. S. Roh, I. H. Son, S. J. Lee, Int. J. Hydrogen Energy, 2013, 38, 4508-4512.

[520] B. Koubaissy, A. Pietraszek, A. C. Roger, A. Kiennemann, Catal. Today, 2010, 157, 436-439.

[521] F. B. Noronha, E. C. Fendley, R. R. Soares, W. E. Alvarez, D. E. Resasco, Chem. Eng. J., 2001, 82, 21-31.

[522] E. Akpan, Y. Sun, P. Kumar, H. Ibrahim, A. Aboudheir, R. Idem, Chem. Eng. Sci., 2007, 62, 4012-4024.

[523] M. Mikkelsen, M. Jørgensen, F. C. Krebs, Energy Environ., Sci., 2010, 3, 43-81.

[524] K. Tomishige, Y. Furusawa, Y. Ikeda, M. Asadullah, K. Fujimoto, Catal. Lett., 2001, 76, 71-74. 
[525] A. H. Tamboli, A. A. Chaugule, S. W. Gosavi, H. Kim, Fuel, 2018, $216,245-254$.

[526] Z. F. Zhang, Z. T. Liu, Z. W. Liu, J. Lu, Catal. Lett., 2009, 129, 428-436.

[527] P. Kumar, P. With, V. C. Srivastava, K. Shukla, R. Glaser, I. M. Mishra, RSC Adv., 2016, 6, 110235-110246.

[528] R. Saada, S. Kellici, T. Heil, D. Morgan, B. Saha, Appl. Catal. B-Environ., 2015, 168-169, 353-362.

[529] H. J. Lee, S. Park, I. K. Song, J. C. Jung, Catal. Lett., 2011, 141, 531-537.

[530] H. J. Lee, S. Park, J. C. Jung, I. K. Song, Korean J. Chem. Eng., 2011, $28,1518-1522$.
[531] Z. F. Zhang, Z. W. Liu, J. A. Lu, Z. T. Lie, Ind. Eng. Chem. Res., 2011, 50, 1981-1988.

[532] P. Kumar, P. With, V. C. Srivastava, R. Glaser, I. M. Mishra, J. Alloys Compd., 2017, 696, 718-726.

[533] K. Almusaiteer, Catal. Commun., 2009, 10, 1127-1131.

[534] R. Renner, Environ. Sci. Technol., 2001, 35, 138A-139A.

[535] P. T. Anastas, L. B. Bartlett, M. M. Kirchhoff, T. C. Williamson, Catal. Today, 2000, 55, 11-22.

[536] Y. Fan, Z. Wang, Y. Xin, Q. Li, Z. Zhang, Y. Wang, PLoS One, 2014, 9, e88236.

[537] M. Remko, Mol. Phys., 1997, 91, 929-936.

[538] J. Tang, Z. Zou, J. Ye, Chem. Mater., 2004, 16, 1644-1649.

\title{
铈锆固溶体的结构、合成及在环境催化领域中的应用
}

\author{
刘计省 ${ }^{\mathrm{a}}$, 赵 震 ${ }^{\mathrm{a}, \mathrm{b}}$, 徐春明 ${ }^{\mathrm{a}}$, 刘 坚, ${ }^{\mathrm{a}}$ * \\ a 中国石油大学(北京)化学工程与环境学院重质油国家重点实验室, 北京102249

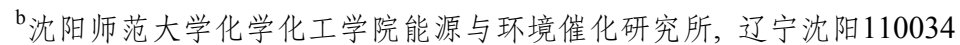

\begin{abstract}
摘要: 二氧化铈作为一种特殊的立方萤石结构, 是应用最为广泛的稀土氧化物. 同时, 它也是一种合适的催化剂载体, 可以 促进活性组分的均匀分布, 提高催化活性. 但纯二氧化铈在高温下容易发生团聚, 导致比表面积严重降低, 而锆 $(\mathrm{Zr})$ 掺杂所 形成的铈锆固溶体 $(\mathrm{CZO})$ 会显著提高铈基催化剂的稳定性. 在Zr含量较低时, CZO主要呈现立方萤石结构, 随着Zr含量增 加, CZO结构逐渐由立方相转变为正方相, 并最终形成单斜相. 此外, 与其它稀土氧化物不同, CZO由于其独特的结构性 质、可控的组成、良好的氧化还原性能以及氧储存性能(OSC)而备受关注.

截至目前, 由于其特殊的物理化学性质和有序的空间形貌,纳米尺寸CZO格外引人关注. 其形貌主要包括纳米粉末、 一维纳米棒、纳米管、纳米带、纳米线、二维纳米薄膜、三维纳米笼、三维介孔、大孔和多级孔. 基于其不同的形貌及 有序的空间结构, CZO材料呈现不同的性质, 并且已被广泛应用于多相催化领域. 然而, 不同形貌CZO材料的性能仍然有 进一步提升的空间, 例如: 提高材料的稳定性及机械强度; 探索环境友好型合成路径; 考察反应时间、温度、溶液 $\mathrm{pH}$ H值、 $\mathrm{Ce}$ 和Zr源的浓度和构型、金属掺杂等对形貌的影响; 研究不同形貌CZO纳米材料的物理化学性质; 阐明CZO结构、形貌与 其催化性能之间的关系.

环境催化可将污染物转化为无害或有价值的物质, 因而被认为是当今减少环境污染最有用的方法之一. 而CZO作为 活性组分、载体和氧存储材料具有优异的催化活性、较高选择性、高稳定性和极强的适应能力, 是环境催化领域消除污染 物过程中必不可少的组分, 因而被广泛应用于催化CO、VOC、Soot、PM和HC燃烧、 $\mathrm{NO}_{x}$ 选择性催化还原和直接降解、 $\mathrm{CO}_{2}$ 转化等反应. 研究发现: 采用合适的制备方法能够改善CZO的结构和物理化学性质; 调节 $\mathrm{Ce} / \mathrm{Zr}$ 摩尔比能促进 CZO基材料 的氧化还原性能; 负载活性金属如贵金属Pt、Rh、Pd或过渡金属 $\mathrm{Mn} 、 \mathrm{Co} 、 \mathrm{Cu}$ 等可提高 $\mathrm{CZO}$ 的催化性能; 引入第三组分不 仅可以增加 CZO晶格氧缺陷, 改善其OSC, 进而提高其催化活性、选择性和稳定性, 还可以抑制晶体转变, 提高 $\mathrm{CZO}$ 催化剂 的热稳定性. 然而, 自1970年代至今, 进一步提高CZO基催化剂的OSC和热稳定性以满足日益严峻的环保要求迫在眉睫.

关键词: 铈锆固溶体; 结构; 合成; 方法; 环境催化
\end{abstract}

收稿日期: 2019-05-28. 接受日期: 2019-07-03. 出版日期: 2019-10-05.

*通讯联系人. 电话: (010)89732278; 传真: (010)69724721; 电子信箱: liujian@cup.edu.cn

基金来源：国家自然科学基金(21673290和U1662103).

本文的电子版全文由Elsevier出版社在ScienceDirect上出版(http://www.sciencedirect.com/science/journal/18722067). 